\title{
MODELAGEM DA PROPAGAÇÃO RADIOMÓVEL NO AMBIENTE CERRADO NAS FAIXAS DENOMINADAS VHF/UHF
}

GIOVANNI CÉSAR GANIME ALVES

TESE DE DOUTORADO EM ENGENHARIA ELÉTRICA

DEPARTAMENTO DE ENGENHARIA ELÉTRICA

\section{UNIVERSIDADE DE BRASÍLIA}




\title{
UNIVERSIDADE DE BRASÍLIA \\ FACULDADE DE TECNOLOGIA \\ DEPARTAMENTO DE ENGENHARIA ELÉTRICA
}

\begin{abstract}
MODELAGEM DA PROPAGAÇÃO RADIOMÓVEL NO AMBIENTE CERRADO NAS FAIXAS DENOMINADAS VHF/UHF
\end{abstract}

GIOVANNI CÉSAR GANIME ALVES

ORIENTADOR: Dr. PAULO HENRIQUE PORTELA DE CARVALHO

TESE DE DOUTORADO EM ENGENHARIA ELÉTRICA

PUBLICAÇÃO: PPGEE.TD - 098/2015

BRASÍLIA/DF: MAIO - 2015 
FICHA CATALOGRÁFICA

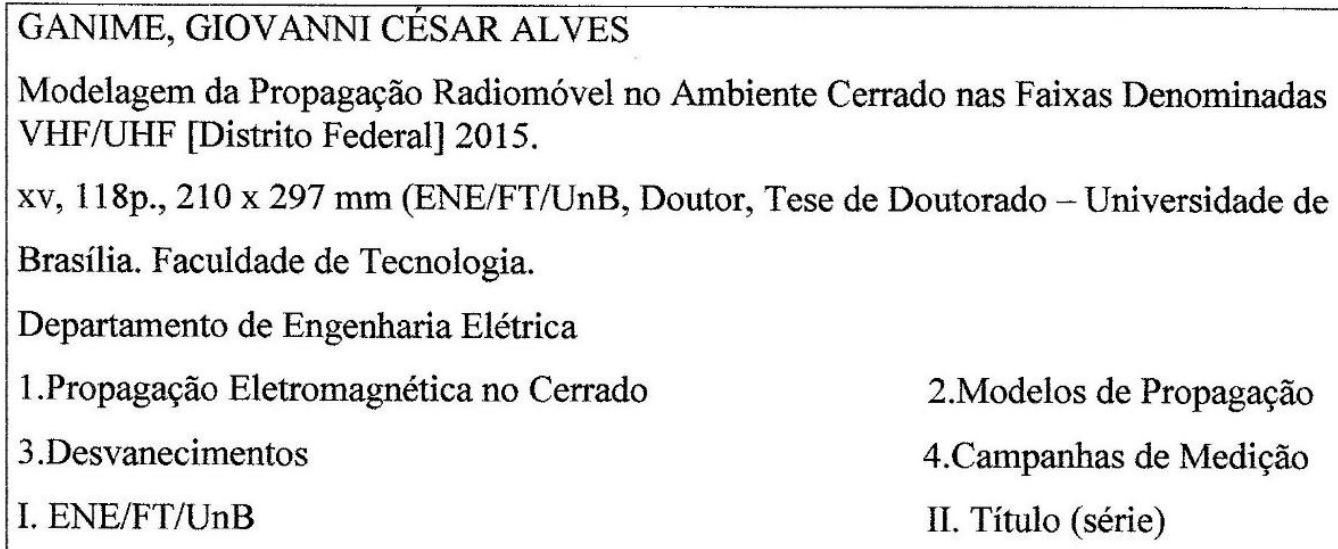

\section{REFERÊNCIA BIBLIOGRÁFICA}

GANIME, G. C. A. (2015). Modelagem da Propagação Radiomóvel no Ambiente Cerrado nas Faixas Denominadas VHF/UHF. Tese de Doutorado em Engenharia Elétrica, Publicação PPGEE.TD-098/2015, Departamento de Engenharia Elétrica, Universidade de Brasília, Brasília, DF, 118p.

\section{CESSÃO DE DIREITOS}

AUTOR: Giovanni César Ganime Alves

TÍTULO: Modelagem da Propagação Radiomóvel no Ambiente Cerrado nas Faixas Denominadas VHF/UHF.

GRAU: Doutor

ANO: 2015

É concedida à Universidade de Brasília permissão para reproduzir cópias desta tese de doutorado e para emprestar ou vender tais cópias somente para propósitos acadêmicos e científicos. $\mathrm{O}$ autor reserva outros direitos de publicação e nenhuma parte dessa tese de doutorado pode ser reproduzida sem autorização por escrito do autor.

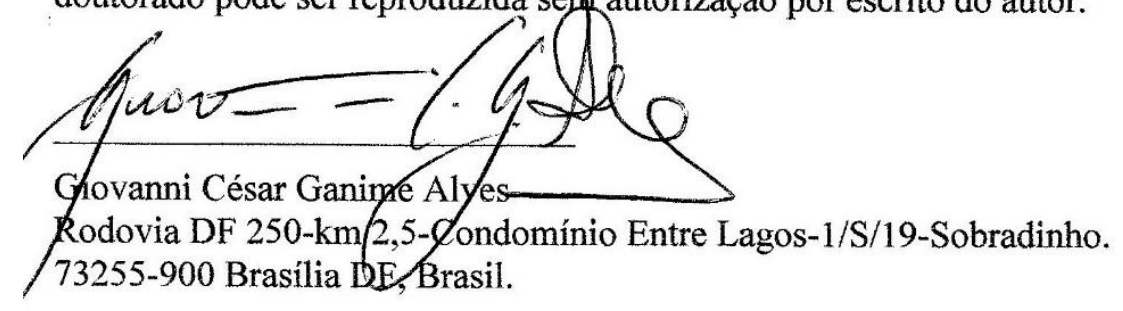


UNIVERSIDADE DE BRASÍLIA

FACULDADE DE TECNOLOGIA

DEPARTAMENTO DE ENGENHARIA ELÉTRICA

\title{
MODELAGEM DA PROPAGAÇÃO RADIOMÓVEL NO AMBIENTE CERRADO NAS FAIXAS DENOMINADAS VHF/UHF
}

\section{GIOVANNI CÉSAR GANIME ALVES}

\begin{abstract}
TESE DE DOUTORADO SUBMETIDA AO DEPARTAMENTO DE ENGENHARIA ELÉTRICA DA FACULDADE DE TECNOLOGIA DA UNIVERSIDADE DE BRASÍLIA, COMO PARTE DOS REQUISITOS NECESSÁRIOS PARA A OBTENÇÃO DO GRAU DE DOUTOR.
\end{abstract}

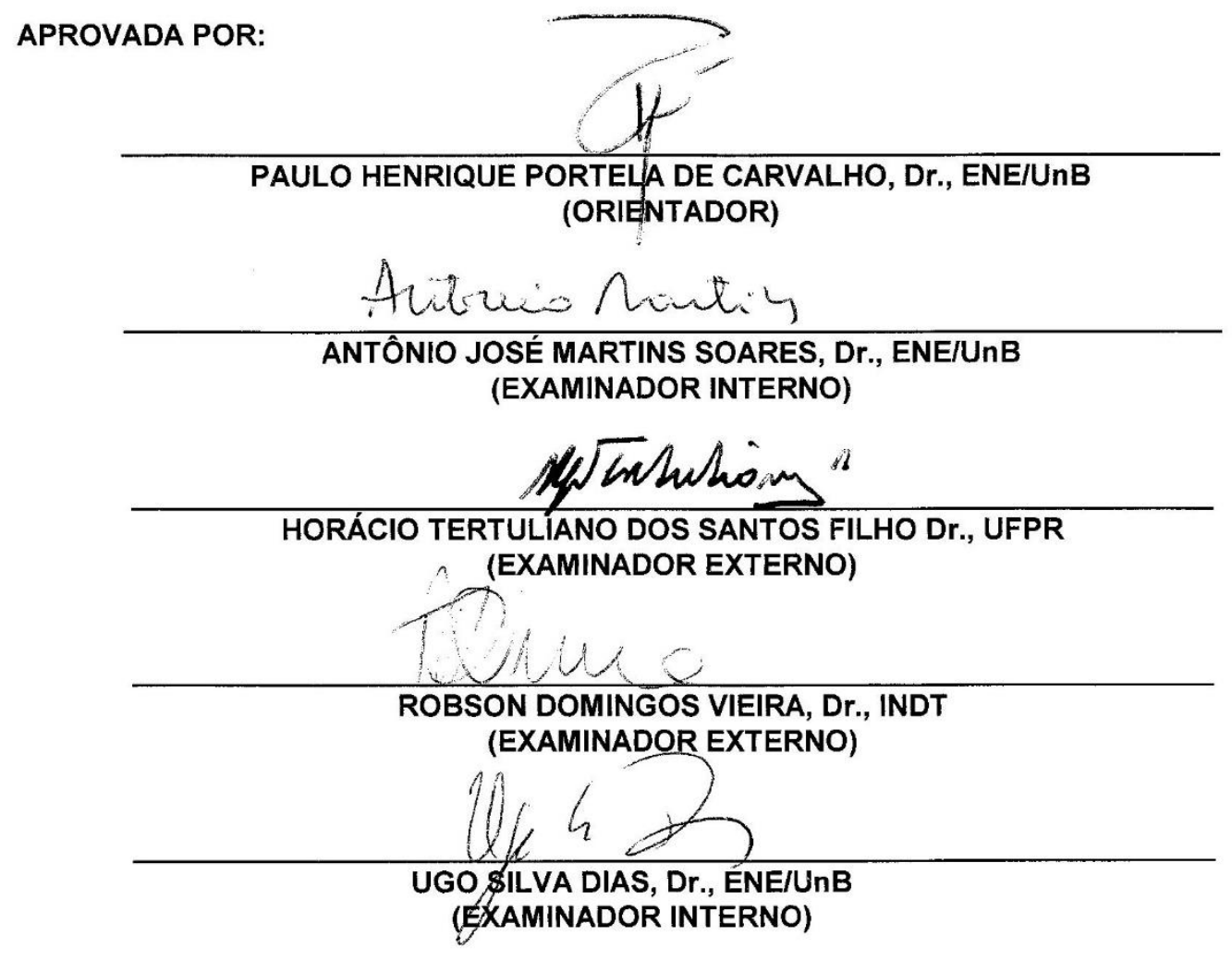

Brasília, 15 de maio de 2015. 


\section{Dedicatória}

In Memoriam da minha mãe, Maria Ganime Alves "Olga"e do meu pai, Plínio Rodrigues Alves, pelos exemplos de vida.

A minha esposa, Maria de Fátima Carvalho Alves, pelo incondicional apoio para que eu pudesse chegar aonde cheguei. Ela nunca mediu esforços para alavancar a continuidade de meus estudos, sacrificando até mesmo sua formação, sua carreira e seu lazer.

As minhas filhas, Beatriz Carvalho Alves e Letícia Carvalho Alves, pela genialidade na elaboração de ilustrações criativas que dão suporte aos resultados obtidos.

A meu irmão, Plínio Ricardo Ganime Alves, pelo amplo apoio: acadêmico, financeiro, nos trabalhos experimentais e, principalmente, na formativa de um caráter voltado à busca do rigor científico.

Giovanni César Ganime Alves. 


\section{Agradecimentos}

Agradeço ...

A Deus, por ter me permitido grandes oportunidades, e por ter colocado em meu caminho pessoas verdadeiramente iluminadas e inspiradas.

Ao professor Dr. Paulo Henrique Portela de Carvalho, por acreditar no meu potencial para desenvolver uma tese elevando desta forma meu nível de conhecimento científico. Ao professor Dr. João Paulo Leite, pelo imprescindivel trabalho desenvolvido na confecção das rotinas de pós-processamento em Matlab, apoio nos trabalhos de campo e pelos ensinamentos repassados no que tange aos fundamentos teóricos e práticos. Ao professor Dr. Plínio Ricardo Ganime Alves, meu estimado irmão, pelo amplo e irrestrito suporte no âmbito da tese e extra-tese.

Ao professor Dr. Mario Benjamim Baptista de Siqueira, por permitir o uso da infraestrutura de torres pertinentes ao projeto CNPq número 486654/2013-3, ”Estudo de Consequências Hidrológicas, Meteorológicas, Climáticas Locais e Regionais da Substituição de Cerrado Nativo por Plantação de Eucalipto".

Aos professores Dr. Diogo, Diretor da Fazenda Água Limpa (FAL-UnB), Dra. Alba e Dr. José Carlos pelas explanações acerca do bioma cerrado e suas nuances.

Ao motorista da FAL, Sr. Milton Machado, pela escolha dos percursos definidores do cerrado e suas especificidades.

Ao Engenheiro Ismar da Radiobras, pelo empréstimo do material para desenvolvimento prático e calibragem do set-up de medidas.

Ao Engenheiro Silvio Boçon pelo fornecimento das cartas plani-altimétricas da FAL. À Professora Dra. Taís Pitta Cotta do Instituto de Química e ao Sr. João Batista, Diretor da Dioxil, pelo incentivo em todas etapas do desenvolvimento da tese. À CAPES, SENAI-DF e CNPq pelos três anos aporte financeiro via bolsas REUNI e $D T I-A$.

Giovanni César Ganime Alves

"Se consegui enxergar mais longe, é porque me apoiei em ombros de gigantes".

Sir Isaac Newton

Muito Obrigado aos "Gigantes": Professores Paulo Portela, João Paulo e Plínio.

"If I have seen further, it is because I have stood on the shoulders of giants". Sir Isaac Newton 


\section{RESUMO}

O cerrado é um bioma que demanda, no seu entorno urbanizado, a conjugação de atividades produtivas e práticas restritivas para conservação do núcleo das reservas de proteção ambiental. Se por um lado, as áreas suburbanas precisam cada vez mais de um avançado sistema de comunicações móveis, por outro lado, as unidades de conservação circunvizinhas destas áreas habitadas precisam dessas facilidades, porém com mínima equipagem invasiva em seus ricos ecossistemas.

A modelagem da propagação do canal móvel com ênfase no cerrado será abordada neste estudo com o objetivo de viabilizar o projeto de sistemas de comunicações móveis que atendam a esses segmentos. A faixa do espectro eletromagnético denominada de VHF/UHF, atualmente licenciada para transmissão de televisão, é altamente propícia a este cenário em termos do alcance e da adaptabilidade. O estudo da propagação no canal móvel baseado em modelos matemáticos determinísticos, empíricos, semi-empíricos e estatísticos foi realizado nas frequências de $144 \mathrm{MHz}$ e $435 \mathrm{MHz}$, com ênfase na caracterização dos fenômenos genericamente denominados de desvanecimentos.

Os dados experimentais advindos das campanhas de medição realizadas na Fazenda Água Limpa (FAL), sítio de permanente preservação ambiental e de desenvolvimento de estudos técnico-científicos da Universidade de Brasília (UnB), permitiram traçar perfis úteis à operação de comunicações móveis de última geração, validando assim o enfoque teórico da pesquisa. A FAL é um ambiente caracterizado pela predominância da matriz arbórea do tipo cerrado. Os dados experimentais foram compilados para o processamento e o pós-processamento utilizando-se de algoritmos computacionais especialmente desenvolvidas para este trabalho no âmbito do Laboratório de Estruturas de Micro-Ondas e Ondas Milimétricas (LEMOM), do Departamento de Engenharia Elétrica (ENE), da Faculdade de Tecnologia (FT), Universidade de Brasília.

Algumas das contribuições da pesquisa podem ser elencadas no seguinte: inédita modelagem analítica dos parâmetros de propagação do bioma cerrado contrastando os resultados das estações chuvosa e seca; adaptação de um transceptor comercial para funcionar como gerador estável de sinal ajustável; e procedimentos para realização de campanhas de medição em ambientes desprovidos de infraestrutura.

Palavras-Chave: bioma cerrado, campanha de medição, perda de propagação, desvanecimento, drive-test. 
The aim of this present study is to explore analytical modeling that validates the electromagnetic propagation at the biome "cerrado" - a Brazilian Savanna Forest. It emphasizes the viability of developing an advanced mobile radio network on a large area of this vegetation, which is the second most extensive ecosystem in Brazil. The study gets its importance by being a viable way to solve the conflict of interest between socialeconomic municipalities for productive land uses and the ecological zoning stations of native "cerrado" for permanent preservation tasks. To equalize the roles of socioeconomic wishes and environment protection, and at the same time be up-to-date with telecommunication segment, a mobile network into the low VHF/UHF electromagnetic spectrum - more precisely near the named " tv white spaces" segments of the spectrum was focused in this work. The methodology applied was based on mathematical empirical, semi-empirical, and statistical confronted with experimental data obtained by realistic drive-tests trails on "cerrado".

The measurements at "cerrado" were conducted on setting up a car for drivetesting trails in order to gather experimental data. The analysis characterizes fading and propagation loss parameters on the rich topographic profile covered with vegetation, predominately by the floristic type classified as "cerrado". The laboratory chosen to validate the theory was the permanent environment preservation station of the University of Brasilia-UnB, located around Brasilia downtown, known as "Fazenda Água Limpa" (FAL).

Some contribution of this research comprises an original analysis of propagation at Brazilian Savanna "cerrado" - similar to Venezuelan and Australian Savannas - on two representative white space frequencies of low VHF/UHF spectrum: $144 \mathrm{MHz}$ and 435 MHz. Another contribution is the step-by-step guideline to take field trail measurements in a wild area absent of energy infrastructure. Additionally a creative circuit was developed to convert a commercial PTT transceiver in a RF stable and adjustable generator. The text also sketches the propagation models, contrasting dry and wet climatic seasons. It could be a usable tool for planning new generation of mobile radio network in rural regions.

Keywords: biome, cerrado, path loss, fading, experimental results, tracks, drivetest. 
1 INTRODUÇÃO

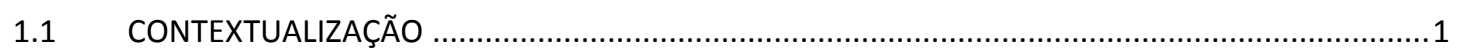

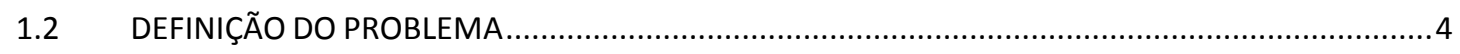

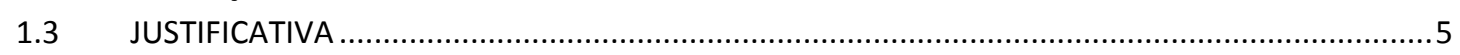

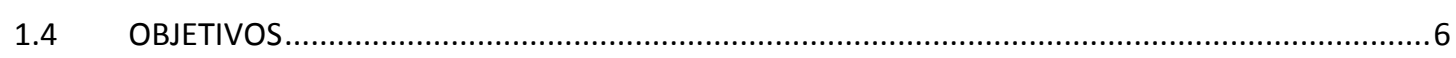

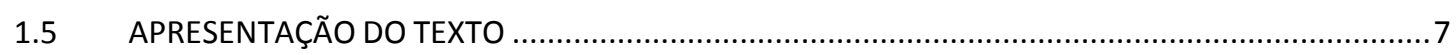

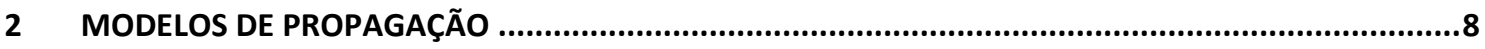

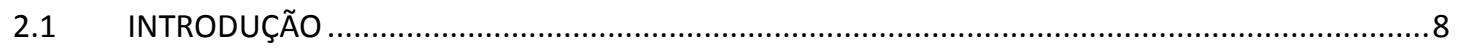

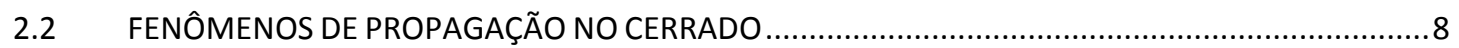

2.3 MODELOS L50

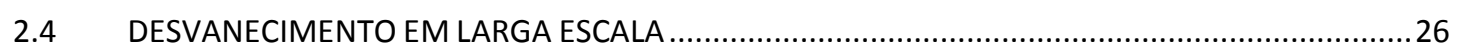

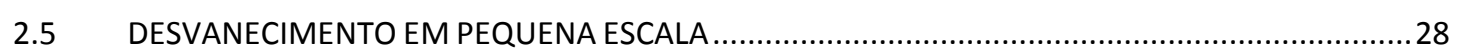

3 FUNDAMENTOS DA MEDIÇÃO DA PROPAGAÇÃO DE ONDAS ELETROMAGNÉTICAS …..................31

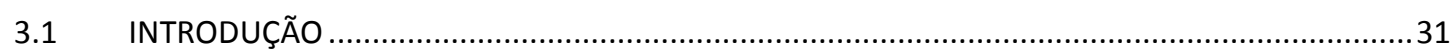

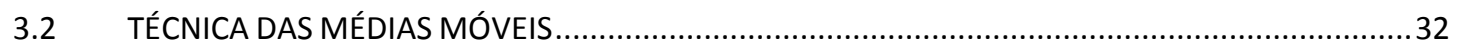

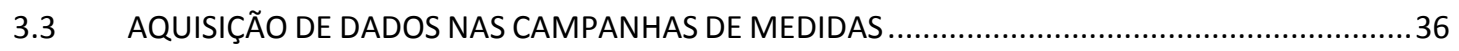

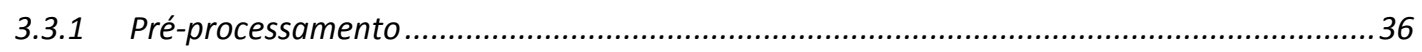

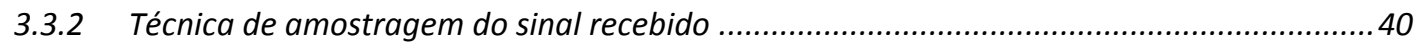

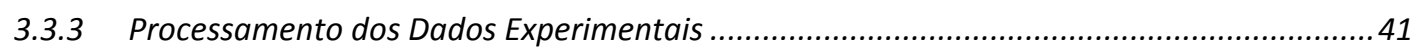

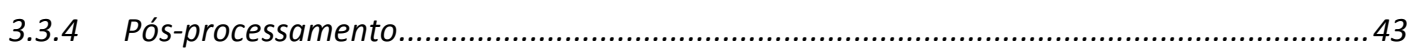

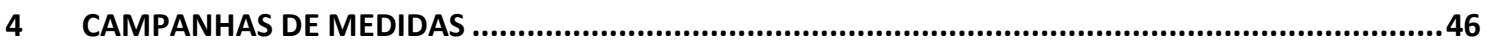

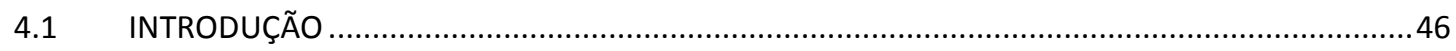

4.2 DESCRIÇÃO GERAL DO AMBIENTE DE MEDIDAS NO CERRADO ................................................46

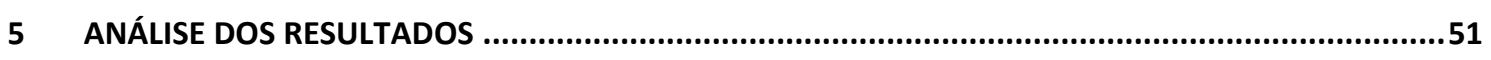

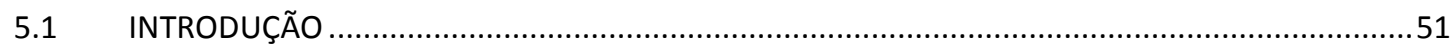

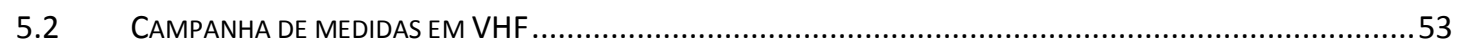

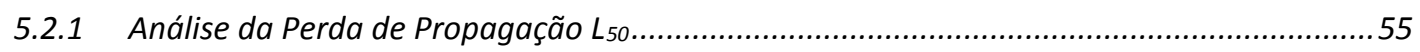

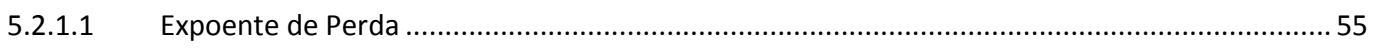

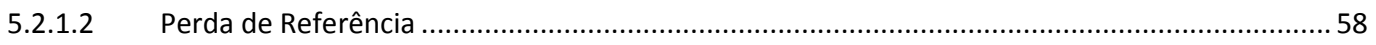

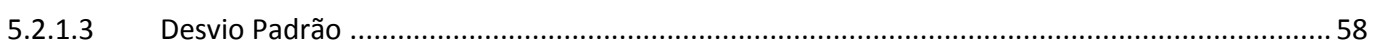

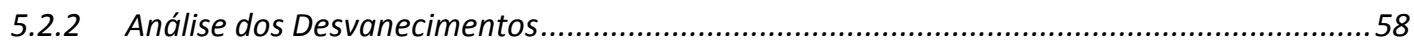

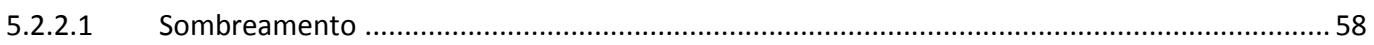

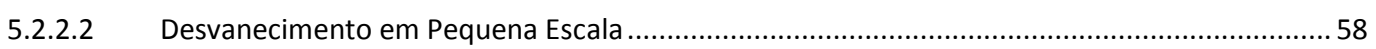

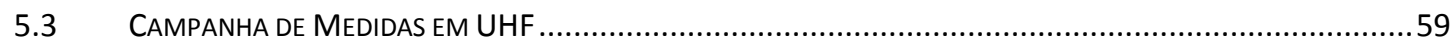

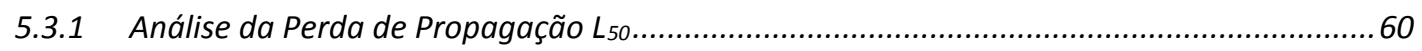

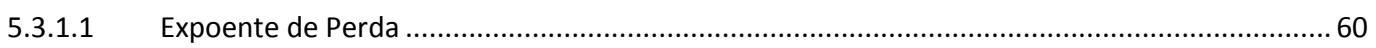

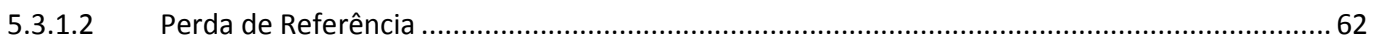

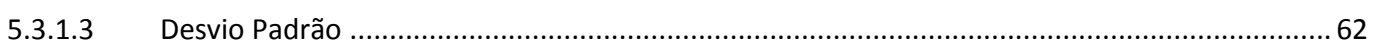

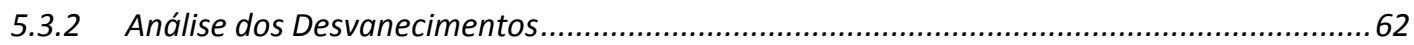

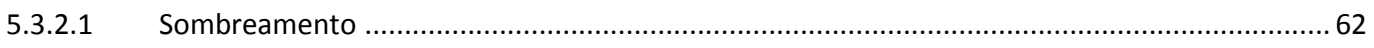

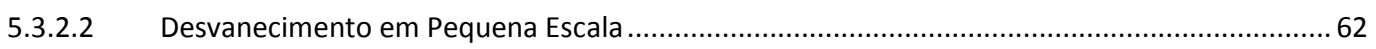

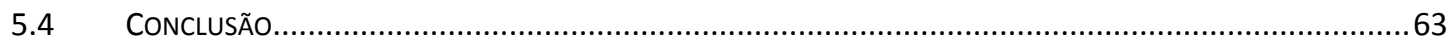




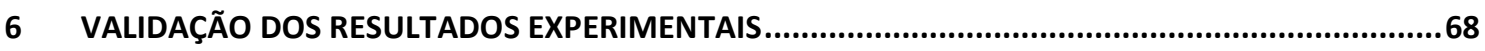

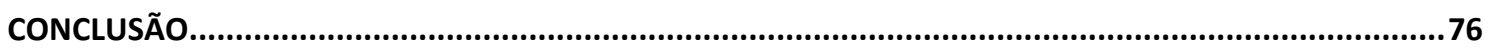

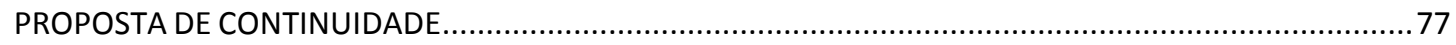

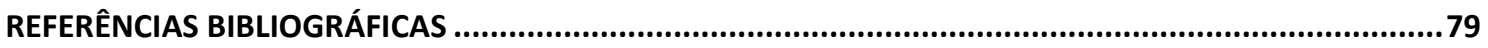

ANEXOS

I DEFORMAÇÕES NOS DIAGRAMAS DE RADIAÇÃO DAS ANTENAS DEVIDO A OBSTÁCULOS

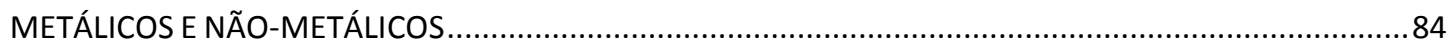

II ADAPTAÇÃO DE TRANSCEPTOR TIPO PTT PARA FUNCIONAR COMO GERADOR CW SINTONIZÁVEL 89

III EQUALIZAÇÃO DA ENERGIA FORNECIDA PELAS FONTES DE POLARIZAÇÃO DO TRANSCEPTOR .....89

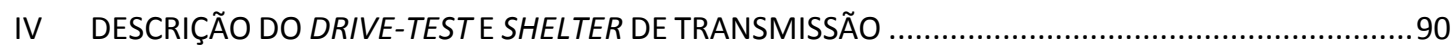

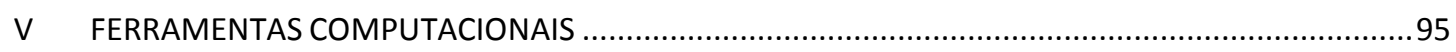

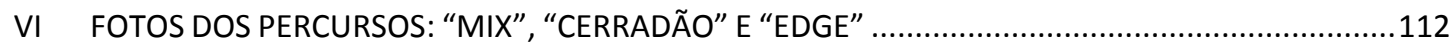




\section{LISTA DE FIGURAS}

Figura 1.1 Diagrama EM BLocos de UM tíPICO ENLACE DE COMUNICAÇÕES. (FonTE: ILUSTRAÇÃo ADAPTADA DE [1]).....1 FIGURA 1.2 DISTRIBUIÇÃO DA FITOFISIONOMIA E FITOGEOGRAFIA TíPICA DO BIOMA CERRADO (FONTE: RETIRADO DE [8]) .....2 FIGURA 1.3 VEGETAÇÃO TÍPICA DO CERRADO (FONTE: AUTOR) ......................................................................... 2 FIGURA 1.4 FRAÇÃO DO ESPECTRO REALÇANDO A FAIXA VHF/UHF BAIXO. (FONTE: AUTOR).........................................

FIGURA 1.5 CONTORNO DE ABRANGÊNCIA E DISTRIBUIÇÃO GEOGRÁFICA DO BIOMA CERRADO. (FONTE: IPEA-MAPA DO DELINEAMENTO AGRO-ECOLÓGICO DO BRASIL).....

FIGURA 2.1 ESBOÇO DE UM AMBIENTE RURAL E OS FENÔMENOS DE PROPAGAÇÃO A ELE ASSOCIADO: 1-ESPALHAMENTO, 2DIFRAÇÃO LAMINAR, 3-DIFRAÇÃO DE QUINA.

FIGURA 2.2 MÚLTIPLAS RESSONÂNCIAS OBSERVADAS NO ESTUDO DE PROPAGAÇÃO ELETROMAGNÉTICA POR ENTRE OS TRONCOS DE UMA FLORESTA CANÔNICA. (FONTE: RETIRADO DE [15] COM ADAPTAÇÕES).

FIGURA 2.3 FENÔMENOS DE PROPAGAÇÃO ADITIVO E MULTIPLICATIVOS QUE IMPACTAM O CANAL MÓVEL. (FONTE: ILUSTRAÇÃO ADAPTADA DE [1]).

FIGURA 2.4 GEOMETRIAS DOS MULTIPERCURSOS INCIDENTES NO SINAL TRANSMITIDO DECORRENTES DOS OBSTÁCULOS

ESTÁTICOS NO AMBIENTE. (FONTE: DESENHO ADAPTADO DE [23] PELO AUTOR) ............................................11

FIGURA 2.5 SINAL RECEBIDO PELA ANTENA DE UM MÓVEL QUE SE DESLOCA POR UMA ESTRADA. (FONTE: AUTOR) ...............12

FIGURA 2.6 ILUSTRAÇÃO DA EQUIVALÊNCIA GEOMÉTRICA DAS COPAS DAS ÁRVORES. (FONTE: AUTOR) .............................13

FIGURA 2.7 ESBOÇO DOS MECANISMOS DE PROPAGAÇÃO NA FLORESTA. (FONTE: AUTOR) ........................................... 14

FIGURA 2.8 DESENHO DA PAISAGEM DO CERRADO NO VERÃo ÚMIDO. (AUTORA: CAMILLA SANTOS DANTAS) .....................15

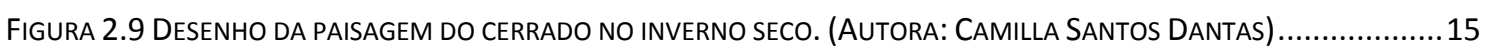

FIGURA 2.10 ILUSTRAÇÃO DA DIFRAÇÃO EM UMA ÁRVORE. (FONTE: AUTOR) ........................................................ 16

FIGURA 2.11 AMBIENTE CONSTITUÍDO POR MÚLTIPLOS OBSTÁCULOS, NESTE ESTUDO, ÁRVORES. (FONTE: AUTOR) .............17

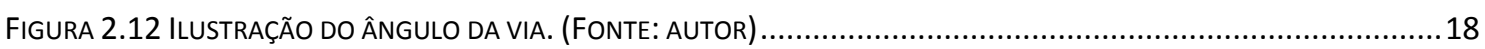

FIGURA 2.13 AMBIENTE PROPÍCIO À APLICAÇÃO DO MODELO MÚLTIPLAS MORFOLOGIAS. (FONTE: AUTOR) ......................25

FIGURA 2.14 AMBIENTE QUE PODE OCASIONAR DIFICULDADES PARA O MODELO MÚLTIPLAS MORFOLOGIAS. (FONTE: AUTOR)

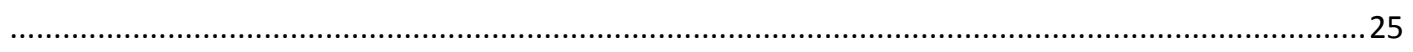

FIGURA 2.15 MODELO DE MÚLTIPLAS MORFOLOGIAS DESTACANDO OS MÚLTIPLOS EXPOENTES DE PERDA.........................26

FIGURA 2.16 DESVANECIMENTO EM LARGA ESCALA: SOMBREAMENTO, HISTOGRAMA EXPERIMENTAL VERSUS DISTRIBUIÇÃO

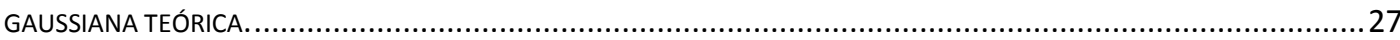

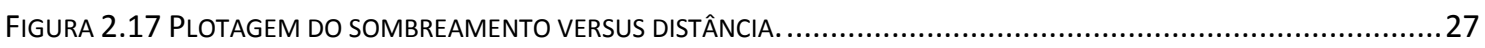

FIGURA 3.1 EM AZUL E VERMELHO ILUSTRA-SE A SOBREPOSIÇÃO DOS DESVANECIMENTOS DE PEQUENA ESCALA E DE LARGA ESCALA, E GRAFADO EM PRETO DESTACA-SE O DESVANECIMENTO EM PEQUENA ESCALA. CAMPANHA DE MEDIDAS REALIZADA NO PERÍMETRO DO CAMPUS DARCY RIBEIRO EM $144 \mathrm{MHZ}$.

FIGURA 3.2 ILUSTRAÇÃO ESBOÇANDO O AVANÇO DA JANELA MÓVEL POR ENTRE AMOSTRAS DE SINAL RECEBIDO EXTRAÍDAS DE UM SUPOSTO ARQUIVO BRUTO DE MEDIDAS DO SINAL MEDIDO PELO DRIVE-TEST EM UMA CAMPANHA DE MEDIDAS QUALQUER

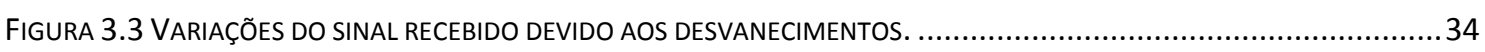

FIGURA 3.4 ESBOÇO DO ALARGAMENTO DO SINAL DE RECEPÇÃO DEVIDO ÀS CONDICIONANTES PRÁTICAS...........................37

FIGURA 3.5 LINHA DO TEMPO DE ATUALIZAÇÃO DO GPS E ARMAZENAMENTO DOS DADOS NO LAPTOP. (FONTE: ILUSTRAÇÃO

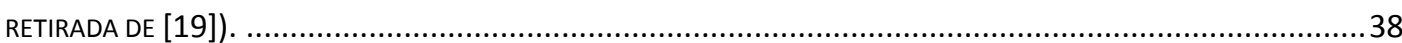

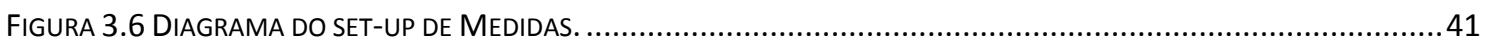

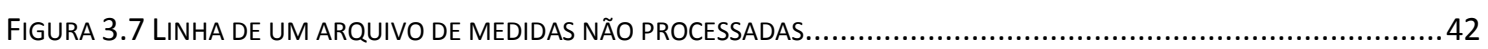

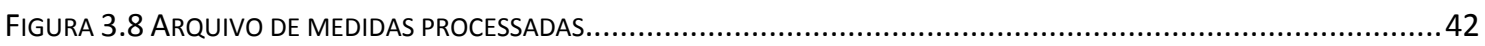

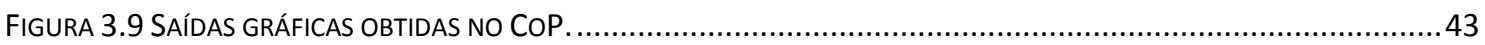

FIGURA 3.10 PROGRESSÃO DO DISTANCIAMENTO DO DRIVE-TEST EM RELAÇÃO À TORRE DE TRANSMISSÃO, RESULTADO DO

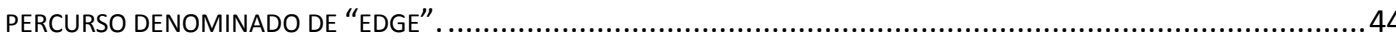

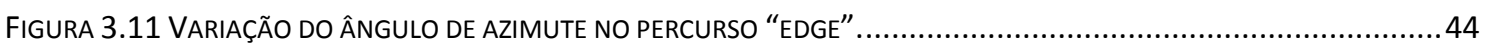




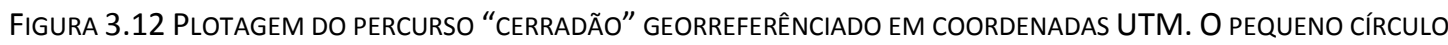
ASSINALADO EM VERMELHO É A LOCALIZAÇÃO DA TORRE E O CÍRCULO VERDE É O PONTO DE PARTIDA DO DRIVE-TEST. . 45

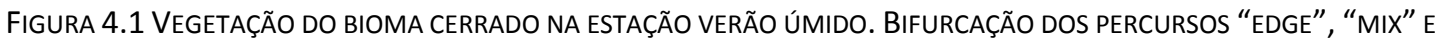

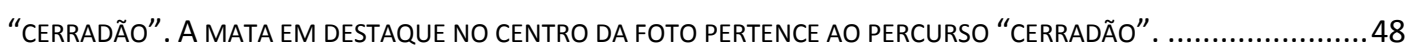

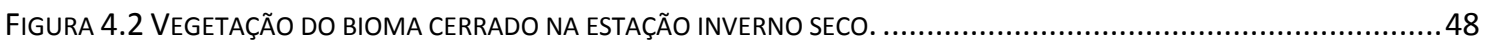

FIGURA 4.3 CURVAS DA PLANA-ALTIMETRIA DA FAL DESTACANDO A VEGETAÇÃO E USO DA TERRA (FONTE: FORNECIDO PELO SETOR DE CARTOGRAFIA DA PolíCIA CIVIL DE BRASÍLIA) .................................................................... 50

FIGURA 5.1 REGRESSÃO LINEAR DOS RESULTADOS EXPERIMENTAIS, TORRE DE 10 METROS, $144 \mathrm{MHZ}$.........................53

FIGURA 5.2 PERdA DE PROPAGAÇÃO, “MIX”, 144 MHz, 24 METROS, ÚMIDO......................................................55

Figura 5.3 PERdA de PROPAGAÇÃO, “EdGE”, 144 MHz, 24 METROS, SECO........................................................56

FIGURA 5.4 PERdA DE PROPAGAÇÃO, “EDGE”, 144 MHz, 10 METROS, ÚMIDO.....................................................56

Figura 5.5 Perda de PropagaçÃo, “CerRadão”, 144 MHz, 10 MEtros, SECO. ................................................57

Figura 5.6 PERdA de PROPAGAÇÃO, “CERRAdão”, 144 MHz, 10 METROS, ÚMIDO. .............................................57

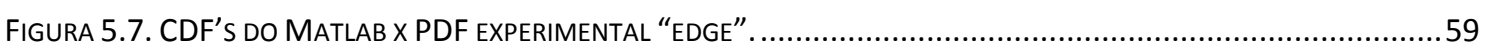

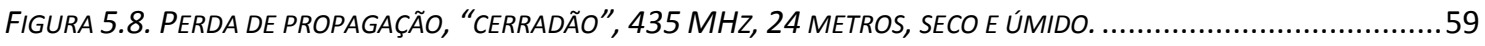

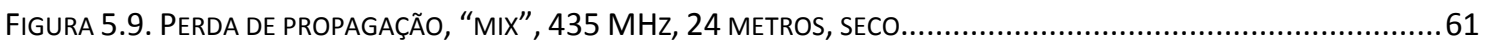

FiguRA 5.10 SOMBREAMENTO do PERCURSO “CERRAdÃO”, SECO, 435MHz, 24 METROS........................................62

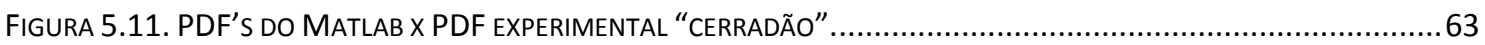

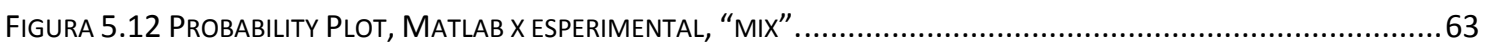

FIGURA 5.13. REgRESSÃo linEAR, “EdGE”, 144 E 435 MHz, 10 METROS, SECO/ÚMIDO.......................................64

FIGURA 5.14. REgRESSÃo linEAR, “CERRAdÃO”, 144/435 MHz, 10 METROS, SECO/ÚMIDO. ...................................65

Figura 5.15. REgRESSÃo lineAR, “CERRAdÃO”, 144/435 MHz, 10/24 METROS, SECO/ÚMIDO................................65

FIGURA 6.1. MODELO UTILIZADO PARA COLIGIR RESULTADOS TEÓRICOS COM RESULTADOS EXPERIMENTAIS......................71

FIGURA 6.2 PERFIL ALTIMÉTRICO: EM VERDE-FLORESTA, EM VERMELHO-LINHA DE VISADA, EM PRETO-RELEVO, EM MARROM SUPERFÍCIE ESFÉRICA IMAGINÁRIA, A - ÂNGULO RASANTE.

FIGURA 6.3 IMAGEM ESBOÇANDO RESULTADO DA SIMULAÇÃO TLM APLICADA EM CONJUNTO DE 100 BLOCOS JUSTAPOSTOS

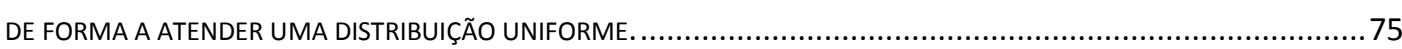

FIGURA I.1 TORRE DE 10 METROS. No VÉRTICE MAIS A DIREITA ESTÁ A ANTENA DE 144 [MHz]..................................84

FIGURA I.2 TOPO DA TORRE DE 24 METROS. NO VÉRTICE MAIS A DIREITA ESTÁ A ANTENA DE 144 [MHZ]. ......................85

FIGURA I.3 ANTENA DE 435 MHZ PRESA À TORRE DE 10 [M] POR UMA ESTRUTURA METÁLICA DO TIPO MÃO-FRANCESA

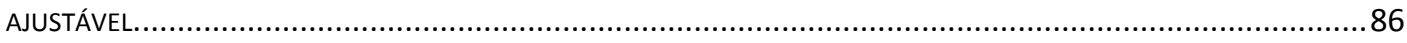

FIGURA I.4 DISPOSIÇÃO DA ANTENA DE 435 MHZ E OBSTÁCULOS (SENSOR+HASTE DO PARA-RAIOS). SAÍDA GRÁFICA dO SOFTWARE DE SIMULAÇÃO [52, 53].

FIGURA I.5 SAÍDA GRÁFICA DO SOFTWARE DE SIMULAÇÃO. DIAGRAMA POLAR DE RADIAÇÃO PLANO HORIZONTAL [52-53]. . 88 FIGURA I.6 SAÍDA GRÁFICA DO SOFTWARE DE SIMULAÇÃO. DIAGRAMA POLAR DE RADIAÇÃO PLANO VERTICAL [52, 53] ......88 FIGURA II.1 ESBOÇO DO CIRCUITO DE ACIONAMENTO PARA TRANSMISSÃO DO MODO CW CONECTADO À ENTRADA DO PTT DO

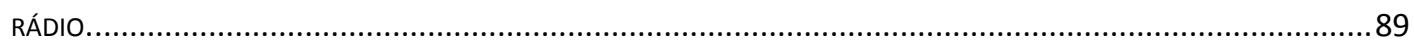

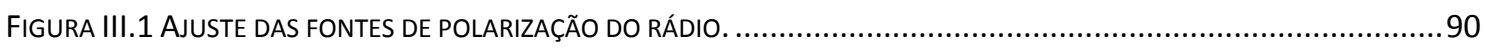

FIGURA IV.1 ESBOÇO DO VEÍCULO USADO NAS CAMPANHAS DE MEDIDAS COMO SHELTER DO TRANSMISSOR ......................93

FIGURA IV.2 EQUIPAMENTOS COLOCADOS NO INTERIOR DO VEÍCULO SHELTER ESTACIONADO AO PÉ DA ANTENA ................93

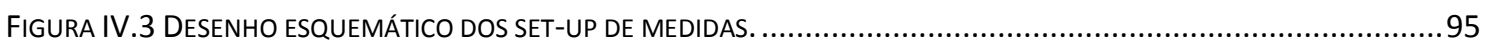

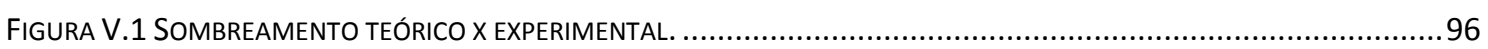

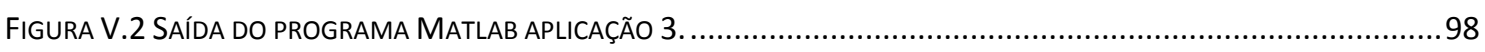

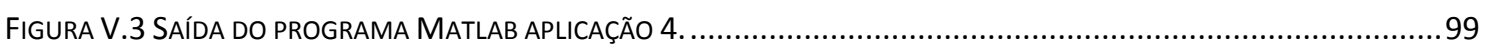

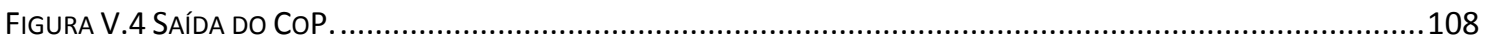

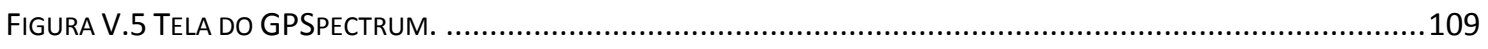

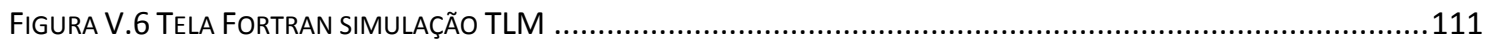

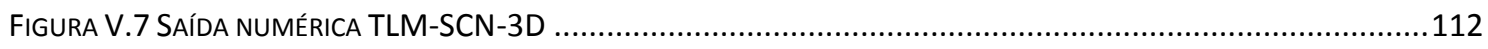

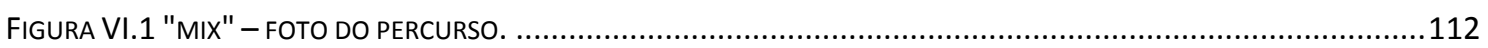

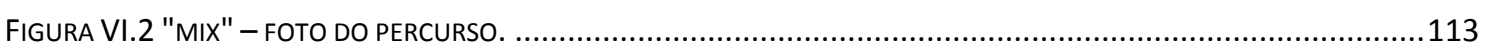


FIGURA VI.3 "MIX" - FOTO DO PERCURSO.

FIGURA VI.4 "CERRADÃO" - FOTO DO PERCURSO

FIGURA VI.5 "CERRADÃO" - FOTO DO PERCURSO

FIGURA VI.6 "CERRADÃO" - FOTO dO PERCURSO

FIGURA VI.7 "EDGE" - FOTO DO PERCURSO.

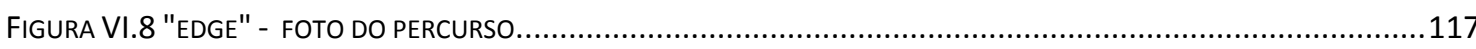

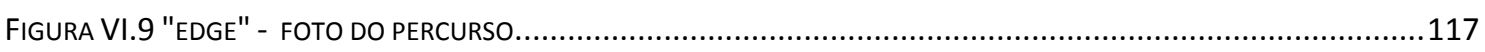

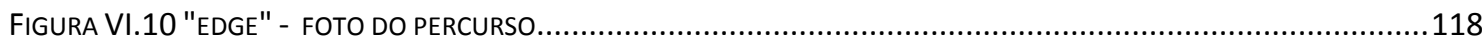

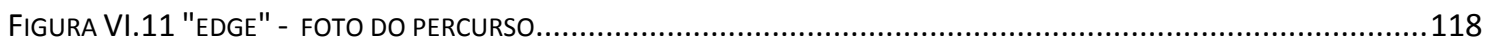




\section{LISTA DE TABELAS}

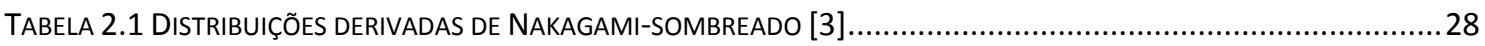

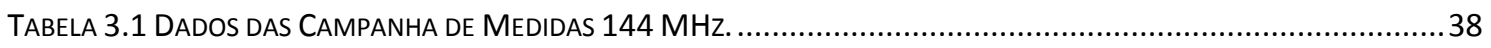

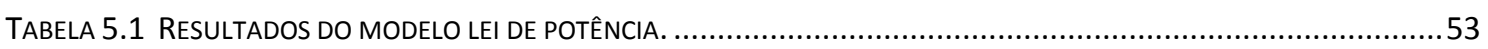

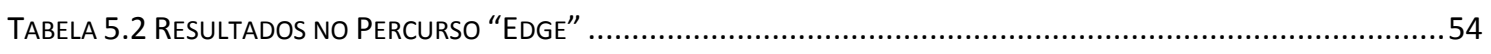

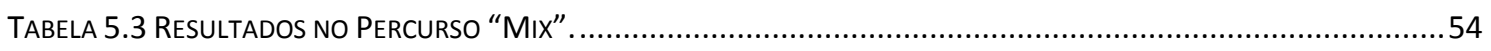

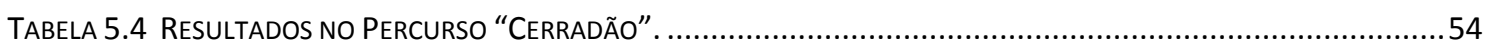

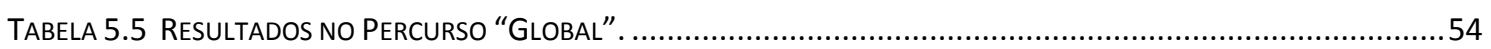

TABELA 5.6 Resultados na PlantaÇão de Eucalipto e CERRAdo CAMPo Sujo......................................................54

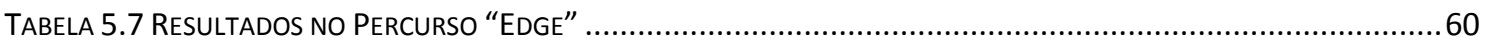

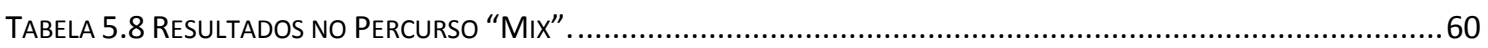

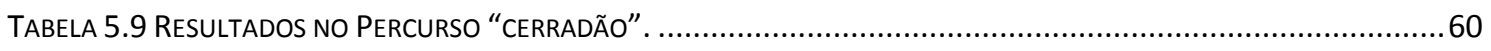

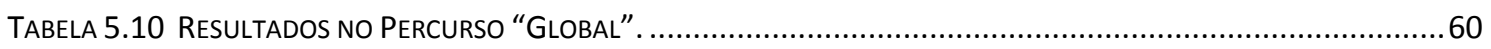

TABELA 6.1 VALIDAÇÃO dOS RESULTADOS EXPERIMENTAIS COM OS MODELOS DE SAUNDERS - IKEGAMI, TORRE DE 10

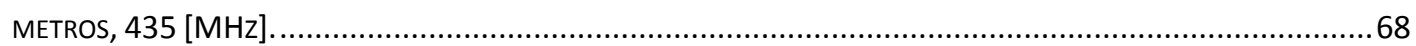




\section{LISTA DE ABREVIAÇÕES}

DEM Digital Elevation Map

ERB Estação Rádio-Base

GIS Informações Geográficas - Geographic Information System

GPS Global Position System

GSM Global Mobile System

ITU-R Radiocommunication Sector of International Telecommunication Union

LEMOM Laboratório de Estruturas de Micro-Ondas e Ondas Milimétricas

(N)LOS Linha de visada (Line of Sight) ou não-linha de visada

RF Frequência de Rádio (Radio Frequency)

VHF Alta Frequência (Very High Frequency)

UHF Ultra Alta Frequência (Ultra High Frequency)

FAL Fazenda Água Limpa (UnB)

FT Faculdade de Tecnologia

ENE Departamento de Engenharia Elétrica (UnB)

COP Programa de Predição de Cobertura (Coverage Predictor)

UTM Coordenadas Geográficas Plano Retangulares (Universal Terrain Measurement)

GIS Geographic Information System

WGS World Geographic System

PTT Push to Talk

CW Portadora de frequência fixa (Continuous Wave)

UnB Universidade de Brasília 
COST European Cooperative Group for Scientific and Technical Research

NMT Nordic Mobile Telecommunication

PDF Função Densidade de Probabilidade (Probability Distribution Function)

CDF Função Distribuição Acumulada (Cumulative Distribution Function) VSWR Razão da voltagem de onda estacionária (Voltage Standing Wave Ratio)

GPIB Cabo interface de comunicação entre instrumentos de medição e notebook (General Purpose Interface Bus)

TLM-SCN-3D Método numérico de análise de estruturas (Transmission Line Modeling Method-Symmetrical condensed node)

LTE Sistemas de comunicações móveis de 4 a geração (Long-term evolution) 


\section{INDEXAÇÃO DE GRÁFICOS E TABELAS}

$\left[\mathrm{F}_{0}, \mathrm{H}_{\mathrm{t}}\right.$, Trajeto, Clima] data

$F_{0}$----------- 1= 144 MHz, 2= 435 MHz

$\mathrm{H}_{\mathrm{t}}$------------- 1= 10 metros, 2= 24 metros

Percursos---- 1= Mix, 2= Edge, 3= Cerradão, 4=Global

Clima-------- 1= Úmido, 2= Seco

Data---------- dia/mês/ano 


\section{INTRODUÇÃO}

\subsection{CONTEXTUALIZAÇÃO}

Os recursos de tratamento de sinal agregando técnicas de précondicionamento antes da transmissão pelo canal são insuficientes para eliminar as distorções causadas pelos fenômenos de propagação eletromagnética no canal móvel no que tange à relação sinal/ruído [1, 2, 3]. Esse é um dos motivos da ocorrência de quedas esporádicas e interrupções intermitentes nas ligações em curso. Adicionalmente, esses recursos comprometem a latência (tempo de processamento) e também provocam maior dispêndio de energia nos sistemas envolvidos: estações rádio-base e, principalmente, dispositivos móveis. O planejamento e o dimensionamento de um sistema de comunicações móveis demandam o conhecimento preditivo dos parâmetros de propagação que influenciam no alcance, na área de cobertura e na disponibilidade do serviço para pretensos usuários. A modelagem do canal móvel é uma ferramenta útil para configurar uma rede de rádios em um ambiente de geomorfologia complexa. A Fig. 1.1 apresenta o diagrama em blocos típico de um transceptor interposto por um canal móvel, o retângulo tracejado destaca o canal, alvo deste estudo.

A modelagem do canal configura-se geralmente na forma de expressões matemáticas que representam o comportamento da propagação no ambiente de interesse. A geomorfologia da região de abrangência de múltiplas estações rádio base que suportam um sistema de comunicações móveis acarreta perfis de respostas distintas em função do tempo, do espaço e da frequência devido à distribuição de obstáculos móveis e estáticos que compõem o ambiente de propagação.

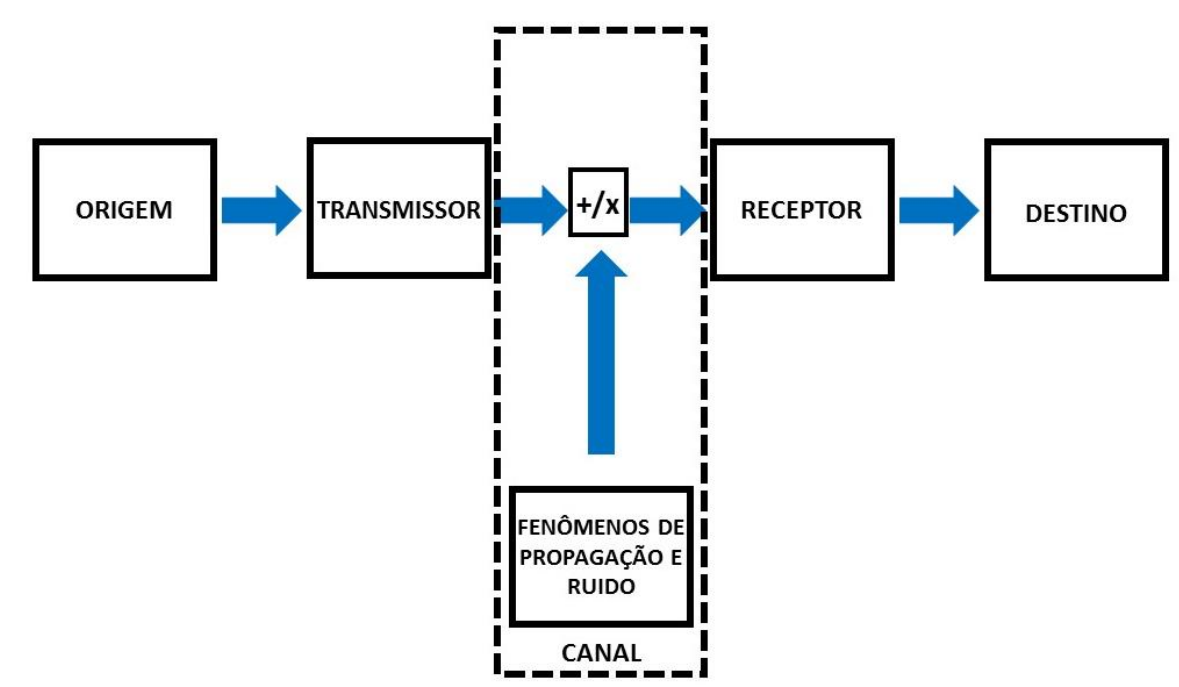

Figura 1.1 Diagrama em blocos de um típico enlace de comunicações. (Fonte: Ilustração adaptada de [1]).

O ambiente de comunicações é abundante em elementos geográficos, urbanísticos e fitogeográficos dispostos de forma arbitrária na linha de visada entre o transmissor e o receptor. Em geral, em um ambiente de comunicações móveis, a estação rádio base está situada acima da altura média das 
edificações enquanto que o dispositivo móvel de recepção se encontra em posição geográfica onde não há uma linha de visada (NLOS) entre a estação e o dispositivo de recepção. A fitogeografia do ambiente rural, núcleo temático deste estudo, pode ser descrita como uma justaposição de obstáculos multiformes.

A vegetação arbórea no bioma cerrado apresenta-se com espaçamentos entre seus elementos distribuídos de forma aleatória e de dimensões verticais e horizontais desuniformes, incrustados em relevo de topografia ligeiramente irregular, conforme mostrado nas Figs. 1.2 e 1.3. A Fig. 1.2 mostra a fitofisionomia do cerrado, destacando os tipos de vegetação encontrados nos percursos das campanhas de medidas. É neste ambiente de elevada complexidade geomorfológica que este trabalho se enquadra e se insere.

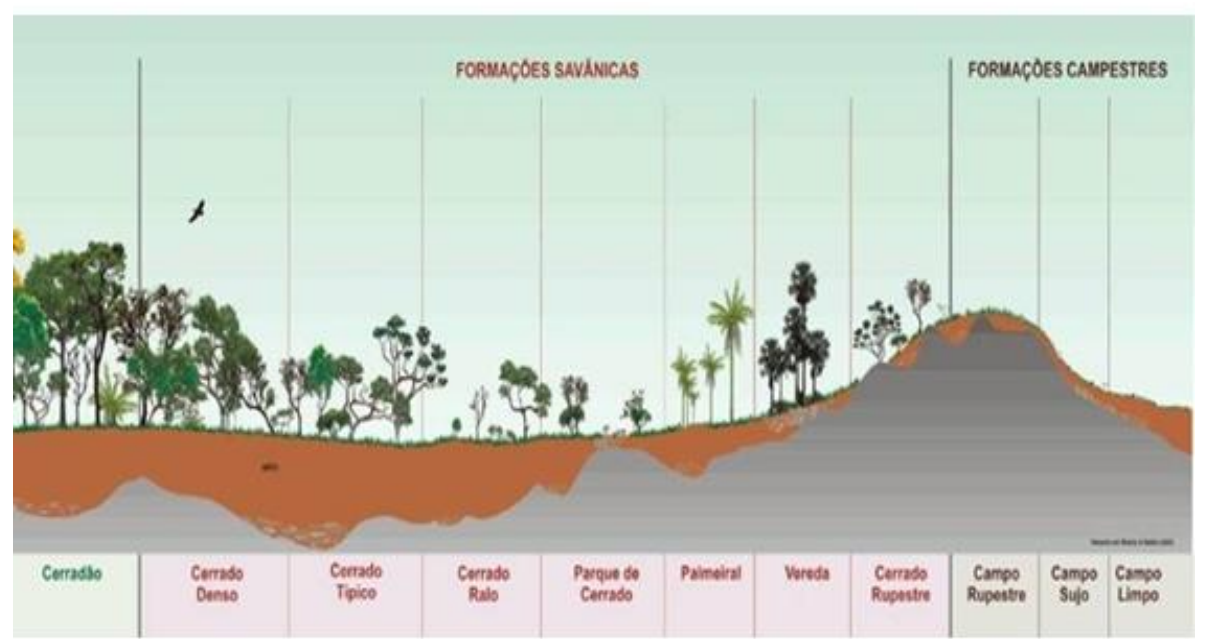

Figura 1.2 Distribuição da fitofisionomia e fitogeografia típica do bioma cerrado (Fonte: retirado de [8])

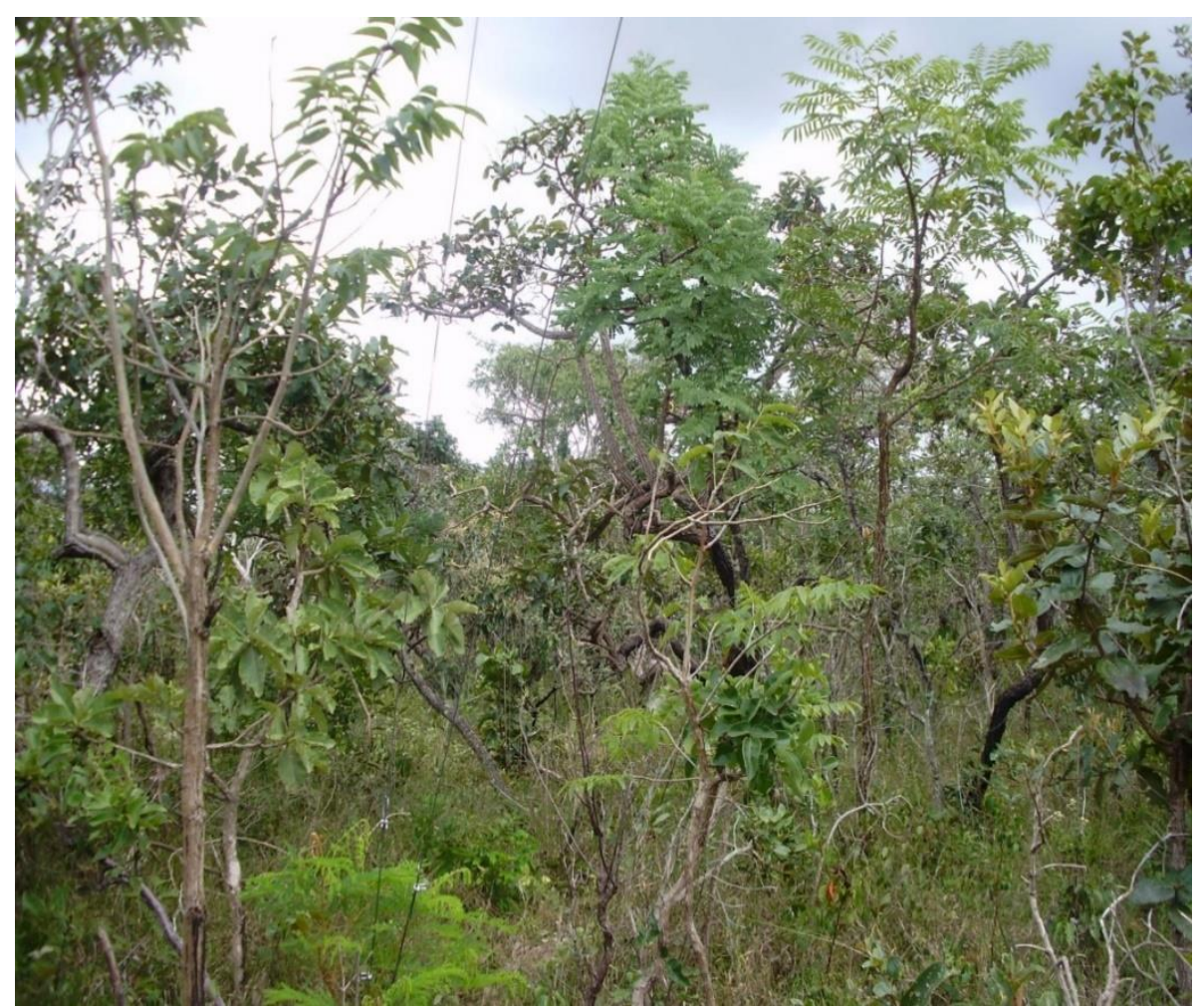

Figura 1.3 Vegetação típica do cerrado (Fonte: autor) 
A banda espectral VHF/UHF tornou-se relevante para a engenharia de comunicações móveis. A reorganização das faixas espectrais visando atender à tecnologia da televisão digital de alta definição resultará ao final do período de realocação na aglutinação de maior número de canais digitais em menor parcela espectral. A relação está em torno de 3 a 5 canais digitais ocupando a parcela espectral de um canal analógico devido à incorporação de novas técnicas de modulação e codificação. Além disso, em fóruns internacionais tem-se discutido e reivindicado esta faixa desocupada, designada como TV White Spaces, para uso rural devido aos atributos intrínsecos de alcance, custos de implantação e operação, além de baixo impacto ambiental [4]. A Fig. 1.4 esboça a divisão do espectro na faixa do VHF/UHF e assinala alguns serviços e designação de canais.

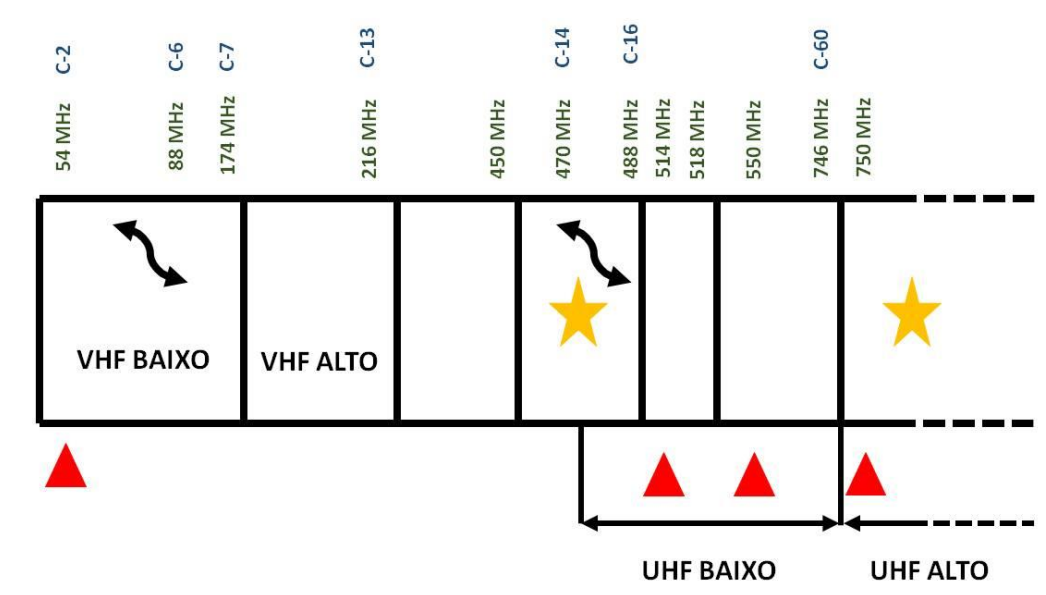

Figura 1.4 Fração do Espectro realçando a faixa VHF/UHF baixo. (Fonte: autor)

Legenda da Fig. 1.4:

- operação não-licenciada de microfones sem fio 450-488 MHz e 72-76 $\mathrm{MHz}$

- operação comercial de sistemas de telefonia móvel (NMT 450 e NMT 700, GSM 480, LTE 750 e 450 existentes)

- fatias de interesse para operar novos sistemas e tecnologias de comunicações móveis.

C-No - designação internacional para canais VHF/UHF

Os resultados teóricos e práticos que fazem parte do escopo deste trabalho são aplicáveis à caracterização das perdas de propagação em duas frequências representativas do VHF e UHF, próximas aos segmentos do espectro reservado para televisão: $144 \mathrm{MHz}$ e $435 \mathrm{MHz}$, conforme Fig. 1.4. O fato é que alguns sistemas de comunicações móveis já operam em diversos adensamentos demográficos, especificamente na faixa de $400 \mathrm{MHz}$, de 411 a $496 \mathrm{MHz}$, sistemas designados como: LTE 450, GSM 480 e NMT-450.

Há uma forte demanda para que uma moderna infraestrutura de comunicações móveis atenda políticas sustentáveis de preservação de cunho socioambiental nos biomas brasileiros [5]. Uma das estratégias consideradas 
trata-se da provisão de meios para a fixação de uma comunidade com elevado grau de consciência ecológica nas regiões que contornam as áreas de preservação permanente. Para isso, um robusto e moderno sistema de comunicações móveis é essencial para dar suporte às operações visando o monitoramento, a guarda e combate a queimadas destas zonas rurais. Concomitantemente a isso, é primordial o acesso a serviços de banda larga para que as comunidades possam usufruir das modernidades oferecidas pelos sistemas de comunicações móveis disponibilizadas nos grandes centros urbanos.

O cerrado é um dos biomas com maior grau de degradação por conta da crescente lucratividade gerada pelo agronegócio nas imensas áreas plantadas com soja, que avança sobre áreas de preservação, fragmentando as áreas de floresta natural $[6,7]$.

\subsection{DEFINIÇÃO DO PROBLEMA}

De forma a estar alinhado com as pesquisas atuais - que estudam a viabilidade técnica de prover sistemas avançados de comunicações móveis em ambientes fora do perímetro urbano, escolheu-se o bioma cerrado para efeito de modelagem. O bioma cerrado foi estudado com maior profundidade e modelado por meio de intensas campanhas de medidas, nas quais se se evidenciou a complexidade em modelar ambientes multifacetados repletos de singularidades e variabilidades. $\mathrm{O}$ trabalho explora as variabilidades climáticas na caracterização da propagação, aspecto de alta relevância em se tratando do bioma cerrado, dando ênfase a essencial caracterização do comportamento do canal móvel nas distintas fitofisionomias do bioma a partir de levantamento experimental.

Faz parte também do escopo do trabalho identificar os melhores modelos de propagação que cobrem as peculiaridades descritas pela fitofisionomia intrínseca ao cerrado [8]. Ressalta-se, na análise dos resultados, a interação da energia propagante com as singularidades da vegetação que caracteriza o cerrado, sendo assim uma abordagem inovadora e necessária para justificar os resultados obtidos.

Os resultados já divulgados e publicados acerca da propagação em ambientes de floresta no Brasil se resumem a florestas tropicais úmidas $[9,10$, 11] que apresentam um regime de chuvas bem distribuído ao longo do ano, sem uma estação seca pronunciada. Esses ambientes possuem elevado grau de uniformidade, independente de fatores sazonais, com formação florestal diversificada e elevado número de indivíduos de mesma espécie por área geográfica, densidade arbórea maior que o bioma cerrado, por isso, apresentam maior conformidade com a expectativa teórica já consagrada para modelagem do canal móvel. 
No estudo presente, as métricas estatísticas (desvio padrão, valor médio, histogramas e distribuições teóricas) que predizem o comportamento da propagação no canal móvel, tais como perda de propagação e desvanecimentos, são analisadas à luz de fatores bióticos e abióticos que caracterizam o bioma cerrado, que é diferente das florestas tropicais densas e subtropicais, por apresentar variações contrastantes entre verão úmido e inverno seco, além de inúmeras formações florísticas.

O estudo da propagação em ambiente de floresta é complexo e os recentes trabalhos científicos $[9,10,11,12,13,14]$ consideram que os resultados experimentais prevalecem sobre modelos advindos de simulações baseadas em distribuições fictícias de vegetação; isto é, modelos canônicos. 0 modelo biofísico, citado por alguns autores [10, 15], não fornece soluções consistentes quando aplicado ao Brasil, pois inexiste um inventário dos elementos constituintes das florestas voltados ao estudo de propagação. A solução analítica mais satisfatória envolve expressões complexas enunciadas em termos de diádicas de Green [14], que modela bem alguns biomas, no entanto tem aplicabilidade prática limitada [16].

A botânica associada à topografia que compõe a morfologia intrínseca ao bioma cerrado é difícil de ser modelada por estruturas uniformes, conforme ilustrado nas fotografias que compõem o Anexo V. No âmbito dos biomas brasileiros, os estudos até o momento concentram em sua maioria na floresta tropical fechada, densa e úmida da região amazônica $[9,10,11]$. Os biomas até então estudados sob o ponto de vista de propagação eletromagnética não se assemelham ao encontrado no cerrado. Por outro lado, a inserção de transmissor e receptor na vegetação do bioma, conforme abordado nos trabalhos de campo deste estudo, é uma abordagem pouco explorada devido às dificuldades práticas para manter o transmissor abrigado e climatizado a valores constantes, conforme será descrito no Anexo IV.

\subsection{JUSTIFICATIVA}

O enfoque deste estudo está na modelagem da propagação móvel no cerrado, bem como na caracterização do canal móvel por meio de campanhas de medidas em distintas morfologias que congregam especificidades demográficas, topográficas, cartográficas, geográficas e florísticas do cerrado. $\mathrm{O}$ tratamento dos dados experimentais no cerrado, abordagem central deste estudo, gerou o desenvolvimento de 14 programas escritos na linguagem Matlab, sintetizados no Anexo $\mathrm{V}$, aplicáveis a estudo de outros biomas, conforme resultados já divulgados em [17].

No bioma cerrado foram realizadas inúmeras coletas de dados de propagação eletromagnética devido à relevância social e econômica para o Centro-Oeste e demais regiões cobertas por este tipo de vegetação. Trata-se do segundo bioma de maior ocorrência na geografia do Brasil. A Fig. 1.5 ilustra 
as manchas territoriais que delimitam a superfície geográfica coberta com vegetação tipificada como cerrado no Brasil.

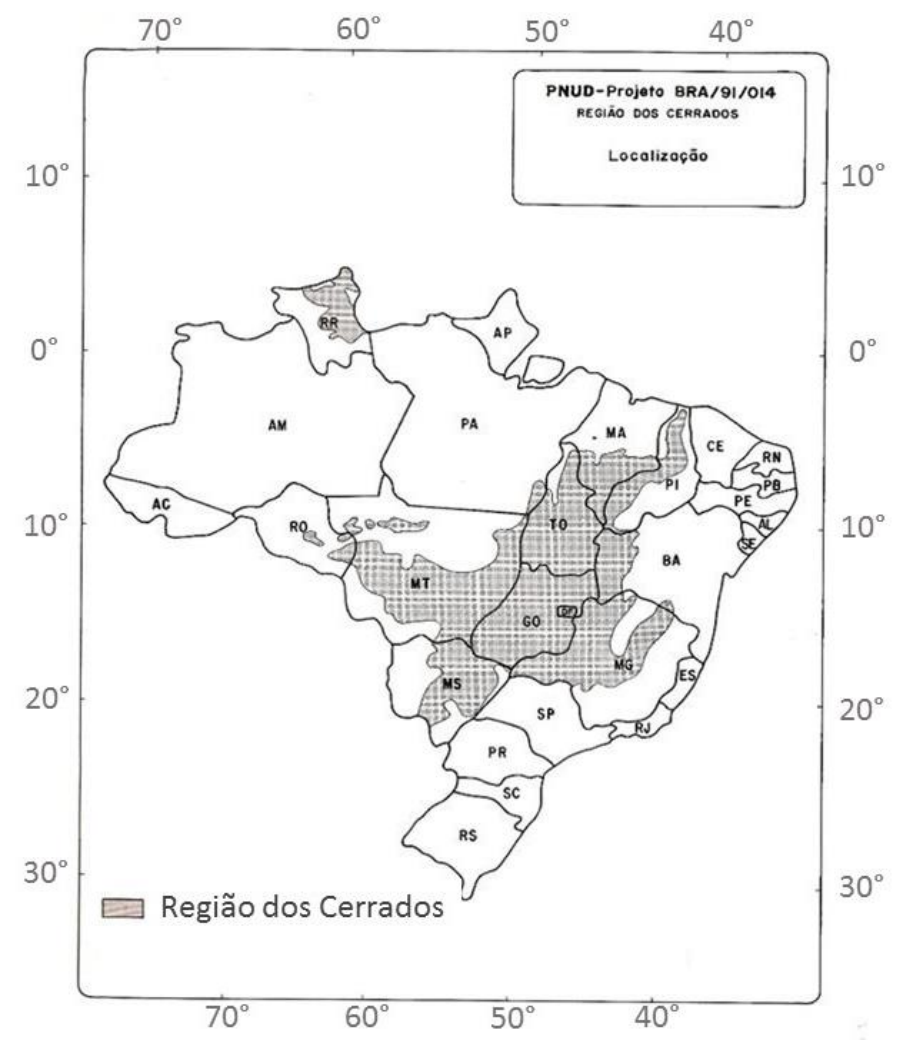

Figura 1.5 Contorno de abrangência e distribuição geográfica do bioma Cerrado. (Fonte: IPEA-Mapa do Delineamento agro-ecológico do Brasil).

\subsection{OBJETIVOS}

O trabalho tem por objetivo geral identificar de forma abrangente os modelos de propagação eletromagnética que melhor se ajustem aos distintos perfis do bioma cerrado contemplando a variabilidade estatística do canal móvel em função do espaço percorrido por um dispositivo móvel. Por conseguinte, os resultados constituem um arcabouço de informações facilitadoras aos desenvolvedores de uma rede móvel em ambientes com adensamento demográfico de graduação variável tendente ao estritamente rural.

O trabalho não se restringe ao aspecto de identificar modelos de propagação válidos para o cerrado, base estratégica para a configuração de redes móveis, mas também explica os fenômenos eletromagnéticos que impactam a perda de propagação e os desvanecimentos. As saídas gráficas e numéricas dos programas montados para o processamento geraram a caracterização dos desvanecimentos: larga escala e pequena escala. Frisa-se que escala aqui se refere à fração do comprimento de onda da portadora transmitida. Os gráficos do enfraquecimento do sinal transmitido em função da distância percorrida fazem parte do arcabouço de resultados associados à propagação em ambiente de floresta.

A estatística dos resultados experimentais explicitada mediante histogramas (polígono de frequências dos dados de medidas) quando confrontada com histogramas teóricos busca de forma interativa atingir como meta um grau de similaridade o mais próximo a 95\% [18]. 
A estatística do sombreamento é modelada como uma função de densidade de probabilidades no formato gaussiano. O desvanecimento de pequena escala tem que ser validado por critérios de aderência, teste de similaridade com diversas distribuições consagradas que constam do estudo de processos estocásticos aplicados ao processamento de sinais randômicos $[19,20,21]$.

\subsection{APRESENTAÇÃO DO TEXTO}

O texto está organizado a partir do primeiro capítulo da seguinte forma: o capítulo 2 é dedicado a apresentar a fundamentação teórica dos modelos de propagação e fenômenos de propagação mediante ilustrações e comentários com enfoques rápidos e essenciais visando dar lastro à discussão dos resultados experimentais. Os modelos e os desvanecimentos fundamentais à compreensão da propagação no cerrado foram descritos com maior nível de detalhamento. Da mesma forma, em seguida, faz-se um apanhado dos conceitos de estatística voltados à caracterização dos desvanecimentos associados à perda de propagação. Por se tratar de tópicos recorrentes nos livros clássicos [1, 2, 3, 22], a abordagem foi desenvolvida sob a perspectiva da propagação no ambiente de floresta nas faixas do VHF e UHF baixo. As teorias de tratamento de sinais randômicos e do processamento estocástico voltado ao estudo de comunicações móveis foram omitidas por razão semelhante.

Em sequência, no capítulo 3, agora no contexto das campanhas de medidas e fazendo referência ao praticado em campo, são tratados os fundamentos de medição de propagação de ondas eletromagnéticas realçando a teoria básica que dá suporte às rotinas de armazenamento dos dados brutos das medidas, filtragem e apresentação gráfica. O capítulo 4, faz uma descrição dos ambientes das medidas, sendo que o cerrado foi detalhado por gravuras, figuras e esboços enfatizando as morfologias ensaiadas nos percursos dentro da FAL. O capítulo 5 aborda a análise dos resultados das campanhas de medidas em VHF e UHF. No sentido de coligir os resultados experimentais com a teoria, o capítulo 6 apresenta resultados da teoria embasada no método numérico TLM-SCN-3D e na abordagem semi-empírica unificada como sendo modelo de Saunders, Bonar e Ikegami.

Após a conclusão, apresentam-se perspectivas para futuros estudos teóricos e práticos. As referências bibliográficas e os anexos compõem o fechamento deste trabalho. 


\section{MODELOS DE PROPAGAÇÃO}

\subsection{INTRODUÇÃO}

Há uma extensa disponibilidade de livros, teses e tutoriais que tratam da teoria dos principais fenômenos e modelos de propagação na faixa de VHF e UHF. De acordo com o estudado na literatura, a propagação eletromagnética aplicada a canais móveis $[1,2,22,23,24]$ engloba modelos matemáticos determinísticos, empíricos, semi-empíricos, estatísticos e os modelos derivados destes por aperfeiçoamentos mediante diversas técnicas de otimização [25]. Da mesma forma, quando se fala de fenômenos de propagação, a bibliografia é ampla [26, 27, 28, 29, 30]. O rol de fenômenos de propagação a serem observados em comunicações móveis na floresta é extenso. Este capítulo descreve de forma sucinta os modelos e fenômenos de maior significância para o estudo de propagação na floresta.

A técnica estatística para modelagem do canal móvel resulta na caracterização deste de forma espontânea; isto é, sem ter que seguir condicionantes restritivas. O pareamento da regressão linear dos resultados experimentais com modelos consagrados de propagação para ambientes urbanos é outra forma de caracterizar o ambiente de floresta, mediante consistentes expressões matemáticas acrescidas de fatores de correção [31, 32 , 33]. Há evidências quantitativas e qualitativas que justificam esta metodologia. Os resultados explicitados na forma de tabelas contendo os parâmetros da regressão linear e os respectivos gráficos da perda de propagação e dos desvanecimentos associados às perdas serão detalhados no capítulo 5.

O objetivo do capítulo 2 é revisar os modelos consagrados de propagação e os fenômenos a eles associados mostrando que, apesar de originalmente desenvolvidos para ambiente urbano, podem ser aplicados ao ambiente de cerrado desde que lhes aplique certas condicionantes e considerações simplificadoras.

Importante frisar que no âmbito deste trabalho os desvanecimentos foram tomados no domínio espacial; larga escala e pequena escala. A designação "escala" refere-se a múltiplos e submúltiplos do comprimento de onda. Assim os desvanecimentos seletivos em frequência e no tempo, bem como em velocidade (rápido e lento) não fazem parte do escopo deste trabalho, podendo ser encontrado em [23-24]. Para garantir que estes desvanecimentos não causassem erros nas medidas dos desvanecimentos de pequena e larga escala o sinal radiado nas campanhas de medidas foi de faixa estreita, o mais próximo de uma portadora $C W$.

\subsection{FENÔMENOS DE PROPAGAÇÃO NO CERRADO}

Em geral, os fenômenos de propagação observados nos sistemas de comunicações móveis podem ser elencados nos seguintes [3, 10, 24]: 
espalhamentos e retroespalhamentos, desvanecimento em larga escala, que é a perda de propagação no percurso concomitante ao sombreamento, difração e reflexão tipificadas como: especular (laminar), difusa e de aresta devido a incidência em vértices e quinas de superfícies difratoras. A Fig. 2.1 ilustra os tipos de reflexão, difração e espalhamento em um hipotético ambiente rural. A refração impacta enlaces com distâncias superiores a $30 \mathrm{~km}$ ou na situação muito especial em termos de ângulo de incidência concomitante com uma mudança de meio de propagação [26].

Destacam-se ainda como fenômenos de propagação no ambiente de floresta o seguinte: ressonância (absorção parcial ou plena). Tendo em vista que este trabalho se restringe ao estudo da propagação em função da distância, desconsidera-se os efeitos dos desvanecimentos seletivos em função do tempo e da frequência com a transmissão de um sinal de banda estreita [34]. Os desvanecimentos em função da distância são investigados neste estudo.

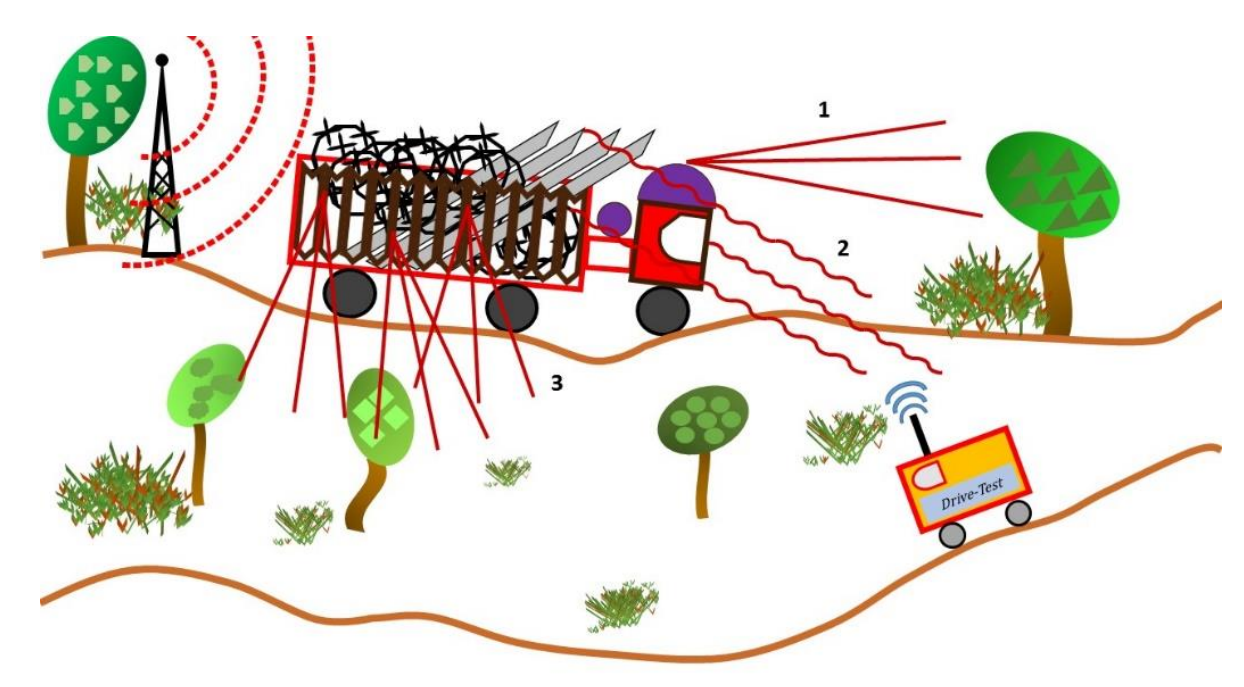

Figura 2.1 Esboço de um ambiente rural e os fenômenos de propagação a ele associado: 1espalhamento, 2-difração laminar, 3-difração de quina.

O desvanecimento pode ser tanto relacionado às variações bruscas e lentas na envoltória do sinal quanto, de certa forma, relacionado às variações bruscas e lentas na fase dos componentes espectrais do sinal. A variação da envoltória, a variação de fase e a composição de ambas geram a variabilidade local no ponto em que o sinal chega ao receptor móvel.

Os resultados dos desvanecimentos seletivos $[23,24]$ no ambiente de floresta devem ser analisados considerando que há um regime oscilatório inerente a múltiplas ressonâncias que ocorrem nas frações espectrais do VHF/UHF afetando o sinal recebido pelo drive-test com picos e vales de ondulação desuniforme. 
A Fig. 2.2 mostra este comportamento oscilatório ao incidir uma onda plana polarizada verticalmente em uma floresta canônica. As múltiplas ressonâncias se esvanecem à medida que se aumenta a frequência de transmissão, praticamente desaparecendo em frequências superiores a $2 \mathrm{GHz}$. O parâmetro " $\rho$ " corresponde à densidade de troncos por metro quadrado e o parâmetro "a" corresponde ao raio dos troncos em metros [15]. Na Fig. 2.2 " $\rho "=1$, , a"

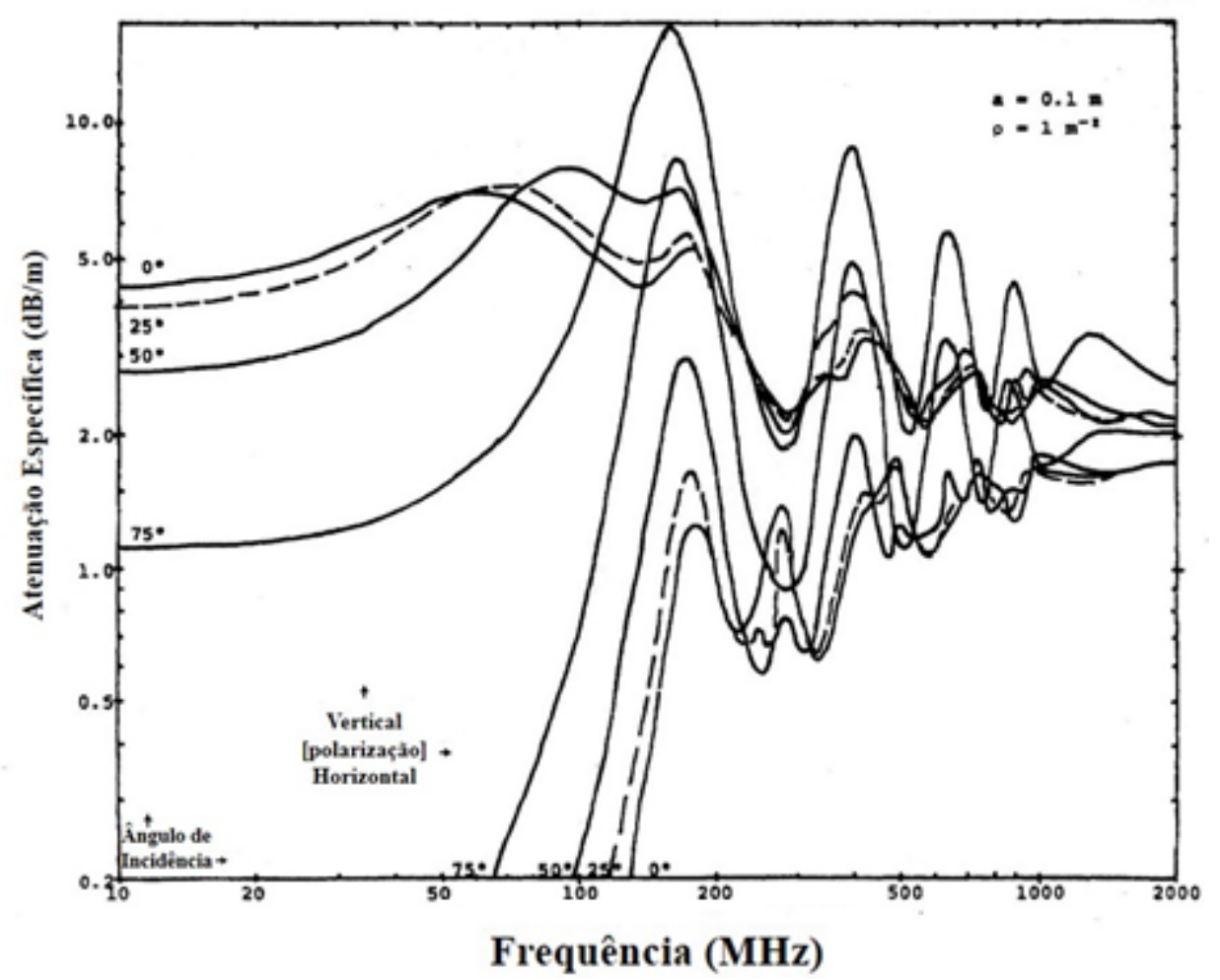

Figura 2.2 Múltiplas ressonâncias observadas no estudo de propagação eletromagnética por entre os troncos de uma floresta canônica. (Fonte: retirado de [15] com adaptações).

O multipercurso inerente à propagação do sinal no ambiente sob estudo faz com que distintas versões do sinal se sobreponham na antena do receptor móvel. A composição dos sinais devido ao fenômeno do multipercurso na antena receptora poderá reforçar (amplificar), enfraquecer (atenuar), modificar a envoltória do sinal recebido ou, até mesmo, aniquilar o sinal. Em síntese, os fenômenos podem ser tipificados na forma de ruídos aditivo e multiplicativo, conforme mostrado na Fig. 2.3.

A Fig. 2.4 mostra o móvel em situação de LOS (line of sight) e a sobreposição do sinal no móvel devido aos multipercursos. O sinal radiado pela estação rádio-base incorre em múltiplas reflexões antes de atingir o veículo que desloca na estrada. Esta é uma ilustração que representa com boa aproximação a porção suburbana limítrofe ao cerrado, um dos percursos estudados neste trabalho, a ser descrito na seção 4.2. Na Fig. 2.4 a linha cheia partindo da estação rádio-base grafada no desenho por "LOS" corresponde à linha de visada, situação de desobstrução entre o transmissor e o receptor.

A Fig. 2.5 ilustra os obstáculos e os multicaminhos (multipercursos) que o sinal transmitido percorre antes de atingir a antena receptora em uma 
estrada margeada por vegetação em ambas as laterais. Na Fig. 2.5 deve-se ter em mente que ocorre a composição de dois raios da seguinte maneira: de um lado, raio 1 devido a difração difusa nas copas das árvores do último bloco de vegetação; e do lado oposto, raio 2, a reflexão na face do primeiro bloco de vegetação situado na margem oposta da via de deslocamento.

A Equação (1) sintetiza, de forma genérica, a composição dos principais fenômenos que incidem com maior ou menor ênfase na montagem dos modelos de propagação entre o terminal do usuário e a estação rádio base [3].

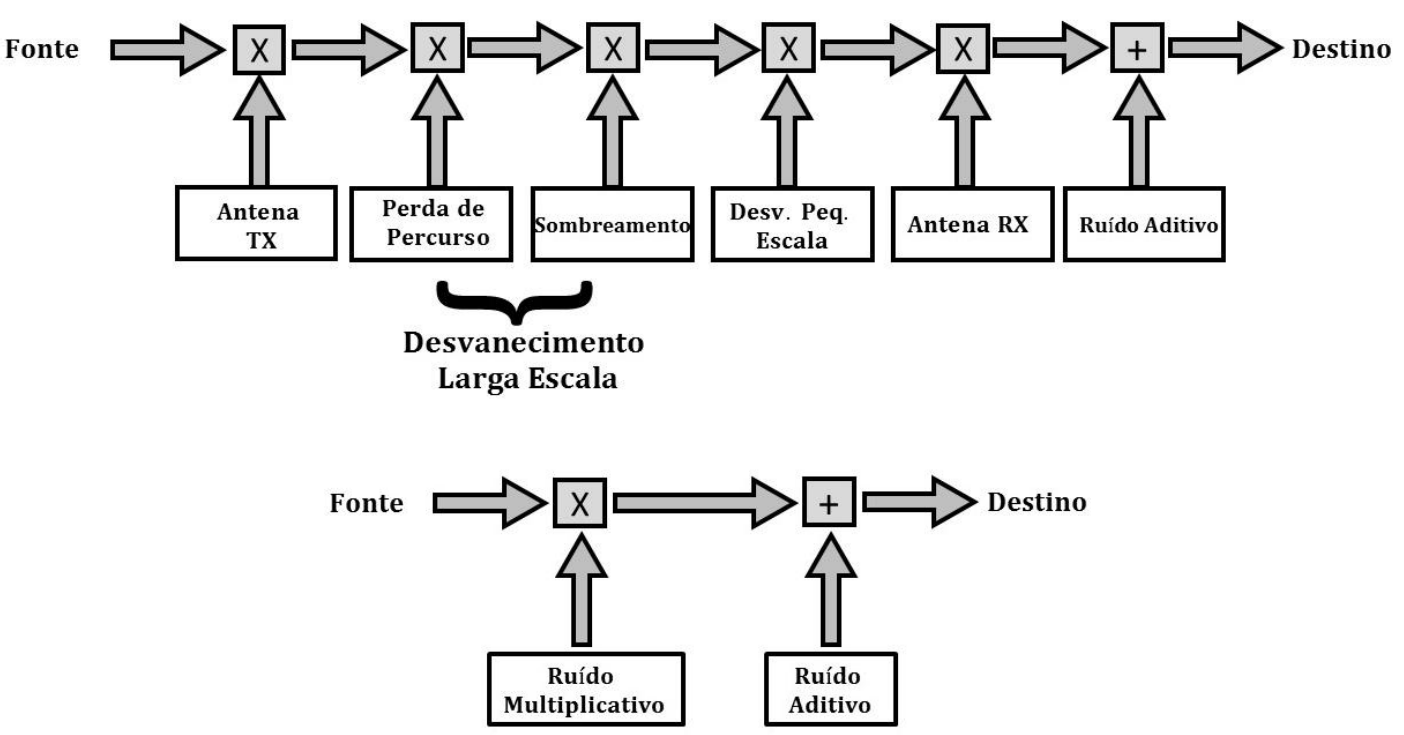

Figura 2.3 Fenômenos de propagação aditivo e multiplicativos que impactam o canal móvel. (Fonte: Ilustração adaptada de [1]).

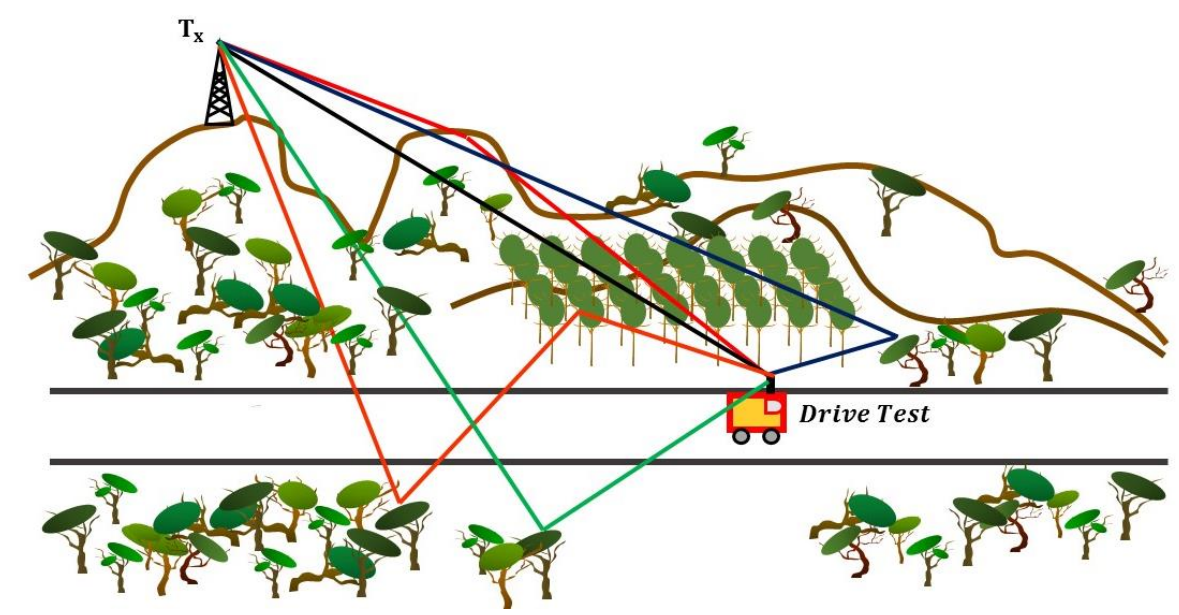

Figura 2.4 Geometrias dos multipercursos incidentes no sinal transmitido decorrentes dos obstáculos estáticos no ambiente. (Fonte: desenho adaptado de [23] pelo autor). 


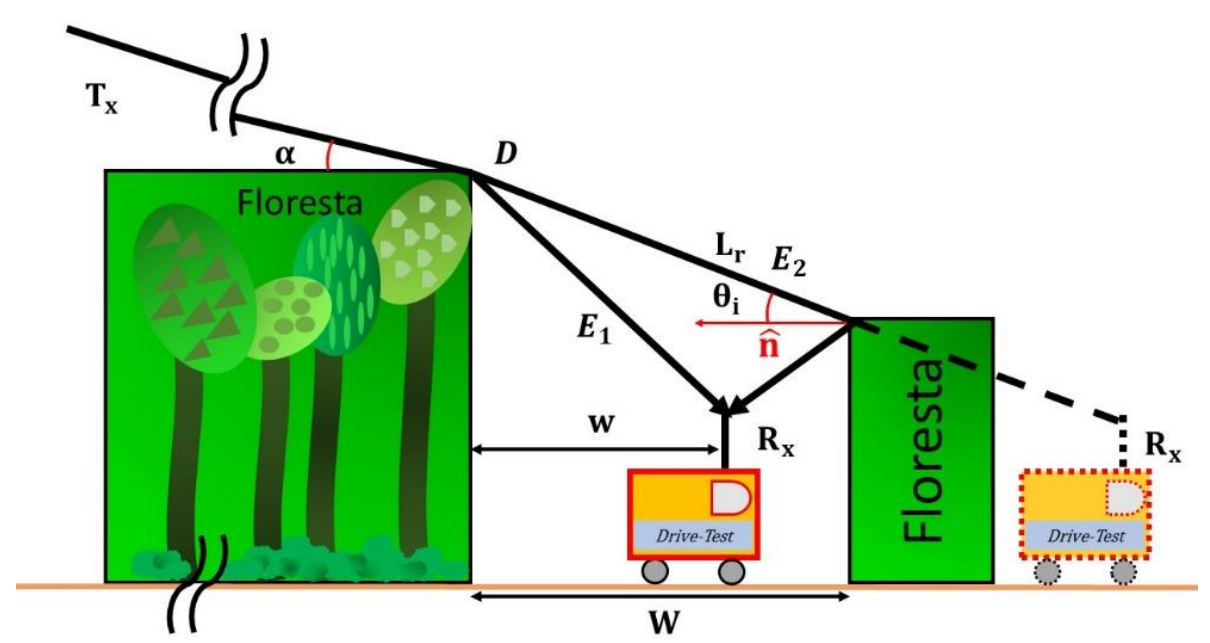

Figura 2.5 Sinal recebido pela antena de um móvel que se desloca por uma estrada. (Fonte: autor)

Na Fig. 2.5, W - largura da via de deslocamento, $\mathrm{w}$ - posição do móvel em relação ao último bloco de floresta, $\mathrm{T}_{\mathrm{x}}-$ Transmissor, $\mathrm{R}_{\mathrm{x}}$ - Receptor e na margem oposta da via imagem do receptor no bloco de floresta e $D$ - ponto de difração no último bloco de floresta.

$\mathrm{Na}$ Eq. (1) L-perda total, $\alpha$ - fatores contributivos a perda total e F função de múltiplos argumentos, no caso, fatores de perda.

$\mathrm{L}=\alpha_{\text {obstruções }} \mathrm{F}\left(\alpha_{\text {reflexões }}+\alpha_{\text {difração }}+\alpha_{\text {espalhamentos/retroespalhamentos }}+\alpha_{\text {absorção }}\right)$

A Eq. (2) relaciona o sinal recebido ao sinal transmitido num instante de tempo qualquer em função dos desvanecimentos envolvidos no enlace transmissor até o receptor [3],

$S^{\prime}(t)=\frac{S(t)}{p(t) \cdot m(t) \cdot r(t)}$

Em que,

$\mathrm{S}(\mathrm{t})$ é o sinal de transmissão $\mathrm{T}_{\mathrm{x}}[\mathrm{dBm}]$,

$S^{\prime}(t)$ é o sinal de recepção $R_{x}[\mathrm{dBm}]$,

$\mathrm{m}(\mathrm{t})$ é o sombreamento $[\mathrm{dB}]$,

$\mathrm{r}(\mathrm{t})$ é o desvanecimento pequena escala $[\mathrm{V}] \mathrm{e}$

$\mathrm{p}(\mathrm{t})$ é a perda de propagação $[\mathrm{dB}]$.

O desvanecimento de pequena escala, por ser um abrupto afundamento do sinal recebido, pode atingir patamares de $20 \mathrm{~dB}$ a $40 \mathrm{~dB}$ de atenuação em relação ao nível médio de $\mathrm{R}_{\mathrm{x}}$, podendo causar interrupção de uma conversação em curso no canal móvel. Sendo assim, trata-se de uma informação de suma importância a ser considerada na modelagem do canal móvel e, por conseguinte, deve ser usada no planejamento de uma rede de rádios avançados [23].

O desvanecimento em larga escala atinge picos de atenuação do nível de $R_{x}$ em torno de $10 d B$ [3], conforme será visto na seção 2.4. O gradiente de 
queda do desvanecimento de larga escala é mais suave do que o do desvanecimento de pequena escala. Isto permite que a estação rádio base mitigue com maior chance de sucesso o desvanecimento de larga escala do que o desvanecimento de pequena escala [23]. Os desvanecimentos de larga escala e de pequena escala estão intimamente relacionados às variações lentas e bruscas na fase do sinal e às múltiplas trajetórias que o ambiente imprime ao sinal radiado pelas antenas das estações e, de forma recíproca, pelas antenas dos dispositivos móveis dos usuários.

No ambiente de abundante vegetação, o fenômeno mais pronunciado é a difração especular que ocorre na interface formada entre o topo do dossel das árvores e a atmosfera acima do dossel, em seguida vem a difração difusa por entre troncos e galhos $[11,14,31]$. Há que considerar também uma parcela de interação de ressonância da portadora transmitida com a variabilidade de tamanhos de galhos, troncos, folhas e ramos do bioma (múltiplos e submúltiplos do comprimento de onda) [15]. Superposto a isso, adiciona-se a parcela de espalhamento que ocorre devido a uma mistura de superfícies geométricas poliédricas dispostas aleatoriamente nas copas das árvores, que se trata de um modelo descrito em $[5,7,10]$. As equivalências de elipses, triângulos e trapézios, de geometrias angulares, faciais e axiais diversas [35] são uma forma usual de visualização pormenorizada da floresta. A Fig. 2.6 ilustra esta equivalência.

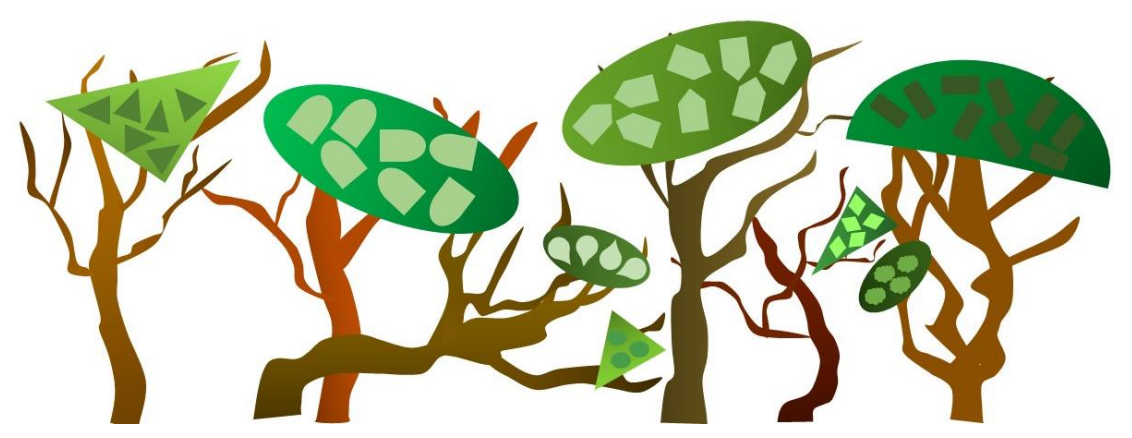

Figura 2.6 Ilustração da equivalência geométrica das copas das árvores. (Fonte: autor)

No cerrado, diferentemente de outros biomas, a densidade arbórea é baixa e a ondulação formada pela sequência de copas tem variação de altura maior que o comprimento de onda do VHF/UHF baixo, em torno de 4 metros. Entretanto, ainda pode-se afirmar que prepondera a propagação por múltiplas difrações sobre as copas das árvores até atingir o móvel, como o observado em outros biomas [12] e conforme será demonstrado no âmbito deste trabalho no capítulo 6. Nas frequências abaixo de $200 \mathrm{MHz}$ em geral o efeito das múltiplas difrações se sobressai, a floresta pode ser tratada como um bloco homogêneo de vegetação. Em frequências superiores a $200 \mathrm{MHz}$, o fenômeno da difração continua a ser preponderante, porém há que considerar componentes de espalhamento e maior interação com a rugosidade das copas das árvores [36]. 
A Fig. 2.7 ilustra os mecanismos de propagação e esboça o perfil resumido de um dos percursos de campanha de medidas na Fazenda Água Limpa, em particular o percurso "edge", a ser descrito na seção 4.2. Os raios traçados em vermelho, amarelo, roxo e azul, na Fig. 2.7, ilustram a configuração das formas de propagação predominantes no ambiente de floresta.

Na Fig. 2.7, o conjunto torretantena está acima da camada da cobertura arbórea. A propagação de maior magnitude se dá no patamar superior na camada formada pelo ar acima das copas das árvores e no patamar inferior pelas copas $[25,33,36]$, na citada literatura denominada onda lateral.

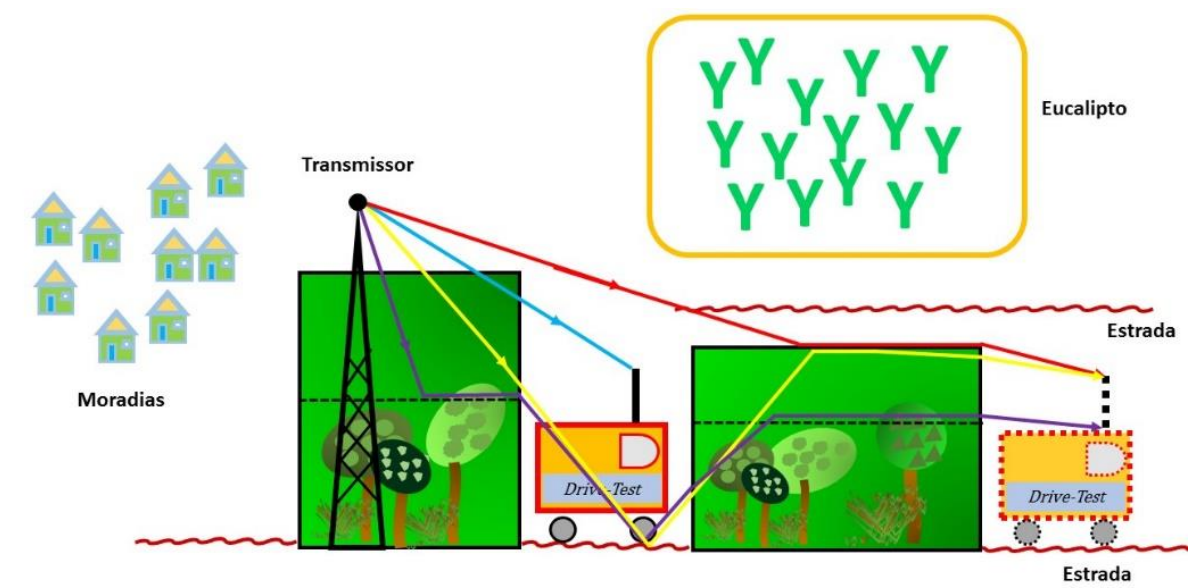

Figura 2.7 Esboço dos mecanismos de propagação na floresta. (Fonte: autor)

Na Fig. 2.7, a linha cheia vermelha representa a onda lateral na interface situada entre copa das árvores e atmosfera superior; em azul, a propagação em linha de visada com o móvel; em amarelo está representada a possível refração do sinal na camada superior do primeiro bloco de floresta e, em sequência, o sinal reflete no leito da estrada, segue por entre troncos e galhos da camada inferior do segundo bloco de floresta e atinge o móvel mediante uma segunda refração conforme modelo proposto em [36]. Em roxo, a propagação ocorre no estrato inferior da floresta pelos troncos, caso típico de uma floresta espaçada, por exemplo, plantação de eucalipto. As flexões do sinal propagado por entre galhos; isto é, as mudanças de direção e sentido dos raios, e a reflectância do solo (coeficiente de reflexão) provocam modificações no sinal captado. Nas campanhas de medidas o drive-test faz o papel do usuário em movimento fazendo uso de seu dispositivo de comunicação.

O cerrado por ser uma vegetação classificada como semidecídua (árvores que perdem grande parte de sua massa foliar), expõe no período de estiagem uma copa constituída de sequências de agulhas puntiformes e pontiagudas, galhos e ramos com baixa densidade foliar. Frisa-se que apesar da ausência de folhas, a seiva continua circulando transversalmente e longitudinalmente mantendo a árvore viva.

Do ponto de vista eletromagnético, o cerrado permite enunciar situações distintas: no período de chuvas ou verão úmido predomina difração 
em uma sequência de obstáculos justapostos de geometria esférica, árvores com copas modeladas por elipses; no período de seca ou inverno seco predomina difração com um adicional de espalhamento, em uma sequência ainda maior de obstáculos do tipo gume de faca dispostos em justaposição e sobreposição, pois a densidade de galhos é maior que de copas de acentuada esfericidade. Além das considerações sobre copas e galhos no cerrado, devese ressaltar que a vegetação abaixo das copas das árvores, isto é, gramíneas, herbáceas e arbustivas, ficam mais expostas no período de estiagem do que no período de chuvas.

As Figs 2.8 e 2.9 esboçam as mudanças de paisagem no cerrado com a mudança de estação. É importante salientar que os galhos e ramos têm dimensões múltiplas e submúltiplas (n.$\lambda$ em que não pode ser um número inteiro ou uma fração) dos comprimentos de onda do VHF e do UHF. Dessa forma, a interação com as singularidades destes elementos é maior no período de estiagem. 0 que se pode comprovar por meio das medidas realizadas, conforme demonstrado no capítulo 5.

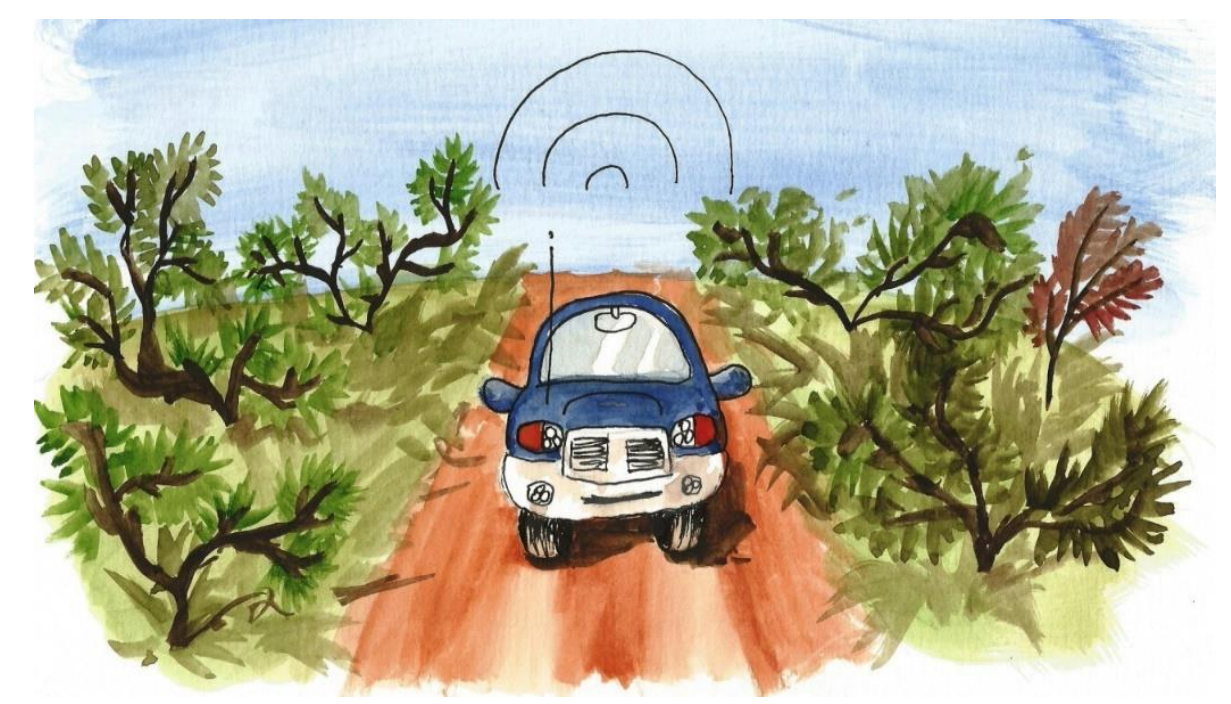

Figura 2.8 Desenho da paisagem do cerrado no verão úmido. (Autora: Camilla Santos Dantas)

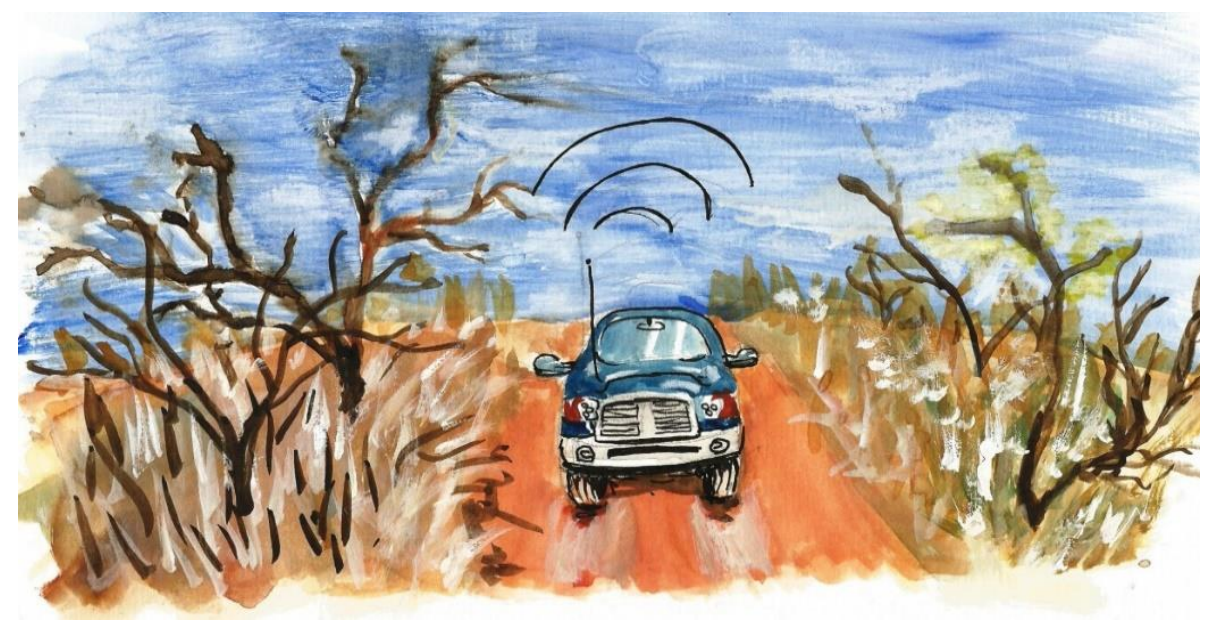

Figura 2.9 Desenho da paisagem do cerrado no inverno seco. (Autora: Camilla Santos Dantas) 
A seguir, são apresentadas as equações básicas atinentes ao estudo de difração [3], tomando-se por base, neste contexto, a notação de perdas $\mathrm{L}_{\text {diff }}(\mathrm{h})$. A Fig. 2.10 ilustra a difração em um obstáculo que, para este estudo, é uma árvore.

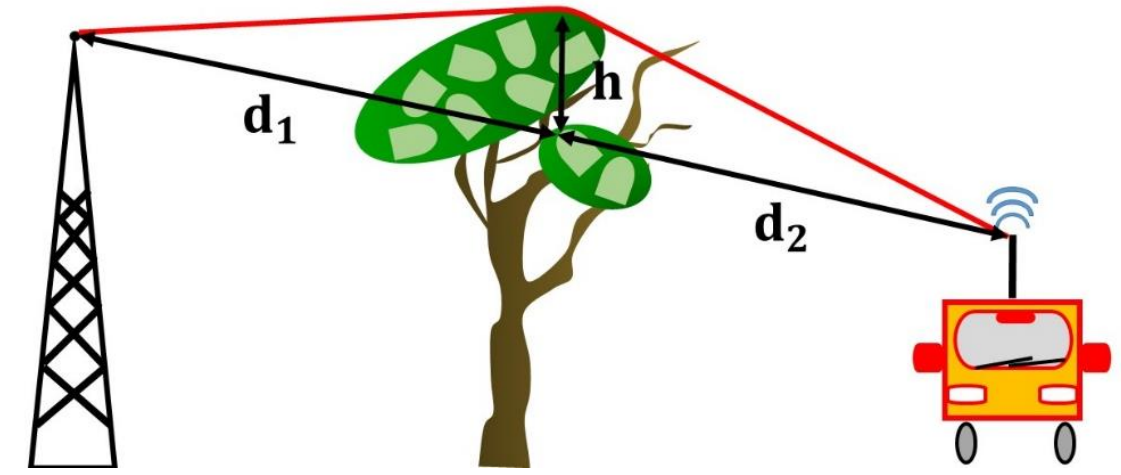

Figura 2.10 Ilustração da difração em uma árvore. (Fonte: autor)

$$
\begin{aligned}
& v=-h \sqrt{\frac{2}{\lambda}\left(\frac{d_{1}+d_{2}}{d_{1} d_{2}}\right)} \\
& \mathrm{L}_{\text {dif }}(\mathrm{h})=0 \quad 1 \leq v \\
& L_{\text {dif }}(h)=-20 \log \left(\frac{1}{2}+0,62 v\right) \quad 0 \leq v<1 \\
& L_{\text {dif }}(h)=-20 \log \left(\frac{e^{0,95 v}}{2}\right) \quad-1 \leq v<0 \\
& \mathrm{~L}_{\mathrm{dif}}(\mathrm{h})=-20 \log \left[0,4-\sqrt{0,1184-\left(\frac{v}{10}+0,38\right)^{2}}\right] \quad-2,4 \leq v<-1 \\
& L_{\text {dif }}(h)=-20 \log \left(-\frac{0,225}{v}\right) \quad v<-2,4
\end{aligned}
$$

Nas Equações (3) - (8), v é o argumento das integrais de Fresnel que, quando devidamente combinadas, resultam nas funções perda ou atenuação de Fresnel. Em (3), h, pode assumir valores positivos (obstrução) ou negativos (desobstrução). As distâncias $d_{1}$ e $d_{2}$ correspondem aos segmentos lineares entre o transmissor e h e entre h e o receptor, respectivamente. Outro aspecto a considerar é que o sinal difratado em termos de direção, sentido e magnitude depende da frequência radiada pela antena, da geometria e das características elétricas dos obstáculos tomados em relação à direção de propagação da frente de onda, ângulos de incidência e seu complemento, ângulo rasante ao topo dos obstáculos. O princípio de Huygens é que rege a física do fenômeno e estabelece que mesmo sob condições de non-line of sight ( $\mathrm{N}-\mathrm{LOS}$ ) a potência radiada pode alcançar o receptor, porém com inevitável flutuação do sinal entre patamares de máximo e mínimo denominado de franja de difração [1].

\subsection{MODELOS $\mathrm{L}_{50}$}

Os principais modelos de propagação [22] que se aplicam às faixas designadas como VHF/UHF podem ser elencadas nos seguintes: empíricos Egli, Okumura-Hata, Cost 231-Hata e Parsons; semi-empíricos - Ibrahim- 
Parsons e Parsons-Modificado [25]; teóricos - Ikegami, Ikegami-Walfisch, Bertoni-Walfisch; experimental: ITU-R 1546-5 [37] e Okumura; estatísticos: Lei de Potência [2, 19]e Múltiplas Morfologias [2].

A Figura 2.11 ilustra o ambiente de floresta típico do cerrado identificando os parâmetros que englobam o tratamento dado pelos modelos de propagação. $O$ espaçamento entre as árvores não é equidistante, porém em termos de área basal pode-se chegar para o bioma cerrado a um quantitativo médio de 0,2 árvores por metro quadrado [35].

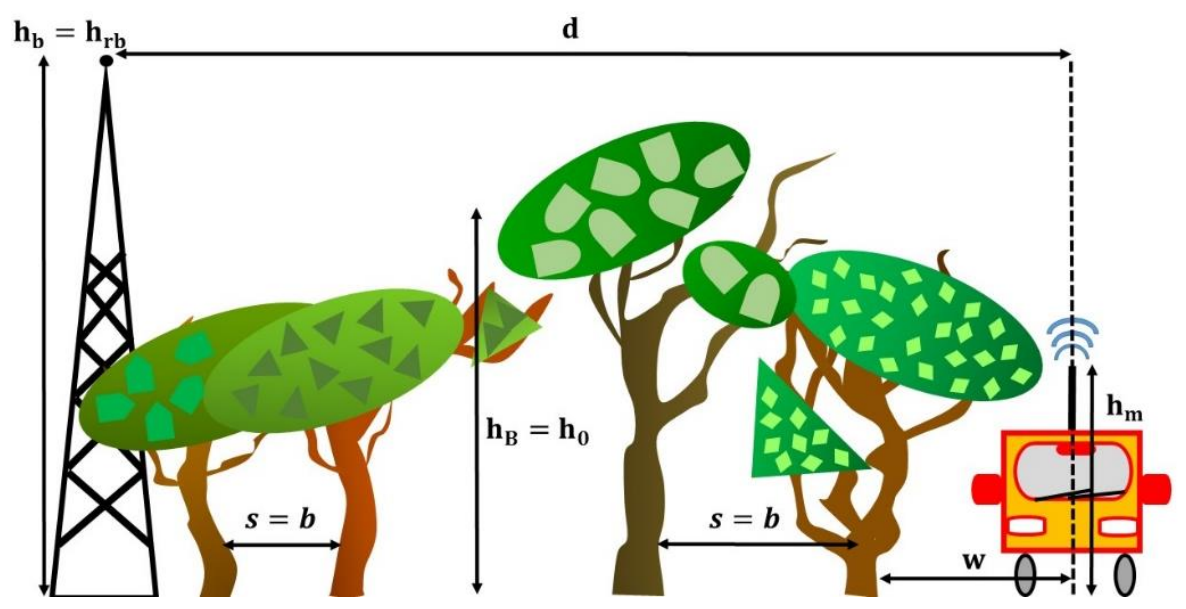

Figura 2.11 Ambiente constituído por múltiplos obstáculos, neste estudo, árvores. (Fonte: autor)

Na Fig. 2.11: $h_{b}=h_{r b}$ altura, em metros, da antena de transmissão em relação ao nível do leito da via de deslocamento; $b$ - distância entre os troncos [m] ou entre os centros de blocos de floresta; $h_{B}=h_{0}$ - altura média das árvores, em metros; $\mathrm{d}$ - distância linear, em metros, entre o mastro da antena e o alongamento da linha que passa pelo mastro da antena do drive-test, $\mathrm{h}_{\mathrm{m}}$ altura da antena do drive-test.

A Fig. 2.12 llustra o ângulo da via $\phi$ formado pela projeção da componente de campo horizontal difratado mediante rebatimento vetorial no plano formado com a via de deslocamento [38]. O ângulo da via pode ser obtido a partir da linha de visada da estação rádio base e o móvel com relação a interseção com a margem da estrada. 


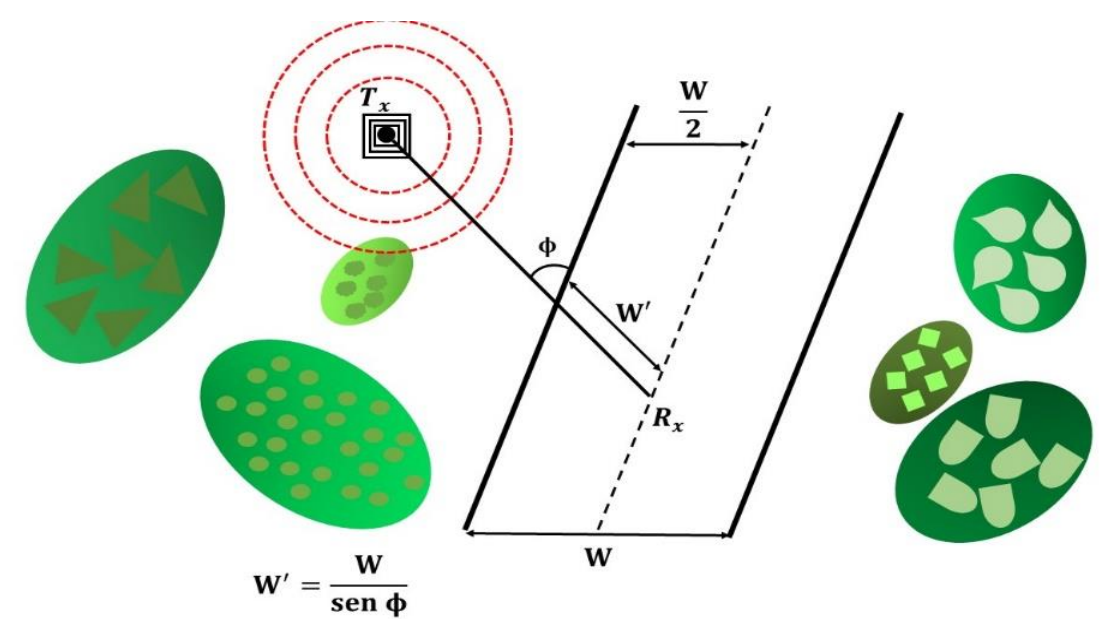

Figura 2.12 Ilustração do ângulo da via. (Fonte: autor)

$\mathrm{Na}$ mesma perspectiva dos fenômenos e do estudo estatístico, a abordagem teórica dos modelos de propagação foi amplamente revisada e aplicada em [17, 19, 20, 21]. O acervo de livros que exploram esses modelos já consolidados é vasto $[1,2,3,22,28,29]$. No entanto a abordagem qualitativa de certos modelos suscita algumas discussões interessantes. Para isso, na fase de revisão bibliográfica, buscou-se esmiuçar as publicações originais acerca dos modelos aplicáveis a comunicações móveis na faixa do VHF/UHF baixo.

O modelo de Okumura-Hata $[39,40]$ é usualmente aplicado na modelagem do comportamento da propagação no canal móvel. O modelo é versátil, pois contempla desde uma área densamente urbanizada com edificações disformes e assimétricas até uma área aberta similar a um grande campo de pastagem.

Outro fato interessante acerca deste modelo é que outros modelos estudados, ensaiados e validados na prática constataram que o descrito por Okumura-Hata aproximava muito de suas observações, dando maior consistência às observações de Yoshihisa Okumura e Masaharu Hata. Por exemplo, o modelo ITU-R P. 1564-5 [37] apresenta resultados similares ao modelo de Okumura-Hata em distâncias de até $10 \mathrm{~km}$.

O modelo enseja o cálculo da altura efetiva da antena da estação rádio base em relação aos aclives e declives do terreno tomando radiais a partir do pé da torre de transmissão embasado em critérios vinculados à abrangência do enlace. Trata-se de um parâmetro importante de explicação e ajustamento do modelo estatístico ao modelo de Okumura-Hata. As equações empíricas da perda média de propagação para o modelo Okumura-Hata podem ser escritas da seguinte forma [40]:

$L /[d B]=69,55+26,16 \log (f[M H z])-13,82 \log h_{b}-\ldots$.

$\ldots .-a\left(h_{m}\right)+\left[44,9-6,55 \log \left(h_{b}\right)\right] \log (d)+C_{m}$

Sendo que $\mathrm{C}_{\mathrm{m}}$ é dado por:

$\mathrm{C}_{\mathrm{m}}=0 \mathrm{~dB}$; cidades médias, pequenas e ambiente suburbano 
$\mathrm{C}_{\mathrm{m}}=3 \mathrm{~dB}$; grandes cidades, ambiente metropolitano,

e maxi-urbano, classificação quanto ao grau de urbanização [3]

$\mathrm{h}_{\mathrm{b}} \rightarrow$ altura efetiva da antena da estação rádio - base (m)

$\mathrm{h}_{\mathrm{m}} \rightarrow$ altura da antena do dispositivo móvel (m)

$\mathrm{d} \rightarrow$ distância entre transmissor e o receptor $(\mathrm{m})$

$\mathrm{f} \rightarrow$ frequência de operação $(\mathrm{MHz})$

Em ambientes rurais, urbanos e suburbanos, tem-se:

$a\left(h_{m}\right)=\left(1,1 \log f_{c}-0,7\right) h_{m}-\left(1,56 \log f_{c}-0,8\right)$

Em grandes cidades, densamente urbanizadas, tem-se:

$a\left(h_{m}\right)=8,29\left[\log \left(1,54 h_{m}\right)\right]^{2}-1,10 ;$ se $f \leq 300 \mathrm{MHz}$

$a\left(h_{m}\right)=3,2\left[\log \left(11,75 h_{m}\right)\right]^{2}-4,97$; se $f>300 \mathrm{MHz}$

O modelo de Okumura-Hata foi posteriormente modificado conforme equações (13) - (15) no intuito de ampliar sua capacidade de modelar ambientes de ocupação demográfica e geográfica com maior grau de diversificação morfológica. Sob a denominação modelo Cost 231-Hata [16], a Eq. (9) ficou inalterada, fazendo o fator $C_{m}=0, L_{50}(d B)=\mathrm{L} / \mathrm{dB}$ e $f_{c}=f$ na Eq. (9), as alterações resultaram no seguinte:

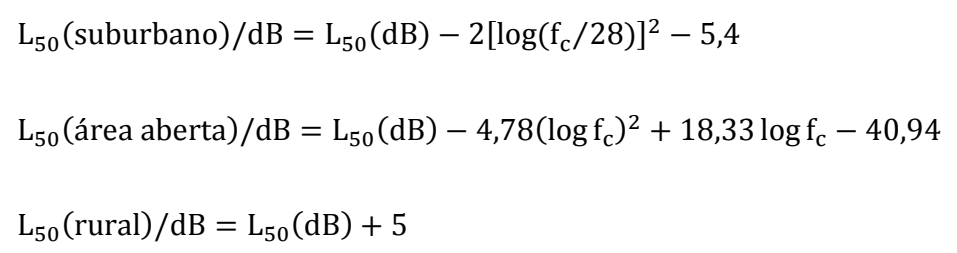

Os modelos publicados por Parsons-Ibrahim-Allesbrook [1, 41, 42, 43] com equacionamento empírico apresenta melhor ajustamento aos resultados experimentais que os modelos desenvolvidos por eles de forma semi-empírica, principalmente em áreas com edificações que seguem um padrão de distribuição aleatória em região planimétrica suave. $O$ modelo foi aprimorado em [25] para aplicação em centros urbanos com maiores aclives e declives resultando no acréscimo de termos e modificações nos fatores multiplicativos das variáveis do modelo original. A Eq. (16) corresponde ao modelo empírico proposto por Parsons-Ibrahim-Allesbrook e a Equação (18) corresponde ao modelo de Parsons-Ibrahim-Allesbrook modificado por técnicas de otimização [25].

$$
\begin{aligned}
& L[d B]=-20 \log \left(0,7 \mathrm{~h}_{\mathrm{b}}\right)-8 \log \left(h_{m}\right)+f / 40+26 \log (f / 40) \\
& -86 \log ((f+100) / 156)+[40+14,15((f+\cdots \\
& \ldots+100) / 156)] \log d\left(k_{m}\right)+0,265 T-0,37 H+K_{1} \\
& \text { O valor de K1 para a área densamente urbanizada [3] é obtido usando- }
\end{aligned}
$$

se a Eq. (17):

$\mathrm{K}_{1}=0,87 \mathrm{U}-5,5 ;$ ou $\mathrm{K}_{1}=0$, para outras morfologias.

Os parâmetros na Equação (16) têm as seguintes relações associativas: $\mathrm{h}_{\mathrm{rb}}=\mathrm{h}_{\mathrm{b}}$ (altura da antena de transmissão em relação ao nível da via); $\mathrm{f}$ é a 
frequência de operação, em $\mathrm{MHz}$; T-fator relativo à percentagem de área construída no ambiente de medidas, neste trabalho, adotou-se 0,58 para área urbanizada, com edificações, e 0,426 para região suburbana tendente a rural e rural plena; U-fator relativo à altura das edificações na área em estudo, neste trabalho, adotou-se 0,54 para área densamente urbanizada e zero para outras morfologias e $\mathrm{H}$-fator relativo à média das irregularidades topográficas do terreno considerando uma quadrícula de 3,5 quilômetros de lado vista pelo drive-test localizado em seu centro, sendo que adotou 0,07 para distâncias menores que dois quilômetros e 0,211 para distâncias superiores a dois quilômetros do drive-test. Os valores $\mathrm{K} 1, \mathrm{U}, \mathrm{T}$ e $\mathrm{H}$ foram estipulados neste trabalho com base na teoria publicada originalmente em [25] pelos autores e aglutinadas em [1]. Procedeu-se a uma avaliação da correspondente similaridade entre valores relatados nos originais publicados transpostos ao ambiente rural tendente a floresta.

A Equação (18) refere-se ao modelo semi-empírico proposto pelos mesmos autores[1]:

$$
L[d B]=40 \log d(k m)-20 \log \left(h_{r b} \cdot h_{m}\right)+\beta
$$

Aqui vale as mesmas considerações acerca dos parâmetros $T, H, U$ e K para obter o termo $-\beta-$, abaixo transcrito:

$$
\beta=20+\frac{f}{40}+0,18 \mathrm{~T}-0,34 \mathrm{H}+\mathrm{K}_{2}
$$

Novamente, tomando o valor de $\mathrm{K}_{2}$ para a área densamente urbanizada como:

$\mathrm{K}_{2}=0,94 \mathrm{U}-5,9$ ou $\mathrm{K}_{2}=0$, para outras morfologias

A Equação (21) abaixo transcrita é fundamentada no modelo de Parsons-Ibrahim-Allesbrook e atende às singularidades topográficas de uma cidade de crescimento não-planejado, situada em região costeira, com edificações assentadas na parte alta das encostas de morros [25].

$$
\begin{aligned}
\mathrm{L}_{\mathrm{p}}(\mathrm{dB})=-20 \log \left(0,7 \mathrm{~h}_{\mathrm{b}}\right)-8 \log \left(\mathrm{h}_{\mathrm{m}}\right)+\frac{\mathrm{f}}{40}+26 \log \left(\frac{\mathrm{f}}{40}\right)-86 \log \left(\frac{\mathrm{f}+100}{156}\right)+\cdots \\
+\left[40+14,15 \log \left(\frac{\mathrm{f}+100}{156}\right)\right] \log \mathrm{d}\left(\mathrm{k}_{\mathrm{m}}\right)+16,536-0,583-\cdots \\
-\left[\frac{0,37\left(-7,474 \mathrm{~d}^{2}+85,225 \mathrm{~d}-91,55\right)}{7}\right]
\end{aligned}
$$

Os modelos de Ikegami [44, 38, 45], Walfisch-Ikegami [46] e WalfischBertoni [47] também foram tomados para efeito de análise no programa de pós-processamento (anexo $\mathrm{V}$ ). Esses modelos de propagação levam em conta a obstrução do sinal por múltiplos anteparos dispostos de forma aleatória ou igualmente espaçados, de perfis abundantes de vértices e formas geométrica oblíquas, cilíndricas, elipses convexas e côncavas, que são excelentes difratores, geralmente associados a perfis do topo de edificações e tetos de casas. As árvores que constituem o ambiente deste estudo podem ser modeladas por estas formas geométricas com boa aproximação [5]. 
A teoria desenvolvida por Ikegami [44, 38, 45] foi estudada de forma aprofundada e os valores teóricos decorrentes da aplicação do modelo serão usados no capítulo 6 para obter a validação dos resultados experimentais. Observa-se na dedução do parâmetro perda de reflexão $L_{r}$ estampado na expressão do modelo, conforme Eq. 22, que o valor requerido tem que ser maior que a unidade para seguir o raciocínio teórico desenvolvido no trabalho original. Assim sendo, não se deve confundir o parâmetro coeficiente de reflexão com o parâmetro perda de reflexão. Sendo que $L_{E}(d B)$ é a perda de propagação do modelo semi-empírico de Ikegami.

$$
L_{E}(d B)=10 \log f_{c}+10 \log (\operatorname{sen} \phi)+20 \log \left(\mathrm{h}_{\mathrm{o}}-h_{m}\right)-10 \log W-10 \log \left(1+\frac{3}{L_{r}^{2}}\right)-5,8
$$

Outro aspecto tratado por Ikegami nos seus estudos diz respeito à simplificação, para efeito de cálculo, do quantitativo de multipercursos que incide no sinal que parte da estação rádio base até atingir o receptor móvel. Para isso, embasado em observações práticas na região metropolitana de Tóquio [44], sintetizou os multipercursos em dois raios: um raio difratado e refletido no obstáculo oposto ao leito da via de deslocamento do drive-test $\left(E_{2}\right)$ e outro raio difratado $\left(E_{1}\right)$, conforme Fig. 2.5. Essa simplificação reúne informações suficientes para caracterizar a propagação do canal móvel no perímetro urbano de uma metrópole. Logo a complexidade dos cálculos é reduzida significativamente. Esta estratégia de cálculo funciona também para determinadas morfologias em ambiente suburbano circundado por floresta tropical úmida [11] e também para o cerrado [17].

Duas avaliações importantes acerca do modelo de Ikegami reforçam o observado na prática. Primeiramente, verifica-se que a equação final não explicita a altura da antena de transmissão. Com isso, alguns modelos baseados no modelo de Ikegami também carregam esta simplificação [33] e, dependendo da área de abrangência do serviço móvel, isto nem sempre pode ser aplicado [22]. Atrelado a isso, a reflexão no solo foi também desconsiderada por Ikegami. O modelo dá ênfase às múltiplas difrações ocasionadas pela sequência de obstáculos situados na linha de visada entre a estação rádio-base e o drive-test. Os obstáculos situados na margem direita e esquerda da via são tratados com maior rigor considerando os ângulos de difração e de incidência do campo radiado até alcançar a antena do móvel.

Seguindo a mesma linha de raciocínio de Ikegami o modelo de WalfischBertoni [47] também dá ênfase às múltiplas difrações por obstáculos supostamente opacos do ponto de vista eletromagnético. Ressalta-se que Walfisch-Bertoni considerou em sua avaliação semi-empírica a obstrução do sinal de transmissão por múltiplos elementos difratores situados na linha de visada com o receptor. $O$ viés analítico do modelo proposto foi embasado no estudo numérico das integrais de Kirchhoff-Huygens voltadas à modelagem da difração por múltiplos obstáculos interceptados parcialmente pelo Elipsoide de Fresnel. A Eq. (23) sintetiza a proposta de Walfisch-Bertoni. 


$$
\begin{aligned}
& L_{e x}(d B)=57,1+A+\log f_{e}+18 \log d-18 \log \left(h_{b}-h\right)-18 \log \left[1-\frac{d^{2}}{17\left(h_{b}-h\right)}\right] \\
& A=5 \log \left[\left(\frac{b}{2}\right)^{2}+\left(h-h_{m}\right)^{2}\right]-9 \log b+20 \log \left\{\tan ^{-1}\left[\frac{2\left(h-h_{m}\right)}{b}\right]\right\}
\end{aligned}
$$

Os termos da equação são os seguintes: $\mathrm{L}_{\mathrm{ex}}$ perda média de propagação, em dB; $f_{e}$ : frequência de transmissão, em $M H z ; h=h_{0}=h_{B}$ : altura das edificações ou altura média das árvores em relação ao nível da via de deslocamento, em metros. Os demais termos estão discriminados nas Figs. 2.11 e 2.12 .

O modelo Walfisch-Ikegami é um refinamento do modelo proposto por Ikegami, considerando a sequência de blocos antes de se chegar aos dois últimos blocos que se situam na margem da pista de deslocamento. A equação da difração nos últimos blocos faz uso do modelo original de lkegami [43, 44, 45]. Os parâmetros considerados são: altura da estação rádio-base $h_{b}=h_{r b}$, altura média da sequência de obstáculos, neste modelo, $h_{0}=h_{B}$, largura da via de deslocamento $\mathrm{W}$, separação entre blocos $b=s$ e o ângulo da via $\phi$. A Equação (25) engloba as parcelas das perdas.

Neste modelo, $\mathrm{L}_{\mathrm{FS}}$ é a perda no espaço livre, $\mathrm{L}_{\mathrm{msd}}$ é a perda por difração em obstáculos do tipo "gume-de-faca", $\mathrm{L}_{\text {sd }}$ é a perda devido à difração na quina do último bloco e espalhamento difuso no primeiro bloco do lado oposto da via de deslocamento. Desta forma tem-se [22]:

$$
L_{s d}=-16,9+10 \log f_{c}+10 \log \frac{\left(h_{0}-h_{m}\right)^{2}}{w_{m}}+L(\phi)
$$

Em que, geralmente, $w_{m}=W / 2$ é a metade da largura da via de deslocamento.

$$
\begin{aligned}
L(\phi) & =\left\{\begin{array}{lr}
-10+0,354 \phi & \text { para } 0^{\circ}<\phi<35^{\circ} \\
2,5+0,075\left(\phi-35^{\circ}\right) & \text { para } 35^{\circ} \leq \phi<55^{\circ} \\
4,0-0,114\left(\phi-55^{\circ}\right) & \text { para } 55^{\circ} \leq \phi \leq 90^{\circ}
\end{array}\right. \\
\mathrm{L}_{\mathrm{msd}} & =\mathrm{L}_{\mathrm{bsh}}+\mathrm{k}_{\mathrm{d}} \log \mathrm{R}+\mathrm{k}_{\mathrm{f}} \log \mathrm{f}_{\mathrm{c}}-9 \log \mathrm{b}
\end{aligned}
$$

em que,

$$
\begin{aligned}
& L_{b s h}= \begin{cases}-18 \log \left[1+\left(h_{b}-h_{0}\right)\right] & \operatorname{para~}_{b}>h_{0} \\
0 & \operatorname{para~}_{b} \leq h_{0}\end{cases} \\
& k_{a}=\left\{\begin{array}{rr}
54 & \begin{array}{r}
\operatorname{para~}_{b}>h_{0} \\
54-0,8\left(h_{b}-h_{0}\right)
\end{array} \\
54-0,8 \frac{\left(h_{b}-h_{0}\right) R}{0,5} & \text { para } R \geq 0,5 \mathrm{Kme}_{b} \leq h_{0}
\end{array}\right. \\
& \mathrm{k}_{\mathrm{d}}= \begin{cases}18 & \text { para }_{\mathrm{b}}>\mathrm{h}_{0} \\
18-15 \frac{\left(\mathrm{h}_{\mathrm{b}}-\mathrm{h}_{0}\right)}{\mathrm{h}_{0}} & \text { para } \mathrm{h}_{\mathrm{b}} \leq \mathrm{h}_{0}\end{cases} \\
& \mathrm{k}_{\mathrm{f}}=-4+0,7\left(\frac{\mathrm{f}_{\mathrm{c}}}{925}-1\right)
\end{aligned}
$$

com densidade média de obstáculos (neste estudo "árvores"). $\mathrm{k}_{\mathrm{f}}=-4+1,5\left(\frac{\mathrm{f}_{\mathrm{c}}}{925}-1\right)$;

para centros metropolitanos com parques e bosques com alta densidade de árvores. 
O modelo Lei de Potência $[19,39]$ é aplicado no ajuste da melhor reta que aproxima os dados obtidos nas campanhas de medidas utilizando como critério de ajustamento dessa reta em relação aos dados experimentais o princípio do erro médio quadrático mínimo. O processo de linearização ajusta os dados experimentais a uma reta resultante da regressão linear, vinculando os dados de medidas a uma proposição matemática dada por uma reta com coeficiente linear "a" e angular " $b$ " regidos pelas Equações (35) e (36):

O método dos mínimos quadrados estabelece:

$$
\begin{aligned}
& a=\frac{N \sum x_{i} y_{i}-\sum x_{i} \sum y_{i}}{N \sum x_{i}^{2}-\left(\sum x_{i}\right)^{2}} \\
& b=\frac{\sum x_{i}^{2} \cdot \sum y_{i}-\sum x_{i} \cdot \sum x_{i} y_{i}}{N \sum x_{i}^{2}-\left(\sum x_{i}\right)^{2}}
\end{aligned}
$$

A perda de propagação é proporcional à relação entre duas distâncias. $\mathrm{O}$ parâmetro $\mathrm{d}_{0}$ corresponde à posição inicial do drive-test, tendo como referência para seu cálculo o segmento que vai do ponto de partida do drivetest até a estação rádio base, geralmente 100 metros. A distância d corresponde a um ponto qualquer tomado no percurso em que se encontra o drive-test. 0 par ordenado $\left(y_{i}, x_{i}\right)$ representam o nível de sinal de recepção no ponto localizado a uma distância correspondente a i. Na Equação $37, \overline{P L}(d)$ é a perda média no percurso e n é o expoente de perda e $\alpha$ indica proporcionalidade.

A lei física mais geral que caracteriza a perda de potência em relação à distância é representada analiticamente pela função matemática:

$$
\overline{\mathrm{PL}}(\mathrm{d}) \alpha\left(\frac{d}{d_{0}}\right)^{\mathrm{n}}
$$

Ao aplicar o logaritmo decimal em ambos os lados da equação (37), tem-se:

$$
\overline{P L(d)}\left|d B=\overline{P L}\left(d_{0}\right)\right| d B+10 n \log \left(\frac{d}{d_{0}}\right)
$$

Em que $\overline{\boldsymbol{P L}}\left(\boldsymbol{d}_{\mathbf{0}}\right) \mid \boldsymbol{d} \boldsymbol{B}$ corresponde à constante que transforma a proporcionalidade em uma igualdade.

A Eq. (38) deve ser acrescida do termo X $\sigma \mathrm{L}$ que representa os desvios residuais em relação à melhor reta obtida pelo procedimento de regressão. Assim finalmente chega-se à expressão da linha de regressão que atende ao ajustamento estatístico efetuado pelo método dos mínimos quadrados:

$$
\overline{P L(d)}\left|d B=\overline{P L}\left(d_{0}\right)\right| d B+10 n \log \left(\frac{d}{d_{0}}\right)+X \sigma L
$$

$\mathrm{n}$ - coeficiente angular (declividade da reta de regressão)

Sabe-se que uma função descrita pela Eq. (38) pode ser representada de forma gráfica por uma reta em eixos coordenados cartesianos, tomando a 
abscissa na escala logarítmica e a ordenada na escala linear, pois $\overline{P L}\left(\boldsymbol{d}_{\mathbf{0}}\right)$ já se encontra em dB.

Levando-se em consideração a potência média recebida pelo drive-test $\overline{\operatorname{Pr}(d)}[\mathrm{dBm}]$ e a potência média de transmissão $\overline{\operatorname{Pt}(d)}[\mathrm{dBm}]$, obtem-se:

$$
\overline{\operatorname{Pr}(d)}[d B m]=\overline{\operatorname{Pt}(d)}[d B m]-\overline{P L(d)}[d B m]
$$

O modelo lei de potência é de fundamental importância para confrontar os resultados de campo com os modelos consagrados: empíricos, semiempíricos e determinísticos. Neste trabalho, a análise dos resultados foi realizada dentro dessa perspectiva: traçaram-se gráficos em função da distância percorrida, em metros, na abscissa e na ordenada a perda de propagação, em dB. A seguir, nos mesmos eixos cartesianos traçaram-se gráficos dos modelos consagrados. O pareamento entre gráficos do modelo lei de potência e dos modelos consagrados, permite perceber a similaridade entre ambos e assim determinar qual modelo melhor se ajusta aos dados experimentais em uma dada fitofisionomia.

A visão dos gráficos dos pares ordenados (distância versus perda de propagação) pode sugerir o melhor ajustamento por retas de regressão com distintos coeficientes angulares, múltiplas flexões na inclinação da reta ajustada, múltiplas declividades. O modelo de perda de propagação móvel em múltiplas morfologias [2] [48] a princípio tem grande aplicabilidade nas regiões de transição entre biomas, onde existe uma variabilidade significativa nos tipos de vegetação, podendo ser segregadas em conglomerados de mesma espécie florística. Sob outro aspecto, sabe-se que no espaço livre o expoente de perda n, Eq. (34), vale 2, no modelo terra plana $n$ vale 4, Eq. (41) e em se tratando de difração tende a $3[1,2]$.

$$
L(d B)=120+40 \log d(k m)-20 \log \left[h_{T}(m) h_{R}(m)\right]-G_{R}\left(d B_{i}\right)-G_{T}(d B i)
$$

O modelo que explora as múltiplas morfologias generaliza o modelo lei de potência, permitindo obter equação unificada para predizer a propagação em um ambiente de múltiplos clustering, como por exemplo a transição cerradocaatinga [2].

A técnica de analise começa com a visualização das inflexões dos pontos experimentais no gráfico obtido pelo modelo lei de potência. Toma-se o arquivo de medidas, uma vez constatadas múltiplas inflexões usando a técnica a ser descrita no item 2.4, deve-se agrupar e analisar em separado as subamostras pelo modelo lei de potência, resultando em múltiplos coeficientes de perda. Finalmente, os resultados podem ser levados a figurar em uma única expressão para a área ensaiada.

As Figs. 2.13 e 2.14 ilustram um exemplo de cenário que pode ser alvo do modelo de múltiplas morfologias e um cenário onde há dificuldades para que o modelo acompanhe as mudanças na morfologia. A repetição de fragmentos 
de mesma espécie pode sobrecarregar o modelo, ou seja, para o caso continuo a curva assintótica ajustada nos pontos de flexão não consegue acompanhar com boa precisão as mudanças de morfologia complexa como esboçado na Fig. 2.14.

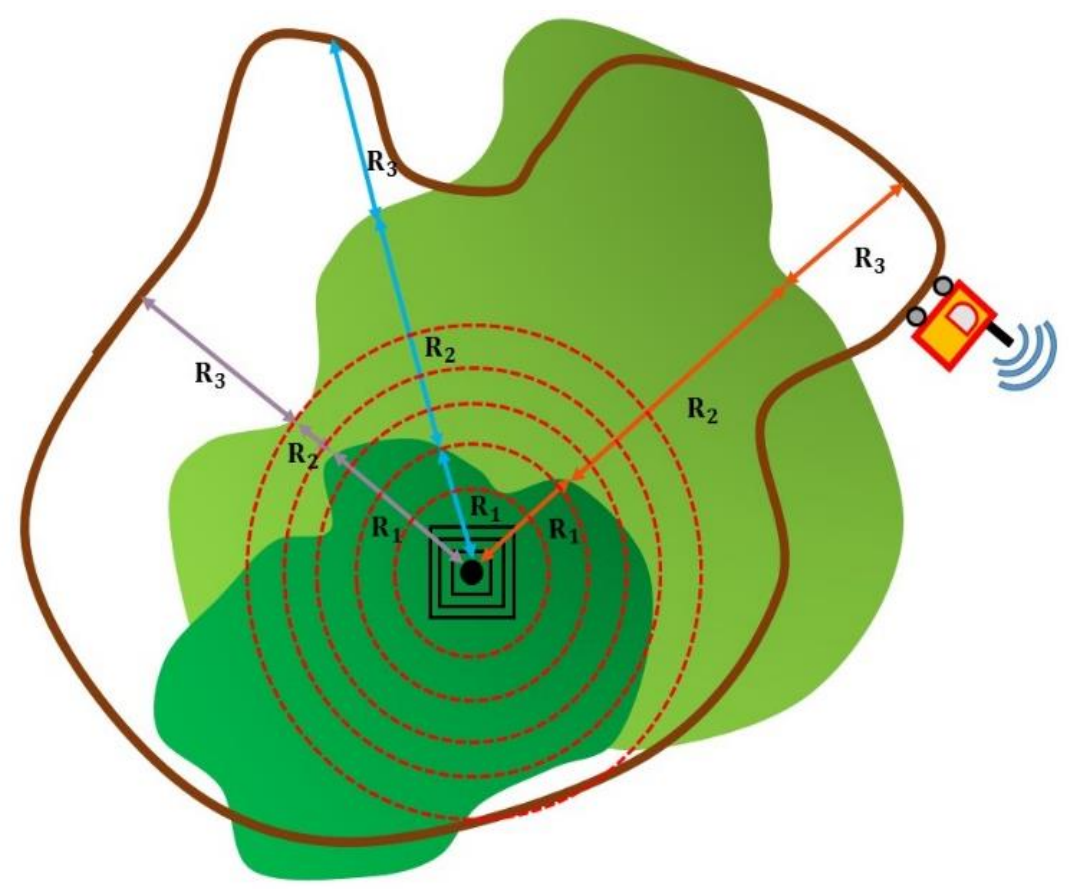

Figura 2.14 Ambiente propício à aplicação do modelo múltiplas morfologias. (Fonte: autor)

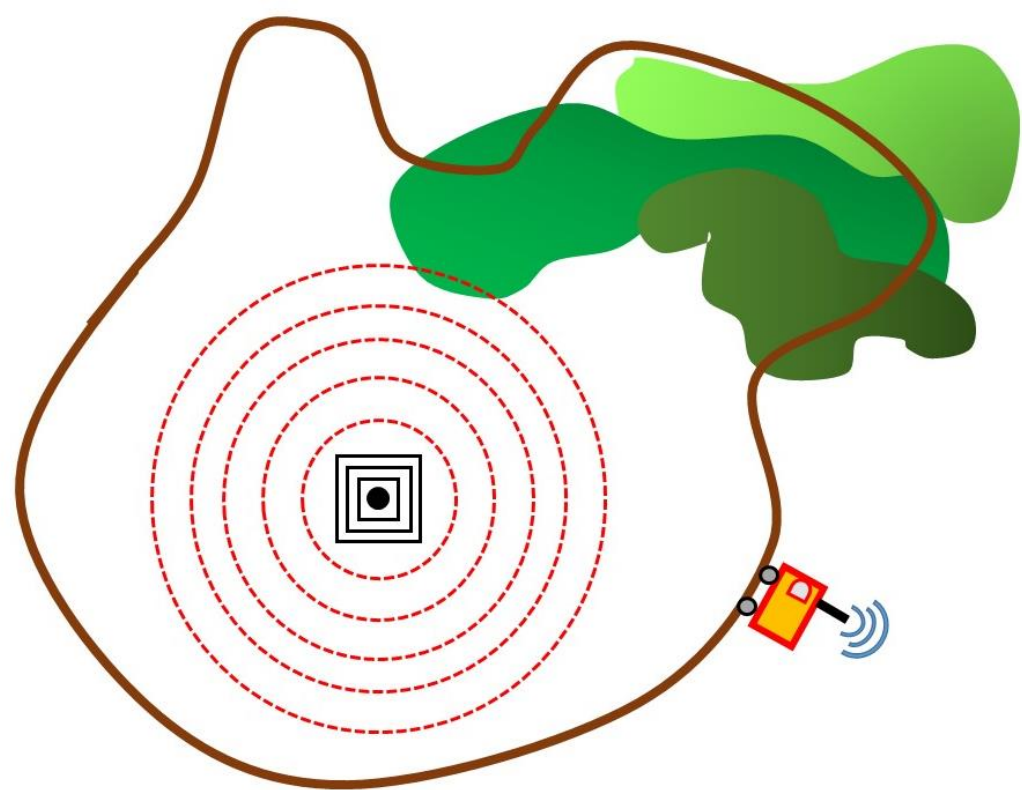

Figura 2.13 Ambiente que pode ocasionar dificuldades para o modelo múltiplas morfologias. (Fonte: autor)

Ressalta-se que múltiplas morfologias não significam necessariamente mudança na vegetação que reveste um dado relevo, mas sim mudança de ambiente e nos fenômenos de propagação inerentes àquele ambiente, conforme Eq. (1).

A Eq. (42) descreve o modelo para o caso descontínuo ou segmentado e a Eq. (43) descreve o modelo no caso contínuo deduzido para duas inflexões [48].

$L[d B]= \begin{cases}L_{1}+10 n_{1} \log (r) & \text { para } r \leq r_{b p} \\ L_{1}+10 n_{2} \log \left(\frac{r}{r_{b p}}\right)+10 n_{1} \log \left(r_{b p}\right) & \text { para } r>r_{b p}\end{cases}$ 


$$
\begin{gathered}
L[d B]=L_{1}+10 n_{1} \log (r)+10\left(n_{2}-n_{1}\right) \log \left(1+\frac{r}{r_{b p}}\right) \\
\begin{array}{c}
L[d B]=L_{1}+10 n_{1} \log (r)+10\left(n_{2}-n_{1}\left(n_{3}\right)\right) \log \left(1+\frac{r}{r_{b p 1}}\right) \log +10\left(n_{3}-n_{2}\left(n_{1}\right)\right) \log \left(1+\frac{r}{r_{b p 2}\left(r_{b p_{1}}\right)}\right) \\
+\cdots+10\left(n_{3}-n_{1}\left(n_{2}\right)\right) \log \left(1+\frac{r}{r_{b p_{2}}}\right)
\end{array}
\end{gathered}
$$

De forma a tornar mais didático o entendimento acerca do encadeamento lógico da aplicação do modelo, as equações podem ser desenvolvidas em termos de perdas crescentes [2]. Observando o gráfico da Fig. 2.15 e as Equações (45)-(51). A Eq. (45) é a generalização do modelo de Lee [2]. Ressalta-se que $\left(\gamma_{N}=n_{i}\right)$ é o expoente de perdas.

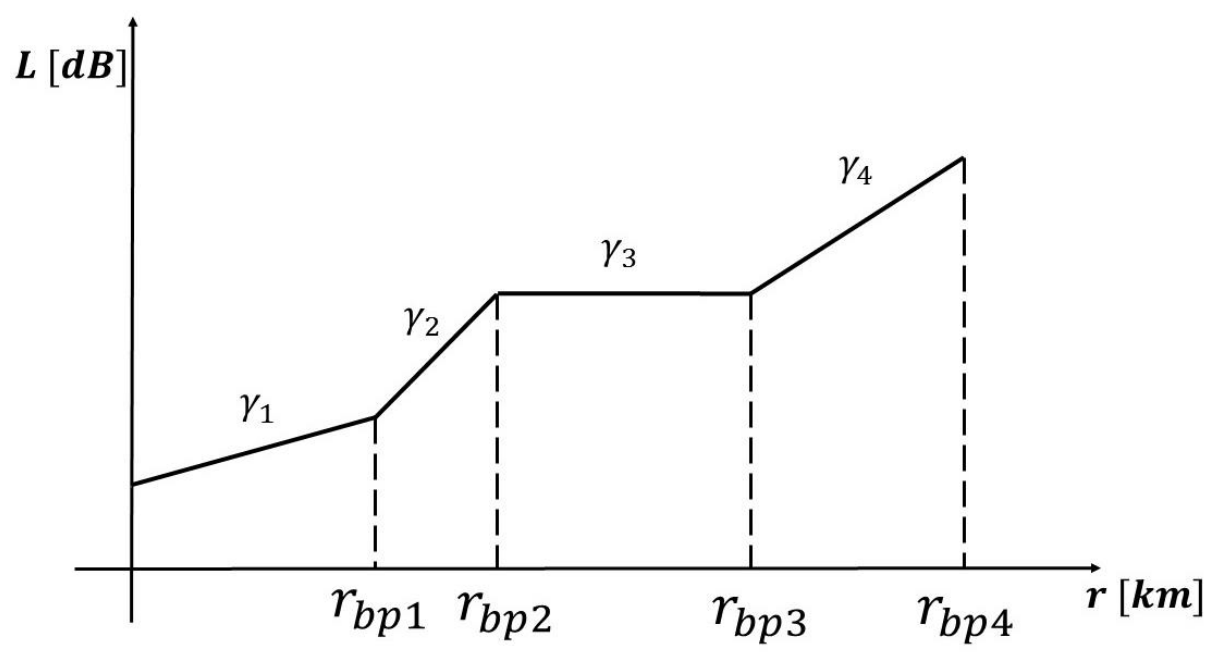

Figura 2.15 Modelo de múltiplas morfologias destacando os múltiplos expoentes de perda.

A perda $L$ deve ser acrescida dos fatores de compensação $\delta$ relativos à altura, aos ganhos das antenas de recepção e transmissão e a frequência de operação conforme [2]:

$$
\begin{aligned}
& L=L_{M}+\delta-\gamma_{N} \log (d)+\sum_{i=1}^{N-1}\left(\gamma_{i+1}-\gamma_{i}\right) \log (d i) \\
& \delta=\delta_{1}+\delta_{2}+\delta_{3}+\delta_{4}+\delta_{5} \\
& \delta_{1}=20 \log \left(\frac{h_{t}}{30,48}\right)[d B] \\
& \delta_{2}=\left\{\begin{array}{l}
10 \log \left(\frac{h_{r}}{3}\right) \\
20 \log \left(\frac{h_{r}}{3}\right) \\
h_{r} \leq 3 m
\end{array}\right. \\
& \delta_{3}=G_{t}-6[d B] \\
& \delta_{4}=G_{r}[d B] \\
& \delta_{5}=\log \left[\frac{f(M H z)}{900}\right]
\end{aligned}
$$

\subsection{DESVANECIMENTO EM LARGA ESCALA}

A sobreposição do sombreamento com a perda de propagação corresponde ao desvanecimento em larga escala. A estatística do sombreamento é modelada como uma função de distribuição de densidade de probabilidade de formato gaussiano. O sombreamento geralmente está relacionado a obstáculos de dimensões maiores que o comprimento de onda 
do sinal transmitido $(\lambda)$ localizados nos entremeios da linha de visada entre a estação rádio base e o usuário da rede móvel. O sombreamento é relevante no sentido de que a ocorrência de acentuada distorção na silhueta gaussiana de seu histograma, montado a partir do polígono de frequências, constitui um forte indício de que a reta de regressão da nuvem de pontos experimentais não se ajustou com boa aproximação em toda faixa de distâncias entre drivetest e a torre de transmissão [3].

O perfil estatístico do sombreamento corresponde às variações residuais em torno da média quando tomado em toda área delimitada por um percurso sobre análise. Desta forma, o sombreamento é uma variável de controle quanto à estimativa realizada pela reta de regressão dos resultados experimentais. A silhueta de uma gaussiana distorcida ou polígono de frequências com traçado destoante de uma PDF gaussiana também revela provável sobreposição de fenômenos de propagação ou estruturas que modificam o efeito do sombreamento realçando a dispersão do sinal além do estimado pela regressão dos resultados experimentais (análogo ao efeito da região de transição crepúsculo-sombra-penumbra da ótica [27]). A Fig. 2.16 mostra os desvios entre perda estimada (Lestimada) e perda experimental (Lexperimental). A Fig. 2.17 apresenta a variabilidade do sombreamento em função da distância.

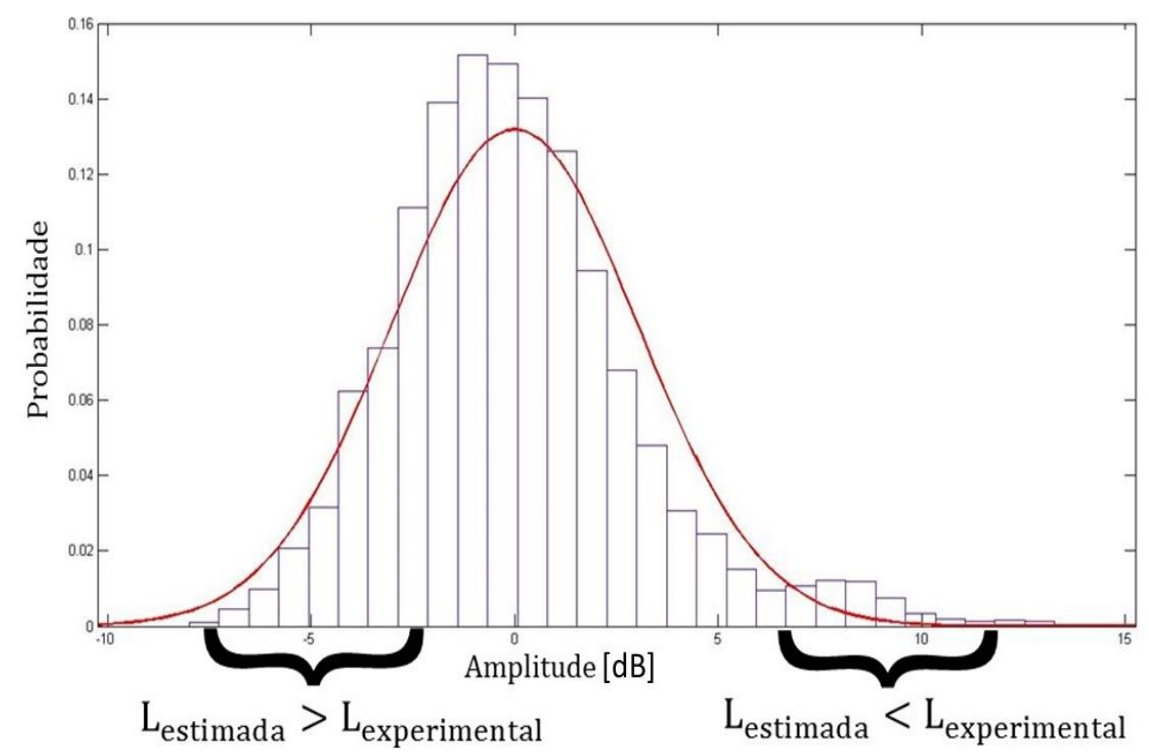

Figura 2.16 Desvanecimento em larga escala: sombreamento, histograma experimental versus distribuição gaussiana teórica.

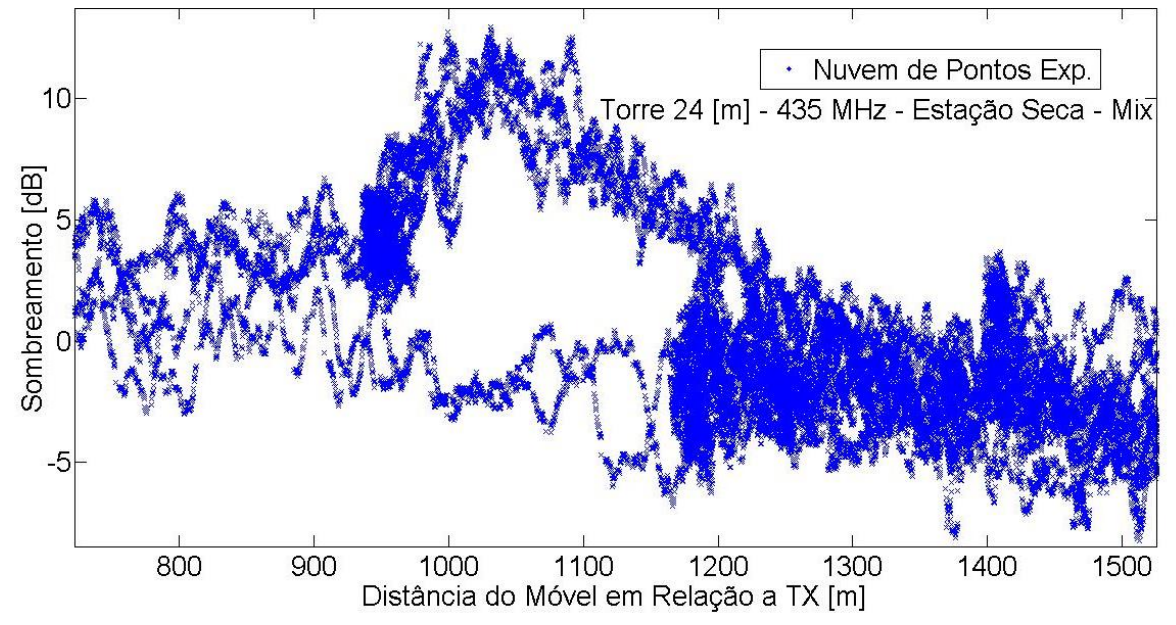

Figura 2.17 Plotagem do sombreamento versus distância. 


\subsection{DESVANECIMENTO EM PEQUENA ESCALA}

O desvanecimento em pequena escala, $r(t)$, está relacionado aos multicaminhos que o sinal percorre até chegar ao receptor. Isto é, várias versões do sinal chegam ao drive-test com diferentes amplitudes, fases e atrasos devido à variabilidade do ambiente em relação à mobilidade do usuário. Os multipercursos são causados pelos fenômenos de propagação que interferem na envoltória do sinal detectado pelo drive-test. As distribuições estatísticas de Weibull, Rayleigh, Rice, Nakagami, Suzuki são as principais estatísticas que se ajustam às distribuições experimentais do desvanecimento de pequena escala dependendo do grau de obstrução entre o drive-test e a estação rádio base. Por se tratar de distribuições lineares faz-se necessário converter os resultados experimentais armazenados em termos de nível de potência $(\mathrm{dBm})$ para volts. Para isso recorre-se à Eq. (52)

$\left.r(t)\right|_{\text {volts }}=0,22361 \times 10^{\left(\frac{\left.r(t)\right|_{\mathrm{dBm}}}{20}\right)}$

O desvanecimento em pequena escala é tomado com uma granularidade temporal de 800 milissegundos. A função distribuição das densidades de probabilidade de Nakagami-sombreado, Eq.53 [3] generaliza grande parte das distribuições usuais que caracterizam o desvanecimento de pequena escala. A Tabela II mostra os valores a serem observados em relação aos parâmetros $m$ e $\sigma$ que levam à generalização a partir da distribuição de Nakagami-sombreado.

$$
P_{N S}(w)=\frac{m^{m}}{\Gamma(m) \sqrt{2 \pi}} \int_{0}^{\infty} \frac{w^{m-1}}{\varpi^{m+1} \sigma} \exp \left[-\frac{m w}{\varpi}-50\left(\frac{\log \varpi-\log m_{w}}{\sigma}\right)^{2}\right] d \varpi
$$

A PDF de Nakagami tem a seguinte expressão:

$$
p(r)=\frac{2}{\Gamma(m)}\left(\frac{m}{\Omega}\right)^{m} r^{2 m-1} \exp \left(-\frac{m}{\Omega} r^{2}\right)
$$

\begin{tabular}{|c|c|c|c|}
\hline \multirow{9}{*}{ Nakagami Sombreado } & Condição para $\sigma$ & Condição para m & Distribuição resultante \\
\hline & $\sigma=0$ & m qualquer & Nakagami \\
\hline & $\sigma=0$ & $m=1$ & Rayleigh \\
\hline & $\sigma=0$ & $\sqrt{m^{2}-m}$ & Rice \\
\hline & & $\kappa=\overline{m-\sqrt{m^{2}-m}}$ & \\
\hline & $\sigma$ qualquer & $m=1$ & Suzuki \\
\hline & $\sigma$ qualquer & $\sqrt{m^{2}-m}$ & Rice Sombreado \\
\hline & & $m-\sqrt{m-\sqrt{m^{2}-m}}$ & \\
\hline & $\sigma$ qualquer & $m \rightarrow \infty$ & Log-normal \\
\hline
\end{tabular}

Tabela 2.1 Distribuições derivadas de Nakagami-sombreado [3]

Em que, $m$ está relacionado ao número de clusters no percurso (denominado também como fator de desvanecimento), $\sigma$ ao desvio padrão da distribuição, $\Gamma(m)$ ao valor da função gama no intervalo de integração, $\varpi$ à constante de integração, $\Omega$ à potência média e $m_{w}$ à média local e $k$ é o fator de Rice (potência média do sinal LOS pelo NLOS).

Quando há uma grande fração de desobstrução na linha de visada a distribuição de Rice é a que melhor se ajusta aos resultados experimentais. Em 
ambientes reflexivos, com significativa densidade de clusters distribuídos aleatoriamente, ambientes com aglomerados de obstáculos de características morfológicas semelhantes, a distribuição de Weibull é a mais adequada. A distribuição de Rayleigh para obstáculos de porte médio interpostos na linha de visada entre estação rádio base e o drive-test ou com predominância de multipercursos em relação ao efeito do sombreamento.

Em ambientes fortemente obstacularizado o melhor ajuste é a distribuição de Nakagami. Suzuki para os ambientes de morfologia moderada em termos de obstáculos causadores de multipercursos e sombreamento [3]. Outras generalizações para modelagem do desvanecimento que abarcam as distribuições estatísticas citadas e são apropriadas para ambientes com morfologia mais complexas foram tratadas forma teórica e experimental em [23] à custa de maior esforço computacional.

O fator $k$ de Rice define a razão é um indicativo do grau de desobstrução do ambiente: quanto menor for o fator $k$ mais a distribuição estatística do desvanecimento de pequena escala se aproxima da distribuição de Rayleigh.

A obtenção da melhor função de distribuição de probabilidade que se ajusta ao desvanecimento de pequena escala experimental neste trabalho foi embasada nos recursos do Matlab. A sequência de acionamento do programa é a seguinte: tool boxes, statistics e distribution fitting tool-dftool. O procedimento de ajuste obedece a seguinte ordem: 1-Verificação visual da função de distribuição das densidades de probabilidades (recurso probability distribution function (PDF)), a PDF que melhor se ajusta à PDF do desvanecimento experimental.

Caso exista incerteza quanto ao ajuste da melhor PDF, parte-se para a comparação visual da cumulative distribution function (CDF). Primeiramente faz-se uma análise visual da região de maior amplitude, em seguida parte-se para análise da região central das distribuições estatísticas e, finalmente, da região de baixa amplitude. Em geral, um bom critério para caracterizar o canal em termos de desvanecimento de pequena escala é admitir a CDF que melhor se aproxima dos resultados experimentais na região central. Com isso assegura-se que 50 \% das ocorrências do desvanecimento de pequena escala foram levadas em conta no dimensionamento da rede.

Existe ainda um terceiro recurso para discriminar qual seria o melhor modelo de desvanecimento em pequena escala, o Probability Plot, que é um teste de aderência constante do Matlab e consiste na confrontação das plotagens das CDFs teórica e experimental em termos de probabilidade de aderência ao experimental.

Por último recorre-se ao parâmetro log likehood de cada distribuição confrontada com a distribuição dos resultados experimentais. O valor deste parâmetro é lido no manage fit, opção edit fit. Quanto maior for o valor do log 
likehood, melhor será a adequação da distribuição teórica à distribuição dos resultados experimentais. 


\section{FUNDAMENTOS DA MEDIÇÃO DA PROPAGAÇÃO DE ONDAS ELETROMAGNÉTICAS}

\subsection{INTRODUÇÃO}

Os modelos de propagação no canal móvel ou estático são embasados na teoria eletromagnética e em medidas de propagação. A medição de Ondas eletromagnéticas tem por objetivo modelar experimentalmente o ambiente de forma realista. Ela pode ser efetuada tomando-se amostras do sinal recebido em termos dos valores médios de campo elétrico ou de potência recebida. Neste estudo, por se tratar de medição de ondas eletromagnética em faixa estreita, domínio espacial, desvanecimento plano, optou-se por adquirir amostras da potência recebida, mediante a emissão de uma onda contínua $(C W)$. Para isso montou-se um sistema de medidas embarcado em um veículo servindo como drive-test (Anexo IV) em que o principal instrumento de captação dos resultados foi um analisador de espectro previamente programado para adquirir os pontos amostrais a uma taxa de 150 amostras por varredura de $800 \mathrm{~ms}[49,50]$.

É importante caracterizar as perdas de propagação que diminuem a intensidade do sinal recebido e a dispersão ou variabilidade ocasionadas pela distribuição espacial da potência emitida devido a distribuição aleatória de obstáculos no ambiente de medidas. $O$ analisador de espectro foi ajustado para detecção do valor de pico do sinal a cada instante de amostragem. A cada varredura de 800 ms foram colhidos 150 pontos de medida com isso conforme dedução apresentada nas próximas seções é possível extrair a perda de propagação e parâmetros de desvanecimento associados à perda de propagação.

Antes de realizar as campanhas de medidas fez-se necessário prospectar no ambiente a ser ensaiado a possível interferência com outras emissões. A morfologia do ambiente tem sua complexidade acentuada a medida que o drive-test afasta do ponto de transmissão. Além disso a realização de uma campanha precursora permite ajustar os patamares de referência no analisador de espectro para evitar saturação ou resultados a patamares próximos do ruído. As características elétricas e de radiação das antenas transmissoras devidamente corrigidas considerando o ambiente das torres de sustentação. A antena receptora de característica omnidirecional demandou apenas correções de VSWR conforme a frequência da campanha de medidas.

$\mathrm{Na}$ antena do drive-test os sinais chegam por diferentes caminhos, incorrendo diferentes atrasos. Acrescente-se a sobreposição dos sinais devido ambiente rico em multipercuros, variações na intensidade do sinal recebido devido ao deslocamento do drive-test pelas vias da área de abrangência do estudo. A caracterização da medição de propagação de ondas 
eletromagnéticas em termos de perdas exige que se obtenha a variação da intensidade do sinal com a distância. Para isso faz se necessário que a medida armazene as informações geográficas dos pontos amostrais por meio de um receptor GPS ou por outro mecanismo de sincronismo qualquer, como por exemplo, a 5a roda acoplada ao drive-test [23].

Para implementar a medição da propagação de ondas eletromagnéticas para projetos de rádio móvel em sistemas deve-se escolher uma metodologia adequada. Todas metodologias têm como objetivo comum o levantamento do sinal recebido em um ambiente externo. Os arquivos de medição darão subsídios para caracterização analítica das perdas de propagação e os desvanecimentos associados.

Tendo em vista que neste trabalho foi implementado a abordagem estatística para fins de análise e o enfoque dos resultados foi tomado no domínio espacial e indiretamente no domínio do tempo. Os fundamentos da medição de um sinal em um ambiente externo exigem além da integração dos instrumentos de medida para a aquisição da intensidade do sinal recebido a implementação de um sistema de coleta georreferênciada. O GPS cumpre este papel. O laboratório móvel para coleta de dados que é o drive-test é apresentado no anexo $\mathrm{O}$ sistema básico de coleta de dados móvel aqui denominado drive-test é apresentado no anexo IV.

A medição é realizada em função da distância, potência transmitida, alturas efetivas das antenas de transmissão e recepção, perfil altimétrico do ambiente, frequência de transmissão, velocidade de deslocamento.

O enfoque da medição em faixa estreita requer a transmissão de um sinal sem modulação para que os efeitos do multipercurso e sombreamento sejam caracterizados em seletividade espacial e não nos domínios do tempo e frequência $[49,50]$.Os desvanecimentos ocorrem simultaneamente e são separados pela técnica das médias moveis conforme descrita na seção

Os mecanismos de propagação envolvidos no ambiente de estudo foram apresentados na seção 2.2 .

A degradação do sinal no receptor está relacionada não só ao enfraquecimento da energia radiada com a distância, acentuada pelos desvanecimentos que de forma genérica está relacionado ao espalhamento das ondas eletromagnéticas no ambiente de operação de um sistema móvel [3].

\subsection{TÉCNICA DAS MÉDIAS MÓVEIS}

A técnica recursiva das médias móveis é empregada na extração dos fenômenos de desvanecimento que distorcem o canal móvel de forma aleatória [18]. A separação dos fenômenos de propagação foi realizada mediante filtragem apropriada aplicada aos dados coletados na fase de 
processamento dos arquivos de medidas. A técnica da filtragem por média móvel separa os desvanecimentos causados pelas obstruções da perda intrínseca à propagação no ambiente ensaiado pelo drive-test.

A Fig. 3.1 ilustra os tipos de desvanecimentos levados em consideração no escopo deste trabalho quando separados pela técnica das médias móveis e a atenuação que impacta negativamente o nível do sinal captado no set-up de medidas do drive-test.

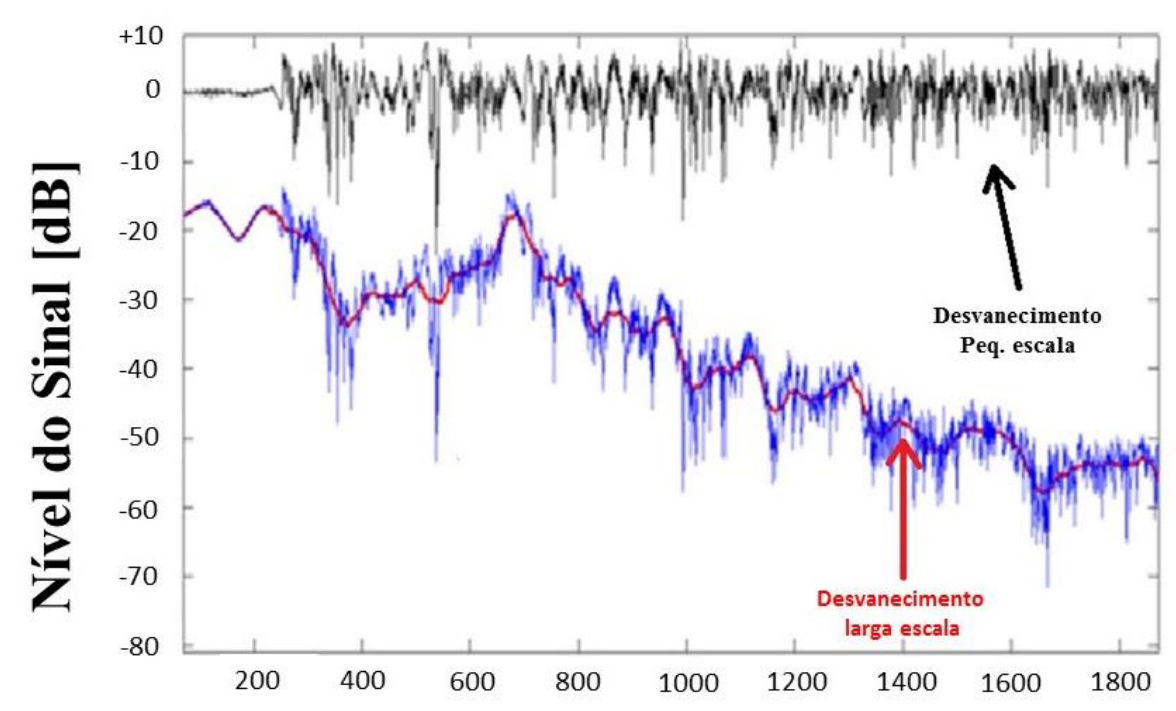

\section{Distância [m]}

Figura 3.1 Em azul e vermelho ilustra-se a sobreposição dos desvanecimentos de pequena escala e de larga escala, e grafado em preto destaca-se o desvanecimento em pequena escala. Campanha de medidas realizada no perímetro do Campus Darcy Ribeiro em $144 \mathrm{MHz}$.

A Fig. 3.2 esboça a progressão incremental da janela pelos dados obtidos em uma fictícia campanha de medidas. A média móvel é a média em $2 K+1$ valores, centrada neste intervalo, tomada de ponto em ponto. A passagem da média móvel suaviza as variações em torno da média do sinal recebido provocadas pelos desvanecimentos.

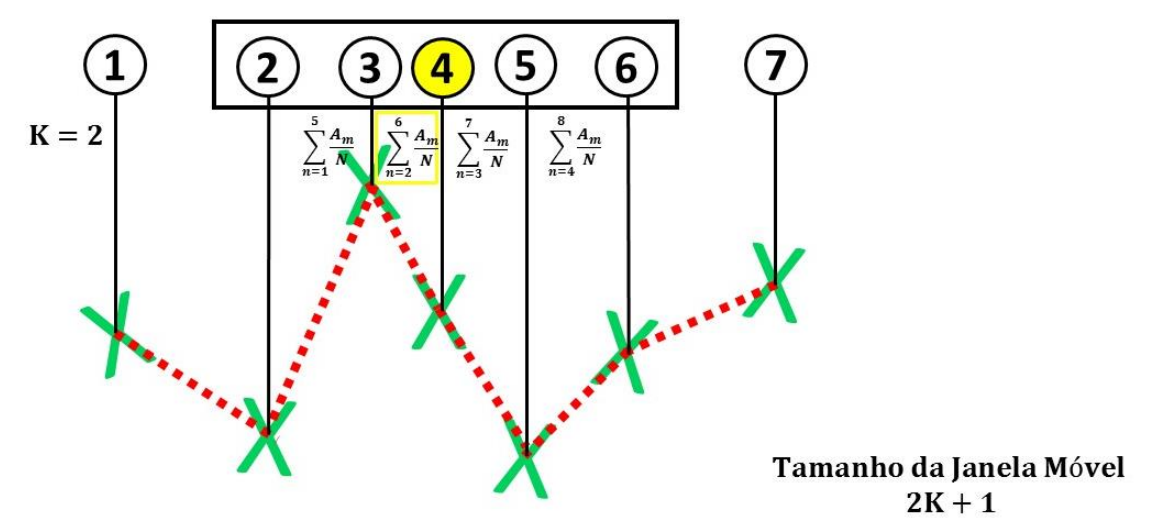

Figura 3.2 llustração esboçando o avanço da Janela Móvel por entre amostras de sinal recebido extraídas de um suposto arquivo bruto de medidas do sinal medido pelo drive-test em uma campanha de medidas qualquer.

A extração dos desvanecimentos segue o seguinte raciocínio: primeiramente, a filtragem é aplicada às amostras contidas no arquivo de dados experimentais, desta forma obtém-se o desvanecimento em pequena 
escala; em seguida, reaplica-se a filtragem nas amostras descorrelacionadas, aquelas distanciadas de $0,38 \lambda$, conforme teoria desenvolvida nos trabalhos basilares de modelagem estatística aplicada a comunicações móveis $[49,50]$. $O$ resultado desta segunda filtragem é o desvanecimento em larga escala.

A perda do sinal, modelo Lei de Potência, é obtida pela aplicação da regressão linear nos dados experimentais descorrelacionados. Ao subtrair a perda de propagação do desvanecimento de larga escala resulta no sombreamento. A função distribuição das densidades de probabilidade do sombreamento aproxima-se da distribuição padrão gaussiana. O método é flexível no sentido de que a filtragem não é forçada a adaptar-se a uma função matemática específica.

As Expressões (55)-(58) exprimem a aritmética de cálculo do deslocamento da janela móvel por entre pontos experimentais fictícios. Em que $2 k+1$ é um número ímpar correspondente à quantidade de amostras inseridas na janela [1].

$\frac{Y_{1}+Y_{2}+Y_{3}+\cdots+Y_{2 K+1}}{2 K+1}$

$\frac{Y_{2}+Y_{3}+\cdots+Y_{2 K+2}}{2 K+1}$

$\frac{Y_{3}+Y_{4}+\cdots+Y_{2 K+3}}{2 K+1}$

$\frac{Y_{n+1-K}+Y_{n+2-K}+\cdots+Y_{n}}{2 K+1}$

O tamanho da janela define o grau de suavização ou amortecimento dos acréscimos e decréscimos em torno da média. Sabendo-se que as variações do desvanecimento de pequena escala atingem picos de $20 \mathrm{~dB}$ e a do desvanecimento de larga escala atingem picos de $15 \mathrm{~dB}$ [23] como ilustrado na Fig. 3.3, a caracterização dos desvanecimentos junto com a perda de propagação dá subsídios ao planejamento de uma rede móvel.

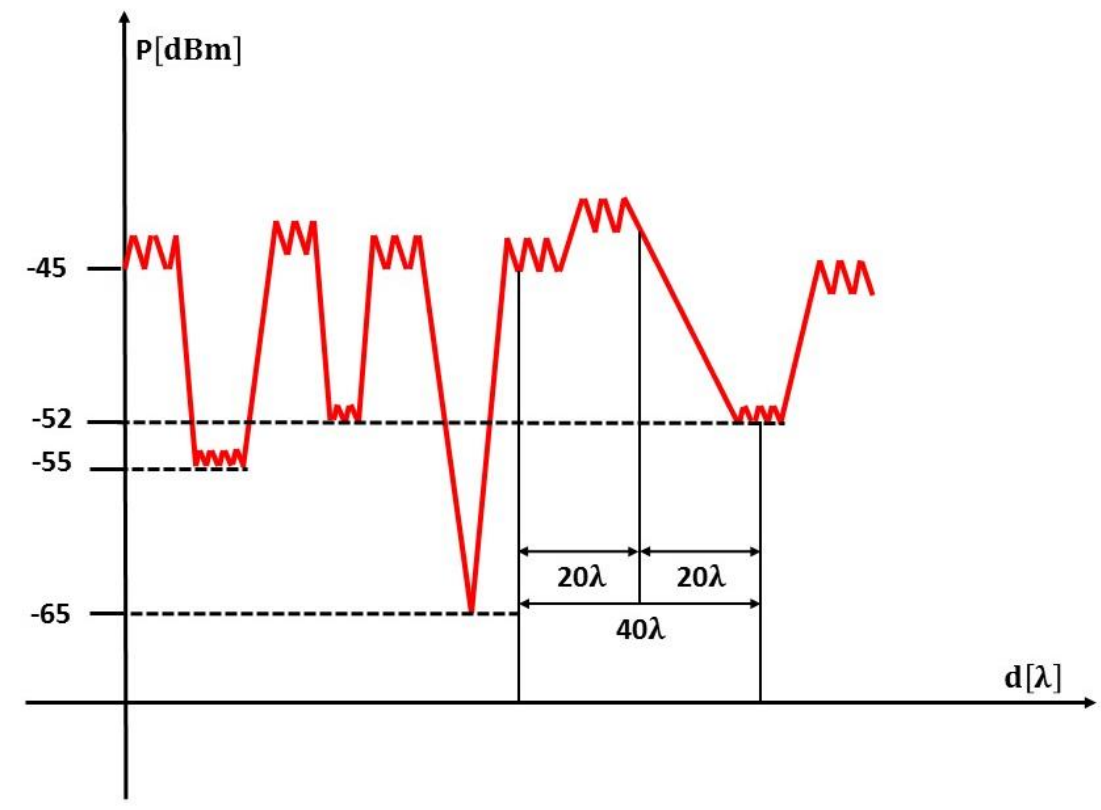

Figura 3.3 Variações do sinal recebido devido aos desvanecimentos. 
O tamanho da janela móvel foi embasado no critério de Parsons [23]. Salienta-se que poder-se-ia adotar como tamanho da janela o critério de Parsons [1] ou o critério de Lee [2], observou-se que os resultados divergem pouco [17]. Neste trabalho aplicou-se o critério de Parsons, a saber: 20 metros para UHF e 40 metros para VHF. De acordo com Lee o comprimento da janela é $20 \lambda$ para UHF e $40 \lambda$ para VHF.

O tamanho do arquivo de dados a ser coletado nas campanhas de medidas, em outras palavras, o quantitativo mínimo de pontos experimentais necessários à extração dos desvanecimentos e à obtenção da estimativa da perda de propagação depende de dois parâmetros fundamentais: nível de significância (risco) ou nível de confiança ( 1 - risco), margem de erro que é definida pela probabilidade de o parâmetro estimado situar-se fora do intervalo de confiança (limite superior e limite inferior).

Dado que se desconhece a variância e a média da distribuição do estimador determina-se a probabilidade do valor real do parâmetro estar dentro dos limites estipulados. O resultado do módulo de 1 menos a probabilidade do valor estimado estar dentro do intervalo de confiança é o risco que se incorre na escolha da função densidade de probabilidade, probability density function (PDF), dos estimadores dos parâmetros de interesse (média ou variância) [18].

A variável aleatória de interesse para o estudo de propagação móvel é a média da perda potência conhecida como $\mathrm{L}_{50}$. Lançando mão dos fundamentos de estatística aplicada [18] para subsidiar o cálculo a partir do conjunto de pontos experimentais deve-se estimar a média e, uma vez estabelecida a média local estimada chega-se a variância do estimador válida no intervalo de confiança estipulado. À medida que o tamanho do arquivo de dados cresce em número de amostras, a variância do estimador deve convergir para zero e assim, mais perto o valor estimado está próximo do valor real.

Dado o elevado número de pontos amostrais e, por conseguinte, fazendo uso do teorema do limite central [18], pode-se afirmar que a variabilidade local poderá ser expressa com boa aproximação por uma função de densidade de probabilidade normal. Assim é possível obter uma margem de erro mais estreita com o quantitativo mínimo de amostras obtido por:

$$
N_{\min }=\frac{Q_{i}^{2}\left(\frac{1-I_{C}}{2}\right) \sigma^{2}}{\varepsilon^{2}}
$$

$\mathrm{Na}$ Equação (59), $\mathrm{N}_{\min }$ é o número mínimo de pontos experimentais requeridos para obtenção da perda de propagação e desvanecimentos, $\mathrm{Q}_{\mathrm{i}}$ é a função complementar da função densidade de probabilidade gaussiana com argumento expresso em função do intervalo de confiança $I_{c}$ do parâmetro estatístico a ser estimado, $\varepsilon$ é a margem de erro assumida para o cálculo de $\mathrm{N}_{\min }, \sigma$ é a quantidade necessária de desvios padrão tomando por base uma 
distribuição gaussiana padrão, para garantir que o valor do parâmetro desconhecido, a ser estimado, atinja a confiabilidade de $95 \%$.

O risco de erro (nível de significância/2) determina o grau ou nível de confiança bicaudal. Usa-se intervalos simétricos de sorte que existe a probabilidade (1-nível de significância ou 1-risco) de que o valor do parâmetro estimado não esteja fora da faixa de valores do intervalo de confiança [18].

Chega-se ao valor de $95 \%$ de nível ou grau de confiança tendo por base a quantidade de amostras analisadas. A quantidade mínima de amostras é obtida ao estabelecer a margem de erro aceitável, neste trabalho estipulou-se uma margem de erro (risco) em 5\%, pois a confiabilidade é de 95\%. Em síntese, a prefixação da quantidade de amostras está estatisticamente vinculada à margem de erro admissível escolhida para caracterizar os desvanecimentos.

A extração do desvanecimento em larga escala requer a separação de um conjunto de sub-amostras, amostras selecionadas com baixo grau de correlação, próximo de zero. Tomando por base que a função distribuição das densidades de probabilidade, relativa à variabilidade do desvanecimento em pequena escala, é em geral satisfatoriamente modelada por uma função do tipo Rayleigh, chega-se ao gráfico da variância do estimador de média local em função do tamanho da janela móvel. O gráfico da margem de erro versus o número de amostras, encontrado em [21], quando plotado nos eixos cartesianos resulta em uma curva com silhueta assintótica em torno de $1 \mathrm{~dB}$ acima de 20 comprimentos de onda.

O teste de aderência das PDFs dos resultados experimentais está vinculado a uma distribuição estatística do tipo Qui-quadrada cuja conceituação está desenvolvida em [18, 21]. Em linhas gerais parte-se de uma média desconhecida da população de possíveis resultados experimentais para construir o estimador de média móvel, supõe-se que a distribuição desta população é gaussiana.

\subsection{AQUISIÇÃO DE DADOS NAS CAMPANHAS DE MEDIDAS}

Os conceitos apresentados nos próximos tópicos são descritos considerando a realidade prática aplicando as condicionantes do cenário experimental vivenciado nas campanhas realizadas na FAL. Esta seção constitui-se nos cálculos preliminares que devem ser realizados antes de partir com o drive-test, ações para configurar o set-up de medidas. A seção concluise com apresentação da metodologia usada para extração de gráficos e métricas estatísticas visando à análise dos resultados.

\subsubsection{Pré-processamento}

O objetivo é configurar o analisador de espectro para que ele funcione como um receptor que meça a variabilidade do sinal da portadora de transmissão provocada pela geomorfologia do ambiente ensaiado. Para isso, o analisador deve ser ajustado de forma a abarcar as expectativas de excursão 
em frequência do sinal da portadora de transmissão devido ao efeito Doppler causado pelo deslocamento relativo entre a torre e o drive-test, bem como as excursões em frequência remanescentes dos osciladores internos do transmissor e do próprio analisador de espectro.

A Fig. 3.4 esboça o alargamento do sinal e sinaliza o ajuste a ser efetuado no filtro de resolução do analisador de espectro. Na Fig. 3.4, $\mathrm{F}_{0}$ é o sinal $\mathrm{CW}$ portadora ideal com espectro de largura infinitesimal, $F_{m}$ é a frequência Doppler. Na Fig. 3.4 é esboçado também o sinal real com espectro alargado e o deslocamento entre patamares de máximo e mínimo devido à excursão Doppler. Recomenda-se na prática ajustar o filtro de discriminação granular ou de resolução do analisador de espectro, RBW- Resolution Bandwith, a um valor de dez vezes a frequência Doppler.

Estas condicionantes são levadas em consideração com o objetivo de garantir acuidade na caracterização do canal móvel nos quesitos desvanecimentos, perdas de propagação, verificando a possível incidência de outros fenômenos. A seguir apresentam-se as equações definidoras do set-up de medidas $[19,20]$.

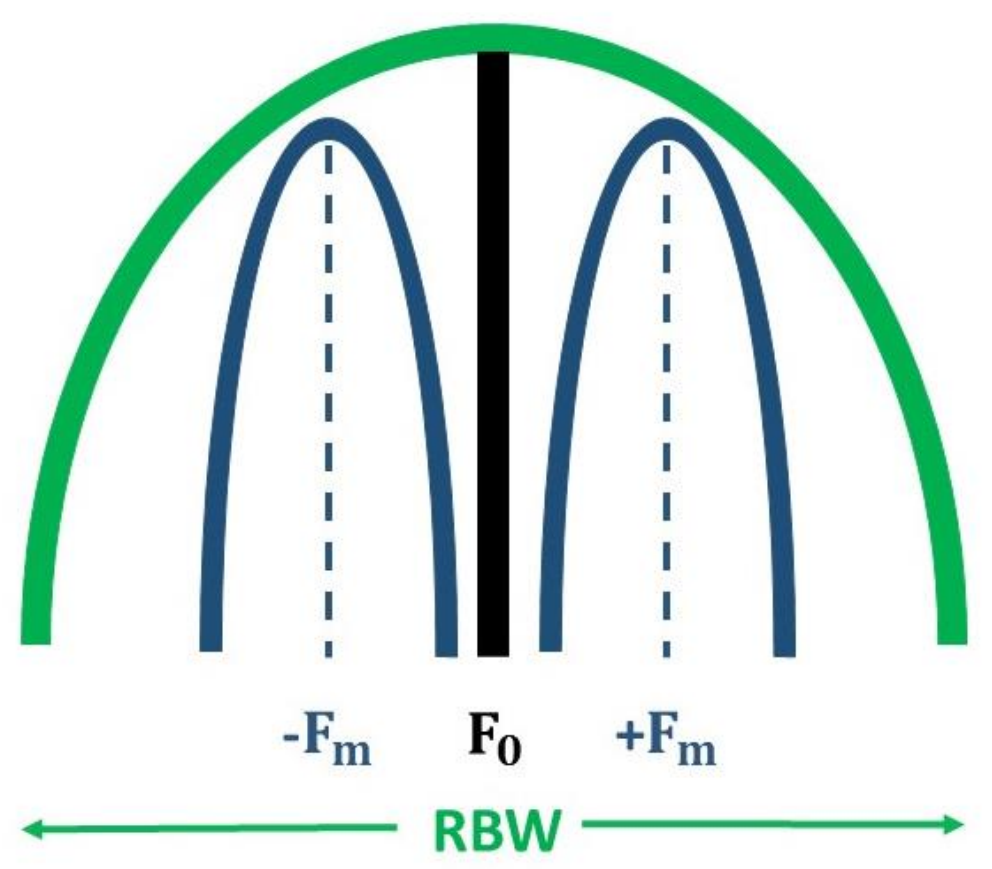

Figura 3.4 Esboço do alargamento do sinal de recepção devido às condicionantes práticas.

Tomando por base a frequência de $144 \mathrm{MHz}$ para ilustrar a metodologia de dedução do quantitativo de amostras, tem-se: $\lambda=2,08$ metros, $40 \lambda=83,20$ metros [43], velocidade do móvel (veículo do drive-test) $=50 \mathrm{~km} /$ hora e a distância entre amostras descorrelacionadas menor ou igual a $0,38 \lambda[49,50]$. Aplicando esses dados na desigualdade expressa na eq. (60) o número de pontos por varredura do analisador de espectro que garanta a confiabilidade estimada em $95 \%[49,50]$, obtém-se $N p_{\text {sweep }}=21$ amostras por varredura de 800 ms:

$\mathrm{v}\left(\frac{\mathrm{T}_{\text {sweep }}}{\mathrm{Np}_{\text {sweep }}}\right) \leq \frac{\lambda}{4}$ 
A distância de descorrelação levada em consideração no processo de filtragem para separação do desvanecimento de larga escala é $0,38 \lambda$ e para extração do desvanecimento de pequena escala, deve-se levar em conta o critério da Eq. (60). A dedução da Equação (60) está embasada na teoria desenvolvida por William C. Jakes e R. H. Clarke $[49,50]$ nos primórdios dos estudos de propagação móvel. A Tabela 3.1 apresenta de forma resumida esses resultados. A Fig. 3.5 ilustra o diagrama de tempos de uma varredura de 1 segundo, em que o tempo correspondente à aquisição de dados é de 0,8 segundos e o tempo gasto para o analisador entregar ao laptop os resultados de uma varredura gravados em sua memória é de 0,2 segundos.

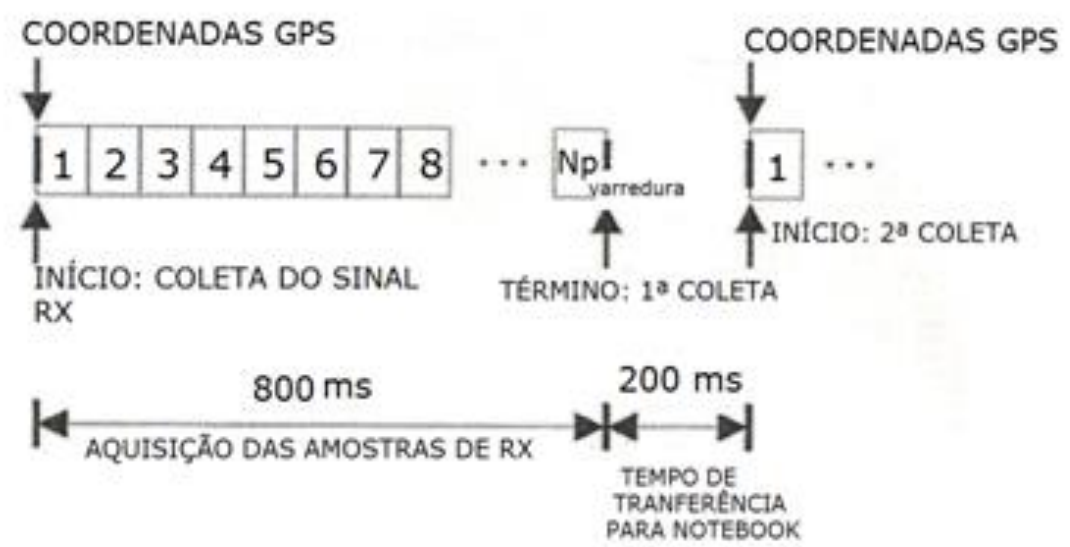

Figura 3.5 Linha do tempo de atualização do GPS e armazenamento dos dados no laptop. (Fonte: Ilustração retirada de [19]).

Tabela 3.1 Dados das Campanha de Medidas $144 \mathrm{MHz}$.

\begin{tabular}{|c|c|}
\hline Frequência & $144 \mathrm{MHz}$ \\
\hline$\lambda$ & $2,08 \mathrm{~m}$ \\
\hline $40 \lambda$ & $82,4 \mathrm{~m}$ \\
\hline Velocidade do móvel - $v$ & $50 \mathrm{~km} / \mathrm{h}$ \\
\hline Tempo de uma varredura & 1 segundo \\
\hline Tempo de aquisição de dados - $T_{\text {sweep }}$ & $800 \mathrm{~ms}$ \\
\hline Altura da torre & $10 \mathrm{~m} / 24 \mathrm{~m}$ \\
\hline$W$-Largura da via & $5-8 \mathrm{~m}$ \\
\hline Distância de descorrelação & $0,38 \lambda$ \\
\hline Polarização & Vertical \\
\hline
\end{tabular}


$\mathrm{O}$ analisador de espectro deve ser ajustado às condições ideais da campanha de medidas; isto é, de forma a satisfazer o que se quer extrair em termos de desvanecimentos. Tomando a título de exemplo a frequência de $144 \mathrm{MHz}$, potência de transmissão de $46,5 \mathrm{dBm}$ a partir da torre de 10 metros na FAL, tem-se o seguinte ajuste:

ref. level $=-40 \mathrm{dBm}$

$\mathrm{RBW}=1 \mathrm{kHz}$

$\mathrm{VBW}=1,5 \mathrm{kHz}$

Sweep time $=800 \mathrm{~ms}(150 \mathrm{pts})$

Span $=0$

Dessa forma, como foram adquiridos 150 pontos amostrais por varredura, a quantidade de amostras suplantou o mínimo teórico necessário para extração e visualização dos desvanecimentos que foi calculado em 21 amostras para $144 \mathrm{MHz}$ e 65 amostras para $435 \mathrm{MHz}$. Uma vez estabelecido o número de amostras por varredura, deve-se ajustar no analisador de espectro a sintonia do filtro de resolução $R B W$ e o filtro de detecção da envoltória do sinal $V B W$. Para isso, o primeiro passo é determinar a excursão do Efeito Doppler.

freq. Doppler $=\frac{\text { velocidade }}{\lambda}$

A excursão do Efeito Doppler pode variar nos seguintes patamares:

$$
\begin{aligned}
& \mathrm{f}_{\mathrm{d}}=2 \frac{\mathrm{v}}{\mathrm{c}} \mathrm{f}_{0} \\
& f_{d}=2 \frac{60[\mathrm{~km} / \mathrm{h}]}{3,6} \frac{\left(144 \times 10^{6}[\mathrm{~Hz}]\right)}{\left(3 \times 10^{8}[\mathrm{~m} / \mathrm{s}]\right)}
\end{aligned}
$$

Então,para $f_{d}=8,0 H z$, vem:

A excursão do Efeito Doppler resulta:

$$
2 \mathrm{f}_{\mathrm{d}}=16,0 \mathrm{~Hz}
$$

Na prática a largura do filtro RBW deve ser ajustada em aproximadamente 10 vezes o valor do deslocamento Doppler, Eq. (65), e o $V B W$ deve ser ajustado igualmente a $R B W$ ou ligeiramente acima, não muito acima para evitar distorcer o sinal captado $[6,7]$. Percebe-se que o ajuste teórico de $R B W$ em $16 \mathrm{~Hz}$ está aquém de $1 \mathrm{kHz}$ ajustado para $R B W$ e $V B W$ nas campanhas de medidas. $O$ sinal transmitido a partir das torres apresentava um alargamento superior à margem teórica. 


\subsubsection{Técnica de amostragem do sinal recebido}

Obtêm-se o tamanho da amostra com base nos desvanecimentos que se quer ressaltar e na dinâmica de deslocamento do móvel. Aos parâmetros apresentados na seção 3.3.1 acrescentam-se as equações definidoras da amostragem no set-up de medidas $[17,51]$.

A Equação (66) explicita o ajuste da frequência de amostragem do analisador de espectro. Sublinha-se que $W_{S}$ (frequência de amostragem do processador interno ao analisador de espectro) pode ser algumas vezes alterada pelo experimentador no ajuste do instrumento, outras vezes ela é ajustada de forma automática, internamente, pelo próprio analisador de espectro.

$$
W_{s} \geq \frac{2 \pi v}{d} \geq 2\left(2 f_{d}\right)
$$

A obtenção do comportamento do desvanecimento em pequena escala requer a amostragem em taxas superiores ao critério de Nyquist [1], Eq. (60). Tomando para efeito de cálculo a distância $d \leq \frac{\lambda}{4}[49,50]$, requerida para garantir a extração do desvanecimento em pequena escala e cumprir o teorema da amostragem de Nyquist, vem:

$\mathrm{f}_{\mathrm{s}} \geq 4\left(2 \mathrm{f}_{\mathrm{d}}\right)$

$\mathrm{f}_{\mathrm{s}} \geq 8$ (Freq. Doppler)

$8 \mathrm{f}_{\mathrm{d}}=\mathrm{f}_{\mathrm{s}} \mid 1 \mathrm{~s}=64,0 \mathrm{~Hz}$

$\mathrm{f}_{\mathrm{s}} \mid 0,8 \mathrm{~s}=80,0 \mathrm{~Hz}$

RBW do analisador $\cong 10$ Freq. Doppler

De acordo com a teoria de Nyquist, a taxa de amostragem deve atender a duas vezes a largura de banda do sinal visualizado no analisador de espectro. Percebe-se pela Eq. (71) que não é necessário se preocupar com o alargamento do espectro devido ao efeito da amostragem. $O$ ajuste de $R B W$ embute com este efeito porque o $R B W$ do analisador $\cong 10$ Freq. Doppler.

A amostragem do sinal recebido na antena ocorre em tempo real. Os pontos amostrais são gravados no notebook a cada evento de atualização de informações geográficas do GPS. Os eventos ocorrem a cada segundo conforme diagrama de tempos da Fig. 3.5. As amostras são igualmente espaçadas e armazenadas no PC que comunica via interface GPIB com o analisador de espectro. Quanto mais próximo a portadora de transmissão assemelhar-se a uma forma de onda impulsiva no domínio da frequência, implicará menor largura de faixa ajustada em $R B W$ e maior liberdade para aumentar o número de pontos amostrais por evento (varredura georreferênciada). A acuidade na análise do comportamento do desvanecimento fica melhor quanto maior for o número de pontos de medidas. Lembrando que para a faixa do VHF/UHF o Efeito Doppler apresenta uma excursão pequena, porém para frequências de transmissão superiores ou maiores velocidades do drive-test a amostragem e o deslocamento Doppler 
podem impactar negativamente na obtenção do quantitativo mínimo de 120 amostras por evento de um segundo.

Os parâmetros deduzidos a partir deste estudo determinam os valores de entrada no programa GPSpectrum [19, 20, 21], Anexo $V$, que automaticamente agirá no ajuste do analisador de espectro. Lembrando que a aparelhagem agregada ao analisador (GPS, GPIB e notebook) deve ser compatível com o programa GPSpectrum residente no laptop que controla o set-up de medidas. A Figura 3.6 mostra os componentes do set-up de medidas.

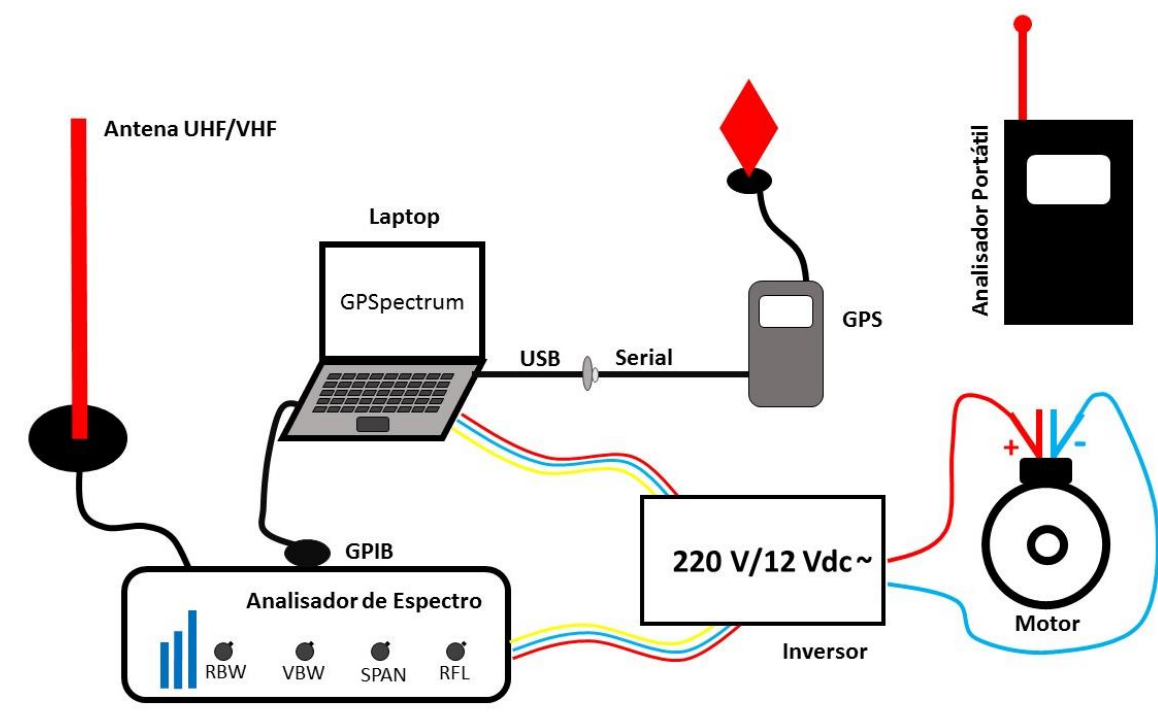

Figura 3.6 Diagrama do set-up de Medidas.

\subsubsection{Processamento dos Dados Experimentais}

Os dados brutos das campanhas de medidas são armazenados no Laptop. O processamento dos dados brutos no CoP $[19,20,21]$ gera arquivos, gráficos e plotagens para análise dos fenômenos de desvanecimento e visualização do nível de sinal recebido pelo drive-test. O CoP, Anexo V, assim como o GPSpectrum são programas desenvolvidos no $\operatorname{LEMOM}[19,20]$. A digitalização do terreno do CoP é útil para uma primeira análise da altimetria do terreno, todavia, para fins de planejamento de rede móveis abrangente, deve-se recorrer a cartas topográficas com curvas de nível de resolução superior a 10 metros.

O processamento no CoP algumas vezes demanda uma prévia restauração dos dados brutos corrompidos por falhas na leitura do GPS ou queda do sinal de transmissão. Esta ferramenta foi implementada em Matlab. O tempo de $200 \mathrm{~ms}$ é reservado para que os dados sejam transferidos do buffer de saída do analisador para a memória do notebook. Assim fica claro que o fator limitante da taxa de amostragem do sinal recebido no conjunto analisador de espectro-GPS-notebook é a taxa de atualização dos dados no notebook. A cada varredura de 150 amostras está associada uma etiqueta com as coordenadas GPS do ponto. A Fig. 3.7 mostra um fragmento de um arquivo de medidas bruto (sem processamento) destacando a etiqueta referenciada em graus-minutos decimais inserida pelo GPS. Os dados mostrados na Fig. 3.7 são valores da potência recebida em (dBm). 
@130907135448S1557113W04754396G013+01112E0000N0000U0000 -56.33755.699 -55.588-55.891-55.869-55.699-56.149-56.161-56.05 -56.184-56.326-56.159-56.15956.223 -55.706-55.733-55.728-55.242-55.07 -55.528-54.768-54.647-55.358-54.671-54.6 55.522 - 54.934-55.036-56.29 -55.426-55.585-57.123-56.159-56.458-57.938-56.967-56.964$58.253-57.375-57.399-58.314-57.69-57.618-58.015-57.813-57.647-58.164-58.199-58.16-$ $58.405-59.069-58.967-59.388-60.362-60.296-60.695-61.91-61.889-62.313-63.22-63.088-$ $63.249-63.823-62.981-62.761-62.696-61.625-61.31-61.206-59.93$-59.666-59.714-58.38458.208 -58.634-57.111-56.72 -57.614-56.224-56.128-56.931-55.642-55.518-56.061-55.19955.127 -55.393-55.138-55.072-55.336-55.336-55.077-55.376-55.769-55.474-55.889-56.54 $56.302-56.669-57.558-57.339-57.625-58.606-58.335-58.674-59.524-58.763-58.904-59.017$ 58.359 -58.137-58.357-57.109-57.006-57.422-55.927-55.995-56.65 -55.335-55.265-56.129$55.003-54.98-55.826-55.399-55.381-55.946-56.306-56.308-56.768-57.421-57.458-58.11-$ $58.838-58.851-58.929-59.6 \quad-59.012-59.038-58.863-58.062-57.938-57.691-57.04 \quad-57.188-$ $57.066-56.301-56.209-56.8 \quad-56.084$

Figura 3.7 Linha de um arquivo de medidas não processadas.

Ao levar estes dados para o CoP os arquivos são submetidos à filtragem, conforme descrito no item 3.2, e extrai-se os desvanecimentos. Os arquivos filtrados pela técnica das medias móveis são armazenados em extensão ".meas" no mesmo diretório dos arquivos ".txt". No bojo do programa CoP nesta fase do processamento os arquivos são etiquetados em coordenadas UTM, conforme mostrado no fragmento de arquivo na Fig. 3.8. Para isso fazse necessário dar entrada com as coordenadas do transmissor em graus decimais no CoP.

@ 8231794.042904 188658.3656532325.886212 -76.414000 -78.006783 1.592783

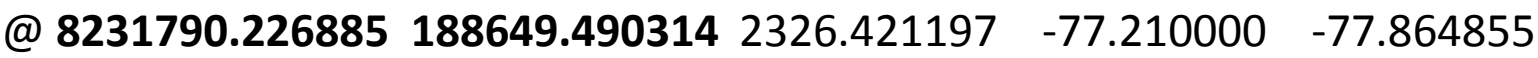
0.654855

@ 8231788.256462 188640.589171 2325.250338 -81.391000 -77.899864 3.491136

@ $8231780.624403188622 .8385042326 .515238-82.370000-77.883365$ 4.486635

Figura 3.8 Arquivo de medidas processadas. 
As conversões de coordenadas são facilmente manipuladas pelo projetista, bastando lembrar que os aparelhos GPS geralmente operam no sistema WGS 84 , Brasília está no meridiano $45^{\circ}$, e a zona de fuso horário correspondente é a de número 23. As medidas são transportadas no CoP para mapas georreferênciados com recursos de cartas topográficas com perfil planialtimétrico. A Fig. 3.9 mostra o resultado gráfico da separação dos componentes de desvanecimentos em pequena escala e larga escala em função do deslocamento do móvel com relação à antena de transmissão.

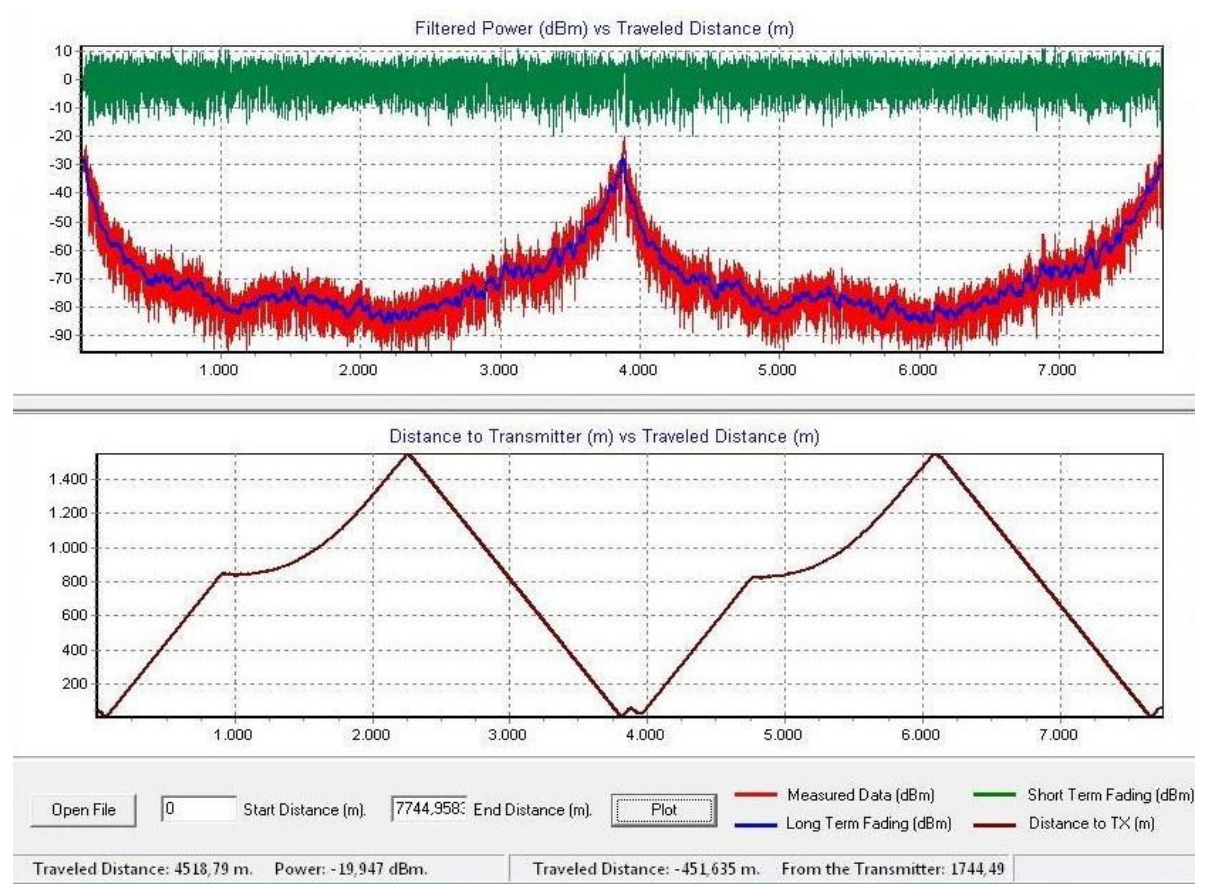

Figura 3.9 Saídas gráficas obtidas no CoP.

É possível distinguir na Fig. 3.9: o traçado roxo, desvanecimento em larga escala, o verde destacado a parte, desvanecimento em pequena escala. Na parte baixa da figura está a distância do móvel em relação à torre de transmissão e a distância trafegada no percurso. Resultado da campanha de medidas realizada na Fazenda Água Limpa em 435 MHz, percurso "Cerradão", torre de 10 [m], clima Úmido.

\subsubsection{Pós-processamento}

Uma vez compilados e processados os dados brutos da campanha de medidas e gerado o arquivo de medidas na extensão ".meas" pelo CoP, recorre-se a outras ferramentas computacionais desenvolvidas no âmbito deste trabalho em Matlab para efeito de visualização e análise dos resultados experimentais na formatação adequada ao projetista de uma rede móvel.

A título de exemplo, foi usado um programa (apresentado no Anexo V) para obtenção da função de correção dos diagramas das antenas de transmissão, em termos de ganhos polares nos planos vertical e horizontal, que leva em conta o relevo do percurso e obstruções, devido à presença da estrutura metálica da torre e outros dispositivos que equipam o seu topo [52, 53].

Os ganhos das antenas corrigidos, picos altos e baixos, são discretizados em arquivos com extensão "txt" e carregados no programa principal (Anexo 
V). As Figs. de 3.10 a 3.12 ilustram três das oito possíveis saídas gráficas desse programa de correção. Os diagramas de radiação estão apresentados no Anexo I.

A Fig. 3.10 mostra no eixo das ordenadas a distância radial entre drivetest e a torre em função do número de pontos experimentais. A abscissa é a progressão acumulativa da distância do veículo drive-test à torre de transmissão. $\mathrm{O}$ gráfico retrata três voltas sucessivas realizadas no mesmo dia de tomada de medidas.

A Fig. 3.11 mostra a variação do ângulo de azimute no percurso em relação ao norte magnético, tomando como referência a marcação "norte" na bússola do GPS, leitura feita no pé da torre de transmissão. O eixo das abscissas está dividido de forma semelhante à Figura 3.10 e o eixo das ordenadas corresponde aos ângulos de azimute.

A Figura 3.12 demonstra o percurso no interior da FAL na região denominada de "cerradão". A abscissa e ordenada estão divididas em coordenadas UTM.

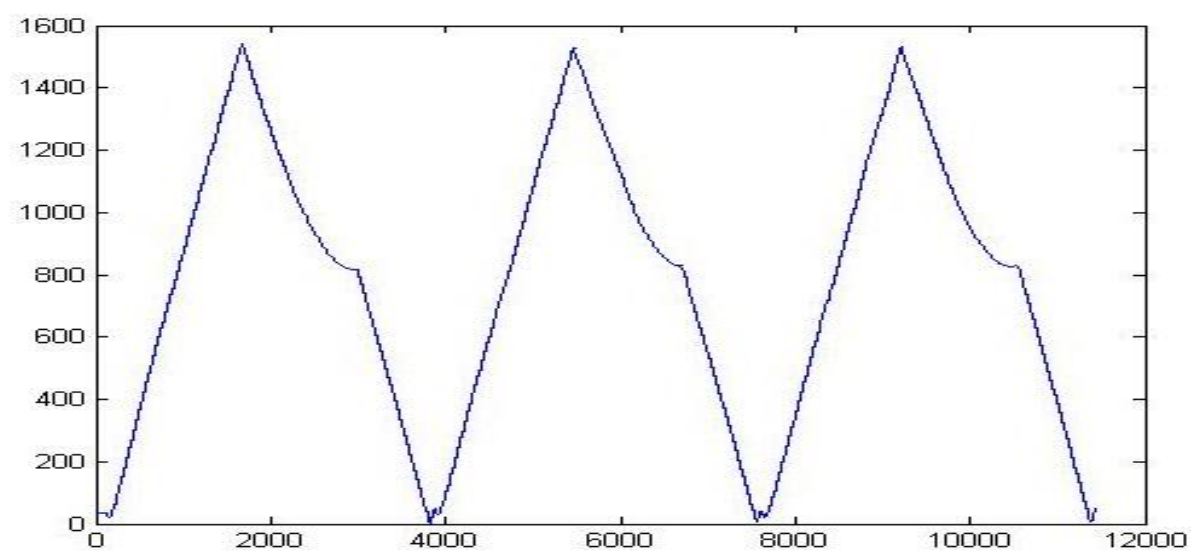

Figura 3.10 Progressão do distanciamento do drive-test em relação à torre de transmissão, resultado do percurso denominado de "edge".

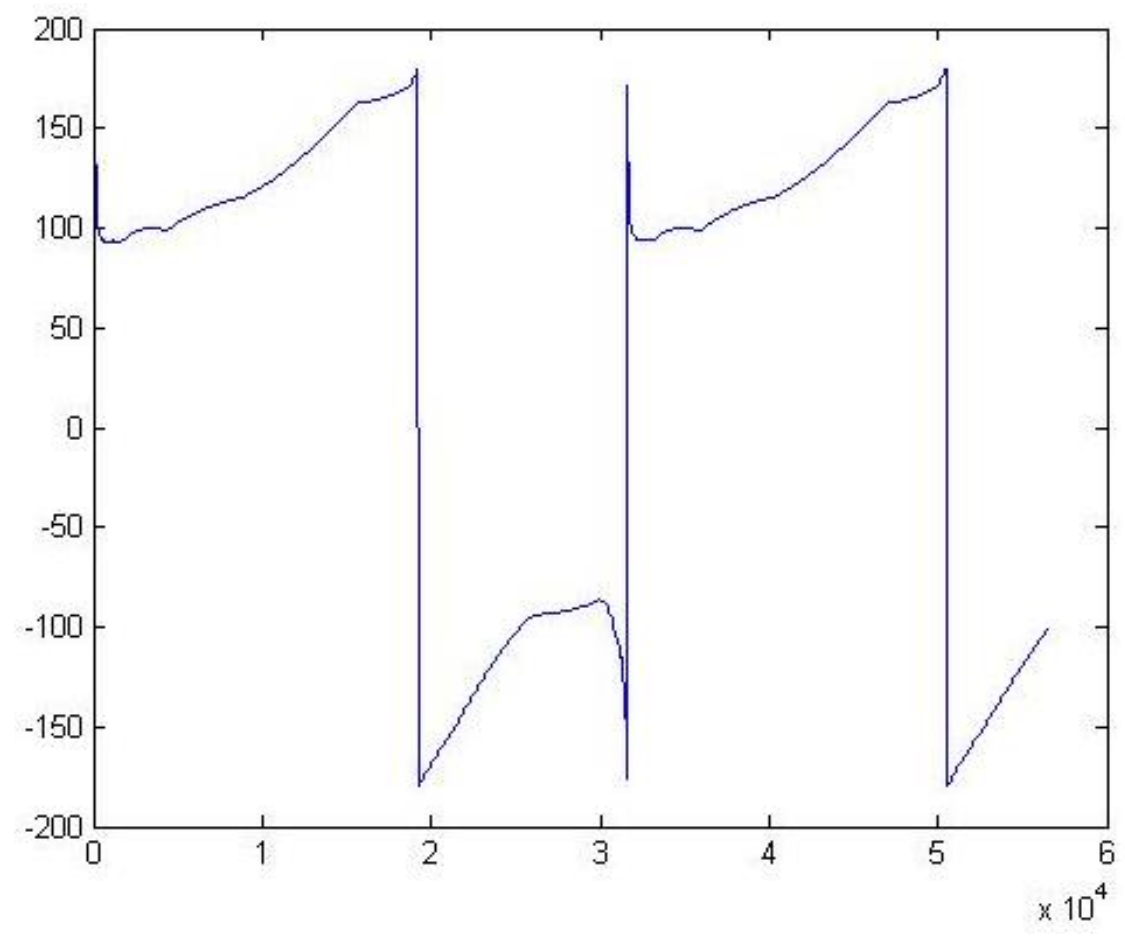

Figura 3.11 Variação do ângulo de azimute no percurso "edge". 


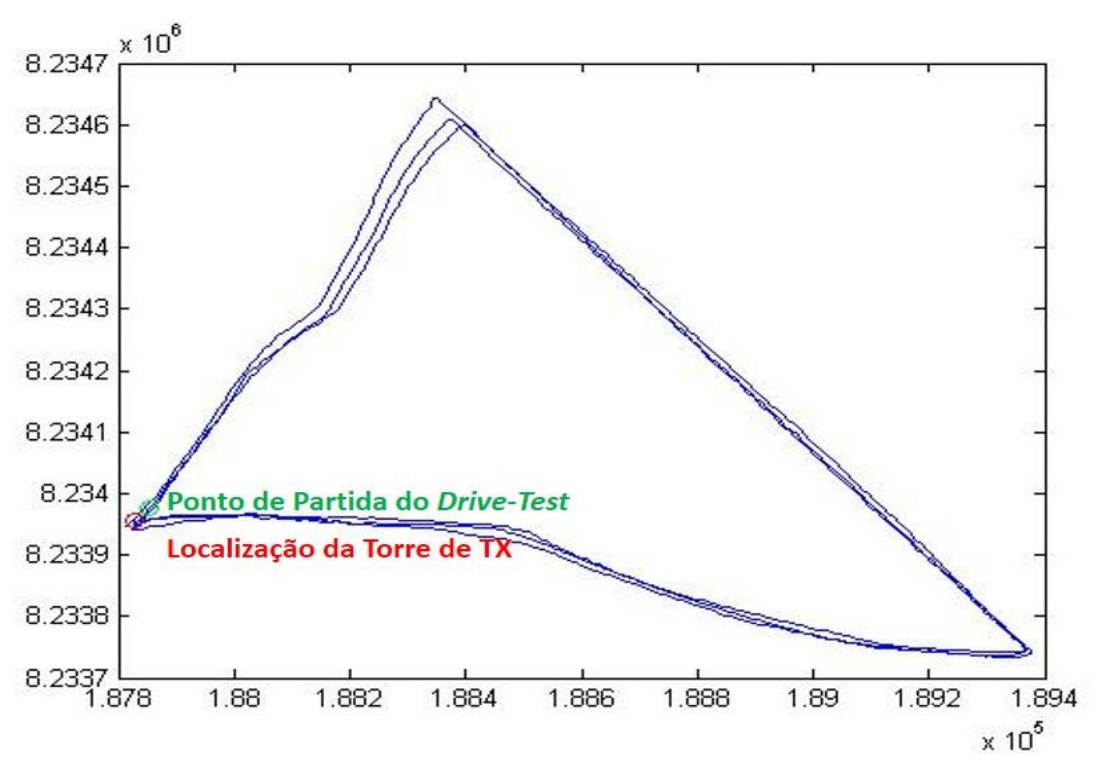

Figura 3.12 Plotagem do percurso "cerradão" georreferênciado em coordenadas UTM. O pequeno círculo assinalado em vermelho é a localização da torre e o círculo verde é o ponto de partida do drive-test. 


\section{CAMPANHAS DE MEDIDAS}

\subsection{INTRODUÇÃO}

O objetivo do capítulo é apresentar os resultados das medidas realizadas em forma de gráficos e tabelas. As tabelas foram indexadas de maneira a facilitar a identificação da morfologia de cerrado e a influência climatológica no comportamento da perda de propagação e desvanecimentos associados. Os resultados estampados nas tabelas referem-se ao modelo matemático Lei de Potência detalhado na seção 2.3, Eq. (39). A engenharia usada para realização das campanhas de medidas está descrita no Anexo IV.

O cenário estudado com profundidade e ensaiado mediante repetidas campanhas de medidas compreende uma área de proteção ambiental, coberta com vegetação nativa de cerrado, classificada como uma das áreas Núcleo de Reserva da Bioesfera do Cerrado, com extensão de 4 mil hectares, localizada na região administrativa de Vargem Bonita, Fazenda Água Limpa - FAL, Unidade de Conservação Ambiental sob a administração da Universidade de Brasília-UnB. As ilustrações do Anexo I mostram com detalhes as estruturas de torres montadas na FAL. Este ambiente permitiu vislumbrar projeções de um ambiente rural intacto com substancial diferenciação de outros ambientes rurais, que apresentam alterações significativas na vegetação por atividades de exploração comercial.

Os dados provenientes dos cálculos realizados no item "préprocessamento" devem ser inseridos na tela disponibilizada pelo GPSpectrum antes de iniciar a campanha de medidas, quais sejam: frequência de operaçãofrequency $[\mathrm{Hz}]$; RBW-resolution bandwidth $[\mathrm{Hz}]$; número de pontos por varredura-number sweep points; nível de referência-reference level ( $\mathrm{dBm})$, Anexo V, (valor de potência recebida no analisador de espectro, tomado geralmente na região próxima à torre de transmissão, respeitando os critérios de campos distantes $[52,53])$.

\subsection{DESCRIÇÃO GERAL DO AMBIENTE DE MEDIDAS NO CERRADO}

A vertente prática do estudo envolveu percorrer com o veículo drivetest polígonos circunscritos e inscritos por vegetação típica de cerrado contemplando praticamente toda diversidade de formações florestais, campestres e savânicas do cerrado. Cada percurso foi ensaiado mediante a passagem do veículo aparelhado com os instrumentos de drive-test a uma velocidade máxima de $50 \mathrm{~km} / \mathrm{h}$, em pelo menos duas voltas visando capturar o maior número de pontos amostrais em torno de 500.000 pontos, com o objetivo de caracterizar com maior fidelidade o comportamento da propagação e os desvanecimentos atinentes às geomorfologias dos ambientes.

A cada campanha de medidas caracterizaram-se 4 percursos: o percurso denominado de "cerradão" - constituído de cerrado denso e grosso; 
o percurso denominado de "edge" - constituído por formações campestres do tipo campo limpo e campo sujo, com ocorrência de pastagens naturais e plantadas; o percurso denominado de "mix" constituído de cerrado de diversificadas especificidades e com ocorrência grande área alterada por atividades de silvicultura (plantações de eucalipto). Por último, o percurso denominado "global" que abrange todas as variantes de cerrado. Este último é um percurso no formato de um polígono no perímetro externo dos percursos "cerradão", "edge" e "mix". O anexo VI detalha por meio de fotografias a vegetação em cada um dos ambientes citados.

Percebe-se que, contrapondo a heterogeneidade da cobertura vegetal do cerrado, as variações climáticas são bem definidas: período de chuvas, que vai de outubro a maio, predominando índices de umidade relativa do ar com variações de médio para alto oscilando em torno de $70 \%$ e temperaturas elevadas atingindo $36^{\circ} \mathrm{C}$; e o período de secas que vai de maio a setembro, predominando índices de umidade relativa do ar com pequenas variações em torno de $40 \%$ atingindo picos de até $10 \%$, temperaturas baixas na parte da manhã e altas no meio da tarde e, no fim da tarde para noite, nova queda de temperatura, estendendo este perfil nas madrugadas com ligeiro decréscimo na temperatura até o alvorecer.

Vale salientar que o rápido reverdecimento do cerrado na passagem do período seco para o chuvoso é outra característica marcante deste bioma. A recuperação plena da estrutura e das espécies originais da vegetação é mantida mesmo sob o impacto das queimadas, principalmente no período do ápice da estiagem compreendido entre agosto e início de setembro [6, 8]. As Figs. 4.1 e 4.2 ilustram o contraste da vegetação em condições de clima de inverno seco e verão úmido, destacando as vias de rolagem usadas pelo veículo drive-test. $\mathrm{O}$ deslocamento no interior da área de cerrado foi realizado em vias despavimentadas, em sua maior parte com largura em torno de 5 metros, alguns trechos chegando a 8 metros de largura. 


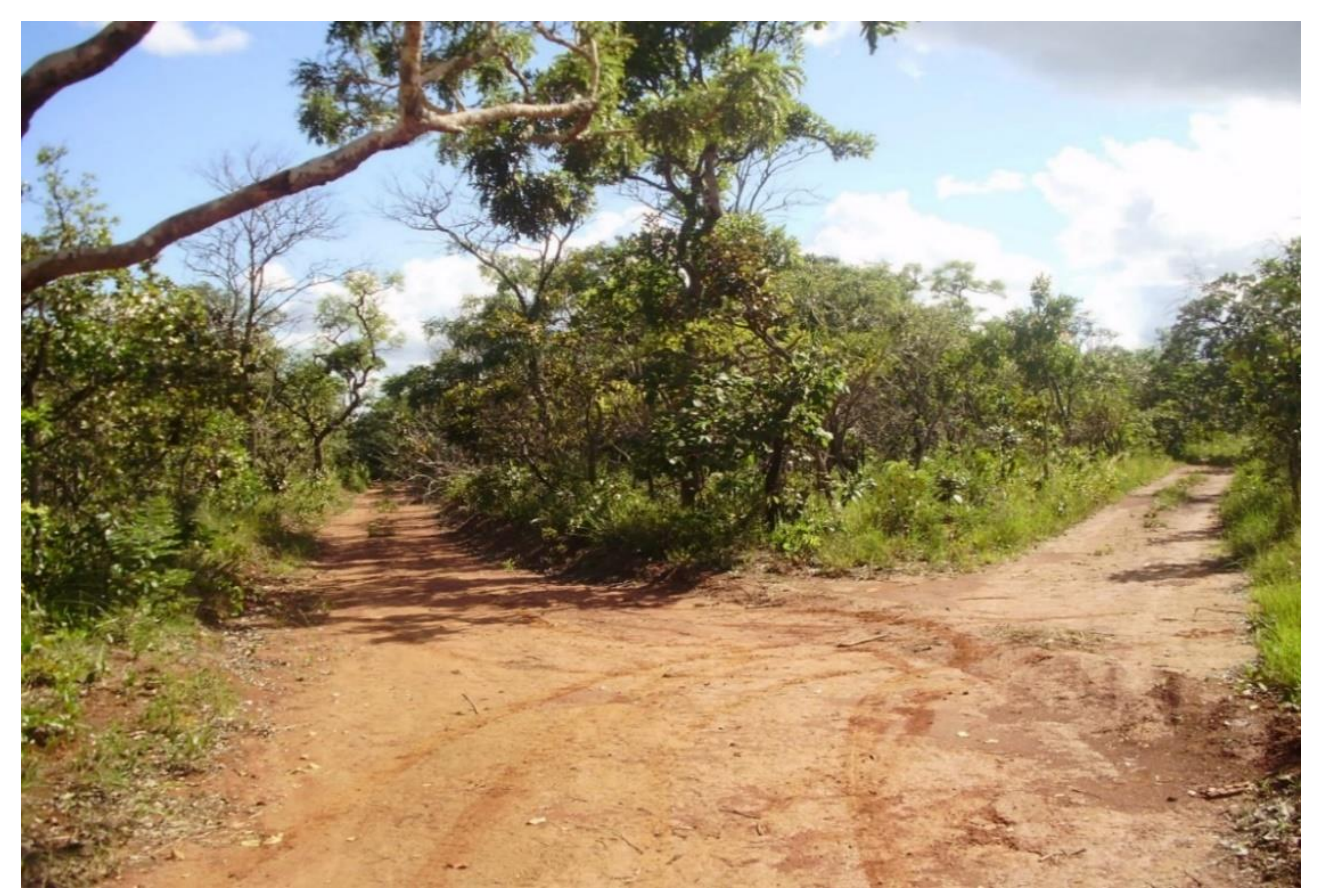

Figura 4.1 Vegetação do bioma cerrado na estação verão úmido. Bifurcação dos percursos "edge", "mix" e "cerradão". A mata em destaque no centro da foto pertence ao percurso "cerradão".

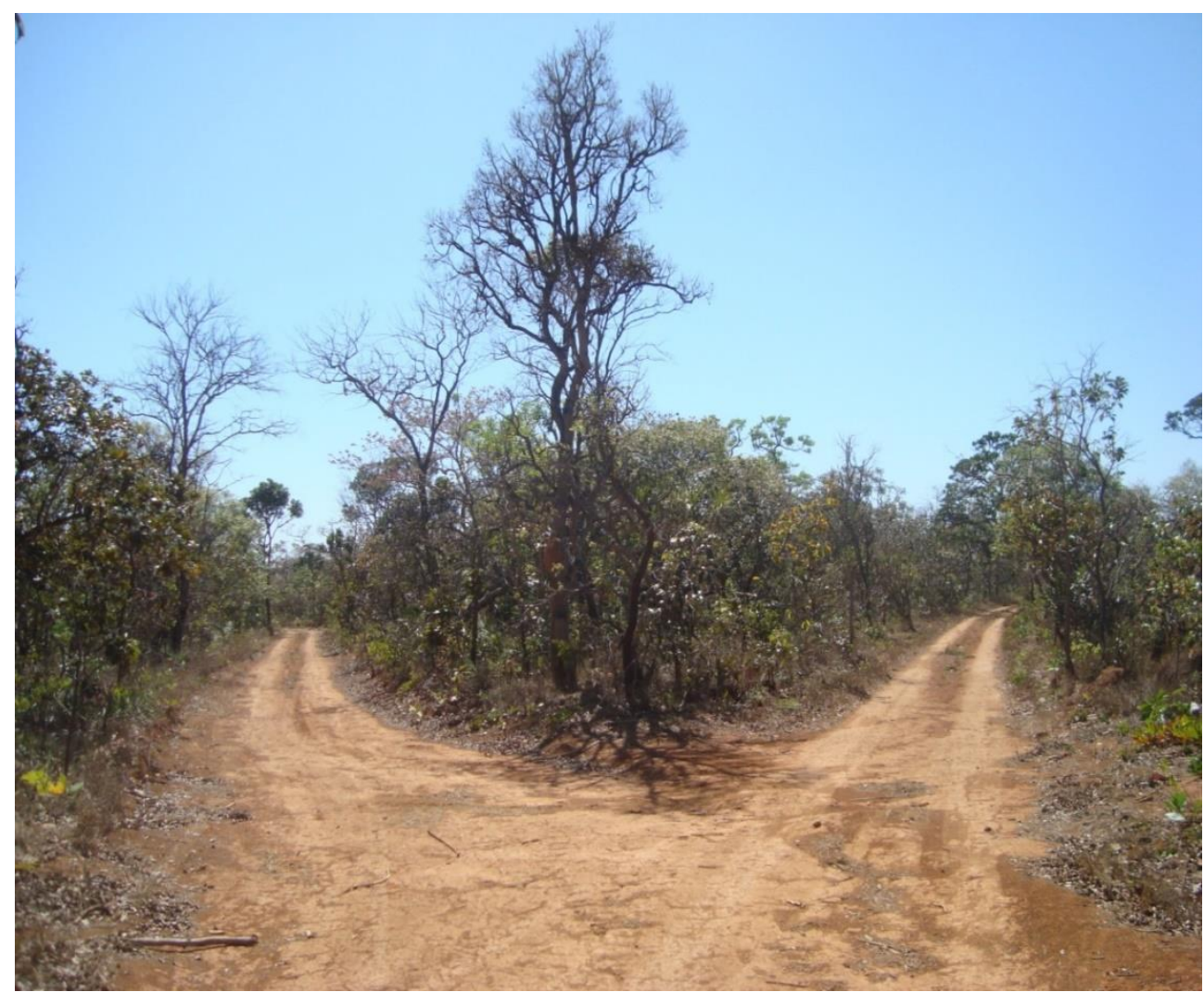

Figura 4.2 Vegetação do bioma cerrado na estação inverno seco.

No que diz respeito ao ambiente estudado, o bioma cerrado $[5,6,7,8]$ é classificado como uma floresta aberta, com formas variadas, ciclo próprio de características marcantes que vai do inverno seco ao verão úmido. As árvores apresentam troncos nodosos, retorcidos, galhos irregulares, copa aberta, predomina folhas grossas e de tamanho médio.

O cerrado sobrevive às queimadas e suporta amplitudes climáticas intensas, possui raízes profundas, formações de floresta com árvores de estatura média, entorno de 3,5 metros, que desfolham parcialmente. Segundo alguns autores [35], as árvores "hibernam" ficando em estado de dormência 
entre maio e setembro até a chegada do período chuvoso, que acontece em outubro e se estende, geralmente, até a primeira quinzena de maio. No período de seca, as árvores se despem parcialmente de sua massa foliar. 0 solo caracterizado como do tipo latossolo vermelho escuro é pobre em termos de fertilidade. Do ponto de vista eletromagnético, trata-se de um substrato dielétrico imperfeito: no período chuvoso apresenta boa reflectância por conta do alto teor de alumínio deste tipo de terreno e no período de seca a condutividade decai devido à absorção e retenção do alumínio na seiva circulante das arvores.

As múltiplas trajetórias percorridas pelo sinal de transmissão, combinadas com as múltiplas obstruções do cerrado, constituído de árvores com configurações multiformes, que se diferenciam conforme a estação do ano em que as campanhas de medidas foram realizadas, levou a distintas respostas relativas aos desvanecimentos e à perda de propagação.

Na estação úmida prevalece um verde dossel, aberto de densidade foliar média, entremeado por árvores de baixa estatura e na estação seca há uma nítida alteração na paisagem do cerrado evidenciando pela dominância de galhos e ramificações. A estação seca revela ainda de forma mais acentuada o estrato herbáceo denso (gramíneas e leguminosas) na parte baixa da vegetação, situada sob o estrato arbóreo, alcançando em média 50 centímetros de altura.

Contrastando com a estação úmida, na estação seca o estrato arbóreo se apresenta com baixa densidade de folhas realçando o relevo e modificando a paisagem. Percebe-se na morfologia do cerrado peculiaridades geográficas, tais como irregularidades topográficas de morros, morretes, depressões, aclives, declives e encraves de fragmentos de florestas em meio a áreas abertas, principalmente em regiões agrícolas desenvolvidas.

Os percursos que foram ensaiados na FAL estão detalhados no mapa fornecido anexo a este trabalho na versão impressa. O campo de provas do drive-test pode ser visualizado na web com recursos de navegação. A FAL situase nas circunvizinhanças das coordenadas geográficas discriminadas de acordo com a localização das torres, conforme: latitude sul $15^{\circ} 57^{\prime} 55,34^{\prime \prime}$ e longitude oeste $47^{\circ} 54^{\prime} 38,79^{\prime \prime}$, localização da torre de 24 metros e latitude sul $15^{\circ} 57^{\prime}$ $14,81^{\prime \prime}$ e longitude oeste $47^{\circ} 54^{\prime} 57,38^{\prime \prime}$, localização da torre de 10 metros. A altimetria da região em estudo destacando as principais radiais e o respectivo perfil altimétrico visto a partir das antenas de 10 metros e 24 metros são ilustrados de forma sintética na Fig. 4.3. No ambiente estudado, após traçar inúmeras raias a partir das torres de 10 metros e 24 metros chega-se a altura média de 1136 metros com flutuação de 50 metros para cima ou para baixo. Trata-se de um terreno de rugosidade média. As antenas foram instaladas na vertical niveladas ao patamar superior das torres, sem aplicação de inclinação mecânica e elétrica. 
A estratificação da vegetação não se aplica para o cerrado como em outros biomas, pois não é possível estabelecer camadas com distintas similaridades: raízes, troncos, galhos e folhagem, à medida que se avança em direção à copa das árvores. O cerrado se distingue pela alta assimetria, as deformações dos indivíduos arbóreos sobressaem nas contorcidas estruturas, que produzem um emaranhado de troncos cruzados.

A representatividade dos tipos de cerrado que se encontram na FAL em ordem crescente de predominância é a seguinte: campos limpos, campos sujos e cerrado denso. A FAL não possui cerrado com características de campo de muruduns (vegetação baixa assentada em relevo ligeiramente ondulado) e de campo rupestre (paisagem de vegetação baixa e rochas esparsas expostas).

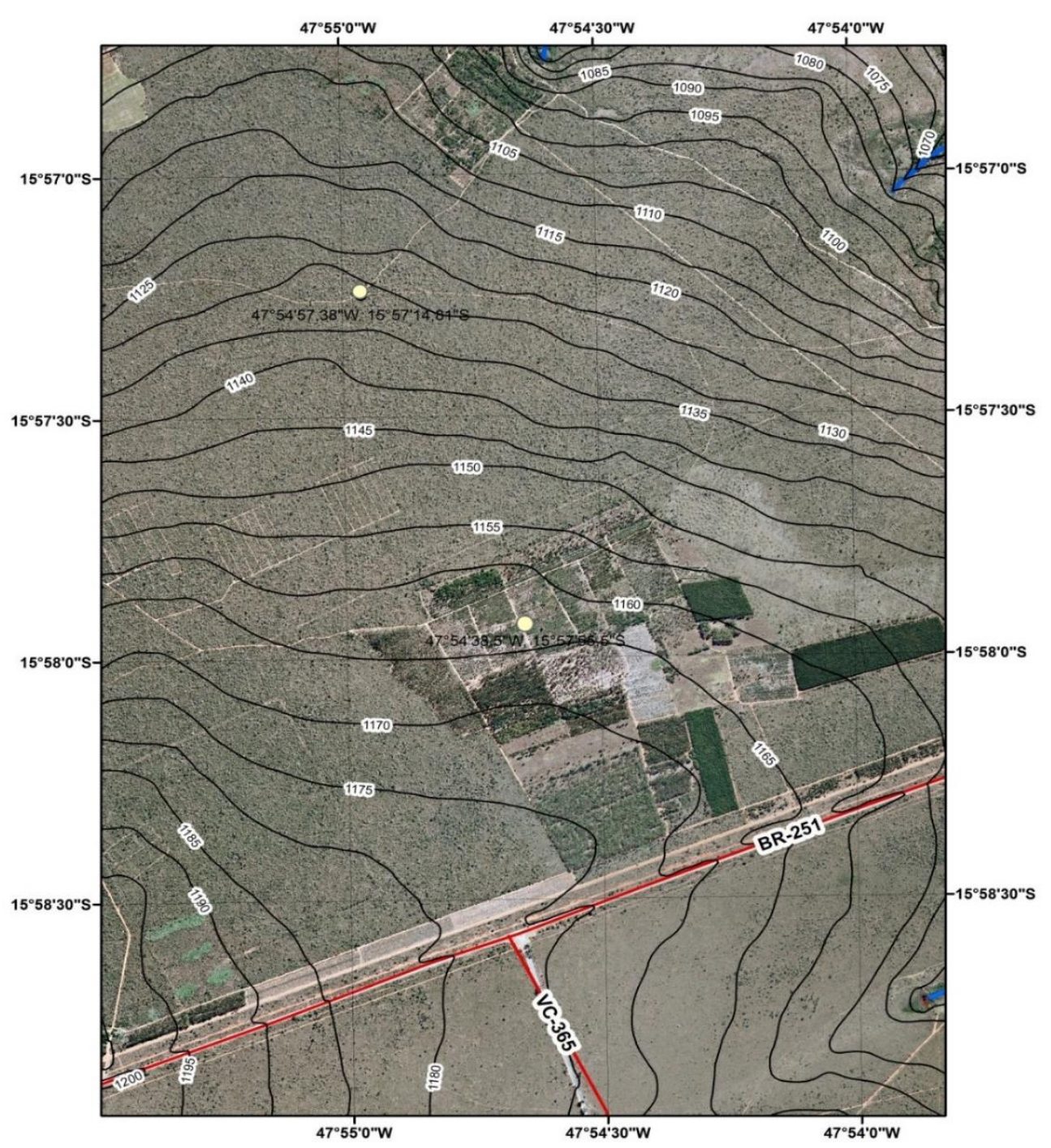

Figura 4.3 Curvas da plana-altimetria da FAL destacando a vegetação e uso da terra (Fonte: Fornecido pelo setor de cartografia da Polícia Civil de Brasília). 


\section{ANÁLISE DOS RESULTADOS}

\subsection{INTRODUÇÃO}

Os gráficos de perda por propagação, as funções densidade de probabilidade e demais métricas estatísticas, que realçam sombreamento e o desvanecimento de pequena escala, são obtidos ao aplicar os programas especialmente montados para esta pesquisa. Quatorze programas foram escritos em linguagem Matlab no âmbito deste trabalho com aplicabilidade à análise dos resultados de propagação (Anexo V).

Em uma primeira análise, o comportamento do canal móvel no cerrado foi demonstrado em forma de tabelas, gráficos, resultados numéricos, e resultados de simulação. De forma a confrontar os modelos estatísticos oriundos dos dados reais das campanhas de medidas desenvolvidas na Fazenda Água Limpa, com modelos de propagação consagrados para diversas geomorfologias, isto é, não limitados especificamente ao escopo floresta, aglutinou-se predição lei de potência e modelos em gráficos cartesianos. Para isto, foram selecionados os modelos que melhor se aproximavam aos resultados experimentais, em termos de inclinação e distanciamento entre retas, deixando assim de plotar os modelos que apresentavam divergência quanto a esses quesitos. A seleção dos modelos está embasada naqueles que dão ênfase aos fenômenos de espalhamento, difração e reflexão.

Alguns resultados de perda por propagação e desvanecimentos são mencionados no texto, porém, por questões de espaço físico não estão mostrados de forma gráfica.

As Tabelas 5.1 a 5.10 explicitam os parâmetros da regressão linear que dão origem à reta ajustada aos dados coletados e linearizados em conformidade com a teoria do modelo Lei de Potência. O expoente de perda corresponde ao coeficiente angular da reta e a perda de referência corresponde ao coeficiente linear da reta.

As campanhas de Medidas no cerrado foram realizadas em 3 percursos distintos ("mix", "edge" e "cerradão") tendo em mente cobrir boa parte das possibilidades e variantes do bioma cerrado. O percurso "global" é um percurso no anel externo englobando a geomorfologia dos três percursos citados, funciona como um modelo de recorrência, em caso de desconhecimento da fitofisionomia de uma dada região tipificada como cerrado.

A Tabela 5.1 sintetiza os resultados obtidos nas torres de 10 metros e 24 metros. Alguns gráficos foram traçados visando à análise numa perspectiva comparada, com o intuito de contrastar os resultados nas torres de 10 e 24 metros nas marcantes estações climáticas do cerrado: verão úmido e inverno seco. A perda de referência foi tomada a 100 metros da torre, conforme 
preconiza [2]. Esse parâmetro do modelo Lei de Potência significa a perda de Clustering [2].

A comparação dos resultados deve ser feita com certas precauções haja vista que os ângulos de incidência nos percursos ensaiados são distintos em dois aspectos: localização das torres em relação aos traçados de cada percurso e linhas de visada entre os traçados de cada percurso e o topo das torres. A torre de 10 metros tangencia o percurso "mix" e "cerradão". A torre de 24 metros localiza-se no interior do percurso "mix. Na Tabela 5.1: $\mathrm{F}_{0}$ é a frequência em $\mathrm{MHz}, \mathrm{H}_{\mathrm{t}}$ é a altura da torre em metros, $P L\left(d_{0}\right)$ é perda de Referência em dB, $n$ é o expoente de perda do modelo lei de potência e $\sigma$ é o desvio Padrão.

As Tabelas 5.2 a 5.10 detalham os percursos em separado especificando as datas das campanhas de medidas, resultados obtidos em VHF e UHF. A indexação das Tabelas 5.2 a 5.10 é também válida para os gráficos comparativos que acompanham a análise de cada percurso, desta forma, temse como indexador a etiqueta entre colchetes, de acordo com o seguinte: [ $\mathbf{F}_{\mathbf{0}}$, $\mathbf{H}_{\mathbf{t}}$, Trajeto, Clima] data; em que:[ $\mathbf{F}_{\mathbf{0}} \rightarrow 1=144 \mathrm{MHz}, 2=435 \mathrm{MHz} ; \mathbf{H}_{\mathbf{t}} \rightarrow 1=10$ metros, $2=24$ metros; percursos $\rightarrow$ 1= Mix, 2= Edge, 3= Cerradão, 4=Global e Clima $\rightarrow$ 1= Úmido, $2=$ Seco] Data $\rightarrow$ dia/mês/ano. (Observação: As campanhas de medidas foram realizadas no período matutino).

Em relação às Tabelas 5.2 e 5.3, há que que se fazer as seguintes considerações: a notação "*" nos percursos "Mix" e "Edge", na campanha de medidas realizada em 04/06/2013, indica que os arquivos foram seccionados devido à perda do sinal GPS em frações dos percursos; as notações "**” e "*+" indicam que no percurso "Mix", na campanha de medidas realizada em 09/08/2014, os arquivos foram restaurados mediante um código desenvolvido neste trabalho (Anexo $V$ ), quando da ocorrência de falhas nos instrumentos ou conexões que compõem o set-up de medidas ou ocorrência de queda de energia no gerador empregado para alimentação do sistema de transmissão. 
Tabela 5.1 Resultados do modelo lei de potência.

\begin{tabular}{|c|c|c|c|c|c|c|}
\hline Percurso & $H t[m]$ & Clima & FO[MHz] & $\sigma$ [dB] & $\begin{array}{c}\text { PL(do ) } \\
\text { [dB] }\end{array}$ & n \\
\hline \multirow{8}{*}{ Cerradăo } & \multirow{4}{*}{10} & \multirow{2}{*}{$\begin{array}{c}\text { Inverno } \\
\text { seco }\end{array}$} & 144 & 2,48 & 72,18 & 3,46 \\
\hline & & & 435 & 4,12 & 90,58 & 3,63 \\
\hline & & \multirow{2}{*}{\begin{tabular}{|l|} 
Veráo \\
úmido
\end{tabular}} & 144 & 2,70 & 73,57 & 3,30 \\
\hline & & & 435 & 3,08 & 88,25 & 3,21 \\
\hline & \multirow{4}{*}{24} & \multirow{2}{*}{$\begin{array}{c}\text { Inverno } \\
\text { seco }\end{array}$} & 144 & 1,99 & 45,29 & 5,23 \\
\hline & & & 435 & 3,02 & 69,96 & 4,71 \\
\hline & & \multirow{2}{*}{$\begin{array}{l}\text { Verăo } \\
\text { úmido }\end{array}$} & 144 & 3,06 & 65,38 & 3,36 \\
\hline & & & 435 & 4,06 & 65,13 & 6,21 \\
\hline \multirow{8}{*}{ Mix } & \multirow{4}{*}{10} & \multirow{2}{*}{$\begin{array}{c}\text { Inverno } \\
\text { seco }\end{array}$} & 144 & 3,45 & 71,08 & 3,66 \\
\hline & & & 435 & 4,63 & 87,89 & 3,65 \\
\hline & & \multirow{2}{*}{$\begin{array}{l}\text { Veråo } \\
\text { úmido } \\
\end{array}$} & 144 & 5,86 & 67,41 & 4,03 \\
\hline & & & 435 & 4,79 & 84,91 & 3,45 \\
\hline & \multirow{4}{*}{24} & \multirow{2}{*}{$\begin{array}{c}\text { Inverno } \\
\text { seco }\end{array}$} & 144 & 3,26 & 59,88 & 4,08 \\
\hline & & & 435 & 3,70 & 77,52 & 4,05 \\
\hline & & \multirow{2}{*}{$\begin{array}{l}\text { Veráo } \\
\text { úmido }\end{array}$} & 144 & 4,43 & 60,98 & 3,70 \\
\hline & & & 435 & 4,51 & 88,47 & 4,04 \\
\hline \multirow{8}{*}{ Edge } & \multirow{4}{*}{10} & \multirow{2}{*}{$\begin{array}{c}\text { Invemo } \\
\text { seco }\end{array}$} & 144 & 5,17 & 70,90 & 3,50 \\
\hline & & & 435 & 5,05 & 90,95 & 3,15 \\
\hline & & \multirow{2}{*}{$\begin{array}{l}\text { Verăo } \\
\text { úmido } \\
\end{array}$} & 144 & 3,61 & 68,72 & 3,61 \\
\hline & & & 435 & 3,74 & 94,99 & 2,32 \\
\hline & \multirow{4}{*}{24} & \multirow{2}{*}{$\begin{array}{c}\text { Invemo } \\
\text { seco }\end{array}$} & 144 & 4,42 & 70,17 & 2,76 \\
\hline & & & 435 & 5,95 & 83,36 & 3,10 \\
\hline & & \multirow{2}{*}{$\begin{array}{l}\text { Veråo } \\
\text { úmido } \\
\end{array}$} & 144 & 4,71 & 66,60 & 2,92 \\
\hline & & & 435 & 5,90 & 93,63 & 3,16 \\
\hline \multirow{4}{*}{ Global } & 10 & $\begin{array}{c}\text { Inverno } \\
\text { seco }\end{array}$ & 435 & 5,19 & 91,17 & 3,31 \\
\hline & \multirow{3}{*}{24} & \multirow{2}{*}{$\begin{array}{c}\text { Invemo } \\
\text { seco }\end{array}$} & 144 & 4,76 & 67,17 & 3,06 \\
\hline & & & 435 & 5,92 & 88,32 & 2,98 \\
\hline & & \begin{tabular}{|l|} 
Verăo \\
úmido
\end{tabular} & 435 & 5,87 & 107,74 & 2,47 \\
\hline
\end{tabular}

\subsection{Campanha de medidas em VHF}

O gráfico da Fig. 5.1, torre de 10 metros, permite visualizar as inclinações e distinguir a diferença em dBs das perdas por propagação no cerrado nas estações seca e úmida. Percebe-se claramente que a perda de propagação no clima seco suplantou ao clima úmido. No percurso "cerradão" a diferença atingiu $8 \mathrm{dBs}$. Na Fig. 5.1 observa-se que as perdas nos percursos se inverteram do clima seco, da maior perda para menor: "cerradão", "mix" e "edge", para o clima úmido: "mix", "edge" e "cerradão", evidenciando a influência marcante das estações no cerrado. As retas de regressão quando plotadas conjuntamente se apresentam paralelas.

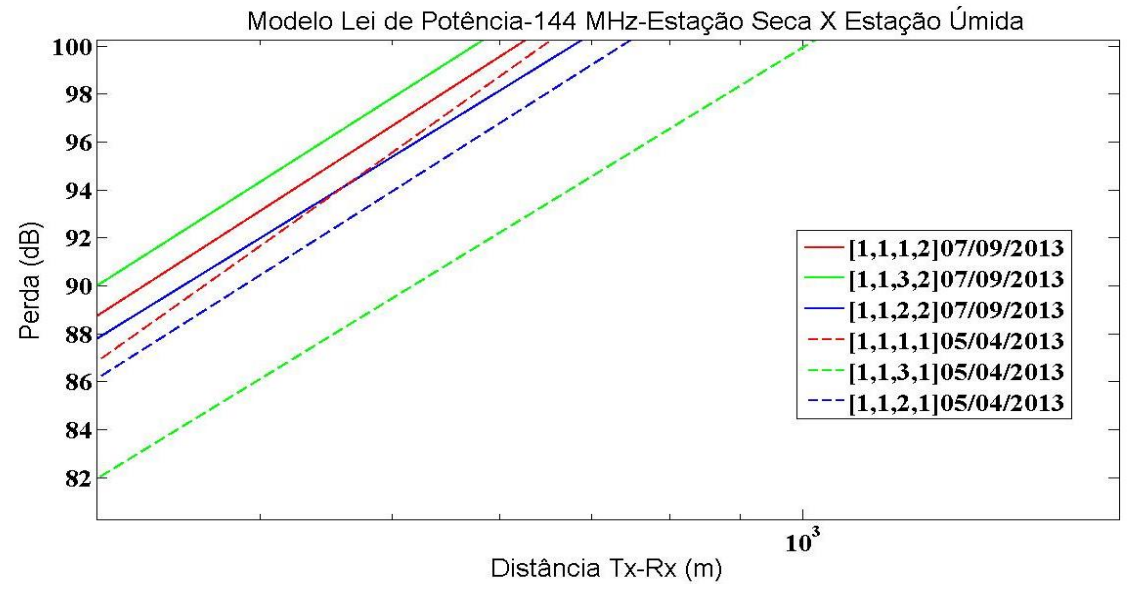

Figura 5.1 Regressão linear dos resultados experimentais, torre de 10 metros, $144 \mathrm{MHz}$. 
Tabela 5.2 Resultados no Percurso "Edge"

\begin{tabular}{|l|l|l|l|}
\hline Freq./Ht/Perc./Clima/Data & $\begin{array}{l}\text { Desvio-Padrão } \\
{[\mathrm{dB}]}\end{array}$ & $\begin{array}{l}\text { Perda Ref. } \\
{[\mathrm{dB}]}\end{array}$ & $\begin{array}{l}\text { Expoente de } \\
\text { Perdas }\end{array}$ \\
\hline$[1,1,2,2] 07 / 09 / 2013$ & 5,17 & 70,90 & 3,50 \\
\hline$[1,1,2,1] 05 / 04 / 2013$ & 4,54 & 68,72 & 3,61 \\
\hline$[1,2,2,2] 23 / 08 / 2014$ & 4,42 & 70,17 & 2,76 \\
\hline$[1,2,2,1] 14 / 06 / 2014$ & 4,71 & 66,60 & 2,92 \\
\hline
\end{tabular}

Tabela 5.3 Resultados no Percurso "Mix".

\begin{tabular}{|l|l|l|l|}
\hline Freq./Ht/Perc./Clima/Data & $\begin{array}{l}\text { Desvio-Padrão } \\
\text { [dB] }\end{array}$ & $\begin{array}{l}\text { Perda } \\
\text { Ref. } \\
{[\mathrm{dB}]}\end{array}$ & $\begin{array}{l}\text { Expoente de } \\
\text { Perdas }\end{array}$ \\
\hline$[1,1,1,2] 07 / 09 / 2013$ & 3,45 & 71,08 & 3,66 \\
\hline$[1,1,1,1] 05 / 04 / 2013$ & 5,86 & 67,41 & 4,03 \\
\hline$[1,2,1,2] 09 / 08 / 2014^{*}+$ & 3,28 & 55,09 & 3,83 \\
\hline$[1,2,1,2] 09 / 08 / 2014^{* *}$ & 3,26 & 59,88 & 4,08 \\
\hline$[1,2,1,2] 23 / 08 / 2014$ & 3,78 & 60,46 & 3,81 \\
\hline$[1,2,1,1] 14 / 06 / 2014$ & 4,43 & 60,98 & 3,70 \\
\hline
\end{tabular}

Tabela 5.4 Resultados no Percurso "Cerradão".

\begin{tabular}{|l|l|l|l|}
\hline Freq./Ht/Perc./Clima/Data & $\begin{array}{l}\text { Desvio-Padrão } \\
{[\mathrm{dB}]}\end{array}$ & $\begin{array}{l}\text { Perda } \\
\text { Ref. } \\
{[\mathrm{dB}]}\end{array}$ & $\begin{array}{l}\text { Expoente de } \\
\text { Perdas }\end{array}$ \\
\hline$[1,1,3,2] 07 / 09 / 2013$ & 2,48 & 72,18 & 3,46 \\
\hline$[1,1,3,1] 05 / 04 / 2013$ & 2,70 & 73,57 & 3,30 \\
\hline$[1,2,3,2] 23 / 08 / 2014$ & 1,99 & 45,29 & 5,23 \\
\hline$[1,2,3,1] 14 / 06 / 2014$ & 3,06 & 65,38 & 3,36 \\
\hline
\end{tabular}

Tabela 5.5 Resultados no Percurso "Global".

\begin{tabular}{|l|l|l|l|}
\hline Freq./Ht/Perc./Clima/Data & $\begin{array}{l}\text { Desvio-Padrão } \\
\text { [dB] }\end{array}$ & $\begin{array}{l}\text { Perda } \\
\text { Ref. } \\
{[\mathrm{dB}]}\end{array}$ & $\begin{array}{l}\text { Expoente de } \\
\text { Perdas }\end{array}$ \\
\hline$[1,2,4,2] 23 / 08 / 2014$ & 4,76 & 67,17 & 3,06 \\
\hline
\end{tabular}

Tabela 5.6 Resultados na Plantação de Eucalipto e Cerrado Campo Sujo.

\begin{tabular}{|l|l|l|l|}
\hline Freq./Ht/Perc./Clima/Data & $\begin{array}{l}\text { Desvio-Padrão } \\
{[\mathrm{dB}]}\end{array}$ & $\begin{array}{l}\text { Perda } \\
\text { Ref. } \\
{[\mathrm{dB}]}\end{array}$ & $\begin{array}{l}\text { Expoente } \\
\text { de } \\
\text { Perda }\end{array}$ \\
\hline$[1,2$, Eucalipto,1] 14/06/2014 & 4,02 & 56,13 & 4,39 \\
\hline$[1,2$, Campo Sujo,1] 14/06/2014 & 2,40 & 52,15 & 2,90 \\
\hline
\end{tabular}




\subsubsection{Análise da Perda de Propagação L50}

\subsubsection{Expoente de Perda}

\section{Percurso Mix}

Examinando as Tabelas 5.1 e 5.3, verifica-se que o expoente de perda de propagação no clima úmido é maior que a do clima seco, porém a perda do clima seco é maior que a do úmido para torre de 24 metros.

Neste percurso foram identificadas três associações de espécies florestais (campo sujo, cerradão e plantação de eucalipto) justapostas em camadas que alicerçam uma dedução intuitiva de que o ambiente é propício à aplicação do modelo de múltiplas morfologias. Tomando a Eq. (45), seção 2.3, e utilizando-se a Tabela 5.4, linha $[1,1,3,1]$ e Tabela 5.6, tem-se que:

$$
\gamma_{1}=3,30-\text { Cerradão } \quad \gamma_{2}=4,39-\text { Eucalipto } \quad \gamma_{3}=2,90 \text {-Campo Sujo }
$$

Aplicando o modelo de Múltiplas Morfologias, chega-se à Eq. 72, para o percurso, tem-se:

$$
L_{50}[d B]=77,44+42,05 \log d
$$

Ao comparar o resultado teórico da Eq. (72) com o resultado experimental transcrito na Tabela 5.3 linha $[1,1,1,1]$, percebe-se há uma aproximação aceitável à reta de regressão dos resultados experimentais.

A Fig. 5.2 mostra que o modelo de Okumura-Hata para ambiente de cidade média na frequência de $144 \mathrm{MHz}$, torre de 24 metros se ajustam bem à inclinação da reta resultante da regressão; isto é, a distância entre a reta ajustada e a reta do modelo é insignificante. A mesma tendência de similaridade foi observada nos resultados a partir da torre de 10 metros.

Ao tomar radiais a partir da torre de 10 metros percebe-se que o relevo obstrui na maior parte do percurso a linha de visada entre torre e o drive-test. Com isso, o expoente de perda próximo de 4, modelo Terra Plana, Eq. (41) corroborado pela Eq. (72); representa muito bem o ambiente.

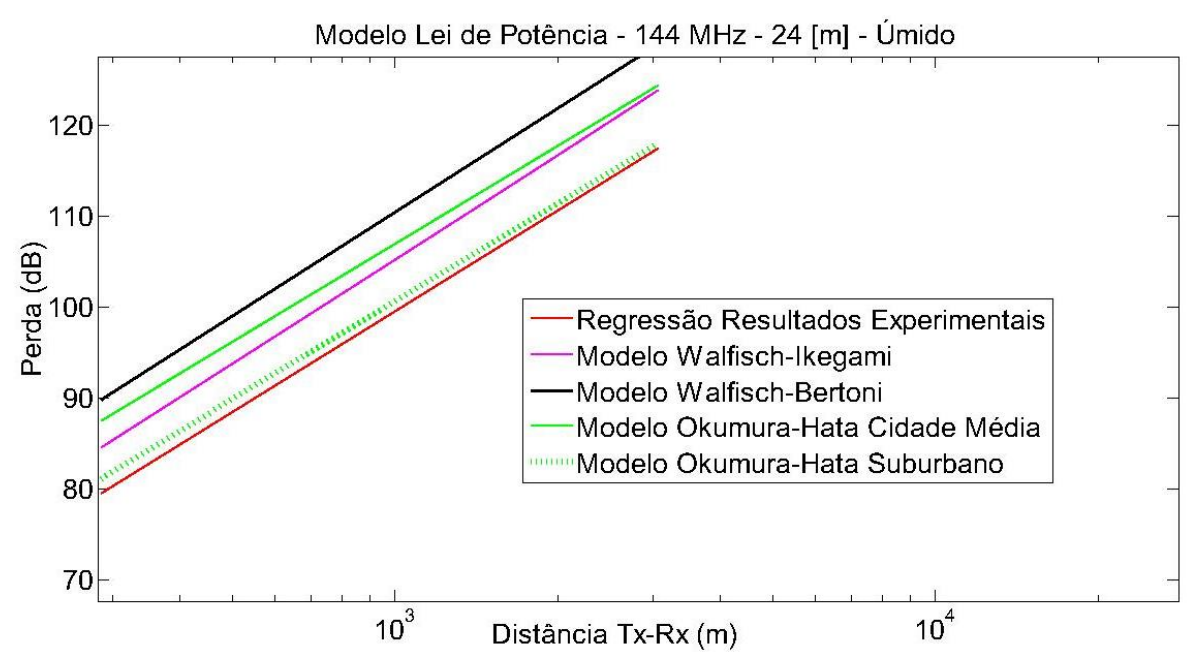

Figura 5.2 Perda de propagação, "mix", 144 MHz, 24 metros, úmido. 


\section{Percurso Edge}

O percurso é circunvizinho a um segmento de ocupação suburbana, o modelo de OKumura-Hata Suburbano apresentou razoável aderência aos resultados da reta de regressão em $144 \mathrm{MHz}$ torre de 10 metros, estações seca e úmida.

Tomando os resultados a partir da torre de 24 metros, a inclinação das retas traçadas para os modelos consagrados divergiu da reta de regressão dos resultados experimentais, conforme mostrado na Fig. 5.3.

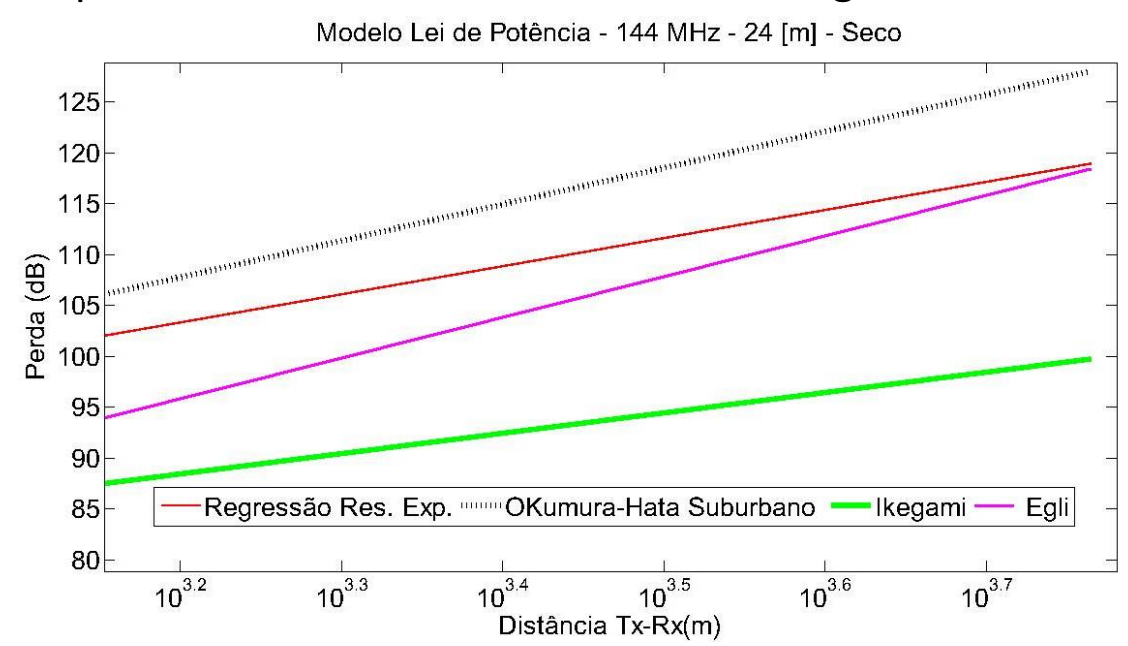

Figura 5.3 Perda de propagação, "edge", $144 \mathrm{MHz}, 24$ metros, seco.

Em relação à torre de 10 metros, admitindo uma pequena divergência nas inclinações entre reta ajustada e modelos, verifica-se que os modelos de Okumura-Hata suburbano e para área aberta estão mais próximos à reta da regressão linear, conforme mostrado na Fig. 5.4. O expoente de perda para torre de 24 metros ficou próximo de 3, enfatizando a perda por difração nos múltiplos blocos de floresta em direção ao drive-test concomitante com a desobstrução com relação ao relevo.

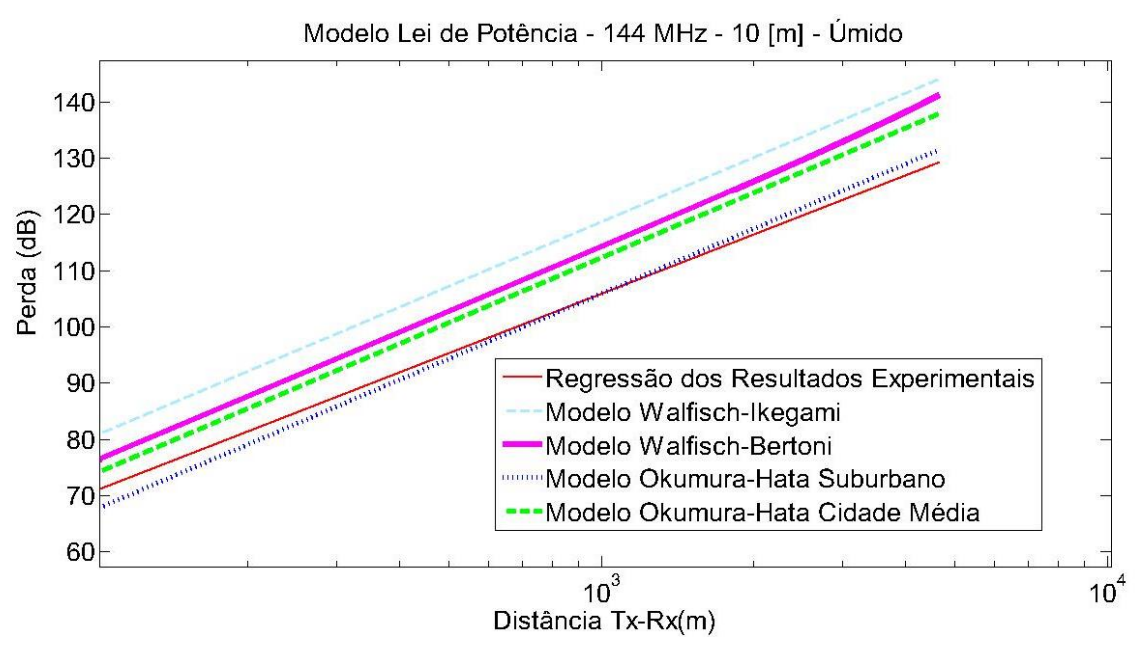

Figura 5.4 Perda de propagação, "edge", $144 \mathrm{MHz}, 10$ metros, úmido. 


\section{Percurso Cerradão}

No ambiente cerrado denso/grosso, aqui denominado de "cerradão", as retas de regressão, clima seco e úmido, torre de 10 metros, se ajustam entre os modelos de Okumura-Hata para cidade média e para ambiente suburbano. O expoente de perda próximo de 3,5 revela a predominância da difração por entre blocos de floresta e a apropriada solução adotada por Ikegami para os 2 últimos blocos de floresta entremeados pela via de deslocamento, em que a reflexão no último bloco de floresta deve ser avaliada no que tange ao parâmetro perda de reflexão. Sob certas condições, por exemplo a floresta úmida, pode ocasionar uma composição desfavorável entre sinal difratado e refletido, enfraquecendo o nível de sinal recebido pelo drive-test.

No clima seco, torre de 24 metros, Parsons empírico e Egli se ajustam na inclinação, porém com diferenças apreciáveis de 7 e $12 \mathrm{db}$, respectivamente, conforme mostrado na Fig. 5.5. O modelo de Okumura-Hata cidade média se apresenta com menor diferença em relação à reta de regressão, porém a inclinação divergente. Em relação à torre de 24 metros, clima úmido, Okumura-Hata suburbano aproximou melhor à regressão dos pontos experimentais conforme Fig. 5.6.

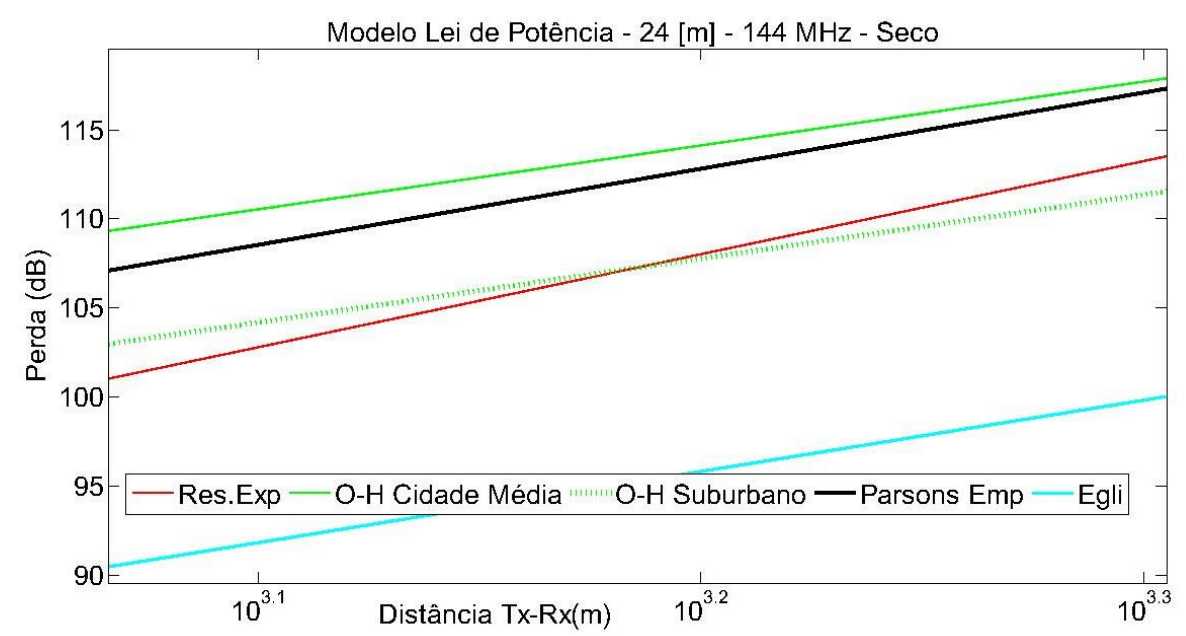

Figura 5.5 Perda de propagação, "cerradão", $144 \mathrm{MHz}, 10$ metros, seco.

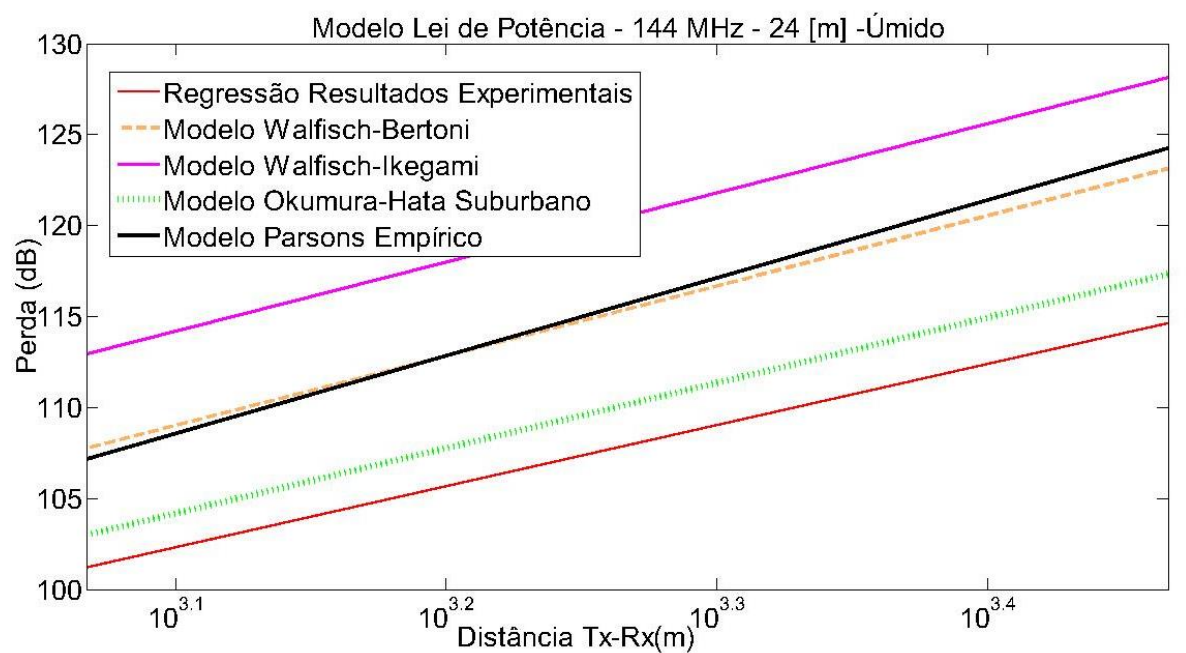

Figura 5.6 Perda de propagação, "cerradão", $144 \mathrm{MHz}, 10$ metros, úmido. 


\subsubsection{Perda de Referência}

A perda de referência em ( $\mathrm{dB}$ ) na Tabela é o clustering e, ao contrário ao observado em relação ao expoente de perda, o valor em clima úmido é maior do que em clima seco.

Os valores das perdas de referência do percurso "edge" são superiores aos valores obtidos nos percursos "cerradão" e "mix". A abundância de aglomerados de espécies diversas de cerrado, distribuídos aleatoriamente, de forma esparsa, na área delimitada pela via de deslocamento que o circunda aumenta a perda devido ao clustering.

\subsubsection{Desvio Padrão}

Em relação ao desvio padrão predominou maior espalhamento no clima úmido em relação ao clima seco nos percursos "mix" e "cerradão" com exceção do percurso "edge", torre de 24 metros.

\subsubsection{Análise dos Desvanecimentos}

\subsubsection{Sombreamento}

$\mathrm{Na}$ estação seca a estatística do sombreamento não tem um comportamento próximo a de uma distribuição gaussiana. Tomando como exemplo, o percurso "cerradão", observa-se no comparativo entre histogramas do sombreamento, tomando para efeito de análise as estações seca e úmida, torre de 10 metros, frequência de $144 \mathrm{MHz}$, que há um significativo salto de 18 para $35 \mathrm{~dB}$ no alargamento da faixa de atenuação desfavorável à estação seca.

\subsubsection{Desvanecimento em Pequena Escala}

\section{Percurso Mix}

O desvanecimento em pequena escala ficou bem ajustado com a função de densidade de probabilidade de Nakagami em ambas alturas de torre.

O resultado está de acordo com o relatado em [50,51]: Rice concebeu uma função de distribuição de probabilidades modelando o desvanecimento em pequena escala de ambientes com multipercursos de complexidade média em termos de obstáculos, com predominância de situações em que a linha de visada encontra-se desobstruída; enquanto que Nakagami concebeu a generalização, capaz de abranger ambientes com elevada desordem em termos da disposição de obstáculos, situações com forte obstrução na linha de visada entre estação rádio-base e o móvel. A distribuição de Nakagami controla melhor o desvanecimento de pequena escala mais profundo.

\section{Percurso Edge}

O desvanecimento em pequena escala ficou melhor modelado por Rice. Percebe-se que algumas frações do deslocamento transcorreram em visada com a torre de transmissão, pelo fato de que diagrama da antena em $144 \mathrm{MHz}$ 
possuir um melhor apontamento para o drive-test $[52,53]$ justificando assim a função de distribuição de densidade de probabilidades do tipo Rice.

\section{Percurso Cerradão}

$\mathrm{Na}$ frequência de $144 \mathrm{MHz}$, o melhor ajuste foi obtido com a distribuição de Nakagami, nas condições de clima seco e úmido.

A Fig. 5.7 apresenta as CDF's experimental e do Matlab para o percurso "edge", torre de 24 metros, clima úmido. Percebe-se que a distribuição de Rice melhor se ajusta aos resultados experimentais.

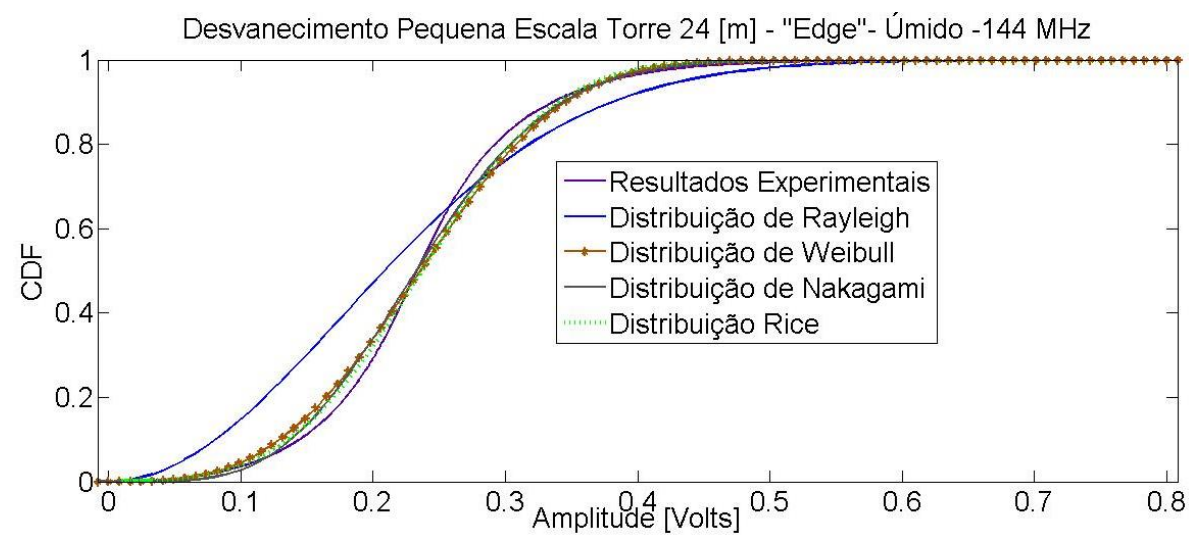

Figura 5.7. CDF's do Matlab x PDF experimental "edge".

\subsection{Campanha de Medidas em UHF}

O gráfico da Fig. 5.8, torre de 24 metros, permite visualizar as inclinações e distinguir a diferença em dBs das perdas por propagação no cerrado nas estações seca e úmida. Percebe-se claramente que a perda de propagação no clima úmido suplantou a do clima seco. Ainda na Fig. 5.8 é notória a diferença entre a perda no seco e no úmido em torno de $10 \mathrm{~dB}$ para os percursos "edge" e "mix" e no "global" $20 \mathrm{~dB}$.

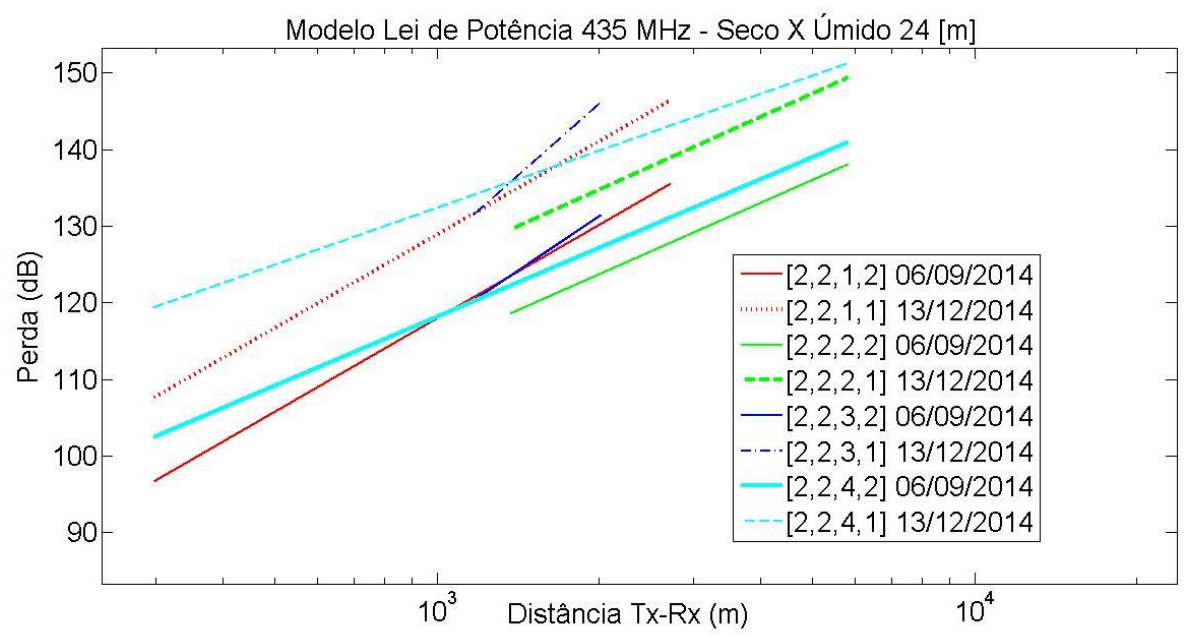

Figura 5.8. Perda de propagação, "cerradão", $435 \mathrm{MHz}, 24$ metros, seco e úmido. 
Tabela 5.7 Resultados no Percurso "Edge"

\begin{tabular}{|l|l|l|l|}
\hline Freq./Ht/Perc./Clima/Data & $\begin{array}{c}\text { Desvio-Padrão } \\
{[\mathrm{dB}]}\end{array}$ & $\begin{array}{c}\text { Perda Ref. } \\
{[\mathrm{dB}]}\end{array}$ & $\begin{array}{l}\text { Expoente de } \\
\text { Perdas }\end{array}$ \\
\hline$[2,1,2,1] 04 / 06 / 2013^{*}$ & 3,01 & 92,39 & 2,37 \\
\hline$[2,1,2,1] 04 / 06 / 2013$ & 3,77 & 94,28 & 2,34 \\
\hline$[2,1,2,1] 03 / 02 / 2012$ & 3,74 & 94,99 & 2,32 \\
\hline$[2,1,2,2] 16 / 08 / 2014$ & 5,05 & 90,95 & 3,15 \\
\hline$[2,2,2,1] 13 / 12 / 2014$ & 5,90 & 93,63 & 3,16 \\
\hline$[2,2,2,2] 06 / 09 / 2014$ & 5,95 & 83,36 & 3,10 \\
\hline
\end{tabular}

Tabela 5.8 Resultados no Percurso "Mix".

\begin{tabular}{|l|l|l|l|}
\hline Freq./Ht/Perc./Clima/Data & $\begin{array}{l}\text { Desvio- } \\
\text { Padrão } \\
{[\mathrm{dB}]}\end{array}$ & $\begin{array}{c}\text { Perda Ref. } \\
{[\mathrm{dB}]}\end{array}$ & $\begin{array}{l}\text { Expoente de } \\
\text { Perdas }\end{array}$ \\
\hline$[2,1,1,1] 04 / 06 / 2013^{*}$ & 3,82 & 86,18 & 3,51 \\
\hline$[2,1,1,1] 04 / 06 / 2013^{*}$ & 4,79 & 84,90 & 3,45 \\
\hline$[2,1,1,1] 03 / 02 / 2012$ & 3,56 & 84,91 & 3,38 \\
\hline$[2,1,1,2] 16 / 08 / 2014$ & 4,63 & 87,89 & 3,65 \\
\hline$[2,2,1,1] 13 / 12 / 2014$ & 4,51 & 88,47 & 4,04 \\
\hline$[2,2,1,2] 06 / 09 / 2014$ & 3,70 & 77,52 & 4,05 \\
\hline
\end{tabular}

Tabela 5.9 Resultados no Percurso "cerradão".

\begin{tabular}{|l|l|l|l|}
\hline Freq./Ht/Perc./Clima/Data & $\begin{array}{l}\text { Desvio- } \\
\text { Padrão } \\
{[\mathrm{dB}]}\end{array}$ & $\begin{array}{l}\text { Perda Ref. } \\
{[\mathrm{dB}]}\end{array}$ & $\begin{array}{l}\text { Expoente de } \\
\text { Perdas }\end{array}$ \\
\hline$[2,1,3,1] 04 / 06 / 2013$ & 3,98 & 92,11 & 2,80 \\
\hline$[2,1,3,1] 03 / 02 / 2012$ & 3,08 & 88,25 & 3,21 \\
\hline$[2,1,3,2] 16 / 08 / 2014$ & 4,12 & 90,58 & 3,63 \\
\hline$[2,2,3,1] 16 / 12 / 2014$ & 4,06 & 65,13 & 6,21 \\
\hline$[2,2,3,2] 06 / 09 / 2014$ & 3,02 & 69,96 & 4,71 \\
\hline
\end{tabular}

Tabela 5.10 Resultados no Percurso "Global".

\begin{tabular}{|l|l|l|l|}
\hline Freq./Ht/Perc./Clima/Data & $\begin{array}{l}\text { Desvio- } \\
\text { Padrão } \\
{[\mathrm{dB}]}\end{array}$ & $\begin{array}{c}\text { Perda Ref. } \\
{[\mathrm{dB}]}\end{array}$ & $\begin{array}{l}\text { Expoente de } \\
\text { Perda }\end{array}$ \\
\hline$[2,1,4,2] 16 / 08 / 2014$ & 5,19 & 91,17 & 3,31 \\
\hline$[2,2,4,2] 06 / 09 / 2014$ & 5,92 & 88,32 & 2,98 \\
\hline$[2,2,4,1] 13 / 12 / 2014$ & 5,87 & 107,74 & 2,47 \\
\hline
\end{tabular}

\subsubsection{Análise da Perda de Propagação L50}

\subsubsection{Expoente de Perda}

Percurso Mix

A Fig. 5.9 mostra que o modelo de Walfish-Bertoni na frequência de 435 $\mathrm{MHz}$, torre de 24 metros se ajustam bem à inclinação da reta resultante da regressão; isto é, a distância entre a reta ajustada e as retas dos modelos é 
desprezível. A reta de regressão no clima úmido, torre de 24 metros, ficou 2,5 dB acima da perda estimada pelo modelo de Walfisch-Bertoni. Considerando a torre de 10m, clima seco, o modelo Okumura-Hata cidade média acompanhou muito de perto a regressão dos resultados experimentais, distância em dBs desprezível.

Na Tabela 5.7, torres de 10 metros e 24 metros, os expoentes de perda no clima seco foram superiores ao do clima úmido.

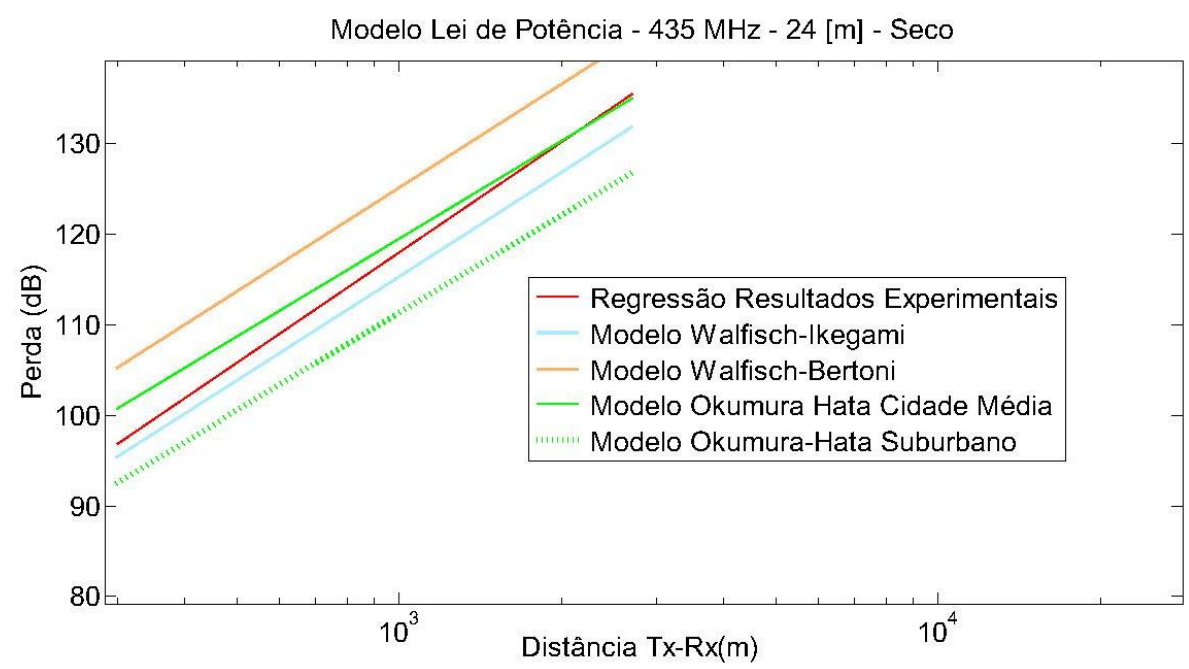

Figura 5.9. Perda de propagação, "mix", $435 \mathrm{MHz}, 24$ metros, seco.

\section{Percurso Edge}

Neste percurso, torre de 10 metros, a inclinação das retas traçada para os modelos consagrados divergiram das retas de regressão dos resultados experimentais em ambas situações climáticas. No entanto, na torre de 24 metros, o modelo de Parsons modificado [25] e Walfisch-Bertoni modelaram com boa aproximação a perda de propagação em clima úmido e OkumuraHata Suburbano modelou com boa aproximação em clima seco.

Ressalta-se que no clima úmido, torre de 10 metros, o modelo de Ikegami apresentou-se com inclinação paralela às retas ajustadas apesar de um distanciamento de aproximadamente $12,5 \mathrm{db}$ a menor na estimativa de perda em relação ao ajustado [17].

\section{Percurso Cerradão}

Neste percurso, climas seco e úmido, torre de 10 metros, o modelo de Walfisch-Bertoni coincide com o modelo de Okumura-Hata cidade média no percurso e foram os que melhor aproximaram da reta de regressão.

Em relação a torre de 24 metros, clima úmido, os modelos, consagrados divergiram da reta ajustada, no entanto, em clima seco os modelos de Walfisch-Bertoni e Okumura-Hata cidade média têm inclinação similar à da reta de regressão. 


\subsubsection{Perda de Referência}

O comportamento da perda devido ao clustering nas campanhas de medidas em UHF foi similar ao das medidas em VHF.

\subsubsection{Desvio Padrão}

Em relação ao desvio padrão predominou maior espalhamento no clima seco em relação ao clima úmido nos percursos com exceção dos percursos "mix" e "cerradão", torre de 24 metros. No percurso global esta tendência se manteve.

\subsubsection{Análise dos Desvanecimentos}

\subsubsection{Sombreamento}

A título de exemplo a Fig. 5.10 apresenta a distribuição dos resultados experimentais comparada com a função de distribuição gaussiana teórica, para o percurso "cerradão", seco, torre de 24 metros.

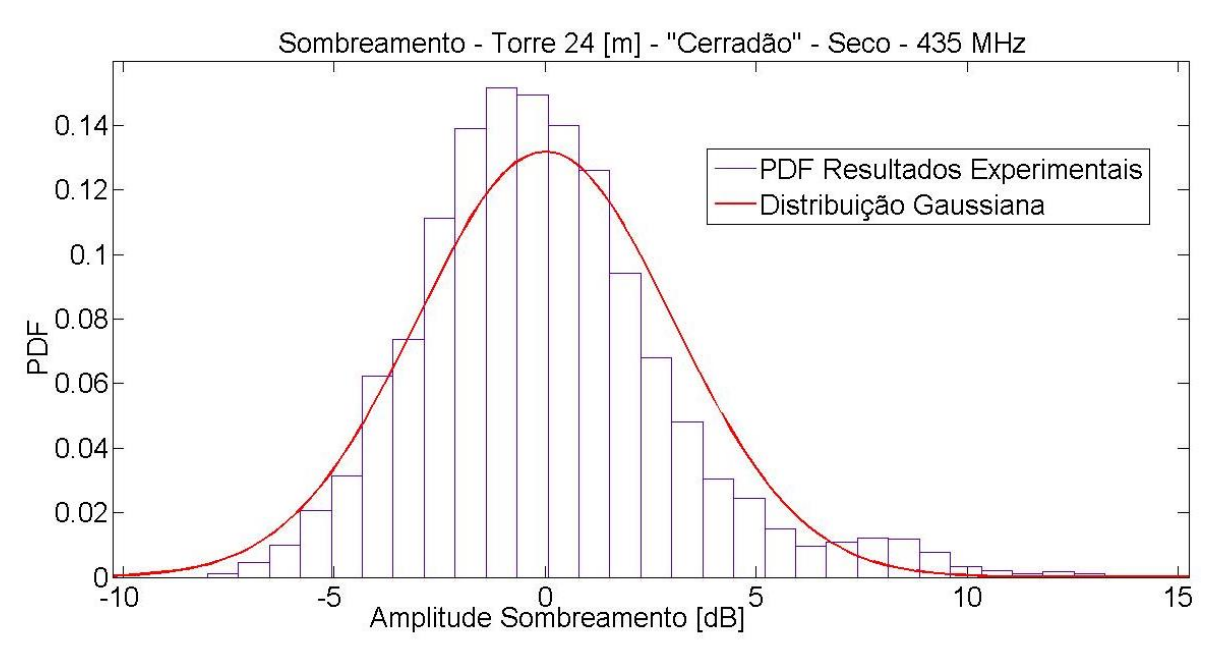

Figura 5.10 Sombreamento do percurso "cerradão", seco, 435MHz, 24 metros

\subsubsection{Desvanecimento em Pequena Escala}

Em relação à torre de 10 metros, o desvanecimento em pequena escala ficou bem ajustado ao modelo de Rayleigh no percurso "cerradão" e "mix". Já para os percursos "edge" o melhor ajuste foi conseguido com a distribuição de Nakagami.

A Fig. 5.11 apresenta a PDF experimental e a PDF do Matlab para o percurso "cerradão", torre de 24 metros, frequência de $435 \mathrm{MHz}$, clima seco. Percebe-se visualmente que a distribuição de Nakagami é o melhor ajuste. 


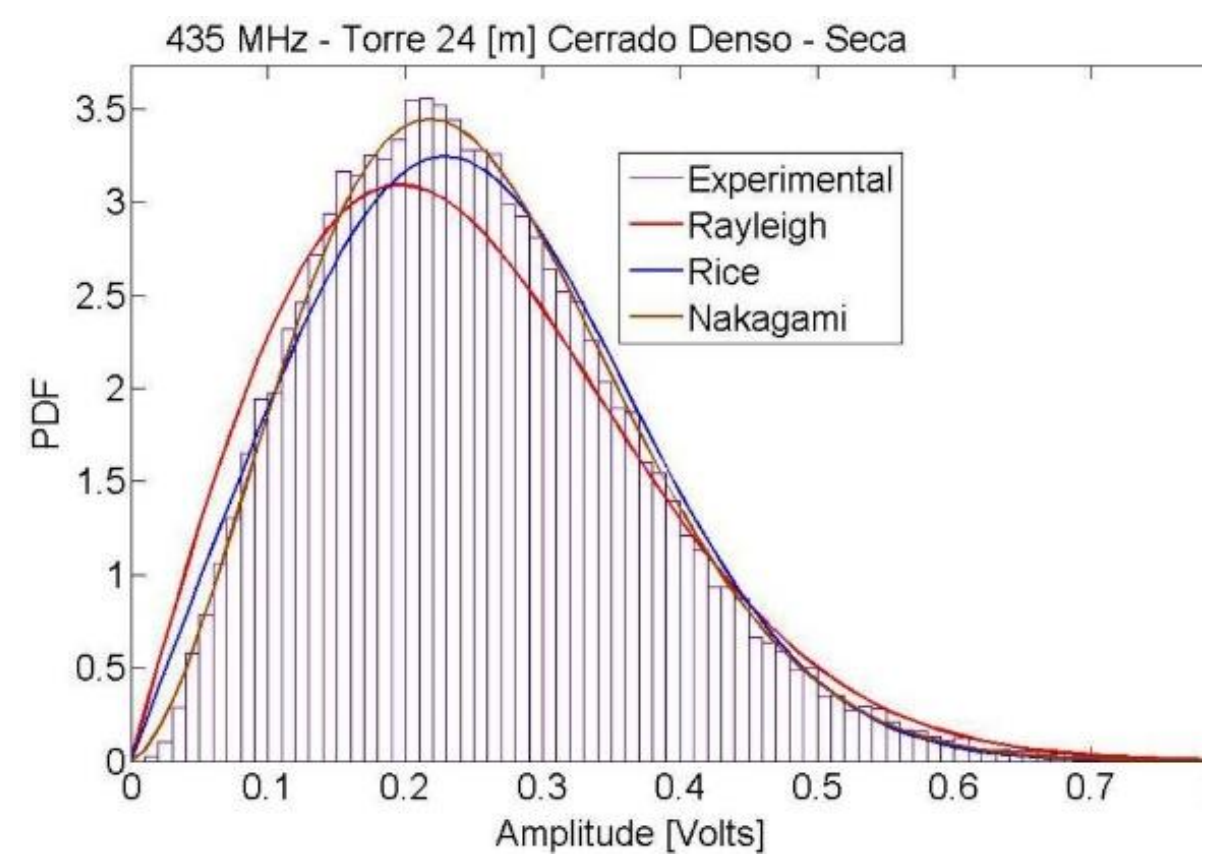

Figura 5.11. PDF's do Matlab x PDF experimental "cerradão".

A Fig. 5.12 apresenta o resultado da aplicação de um dos recursos do Matlab para análise do desvanecimento em pequena escala. Da aplicação do Probability Plot, no percurso "mix", torre de 24 metros, percebe-se que o modelo de Nakagami se adapta ligeiramente melhor que o modelo de Weibull nas condições doambiente do cerrado+eucalipto+campo sujo.

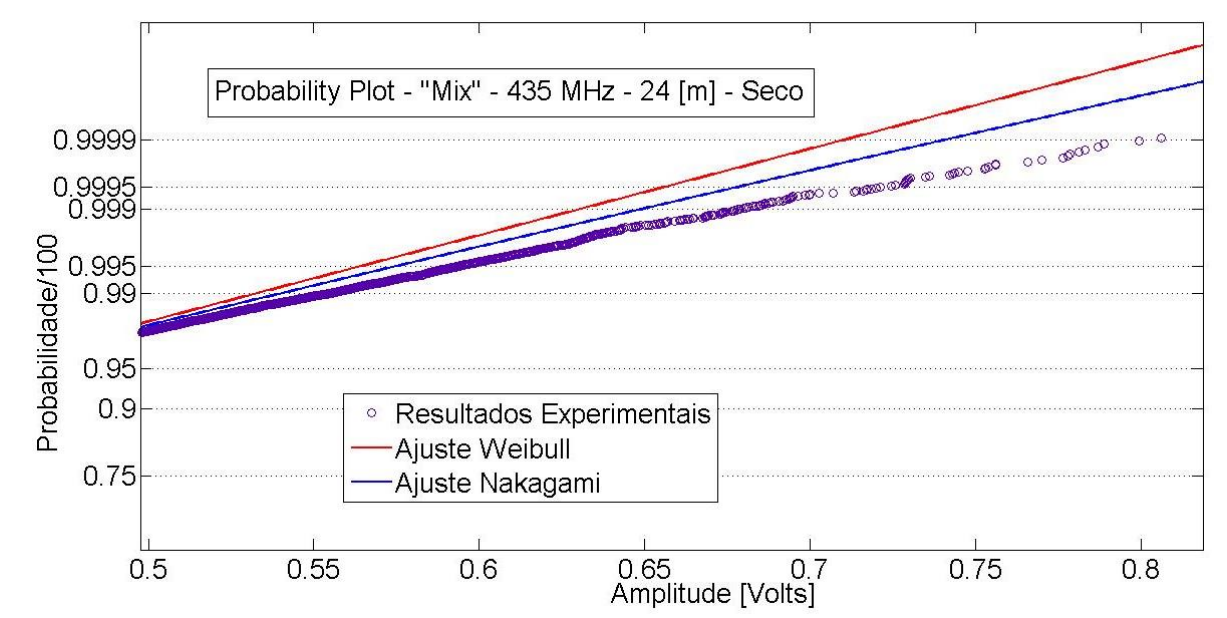

Figura 5.12 Probability Plot, Matlab x esperimental, "mix".

\subsection{Conclusão}

O gráfico da Fig. 5.13 apresenta o resultado comparativo entre o clima seco e úmido, torre de 10 metros, percurso "edge". Percebe-se que o clima seco apresenta perda superior ao clima úmido (em torno de $2,5 \mathrm{~dB}$ ) em praticamente todas as distâncias em relação a torre de 10 metros, frequência de $144 \mathrm{MHz}$. Na frequência de $435 \mathrm{MHz}$ a perda do clima seco é superior ao clima úmido à medida que se afasta da torre de transmissão, revelando que no clima seco, o estrato inferior da mata, formado por gramíneas e leguminosas, com altura média em torno de $50 \mathrm{~cm}$, acarreta maior absorção devido a maior interação com a energia emitida. 


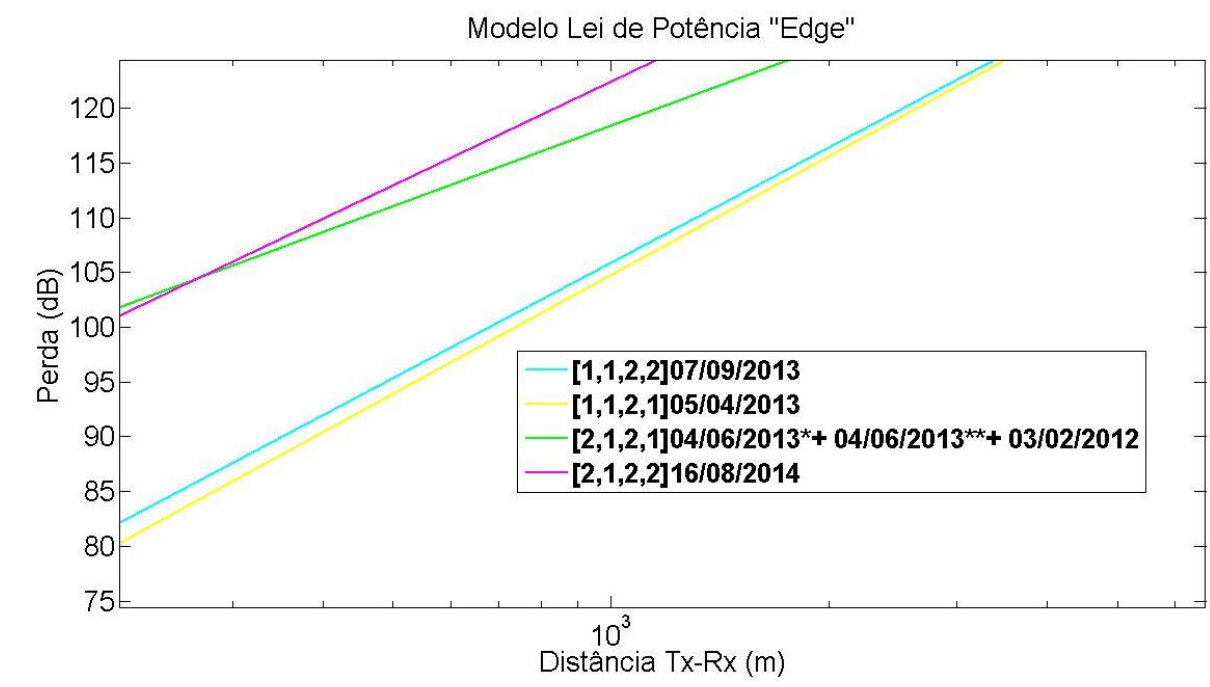

Figura 5.13. Regressão linear, "edge", 144 e $435 \mathrm{MHz}, 10$ metros, seco/úmido.

Percebe-se das Tabelas 5.3, 5.4 e 5.8 que os percursos "mix" e "cerradão", regiões com maior cobertura de vegetação, apresentam o expoente de perda do clima seco superior ao clima úmido no ambiente da FAL.

As torres de 24 metros e 10 metros praticamente cobrem a área delimitada pelo perímetro do percurso mix com similar abrangência, pois ambas estão próximas às margens da via que contorna o polígono de vegetação inerente ao percurso. A torre de 24 metros está contida no percurso, a 300 metros da via, e a torre de 10 metros está a 57 metros da borda da via. Examinando a planialtimetria verifica-se que a partir da torre de 10 metros o drive-test encontra forte obstrução devido ao relevo em grande parte do percurso, enquanto que a partir da torre de 24 metros não há obstrução devido ao relevo. Ao tomar os resultados dos expoentes de perda em ambas faixas, percebe-se que coeficiente para torre de 24 metros é superior ao da torre de 10 metros, conclui-se então que os expoentes de perda não acompanham não tão somente o relevo, mas sim a fitofisionomia e a geomorfologia do ambiente. Desta forma, isto confirma o preconizado por [36] acerca da propagação em ambiente de floresta: a vegetação acompanha o relevo e aproximadamente $60 \%$ da energia trafega no estrato superior formado pelas copas e o ar acima das copas, onda lateral conforme [14, 15] ou onda de superfície conforme [26].

A Fig. 5.14 apresenta as retas de regressão oriundas dos resultados experimentais na torre de 10 metros, percurso "cerradão". É notável que a perda no clima seco foi superior à do clima úmido em ambas frequências. Examinando a Fig. 5.15, percebe-se que a torre de 24 metros em $144 \mathrm{MHz}$ não houve mudança na tendência de maior perda no clima seco em relação ao úmido. Por outro lado, em $435 \mathrm{MHz}$, a perda de propagação do clima úmido foi maior que no clima seco. A diferença de perda entre $144 \mathrm{MHz}$ e $435 \mathrm{MHz}$ em clima úmido atinge aproximadamente $25 \mathrm{~dB}$ no percurso "cerradão", torre de 24 metros e diferença de $10 \mathrm{~dB}$ no percurso "mix", torre de 10 metros e torre de 24 metros. 
Salienta-se que conforme relatado anteriormente no início dessa seção, os resultados em $435 \mathrm{MHz}$, torre de 24 metros, clima úmido, carecem de um reexame devido às condições climáticas não serem as usuais das demais campanhas realizadas.

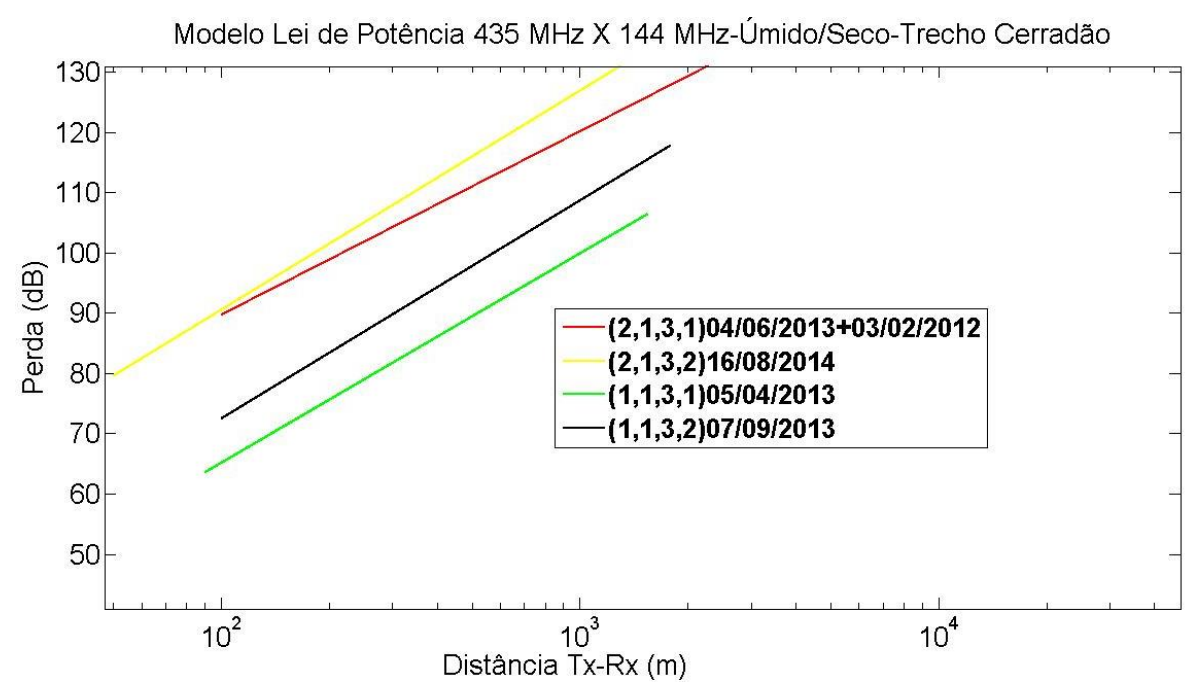

Figura 5.14. Regressão linear, "cerradão", 144/435 MHz, 10 metros, seco/úmido.

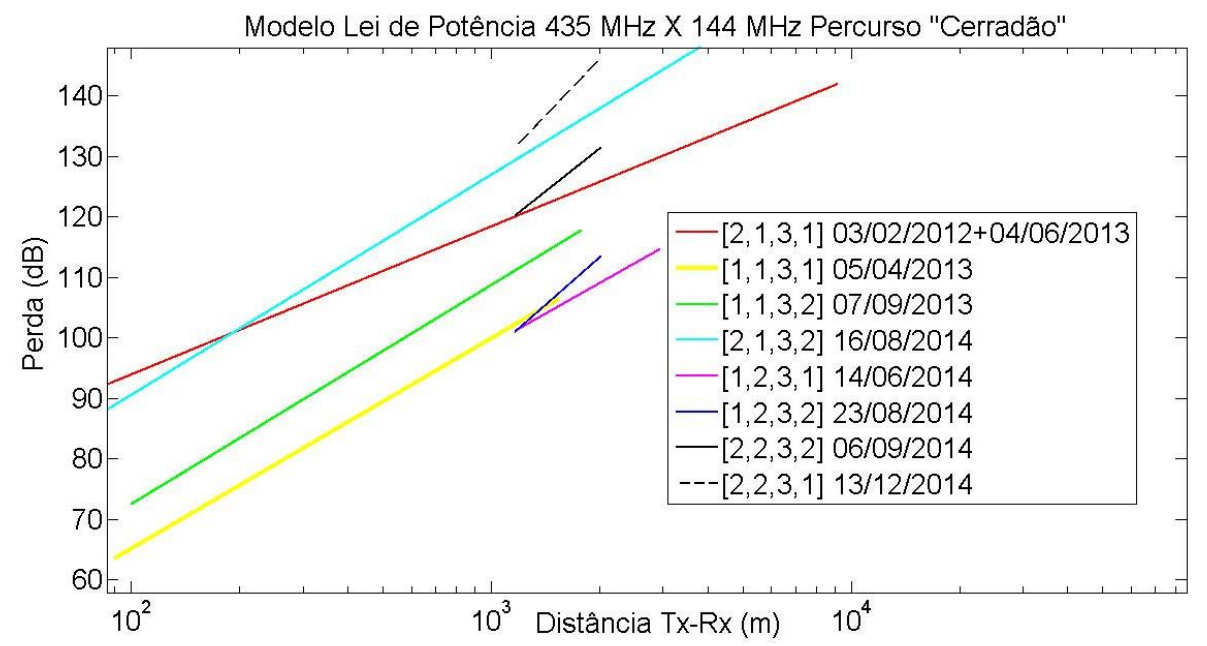

Figura 5.15. Regressão linear, "cerradão", 144/435 MHz, 10/24 metros, seco/úmido.

No percurso "cerradão" a inclinação em $144 \mathrm{MHz}$ torre de $10 \mathrm{~m}$ apresenta-se com razoável concordância com a inclinação de $144 \mathrm{MHz}$, torre de $24 \mathrm{~m}$. Na Fig. 5.1 observa-se que as perdas nos percursos se inverteram do clima seco, da maior perda para menor: "cerradão", "mix" e "edge", para o clima úmido: "mix", "edge" e "cerradão", evidenciando a influência marcante das estações no cerrado.

Perda de Referência

Os efeitos da morfologia do ambiente, tecnicamente denominado de perda devido ao clustering incidem mais em $435 \mathrm{MHz}$ do que em $144 \mathrm{MHz}$, conforme se vê nas Tabelas 5.2 a 5.10 graças a maior interação com a floresta, pois o modelo da floresta estratificada explica melhor os fenômenos de propagação nesta faixa de frequência [36].

A perda de referência, perda devido ao clustering é maior no percurso edge, uma vez que este percurso possui aglomerados com maior diversidade 
fitofisionômica de cerrado, portanto o resultado está de acordo com a teoria consolidada para ambientes urbanos [1, 2].

\section{Desvanecimento de Pequena Escala}

O desvanecimento em pequena escala teórico não sofreu alterações relevantes quanto à climatologia e à geomorfologia do cerrado. No entanto as distribuições estatísticas dos resultados experimentais em $144 \mathrm{MHz}$ apresentaram PDFs de silhuetas mais concentradas do que em $435 \mathrm{MHz}$ revelando assim menor probabilidade de queda de sinal recebido por conta da dinâmica de multipercursos no cerrado. Observou-se que a estatística do desvanecimento em pequena escala difere muito pouco devido a mudança de fisionomia de verão úmido para o inverno seco.

\section{Sombreamento}

Depreende-se da análise dos resultados estatísticos que o sombreamento na frequência de $144 \mathrm{MHz}$ apresenta uma silhueta mais distorcida em relação a uma gaussiana ideal do que nas medias tomadas para frequência de $435 \mathrm{MHz}$. A princípio isto pode ser atribuído à maior interação da transmissão com os elementos florísticos constituintes do bioma cerrado (galhos, gravetos, ramos e troncos secundários e primários da vegetação), com métricas proporcionais a múltiplos e submúltiplos do comprimento de onda em $144 \mathrm{MHz}$. Nota-se que em ambas frequências as PDFs do sombreamento, nos percursos "mix" e "cerradão", subestimaram a perda para distâncias maiores que 1000 metros, conforme se vê na Fig. 5.10. Em outras palavras, a perda medida é maior que a perda estimada para situações em que o receptor móvel está mais distante da torre de transmissão, conforme relatado por [9, 12], trata-se de um resultado esperado para ambientes de morfologia complexa como é o caso de florestas.

No percurso "cerradão" nota-se que, no comparativo entre histogramas do sombreamento, tomando para efeito de análise as estações seca e úmida, torre de 10 metros, frequência de $144 \mathrm{MHz}$, há um significativo salto de 18 para $35 \mathrm{~dB}$ no alargamento da faixa de atenuação desfavorável à estação seca. O cerrado por ser uma floresta aberta classificada como semi-decídua [5] perde grande parte de sua massa foliar na estação seca, quando então sobressai o dossel desnudo povoado de galhos, ramos, gravetos e troncos de arquitetura de feições irregular: retorcidos, contorcidos, nodosos, tortuosos e rugosos. Assim, na estação seca a estatística do sombreamento não tem um comportamento próximo a de uma distribuição gaussiana principalmente na frequência de $144 \mathrm{MHz}$.

A climatologia do cerrado afeta o sombreamento da seguinte forma: no percurso "edge" o sombreamento, estação úmida, apresenta maior 
variabilidade que os resultados analisados para os percursos "mix" e "cerradão". Isto ocorreu devido a maior dispersão provocada pela vegetação arbustiva constituída de aglomerados de arvoretas, gramíneas e leguminosas, característica prevalente em formações campestres, com componentes florísticos de dimensões mais próximas ao comprimento de onda na frequência de $435 \mathrm{MHz}$. 


\section{VALIDAÇÃO DOS RESULTADOS EXPERIMENTAIS}

A Tabela 6.1 apresenta os Resultados considerando seis radiais a partir da torre de 10 metros, na frequência de 435 $\mathrm{MHz}$. O bloco de floresta situado no lado oposto da via absorve todo sinal que chega até ele, desta forma não há uma combinação colaborativa com o campo difratado no último bloco de floresta na antena receptora do drive-test no sentido de aumentar a magnitude da potência de recepção. Admitindo que a constituição arbórea do cerrado apresente altura média de 3,5 metros de acordo com [5], chega-se a um ângulo de incidência de $15^{\circ}$, ao plotar em escala as correspondentes alturas. Fazendo uso de software de simulação TLM baseado na teoria $[54,55]$, resulta em um coeficiente de perda de reflexão elevado [43-45]; isto é, o retorno do campo refletido do bloco de floresta oposto à via é desprezível.

Tabela 6.1 Validação dos resultados experimentais com os modelos de Saunders - Ikegami, torre de 10 metros, 435 [MHz].

\begin{tabular}{|c|c|c|c|c|c|c|c|c|c|c|c|}
\hline Link [m] & $\varnothing\left[{ }^{\circ}\right]$ & $\alpha\left[^{\circ}\right]$ & No de blocos & $\mathrm{L}_{\mathrm{s}}[\mathrm{dB}]_{\mathrm{V}}$ & $\mathrm{L}_{\mathrm{IK}}[\mathrm{dB}]$ & $\mathrm{L}_{\mathrm{FS}}[\mathrm{dB}]$ & $\begin{array}{c}L_{T}[d B] \\
\left(L_{S}+L_{I K}+L_{F S}\right)-\end{array}$ & $\mathrm{L}_{\text {Exp }}[\mathrm{dB}]$ & $\mathrm{P}_{\mathrm{RX}}[\mathrm{dB}]$ & $\mathrm{L}_{\mathrm{ESF}}[\mathrm{dB}]$ & Radial [№] \\
\hline 1900,00 & 12,500 & $-0,307$ & 275 & 34 & 12,97 & 93,08 & 140,05 & 130,37 & $-83,87$ & 131,97 & 07-08 \\
\hline 1750,00 & 37,000 & $-2,730$ & 205 & 54 & 17,41 & 92,37 & 163,78 & 131,23 & $-84,73$ & 148,53 & 19 \\
\hline 1450,00 & 52,000 & $-0,546$ & 125 & 31 & 18,64 & 90,73 & 140,37 & 124,90 & $-78,40$ & & 20 \\
\hline 800,00 & 63,000 & 1,750 & 17 & 11 & 19,11 & 85,57 & 115,68 & 110,90 & $-64,40$ & & 24 \\
\hline 772,50 & 5,000 & 0,570 & 50 & 24,6 & 9,00 & 85,27 & 118,97 & 119,90 & $-73,40$ & & 22 \\
\hline 600,00 & 12,000 & 0,700 & 34 & 16,6 & 12,79 & 83,07 & 112,49 & 110,65 & $-64,15$ & & $18-19$ \\
\hline
\end{tabular}

Na Tabela 6.1: Link [m] - é o tamanho da radial em metros; $\varnothing^{\circ}$ - é o ângulo da via; $\alpha$ - é o ângulo rasante à floresta, ver Fig. 2.12; № Blcs- é a quantidade de blocos de floresta tendo por base o modelo considerado para os indivíduos arbóreos do cerrado [7]. A partir do perfil altimétrico em escala chega-se a parcela em metros em que a linha de visada penetra na floresta e, daí chega-se ao número de blocos ao aplicar o modelo apresentado na Fig. 6.1. $\mathrm{L}_{\mathrm{S}}[\mathrm{dB}]$ - é a perda devido a teoria 
de difração em múltiplos blocos de edificações desenvolvida em [22]; $\mathrm{L}_{\mathrm{IK}}[\mathrm{dB}]$ - é a perda devido a teoria de difração nos dois últimos blocos situados nas margens da via de deslocamento do drive-test, Eq. (22); LFS[dB]- é a perda de propagação no espaço livre Eq. (34) e $\mathrm{L}_{\mathrm{T}}=\left(\mathrm{L}_{\mathrm{IK}}+\mathrm{L}_{\mathrm{S}}+\mathrm{L}_{\mathrm{FS}}\right)[\mathrm{dB}]$-é a perda teórica total, nos seguintes termos: $L_{\text {Teórico Total }}=L_{f s}+L_{\text {Conectores }}+$ Cabos + Adaptadores $+L_{50 \text { Modelo }} ; L_{\text {Exp }}[d B]=P_{\text {Transmitida }}[\mathrm{dBm}]-$ $P_{\text {Recebida }}[d B m][d B]$ 


$$
\mathrm{P}_{\text {Transmitida }}[\mathrm{dBm}]=46,5 \mathrm{em} 435 \mathrm{MHz} ; \quad \mathrm{P}_{\mathrm{Rx}} \quad[\mathrm{dBm}] \quad \text { - Potência }
$$

recebida lida no arquivo de medidas; $\mathrm{L}_{\mathrm{ESF}}[\mathrm{dB}]$ - Perda em obstáculos com feições esféricas conforme teoria desenvolvida em [28].

No conhecimento do autor os trabalhos teóricos até hoje publicados acerca de propagação na floresta podem ser sintetizados no seguinte: modelos determinísticos que consideram a biofísica [10], funções diadícas de Green [12]. As vertentes empíricas, semi-empírica [36] e estatística [13] foram tratadas e analisadas neste trabalho por meio da comparação gráfica entre os modelos consagrados e o modelo lei de potência oriundos da regressão linear aplicada aos resultados experimentais. Intensas campanhas de medidas foram executadas em ambiente de cerrado nativo contemplando as variantes fitofisionômicas do bioma. Do conjunto de arquivos de medidas traçaram-se gráficos e confeccionaram-se tabelas. A modelagem da propagação móvel no ambiente de floresta é um estudo complexo em que a forma de dividi-lo consiste em separar por faixas de frequência [36]. O trabalho contempla duas frequências que implicam em modelos distintos.

O conceito de onda lateral em termos eletromagnéticos consiste em aplicar o conceito de ângulo crítico [26, 27] admitindo a passagem da onda radiada de um meio denso, neste estudo floresta, para o ar. Este enfoque enseja as frequências de 144 e $435 \mathrm{MHz}$ sendo que a iteração com elementos da floresta é uma particularidade de cada bioma. A título de exemplo, uma série de trabalhos aperfeiçoou a camada densa de floresta subdividindo-a em camadas ou lâminas pode se citar os trabalhos de [10]. Recentemente, outra abordagem foi explorada baseada na forma reduzida da equação de onda conhecida como equação parabólica [14]. É uma equação de onda onde um dos parâmetros no caso o índice de refração varia lentamente com a distância e a daí a solução da equação de onda fica reduzida.

Consultando as publicações acerca do bioma cerrado, verificou-se que sua vegetação pode ser representada na média com um conjunto de árvores com geometria de copa e tronco praticamente em dois tamanhos. Para confrontar os resultados de perda por propagação medidos experimentalmente com a teoria, vislumbrou-se uma predição baseada em 
dois aspectos: modelar as árvores do cerrado com base nos estudos de [8, $35,36]$ no qual árvores de alturas distintas, assentadas em um terreno de topografia regular apresentam razoável similaridade com o previsto em [22] para edifícios justapostos. Essa abordagem, com boa aproximação, soluciona o problema de propagação na floresta. Estudou-se, ainda, como alternativa, o modelo de Ikegami [43, 44, 45] para determinar a propagação entre os blocos de floresta situados às margens opostas da via de deslocamento.

Transpondo o método de múltiplas difrações em áreas urbanas para o estudo de floresta, considerando a substituição dos blocos edificados nos centros urbanos por células de cerrado de dimensões: largura $12 \mathrm{~m}$, profundidade 6,2 m e altura $7 \mathrm{~m}$, sendo que tal escolha baseou-se em dados fornecidos em [35], grupo de pesquisa voltado ao estudo do bioma cerrado. A Fig. 6.1 ilustra o modelo utilizado.

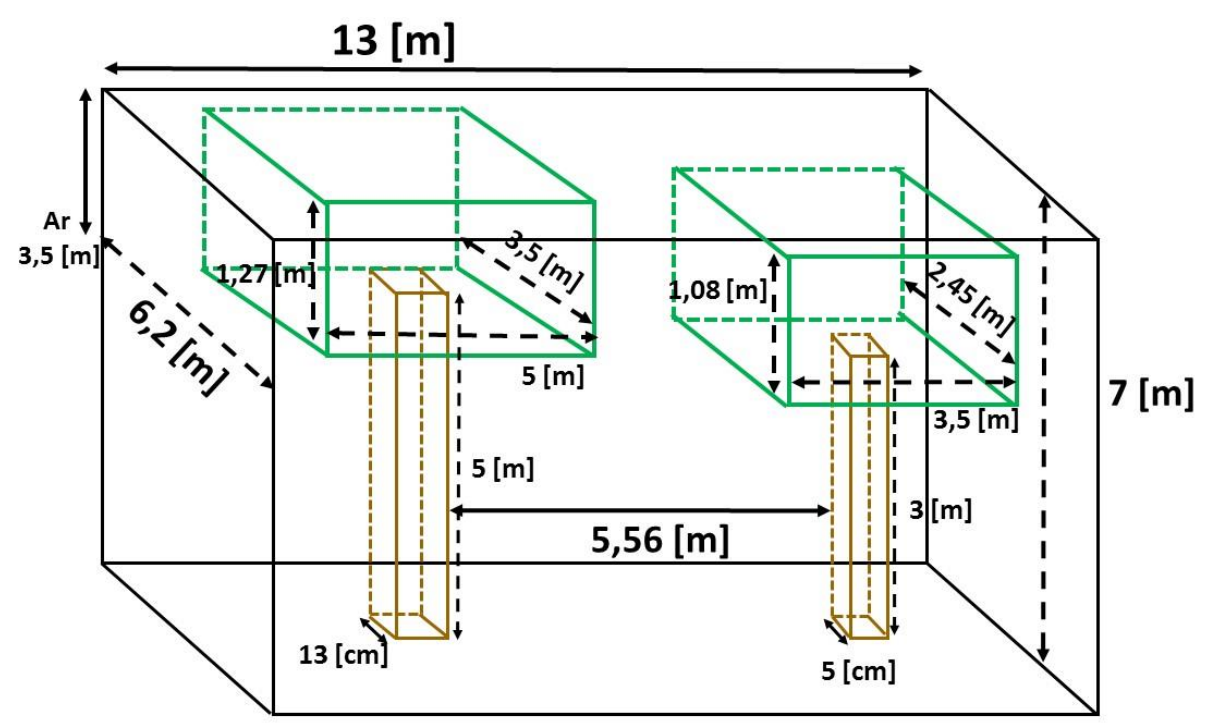

Figura 6.1. Modelo utilizado para coligir resultados teóricos com resultados experimentais.

No caso do conjunto relevo+cobertura da floresta interferirem razoavelmente com a linha de visada foi adotado um único difrator esférico como excesso de atenuação. Chegou-se ao difrator esférico mediante o estudo do perfil altimétrico detalhado. Nesse caso, observou-se no levantamento planoaltimétrico, que a linha de visada tocava a floresta, penetrava no terreno, saia do terreno de volta à floresta e, finalmente, difratava em direção ao móvel. Outra análise baseada em método semiempírico tal como descrito em [22] foi realizada a partir de 6 radiais 
tomadas em relação a torre de 10 metros na frequência de $435[\mathrm{MHz}]$ nas direções azimutais conforme Tabela 10. Neste caso verificou-se uma discrepância de no máximo $5[\mathrm{~dB}]$ entre o valor da perda experimental e da perda teórica.

De acordo com a literatura [22] os métodos são geralmente corrigidos a partir do último bloco, pois, sem perda de generalidade, os blocos anteriores (blocos de floresta ou edifícios em linha), constituem uma sequência de copas de árvores justapostas como uma estrutura periódica apresentando pouca variação nos ângulos de difração e incidência em relação a interface entre os blocos. Neste trabalho, convencionalmente usa-se a técnica de Ikegami $[43,44,45]$ para tratar os últimos blocos de floresta.

Desta forma, no caso do cerrado supõe-se que os blocos de edifícios substituem a vegetação e o último bloco é tratado como um dielétrico imperfeito, com perdas cuja constante dielétrica efetiva complexa pode ser, de forma aproximada, obtida por analogia a um conjunto de capacitores associados em série. Tal aproximação é respaldada pela análise quaseestática de campos eletromagnéticos [55].

Daí a solução da última célula, no caso de múltiplas difrações na floresta, passa a ser de campo incidente de forma oblíqua em dielétrico com perda [26]. Um algoritmo simples explorou a teoria e após algumas manipulações é possível extrair um ângulo de transmissão máximo e perda desprezível na interface de passagem do ar para o dielétrico. Em seguida obteve-se um ângulo de refração dentro do dielétrico muito pequeno que quando projetado na direção de propagação da onda resulta em uma perda apreciável. Neste ponto o fenômeno passa a ser o relacionado a uma onda guiada espalhada em vários obstáculos, ou seja, o modelo da incidência de uma onda plana na célula que simula um infinitesimal de cerrado, até atingir o receptor.

A confrontação entre os resultados experimentais, obtidos nas campanhas de medidas, com esta análise teórica apresenta razoável concordância. Face ao exposto, pode-se afirmar que o modelo teórico de múltiplas difrações vai ao encontro das teorias mais elaboradas do ponto 
de vista matemático sobre propagação na floresta [14], desde que se façam algumas considerações no estudo do último difrator. No caso do bioma cerrado, tendo em vista que a altura da vegetação fica em média em torno de 3,5 metros, a perda de reflexão relatada por Ikegami no último obstáculo, situado no lado oposto da via de deslocamento do drive-test, é muito alta, atingindo mais de $6 \mathrm{~dB}$, pois se trata de um bloco de floresta esparso que pouco reflete o sinal de volta ao leito da via.

Paralelo aos trabalhos já citados anteriormente, verifica-se que poucos exploram a possibilidade de uma análise numérica full wave, onde a propagação é obtida a partir das equações de Maxwell. A complexidade da floresta [5] torna-se intratável, em outras palavras, a complexidade da floresta afasta a possibilidade da análise full wave para grandes distâncias entre estação rádio base e o dispositivo móvel.

Outra abordagem ainda mais rigorosa do ponto de vista teórico explorada neste trabalho admite as seguintes hipóteses simplificadoras: a onda ao ser radiada a partir de um dipolo vertical seja considerada plana ao atingir a floresta, hipótese também explorada no trabalho de difração sobre edifícios por [47], desconsidera-se a vegetação de formação campestre arbustos e gramíneas. Considerando a floresta como um dielétrico complexo, conforme [36], sabe-se que a incidência oblíqua em um dielétrico complexo admite transmissão máxima para um ângulo obtido a partir do emprego do conceito de coeficiente de reflexão de Fresnel [26, 27].

O bloco de floresta da Fig. 6.1 foi estudado rigorosamente pelo emprego do método numérico TLM-SCN-3D, graded, (Anexo V) (Transmission Line Modeling Method-Symmetrical Condensed Node Three Dimensional). O método permite obter os parâmetros de espalhamento escolhendo-se uma radial devidamente representada no perfil de terreno, conforme esboço ilustrativo da Fig. 6.2. Os blocos foram conectados em cadeia ao longo da radial e suas respectivas matrizes de transmissão de onda foram multiplicadas fornecendo o resultado final da cadeia de matrizes "As" [54]. 


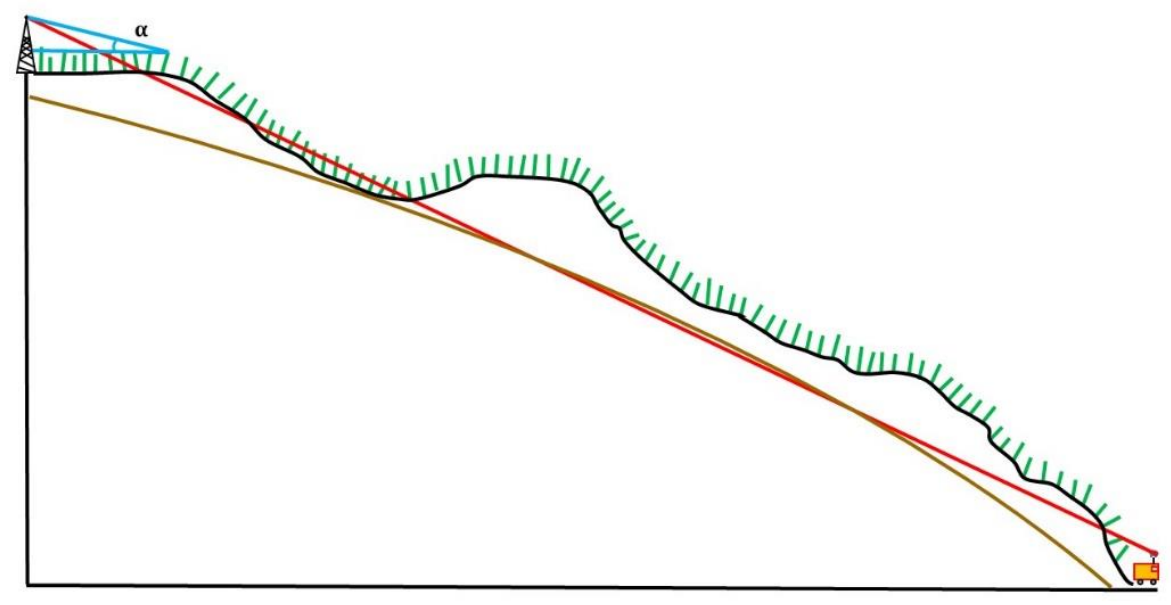

Figura 6.2 Perfil altimétrico: em verde-floresta, em vermelho-linha de visada, em preto-relevo, em marrom -superfície esférica imaginária, $\alpha$ - ângulo rasante.

A excitação do bloco obtida da reflexão de Fresnel é do tipo TMTransverse Magnetic conforme [26]. Vários ensaios foram feitos começando com a simples conexão dos blocos tais como se apresenta na Fig. 6.1, passando pela inversão das árvores no bloco até a distribuição uniforme com gerador randômico dos blocos ao longo da radial. 0 resultado estampado na Fig. 6.3, mostra que a atenuação resultante é mensurável em certas regiões do bloco. Nota-se que a atenuação é relativamente baixa na parte superior de certa forma evidenciando o resultado compatível com estudos a partir da onda lateral [36].

Além disso, verifica-se uma região bem ao nível do móvel, a aproximadamente 1,5 metros do nível do terreno, possui na média atenuação baixa, evidenciando a propagação copa-tronco [12,15]. Os códigos TLM rodam em computadores portáteis com tempo de processamento da ordem de 2 horas em Pentium 4 assim como os códigos Fresnel e o de multiplicação das matrizes "As". Como TLM é temporal e a matriz " $A$ " é espacial, no intuito de evitar os transientes, aplica-se aceleração nos ciclos de tempo de processamento do TLM, desta forma alcançando o regime permanente de forma adequada a manipular valores complexos. Este procedimento intrínseco ao TLM incorre em aproximadamente de 2 horas de tempo de processamento no notebook. 


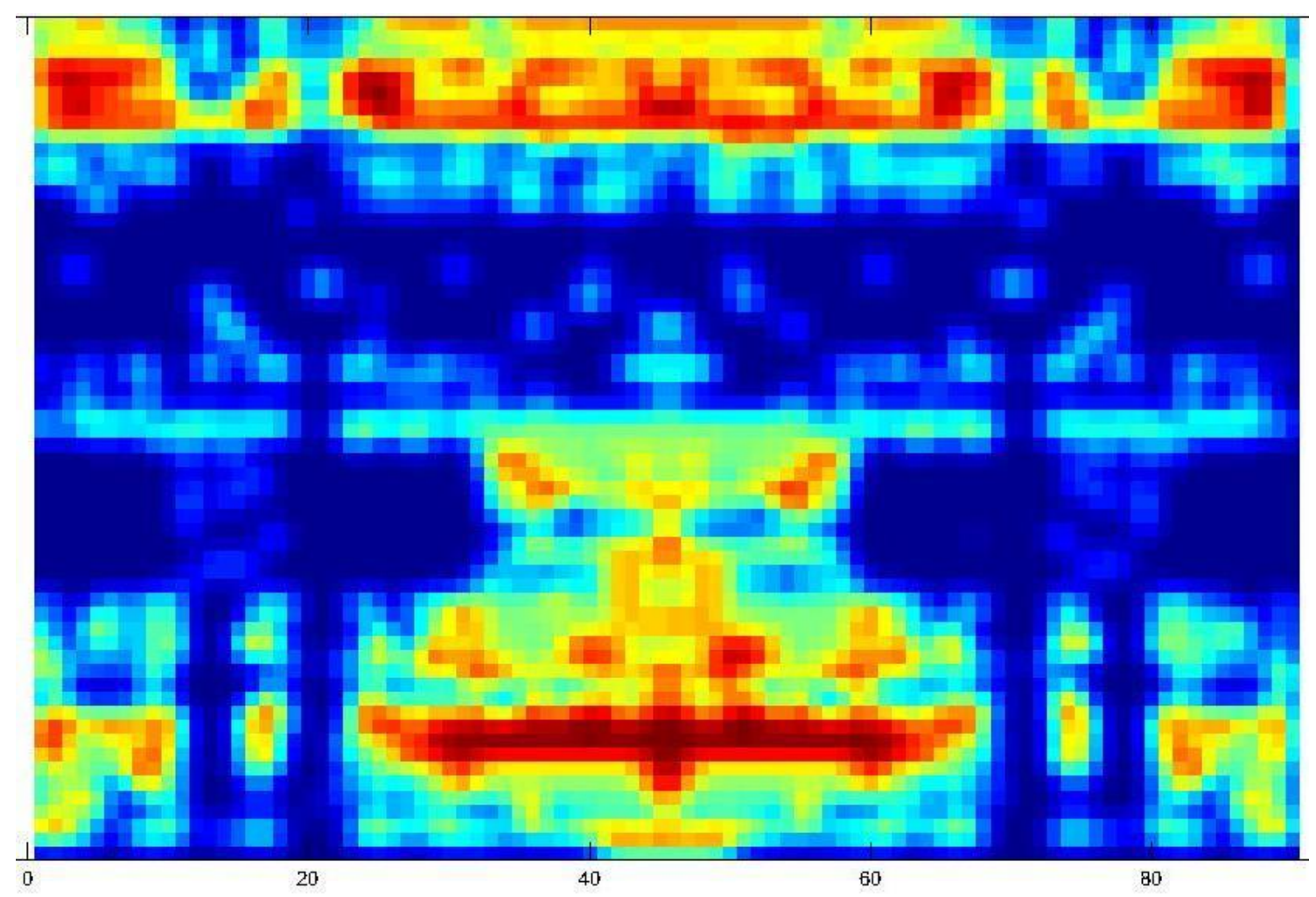

Figura 6.3 Imagem esboçando resultado da simulação TLM aplicada em conjunto de 100 blocos justapostos de forma a atender uma distribuição uniforme. 


\section{CONCLUSÃO}

Os resultados obtidos neste trabalho além de suprir a lacuna da ausência de modelagem de propagação no cerrado, apresenta uma metodologia voltada à caracterização eletromagnética de biomas sob a circunstância de ausência de infraestrutura básica. A conjugação da teoria com a prática para chegar aos mais adaptados modelos de propagação eletromagnética na faixa VHF/UHF baixo abre caminho para que se aplique a metodologia apresentada neste trabalho a outros biomas.

Em função dos atributos da propagação em VHF e UHF os resultados da pesquisa vão ao encontro das orientações nacionais e internacionais de evitar a ocupação invasiva e impactante do meio ambiente. Nesse contexto, a faixa do VHF/UHF oferece condições para a implantação de uma rede de comunicações móveis com menor interferência na biodiversidade do cerrado, reduzindo assim o desmatamento para implantação de torres. Ressalta-se que o cerrado ocupa uma área equivalente a $25 \%$ do território brasileiro.

A ciclagem entre período seco e úmido desempenha um papel importante na característica de propagação do cerrado e do ponto de vista de comunicações móveis acarretando variações importantes nos parâmetros estatísticos associados. A perda de propagação na estação verão úmido é muitas das vezes ligeiramente inferior à perda de propagação na estação inverno seco. As campanhas de medidas contemplaram fatores bióticos e abióticos em duas frequências representativas do VHF e UHF com torres de alturas distintas.

Afora as pesquisas desenvolvidas na floresta amazônica $[9,25,33]$ há poucas iniciativas técnico-científicas versando sobre a caracterização do canal móvel em outros biomas brasileiros. Há recentes trabalhos desenvolvidos na mata atlântica [15]. Os pesquisadores são unânimes em afirmar que o comportamento da propagação é fortemente modificado conforme a frequência de transmissão [12].

Devido à heterogeneidade do bioma cerrado o modelo estatístico baseado na regressão dos pontos experimentais se mostrou adequado para expressar por meio de equações a perda de propagação neste ambiente de 
geomorfologia diversificada. Os modelos empíricos e semi-empíricos por terem sido desenvolvidos para atender morfologias específicas sem se preocupar com rigor matemático algumas vezes fitam de forma razoável aos resultados oriundos da reta de regressão no ambiente de floresta.

Os contraexemplos foram testados a fim de validar para o bioma cerrado a teoria amplamente consolidada [36] sobre a propagação na floresta, que afirma que a maior parte da energia propagante se faz na camada superior da floresta interface copas das árvores-ar. Ficou claro nos resultados de simulação que a perda teórica fica muito elevada quando se tenta considerar a propagação por todo cerrado; isto é, do solo passando pelas raízes até as copas. Dos resultados apurados neste trabalho para torre de 10 metros, considerando o confronto das curvas experimentais com as curvas teóricas nas diversas morfologias de cerrado contempladas, depreende-se que a teoria desenvolvida Okumura-Hata [38-39], em primeira análise [17] pode ser ampliada, isto é, não necessariamente ficar restrita a altura de torres acima 30 metros [17]. A solução full wave constata que a propagação se dá no estrato inferior e superior da floresta.

As pesquisas relativas a modelos biofísicos voltadas ao estudo de propagação eletromagnética [42], como forma de mensurar a atenuação na floresta, poderiam até ser mais precisas, porém, o principal impedimento em utilizá-los está na ausência de dados dos biomas, principalmente no Brasil.

\section{PROPOSTA DE CONTINUIDADE}

A pesquisa pode ser alvo de novos desdobramentos sintetizados nos seguintes desafios práticos e teóricos:

1 - Disseminar a metodologia para experimentação em outros biomas do Brasil ainda pouco explorados: caatinga, pampas, pantanal e ecossistemas inundáveis. Pleitear o uso de torres de observação ou de pesquisa científica para estudo de propagação móvel em floresta.

2 - Aperfeiçoar o diagrama de radiação da antena de $435 \mathrm{MHz}$ adicionando radiais inclinadas às radiais axiais do plano de reflexão na expectativa de melhorar o apontamento da energia na direção das vias de deslocamento do móvel $[52,53]$; 
3 - Levantamento dos dados biofísicos do cerrado [43, 10];

4 - Realizar campanhas de medidas em $435 \mathrm{MHz}$ e $144 \mathrm{MHz}$ para validar, o canal reverso e o princípio da reciprocidade [31]. Isto é, transmissor no drive-test e montagem do set-up de medidas na base da torre;

5 - Fazer campanhas de medidas nos períodos noturnos e vespertino nas faixas de 144 e $435 \mathrm{MHz}$ no intuito de observar variabilidade com a hora do dia e a influência da dinâmica transpiração do cerrado

6 - Realizar campanhas de medidas na polarização horizontal; e

7 - Realizar campanhas de medidas estáticas, antenas receptoras e transmissoras em posição fixa no cerrado. 


\section{REFERÊNCIAS BIBLIOGRÁFICAS}

[1] J. D. Parsons, The Mobile Radio Propagation Channel, 2nd ed., John Wiley \& Sons, 2000.

[2] W. C. Y. Lee, Mobile Communications Engineering, 2nd ed., McGraw Hill, 1997.

[3] M. D. Yacoub, Foundations of Mobile Radio Engineering, CRC, 1993.

[4] G. Ko, A. A. Franklin, S.-J. You, J.-S. Pak, M.-S. Song and C.-J. Kim, "Channel Management in IEEE 802.22 WRAN Systems," IEEE Communications Magazine, vol. 49, no. n³, pp. 82-89, 2010.

[5] Departamento de Conservação da Biodiversidade do Ministério do Meio Ambiente, Cerrado e Pantanal - Áreas e Ações Prioritárias para a Conservação da Biodiversidade, Avaliação e Ações Prioritárias para a Conservação da Biodiversidade do Cerrado e do Pantanal, 2008.

[6] P. Borges, "Cerrado Serrado: A Agonia de Um Gigante.," Revista Darcy - Revista de Jornalismo Científico e Cultural da UnB, no Setembro/Outubro, pp. 24-29, 2009.

[7] R. D. Ottmar, R. E. Vihnanek, H. S. Miranda, M. N. Sato e S. M. A. Andrade, Séries de Estéreo-Fotografias Para Quantificar a Biomassa da Vegetação do Cerrado do Brasil Central, vol. I, Junho 2001.

[8] J. M. Felfili, "Subsídios ao Plano de Manejo da Estação Ecológica e ao Plano Diretor da Fazenda Água Limpa da Universidade de Brasília," Brasília, Outubro de 2007.

[9] R. A. N. Oliveira, J. F. Souza, F. N. B. Magno, K. Cozzolino and G. P. d. S. Cavalcante, "Inversion Method for Obtaining Electrical Parameters for Soil and Vegetation in the Amazon Region," in 7th European Conference on Antennas and Propagation (EuCAP), 2013.

[10] A. M. Cavalcante, "Estrategias Computacionais Aplicadas em Técnicas de Traçado de Raios 3D Para Aumento da Eficiência na Caracterização de Canais de Propagação de Redes Sem Fio," Belém, Agosto de 2007.

[11] A. Palaios, Y. Labou e P. Mähönen, "A Study on the Forest Radio Propagation Characteristics in European Mixed Forest Environment," em 2014 IEEE Military Communications Conference, 2014.

[12] M. Ghoraishi, J.-i. Takada and T. Imai, Radio Wave Propagation Through Vegetation, Intech, 2013. 
[13] Z. Lijun and T. Yushu, "Theory and Experiment Validation of Radio Wave Propagation in the Forest and Its Application for Extended Frequency," in Proceedings of the 10th International Symposium on Antennas and Propagation (ISAP), 2012.

[14] Q. Zhang, C. Liao, N. Sheng and L. Chen, "Research of Radio Wave Propagation in Forest based on Non-uniform Mesh Parabolic Equation," in ISAP, 2013.

[15] M. H. C. Dias, R. A. Alem, J. C. A. Santos, E. B. Nogueira and T. P. Vuong, "Analysis of the Impedance Changes of a HF/VHF Monopole Antenna in a Brazilian Atlantic Rainforest Urban site," in Topical Conference on Antennas and Propagation in Wireless Communications, 2013.

[16] C. Philips, D. Sicker and D. Grunwald, "A Survey of Wireless Path Loss Prediction and Coverage Mapping Methods," Communication Surveys \& Tutorials IEEE, vol. 15, pp. 255270, 2013.

[17] G. C. G. Alves, J. P. L. Leite and P. R. G. Carvalho, "Evaluation of Mobile Radio Wave Propagation by Measurements Campaigns Through Different Types of "Cerrado Biome"," 2014.

[18] J. S. Fonseca, G. d. A. Martins e G. L. Toledo, Estatística Aplicada, São Paulo: Atlas, 1938.

[19] E. P. L. de Almeida, J. P. Leite, P. H. P. de Carvalho e R. G. A. de Oliveira, "Narrowband Fading Characterization in Brasília to Aid in The Designg of Public Safety Communication systems," em Microwave Optoeletronics Conference, 2007.

[20] M. A. S. Mayrink, F. J. S. Moreira, C. G. Rego, M. Burian, P. H. P. Carvalho, A. J. M. Soares e E. V. Melo, "Improving the Treatment of Mixed-Terrain Paths of The Recommendation ITUR P.1546 For The Path-Loss Prediction of Short UHF links," em Microwave and Optoeletronics, IEEE, 2005.

[21] A. J. M. Soares, C. G. Rego, E. V. Melo, F. J. S. Moreira, G. W. O. Costa, J. P. D. M. Pinto, M. A. S. Mayrink, N. Pasquali, P. H. P. de Carvalho and W. K. Guimaraes, "Signal Sampling Method for Power Measurements in Mobile UHF Environments," in Microwave and Optoeletronics International Conference, 2005.

[22] S. R. Saunders and A. A. Zavala, Antennas and Propagation for Wireless Communication Systems, 2nd ed., Wiley, 2007.

[23] U. S. Dias, "Distribuição de Fase e Estatísticas Correlacionadas em Ambientes Sem Fio: Teoria e Validação Experimental," Campinas, 2010.

[24] R. D. Vieira, "Medidas do Canal MIMO Indoor: Análise da Capacidade e dos Parâmetros do Canal," Rio de Janeiro, 2005. 
[25] F. M. Soares, A. M. Cavalcante, G. P. S. Cavalcante e J. C. W. A. Costa, "Modelos NeuroAdaptativo para Predição de Rádio-Propagação em Ambientes Florestais," em MOMAG, Belo Horizonte, 2006.

[26] J. A. Stratton, Eletromagnetic Theory, McGraw-Hill Book Company, 1941.

[27] M. Born and E. Wolf, Priciples of Optics: Eletromagnetic Theory of Propagation, Interference and Diffraction of Light, New York: Cambridge University Press, 1999.

[28] P. Angueira and J. A. Romo, Microwave Line of Sight Link Engineering, Bilbao: Wiley, 2012.

[29] H. L. Bertoni, Radio Propagation for Modern Wireless Systems, Prentice-Hall, 2000.

[30] The Institution of Engineering and Technology, Propagation of Radiowaves, Stevenage Herts: IET, 2011.

[31] D. M. do Rosário, "Modelo de Radiocomunicação Móvel em Ambiente Florestal," Revista Científica da UFPA, Vols. \%1 de \%26, no 01, 2007.

[32] P. R. Zanetti, “Modelagem de Canal Sem Fio para LTE em Brasília," Brasília, 2011.

[33] D. C. de Souza and G. P. d. S. Cavalcante, "A K-Ray Model for Mobile Systems in Environments With Abrupt Terrain Discontinuities," in Antennas an Propagation Society International Symposium, Baltimore, 1996.

[34] S. Johansson, Understanding Linear Regression, Microwaves \& RF, 2006, p. 118.

[35] A. V. Rezende, "Diversidade, Estrutura, Dinâmica e Prognose do Crescimento de um Cerrado Sensu Stricto Submetido a Diferentes Distúrbios por Desmatamento," Curitiba, 2002.

[36] T. Tamir, "On Radio-Wave Propagation in Forest Environments," IEEE Transactions on Antennas and Propagation, Vols. \%1 de \%2AP-15, pp. 806-817, 1967.

[37] ITU-R, Recommendation ITU-R P.1546-5, Method for Point-to-Area Predictions for Terrestrial Services in the Frequency Range $30 \mathrm{MHz}$ to 3000 MHz, Geneva: ITU, 2013.

[38] F. Ikegami, T. Takeuchi e S. Yoshida, "Theoretical Prediction of Mean Field Strength for Urban Mobile Radio," IEEE Transactions on Antennas and Propagation, vol. 39 (3), pp. 299302, 1991.

[39] Y. Okumura, E. Ohmori, T. Kawano and K. Fukuda, "Field Strength and its Variability in VHF and UHF Land-Mobile Radio Service," Review Electrical Communications Laboratory, Vols. 16, no 9, pp. 825-873, 1968. 
[40] M. Hata, "Empirical Formula for Propagation Loss in Land Mobile Radio Services," IEEE Transactions on Vehicular Technology, Vols. \%1 de \%2VT - 29, n3, pp. 317-325, 1980.

[41] J. D. Parsons and M. F. Ibrahim, "Signal Strength Prediction in Built-up areas. Part 2: Signal Variability," IEEE Proceedings F (Communications, Radar and Signal Processing), vol. 130 (5), pp. 385-391, 1983.

[42] K. Allsebrook e J. D. Parsons, "Mobile Radio Propagation in British Cities at Frequencies in the VHF and UHF Bands," IEEE Transactions on Vehicular Technology, vol. 26 (4), pp. 313 323, 1977.

[43] M. F. Ibrahim and J. D. Parsons, "Signal Strength Prediction in Built-up Areas. Part 1: Median Signal Strength," Communications, Radar and Signal,Processing, IEEE Proceedings F, vol. 130, pp. 377-384, 2008.

[44] F. Ikegami e S. Yoshida, "Analysis of Multipath Propagation Structure in Urban Mobile Radio Environments," IEEE Transactions on Antennas and Propagation, vol. 28 (4), pp. 531 $537,1980$.

[45] F. Ikegami, S. Yoshida, T. Takeuchi e M. Umehira, "Propagation Factors Controlling Mean Field Strength on Urban Streets," IEEE Transactions on Antennas and Propagation, vol. 32 (8), pp. 822-829, 1984.

[46] COST 231 Final Report, "Digital Mobile Radio: COST 231 View on the Evolution Towards 3rd Generation Systems," em Commission of the European Communities and COST Telecommunications, Brussels, 1999.

[47] H. L. Bertoni, W. Honcharenko, L. R. Macel e H. Xia, "UHF Propagation Prediction for Wireless Personal Communications," Proceedings of the IEEE, vol. 82 (9), pp. 1333-1359, 1994.

[48] A. M. D. Turkmani e Arowojolu, "Estimation of Signal Strength Characteristics in Typical Microcell Environments for PCN Networks," em Personal Communications: Gateway to the 21st Century. 2nd International conference on Conference Record, Ottawa, 1993.

[49] W. C. Jakes, Microwave Mobile Communications, 1974.

[50] R. H. Clarke, "A Statistical Theory of Mobile-Radio Reception," Bell Syst. Tech. J., vol. 47, pp. 957-1000, 1968.

[51] J. P. Leite, E. P. Lopes de Almeida, R. G. Alves de Oliveira e M. R. M., "Desenvolvimento de Um Ambiente GIS Dedicado à Caracterização/Medição do Canal RF e à Análise de Desempenho de Sistemas Wireless," Brasília, Julho 2007.

[52] P. A. Tirkas e C. A. Balanis, "Finite-Difference Time-Domain Method for Antenna Radiation," IEEE Transactions on Antennas and Propagation, vol. 40 (3), pp. 334-340, 1992. 
[53] R. P. Picanço, "Desenvolvimento de uma Interface Integrada para o Projeto e Análise de Antenas Utilizando o Método das Diferenças Finitas no Domínio do Tempo (FDTD)," Brasília, 2006.

[54] R. E. Collin, Foundations for Microwave Engineering, Wiley, 2001.

[55] S. Ramo, J. R. Whinnery e T. V. Duzer, Fields and Waves in Communication Eletronics, John Wiley \& Sons, Inc, 1994. 


\section{ANEXOS}

\section{DEFORMAÇÕES NOS DIAGRAMAS DE RADIAÇÃO DAS ANTENAS DEVIDO A OBSTÁCULOS METÁLICOS E NÃO-METÁLICOS}

Os recursos matemáticos de simulação de estruturas embasados na discretização de suas reais dimensões por meio de malhas de trama de tamanho variável permitem obter uma solução completa de todo conjunto instalado em uma torre. $\mathrm{O}$ cálculo é embasado em métodos numéricos, mais precisamente na técnica das diferenças finitas no domínio do tempo, Finite Difference Time Domain - FDTD. O método FDTD tem sido usado na determinação da interação da energia eletromagnética com material biológico, estruturas condutoras e dielétricas. $\mathrm{O}$ algoritmo admite qualquer quantidade de incógnitas, o limite é imposto pela capacidade de processamento do computador que roda o programa de simulação [52-53]. As Figuras 1.1 e 1.2 mostram as torres montadas em estruturas de treliças metálicas. Os sensores de monitoração ambiental e o para-raios coexistem com as antenas de transmissão na mesma plataforma das torres.

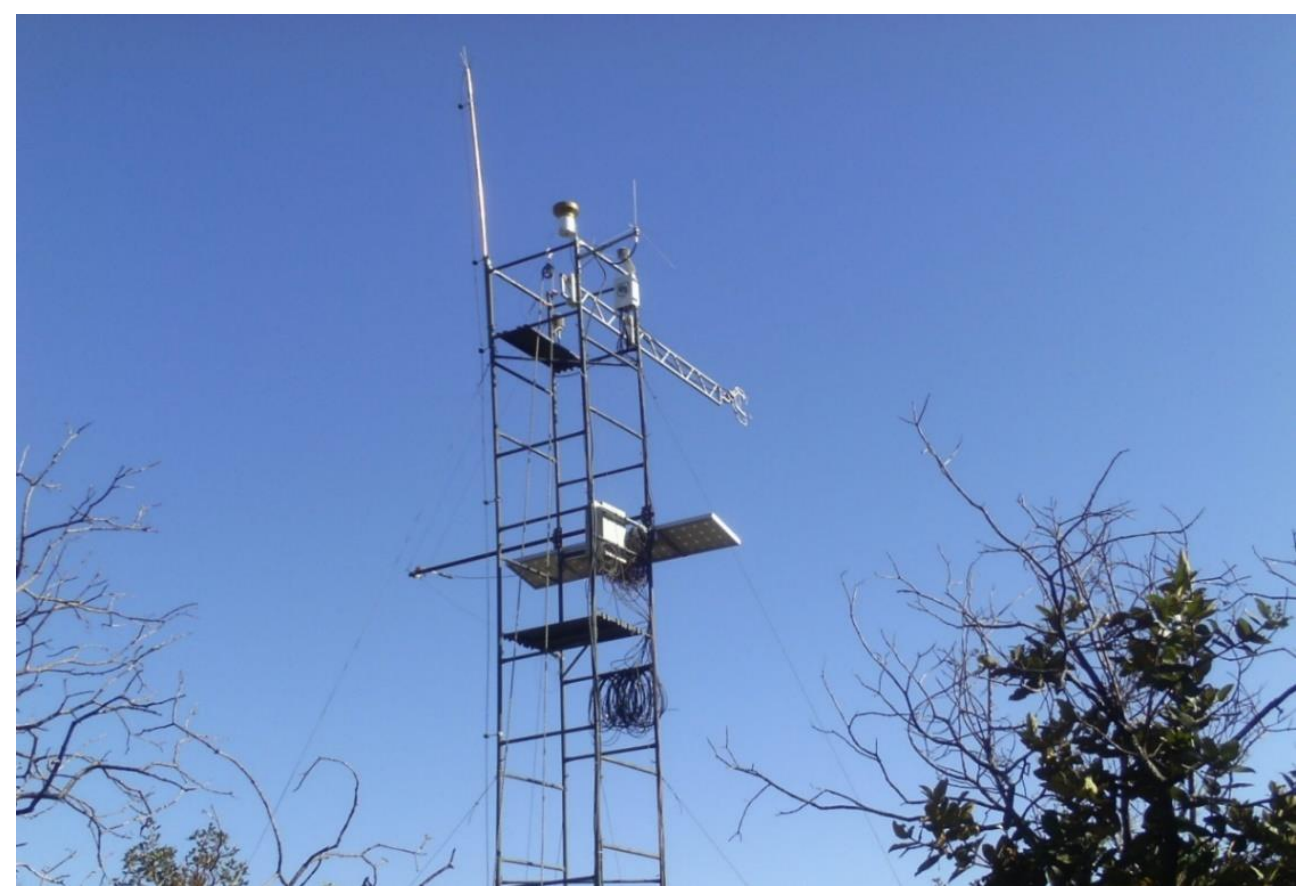

Figura I.1 Torre de 10 metros. No vértice mais a direita está a antena de 144 [MHz].

As torres de Experimentação da Engenharia Mecânica montada na FAL em ambiente de cerrado. As antenas de transmissão compartilham o espaço com os sensores para estudos hidrológicos, climatológicos e 
meteorológicos do cerrado, projeto de pesquisa do Laboratório de Energia e Ambiente do Departamento de Engenharia Mecânica-ENM da UnB.

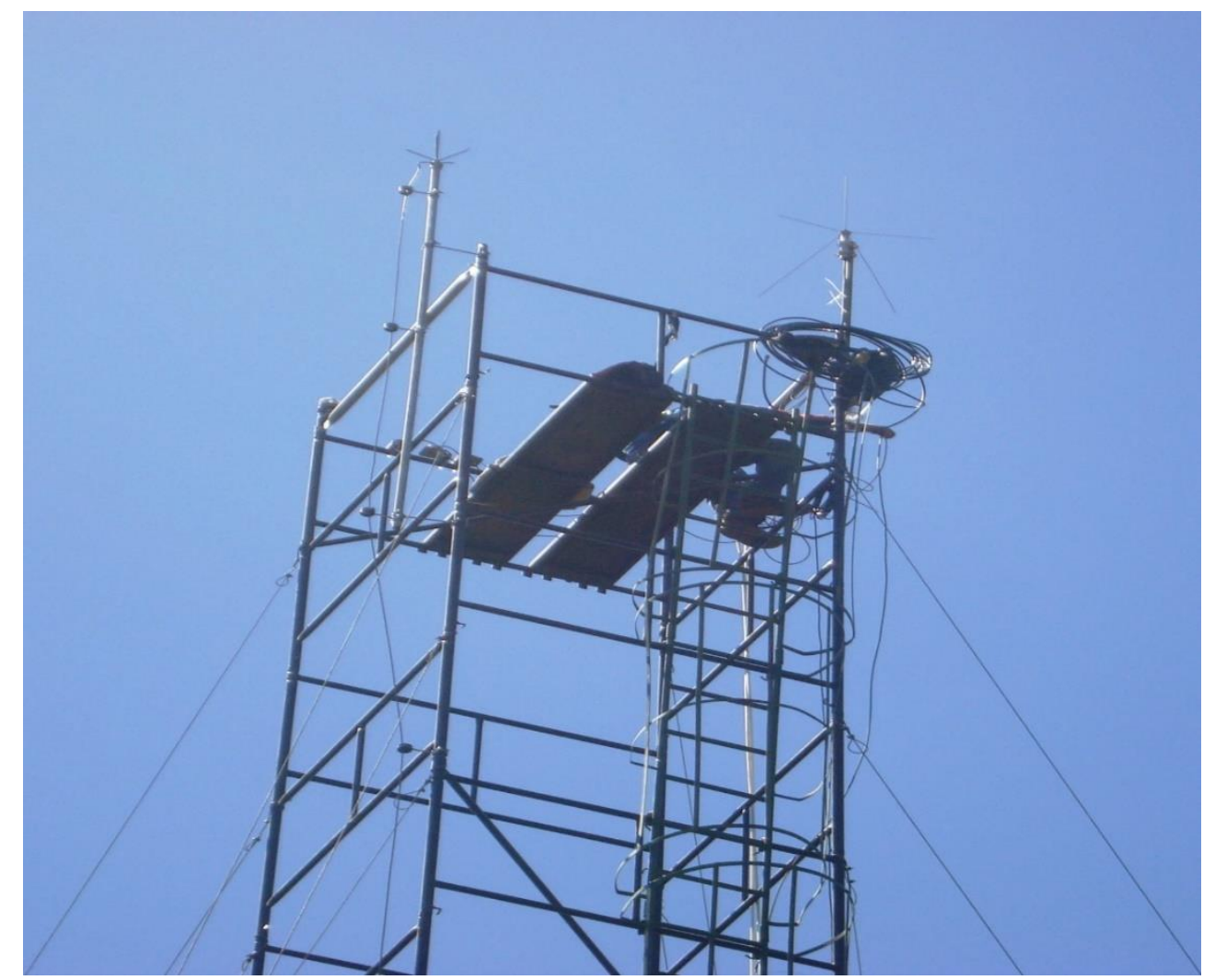

Figura I.2 Topo da torre de 24 metros. No vértice mais a direita está a antena de 144 [MHz].

A influência da estrutura metálica da torre de transmissão acrescida da influência dos obstáculos metálicos e não metálicos coexistentes foram mapeados pelo software desenvolvido no âmbito do Departamento de Engenharia Elétrica da UnB-ENE. De posse das matrizes de valores a serem ajustados, os resultados das campanhas de medidas foram corrigidos de acordo com os diagramas de radiação modificados pelos obstáculos presentes no topo da torre.

A Fig. I.3 mostra a presença de sensores meteorológicos do experimento da ENM coexistente com antena de $435 \mathrm{MHz}$. A Figura I.4 apresenta a representação destes obstáculos, antena e, sobreposto a estes, a malha de discretização do método FDTD. A antena de $435 \mathrm{MHz}$ está em vermelho. Cabe salientar que a antena de $435 \mathrm{MHz}$ sofreu pronunciadas alterações em seus diagramas nos planos horizontal e vertical devido aos obstáculos. A antena de $144 \mathrm{MHz}$ manteve seus diagramas de radiação 
praticamente inalterados na presença dos obstáculos da torre. As Figs. I.5 e I.6 mostram os diagramas no plano horizontal e vertical da antena de 435 $\mathrm{MHz}$ e as variações atuantes nos diagramas. Ao levar em conta no pósprocessamento as ondulações ocorridas nos diagramas de radiação, os resultados das campanhas de medidas ficam mais próximo de uma real instalação de uma estação rádio-base. Digno de nota a relevância do software [52, 53] tendo em vista o usual compartilhamento de infraestrutura de torre entre diferentes operadoras e a presença de obstáculos metálicos e não metálicos afora os sistemas radiantes.

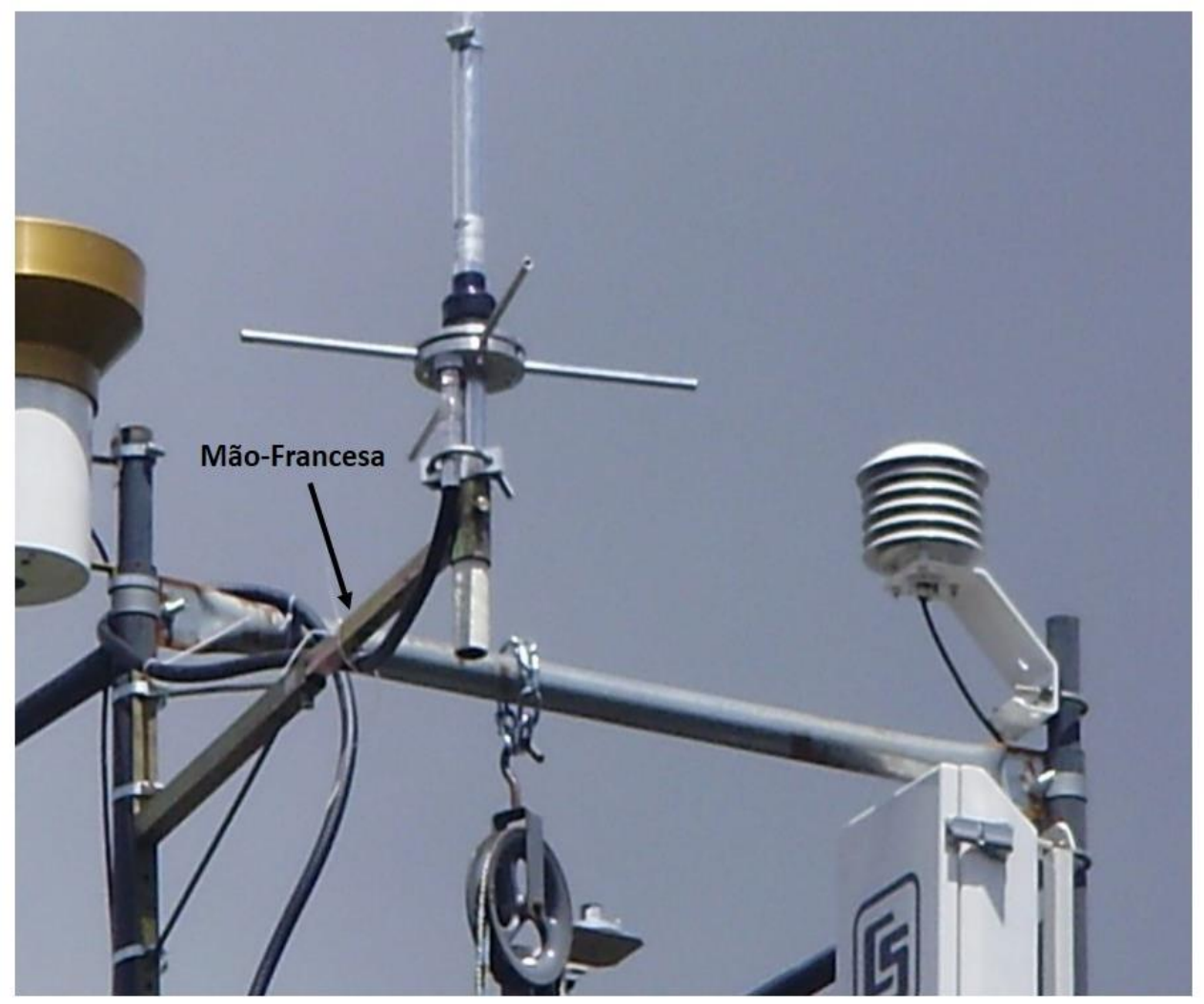

Figura l.3 Antena de $435 \mathrm{MHz}$ presa à torre de 10 [m] por uma estrutura metálica do tipo mãofrancesa ajustável.

A escolha das antenas ARS G3E (395-525 MHz) de $5 / 8 \lambda, \mathrm{G}=5,2 \mathrm{dBi}$ para transmissão em $435 \mathrm{MHz}$ e Aquário $\mathrm{M} 100 \mathrm{~A}$ (134-174 MHz) de $1 / 4 \lambda$, $\mathrm{G}=1,5 \mathrm{dBi}$ para transmissão em $144 \mathrm{MHz}$, A antena $\mathrm{M} 300 \mathrm{C}$ da Aquário de $1 / 4 \lambda$ monopolo que capta o sinal do ambiente presa ao carro por força magnética de um imã permanente preso a sua base. Os cabos de RF são Heliax LDF 4-50A, da Andrew. Os conectores são também da Andrew 
compatível com o cabo coaxial. O cabo coaxial que leva o sinal até o analisador de espectro do drive-test é do tipo RG 58.

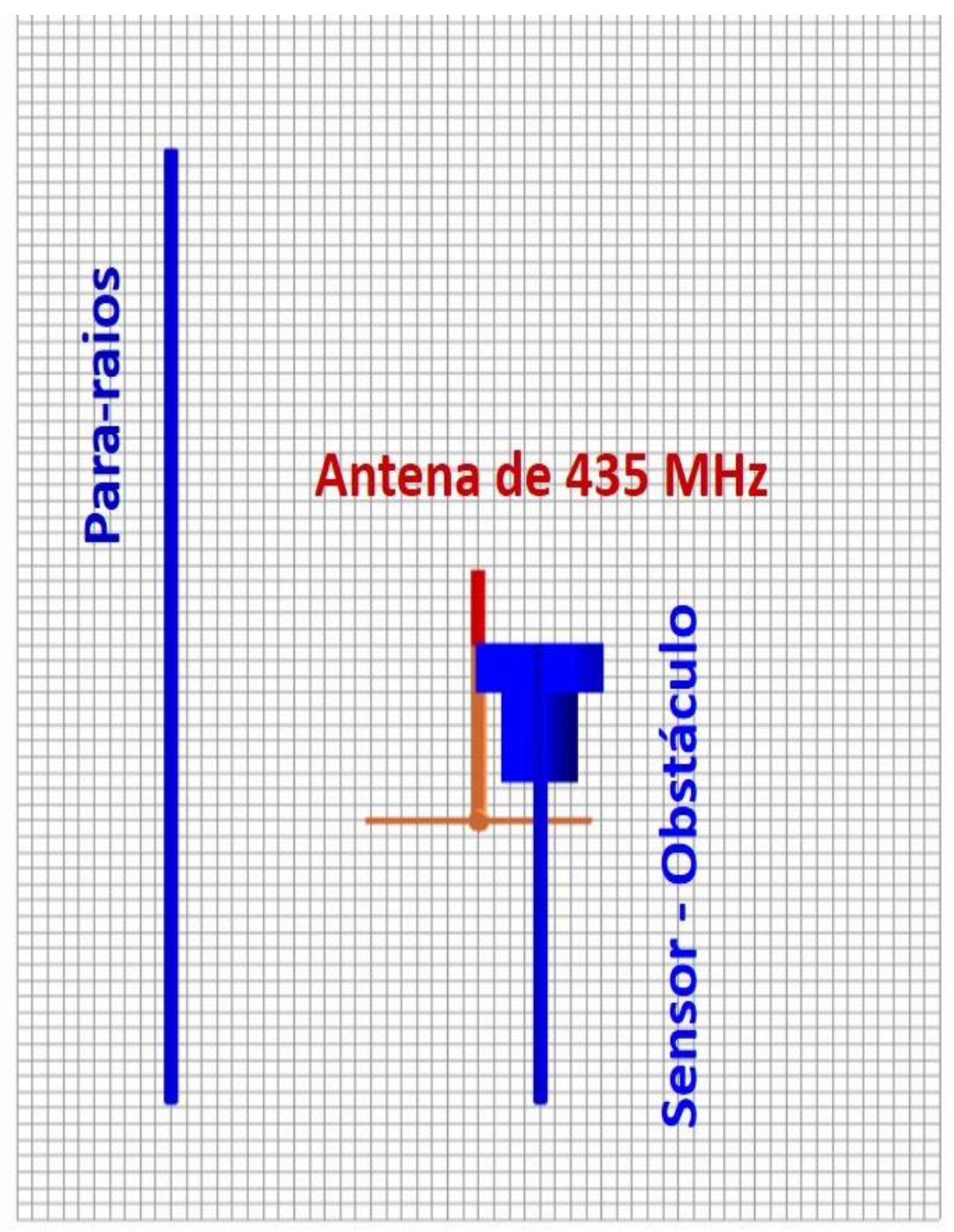

Figura I.4 Disposição da antena de $435 \mathrm{MHz}$ e obstáculos (sensor+haste do para-raios). Saída gráfica do software de simulação [52, 53]. 


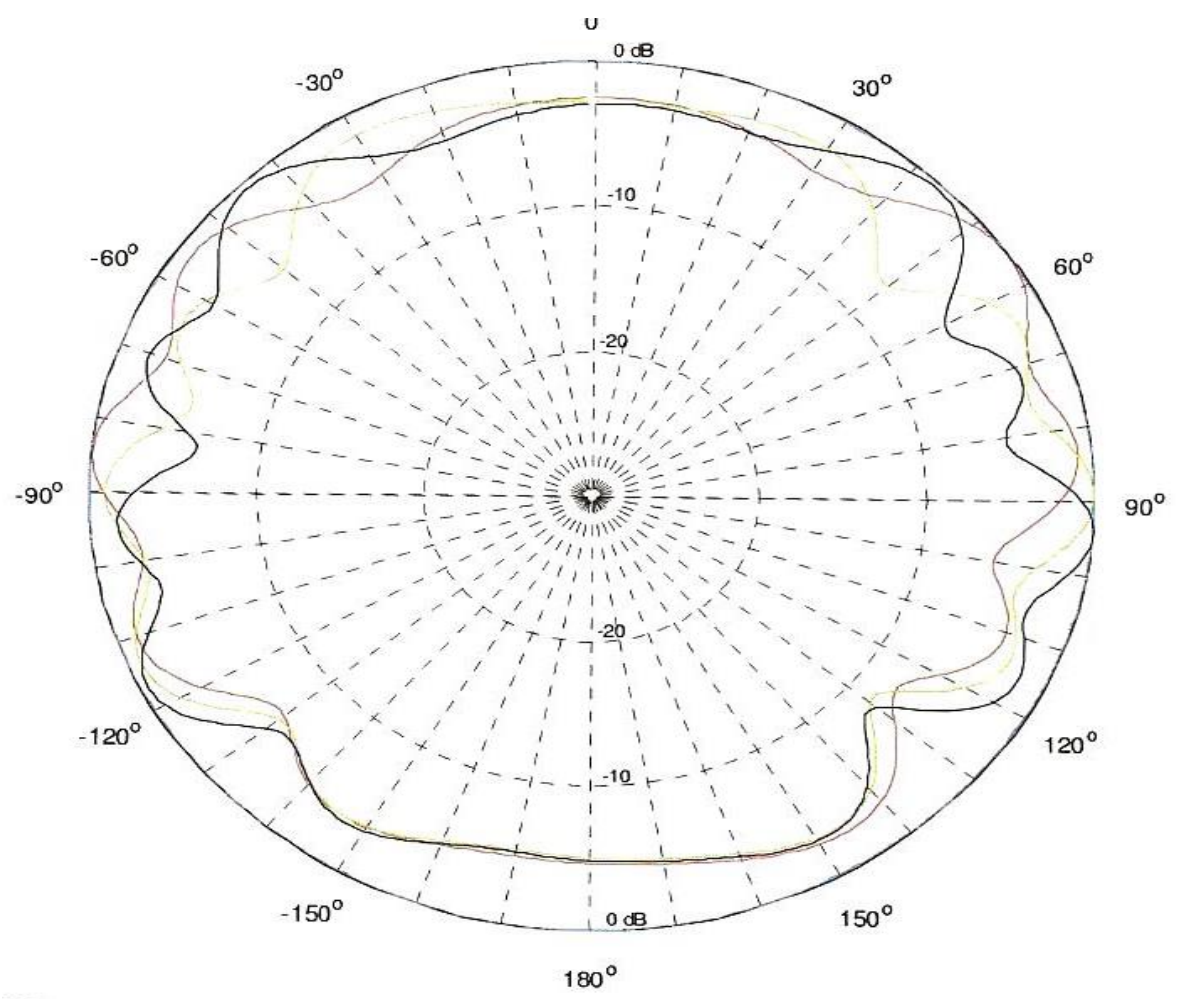

Figura I.6 Saída gráfica do software de simulação. Diagrama polar de radiação plano horizontal [52-53].

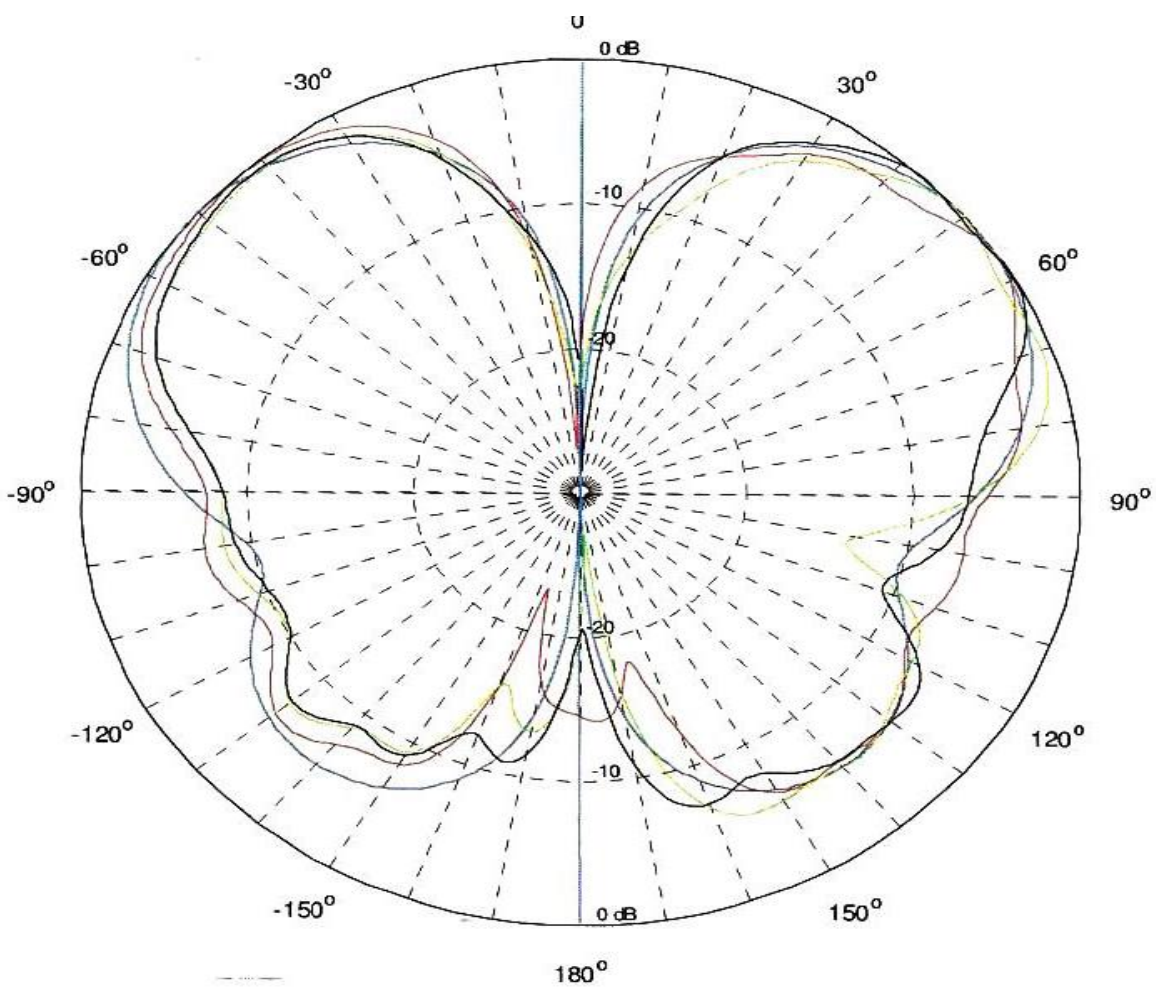

Figura I.5 Saída gráfica do software de simulação. Diagrama polar de radiação plano vertical $[52,53]$ 


\section{ADAPTAÇÃO DE TRANSCEPTOR TIPO PTT PARA FUNCIONAR COMO GERADOR CW SINTONIZÁVEL}

A substituição do PTT original do radio Yaesu por um sistema com chave de acionamento ligado/desligado foi conseguida após constatação experimental de que o simples travamento do mecanismo de acionamento não era suficiente para cancelar a modulação inerente à operação de um rádio deste tipo.

As adaptações realizadas no circuito do rádio PTT constituíram em uma ótima alternativa para converter o transceptor em um transmissor de RF sintonizável com nível de potência de transmissão acima dos convencionais geradores de laboratório. A Fig. II.1 esboça o circuito utilizado no Yaesu FT 7900 R/E.
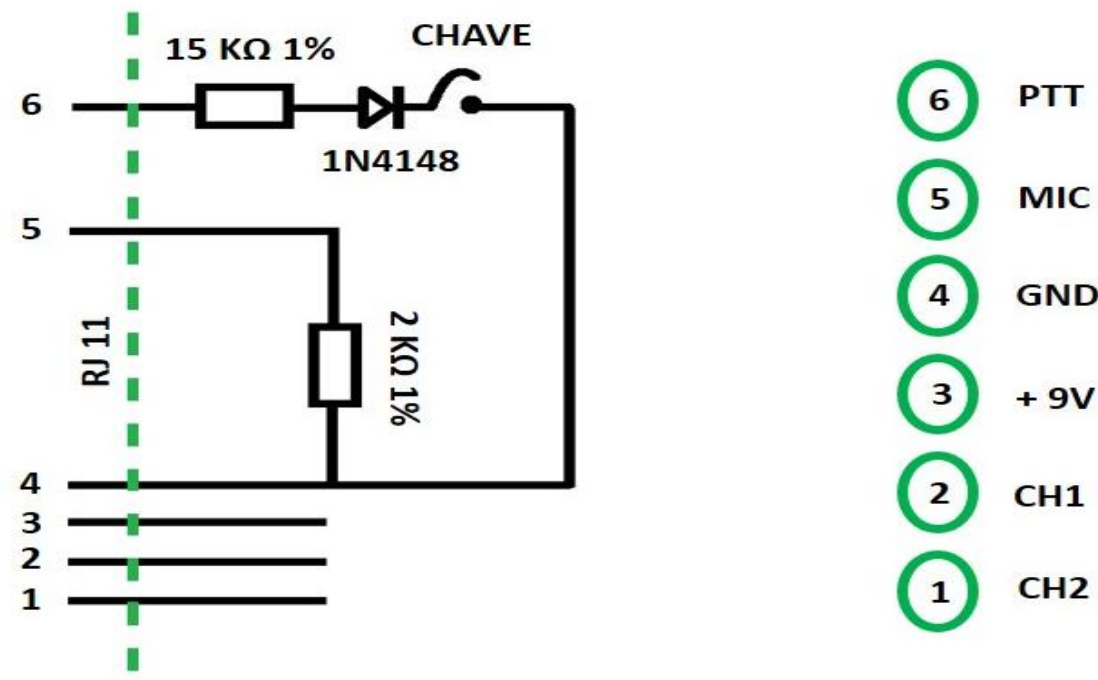

Figura II.1 Esboço do circuito de acionamento para transmissão do modo CW conectado à entrada do PTT do rádio.

\section{EQUALIZAÇÃO DA ENERGIA FORNECIDA PELAS FONTES DE POLARIZAÇÃO DO TRANSCEPTOR}

Observou-se na primeira Campanha de Medidas que decorrido três horas de funcionamento ininterrupto, o rádio deixou de funcionar devido a falta de energia fornecida pelas fontes de polarização. Aleatoriamente uma das fontes desligava por sobreaquecimento. 
Diante disso, realizou-se na bancada a simulação do carregamento das fontes por intermédio de um reostato apropriado fins obter a polarização para o máximo de potência útil na transmissão sem comprometer a operação das fontes. Para isso as fontes de energia primária que alimentam o rádio foram ligadas ao gerador de energia à gasolina, utilizado nas campanhas de medidas no cerrado, visto que este era o pior caso. Para simular a demanda de energia do rádio conectou-se nas fontes um reostato que suportasse até 1,2 Ampères a uma tensão nominal de 14,1 Volts. Sob estas condições obteve-se a máxima transferência de potência para o rádio de forma que as fontes dividiram de forma equânime a demanda de energia de polarização necessária para alimentar o rádio. A Fig. III.1 ilustra a montagem realizada no laboratório com destaque para as fontes e a resistência variável.

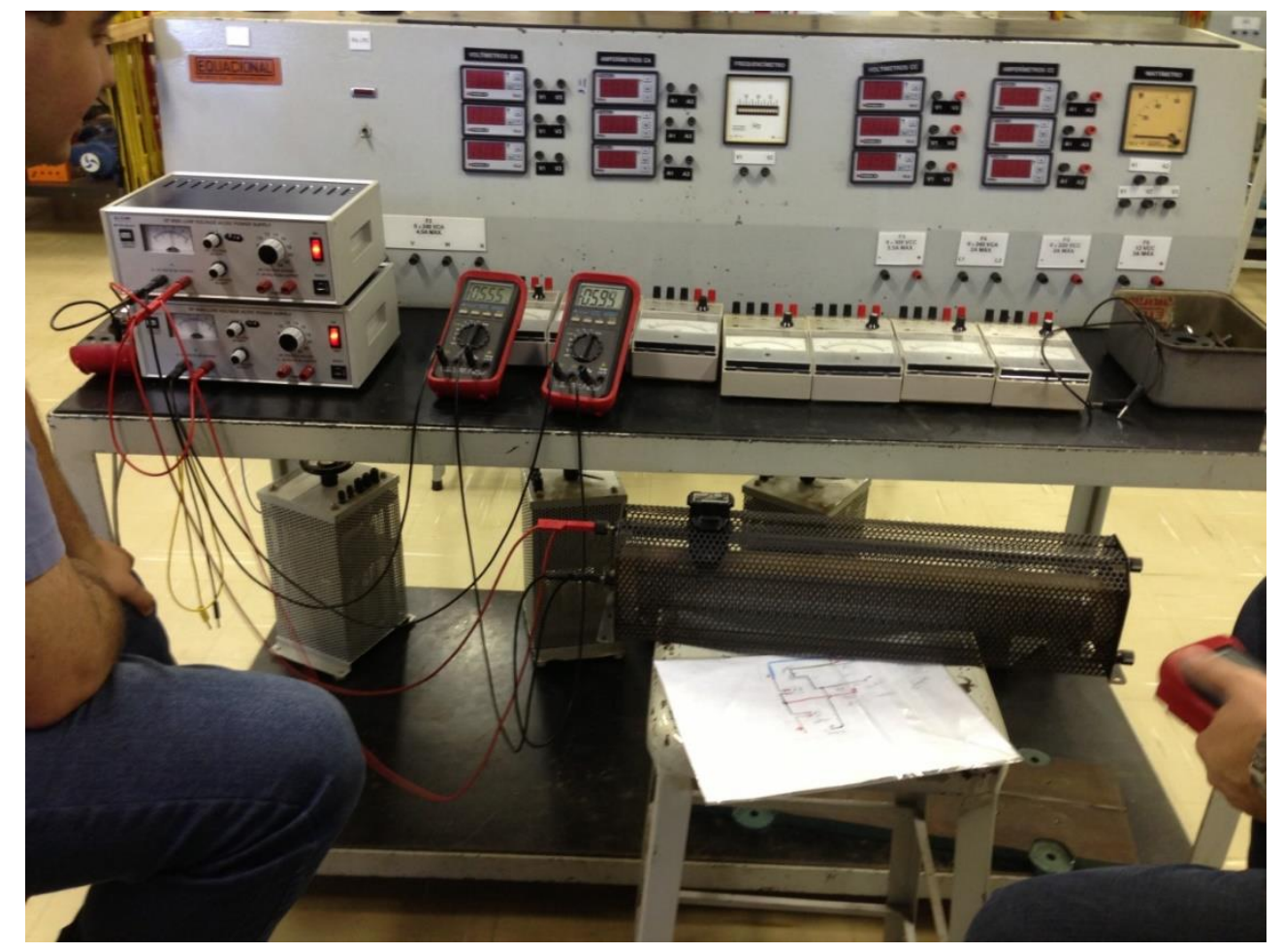

Figura III.1 Ajuste das fontes de polarização do rádio.

\section{DESCRIÇÃO DO DRIVE-TEST E SHELTER DE TRANSMISSÃO}

Os relevantes procedimentos práticos para repetir as campanhas de medidas em outros biomas estão inseridos no corpo do texto. No entanto vale a pena acrescentar outras soluções inovadoras, adequações e adaptações arquitetadas para permitir a obtenção dos resultados experimentais. $O$ viés prático do estudo contempla soluções de baixo custo 
para viabilizar a realização de campanhas de medidas em ambientes desprovidos de infraestrutura; útil para modelar outros biomas.

A descrição das montagens nos veículos pode ser sintetizada no seguinte: o carro colocado ao pé da torre com função de abrigar o transmissor foi preparado com a seguinte equipagem interna: além do rádio Yaesu FT $7900 \mathrm{R}$, fontes de energia CC estabilizadas, ventiladores para circulação; equipagem externa próximo ao carro: gerador a gasolina, analisador de estação rádio base. Utilizou-se um rádio transceptor do tipo PTT VHF/UHF DUAL-BAND, potência de 50 Watts na faixa que se estende de 144 a $146 \mathrm{MHz}$ e com potência de 45 Watts, na faixa que se estende de 430 a $440 \mathrm{MHz}$.

A escolha de um rádio PTT adaptado para funcionar como transmissor de uma rádio-base deve-se ao fato da dificuldade laboratorial em encontrar um gerador de RF que alcance patamares de potência de RF acima de $28 \mathrm{dBm}=0,1 \mathrm{Watt}$, sem incorrer em amplificadores de alto custo e, que por sua vez, injetem distorções harmônicas no sistema radiante. As antenas foram escolhidas buscando as que melhor se aproximassem de um diagrama de radiação isotrópico nas bandas de interesse. $\mathrm{O}$ cabo de RF escolhido foi o Heliax LDF 50A da Andrew com perda menor que 0,03 $\mathrm{dB} /$ metro com conectorização Andrew L4PS. O conjunto cabo e conectores apresentam perdas de inserção menor que os típicos conjuntos usados pelas operadoras de telefonia móvel porque trata-se de um cabo de alta performance para uso primordial em testes de conceito e homologação de sistemas de comunicações móveis.

O conjunto suportou muito bem as ondulações do leito da estrada despavimentada no interior do cerrado. As antenas de transmissão encontradas no mercado com melhor relação custo-desempenho foram: $M$

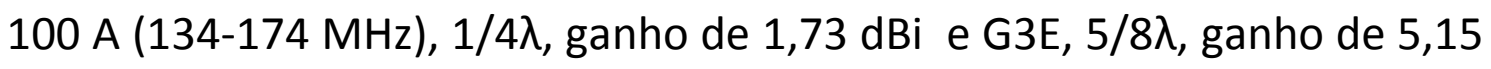
dBi. As fontes da marca Pasco Scientific, modelo SF 9584-AC/DC Power Supply fornecem a tensão de 14 Volts contínuos e a corrente de 8,5 Ampères continua necessárias à polarização do rádio. A climatização do rádio no interior do veículo foi homogeneizada por meio de ventilação alimentada pelo gerador a gasolina Toyama modelo TG/TF 1200 CX. O 
gerador cumpriu o papel de aliviar o consumo de energia da bateria do carro que acondiciona todo sistema de transmissão.

O carro estacionado ao pé da torre com rádio, fontes, ventiladores e armações metálicas reticuladas, para facilitar a circulação de ar, foi mantido em funcionamento com o ar-condicionado de bordo ligado no ponto de operação de máximo resfriamento no intuito de evitar a excursão do sinal transmitido com a temperatura interna do veículo. $O$ vidro lateral esquerdo do carro foi suspenso até atingir a capa de isolamento do cabo de RF e o vidro lateral direito foi suspenso até atingir a capa de isolamento dos fios que alimentam a régua de energia colocada no assoalho do carro. Após certificação do funcionamento do rádio, as frestas entre cabos e os vidros laterais do carro foram lacrados com fitas adesivas para mitigar a perda de ar frio interno com ambiente externo. $O$ para-brisa externo foi coberto com placas de papelão presas por fita adesiva e em algumas ocasiões com tecido isolante de sisal fins manter a temperatura no interior do carro constante entorno de $18^{\circ} \mathrm{C}$.

A Fig. IV.1 apresenta um esboço esquematizado do veículo que fica estacionado ao pé da torre abrigando o rádio, a eletrônica associada ao rádio e os acessórios de transmissão. A Fig IV.2 destaca os equipamentos e acessórios colocados no interior do veículo adaptado a funcionar como compartimento e abrigo do rádio transmissor. Destacando alimentação de energia primária fornecida pelo gerador via vidro lateral do passageiro e o cabo de RF que vai até a torre passando pelo vidro lateral da cabine do motorista.

A Fig. IV.2 esboça o material utilizado no interior do carro que funciona com abrigo do transmissor: fontes, rádio, ventilação, tomada de energia, armações para circulação do ar frio, circuito de acionamento do rádio em modo $\mathrm{CW}$. O ar-condicionado do carro é ajustado para prover resfriamento no ponto máximo. 

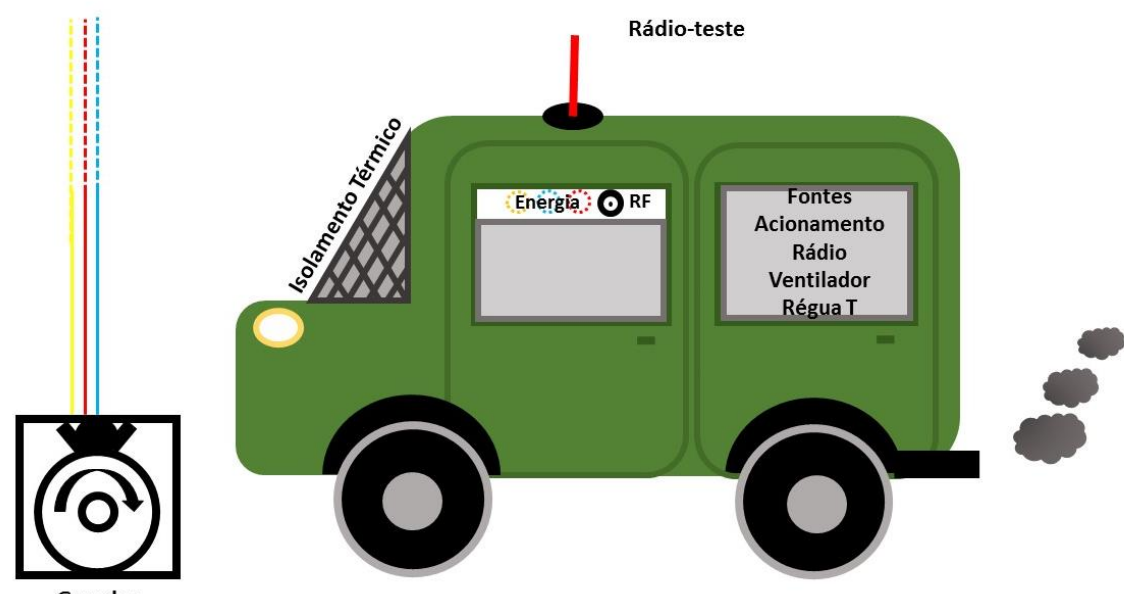

Figura IV.1 Esboço do veículo usado nas campanhas de medidas como shelter do transmissor

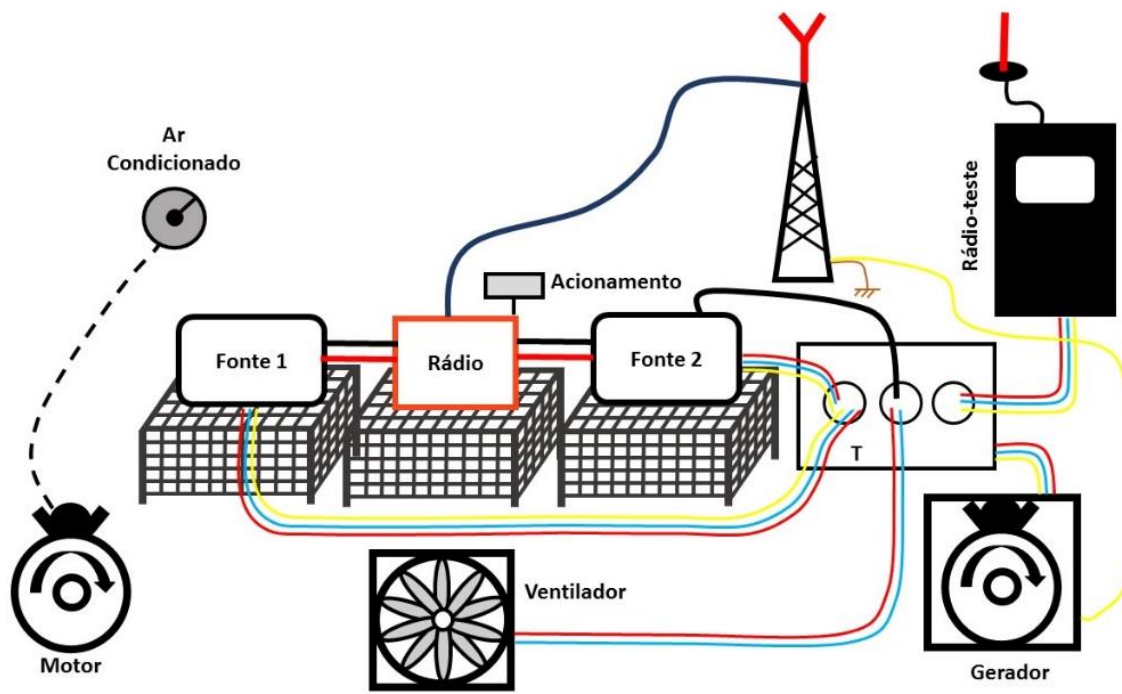

Figura IV.2 Equipamentos colocados no interior do veículo shelter estacionado ao pé da antena

Há ainda a ventilação forçada fornecida por um ventilador colocado no banco traseiro. $\mathrm{O}$ enlace torre-rádio é conectado via um cabo de RF que passa pelo vidro dianteiro da porta do motorista (o vidro fica entreaberto para evitar perda no fluxo de ventilação). A alimentação primária de energia (fase, neutro e terra) proveniente do gerador à gasolina chega até a régua de energia pelo vidro do passageiro dianteiro. 
Os dados das campanhas de medidas foram captados por um veículo que opera como drive-test, especialmente preparado para acomodar os seguintes equipamentos: analisador de espectro Agilent E4402B, notebook HP Pavilion ZE 5400, cabo USB/GPIB 82357B para interfacear a entrega dos dados brutos de medidas do analisador de espectro para o notebook, antena externa para captação do sinal transmitido $\mathrm{M} 300 \mathrm{C}(131-900 \mathrm{MHz})$, $1 / 4 \lambda$, com característica de radiação quase-isotrópica, pequeno ganho de $1,5 \mathrm{dBi}$, base magnética aderente ao teto do veículo do drive-test, GPS portátil Garmin 76 CS, antena externa do GPS GA 25 MCX e inversor de energia DC para AC de 600 KVA.

O programa previamente prepara o analisador de espectro nos parâmetros RBW (banda de resolução espectral), RF Reference Level (nível de referência), span (tempo de varredura)-neste caso é ajustado a zero conforme estipula o manual do analisador para medir a envoltória do sinal recebido, funcionando similar a um osciloscópio.

Após estes ajustes o programa GPSpectrum [51] providencia o desligamento dos subsistemas de visualização e das interfaces de saída desnecessárias à campanha de medidas. Com isso a energia do inversor conectado na bateria do carro para o drive-test fica concentrada em alimentar os sistemas essenciais do analisador e o laptop, sem sobrecarregar o funcionamento da parte elétrica do automóvel. O GPS é alimentado com 2 baterias AA de 1,5 volts.

A Fig. IV.3 apresenta um esboço esquematizado dos equipamentos embarcados no veículo drive-test. O set-up de medidas e as respectivas conexões são mostradas com destaque para o analisador de espectro, cabo GPIB, cabo do GPS ligados ao laptop. Os equipamentos são colocados no banco traseiro do veículo. 


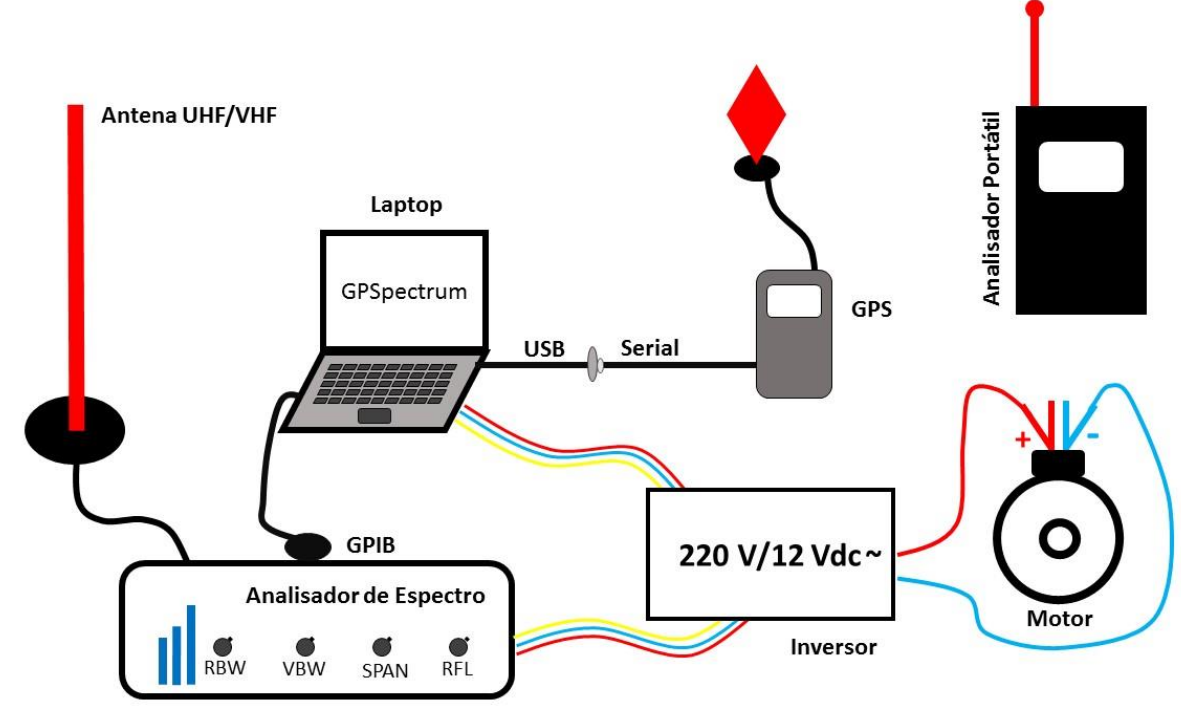

Figura IV.3 Desenho esquemático dos set-up de medidas.

\section{FERRAMENTAS COMPUTACIONAIS}

Programas em Matlab

1- Aplicação: Desvanecimento de larga escala enfocando a avaliação da estatística do Sombreamento. Comparação dos resultados do sombreamento entre arquivos distintos.

Tela:

load('SetembroSeco1.mat');

$[f, x]=$ ksdensity(sombreamento,'function','pdf');

pdf_gaussiana = pdf('Normal', $x$,media,sqrt(variancia));

plot $(x, f, ' g ')$

hold on

plot(x,pdf_gaussiana,'g--')

Entradas:

Arquivo de dados das campanhas de medidas processados pelo CoP.

Saídas:

Distribuições teóricas confrontadas com distribuições experimentais. 


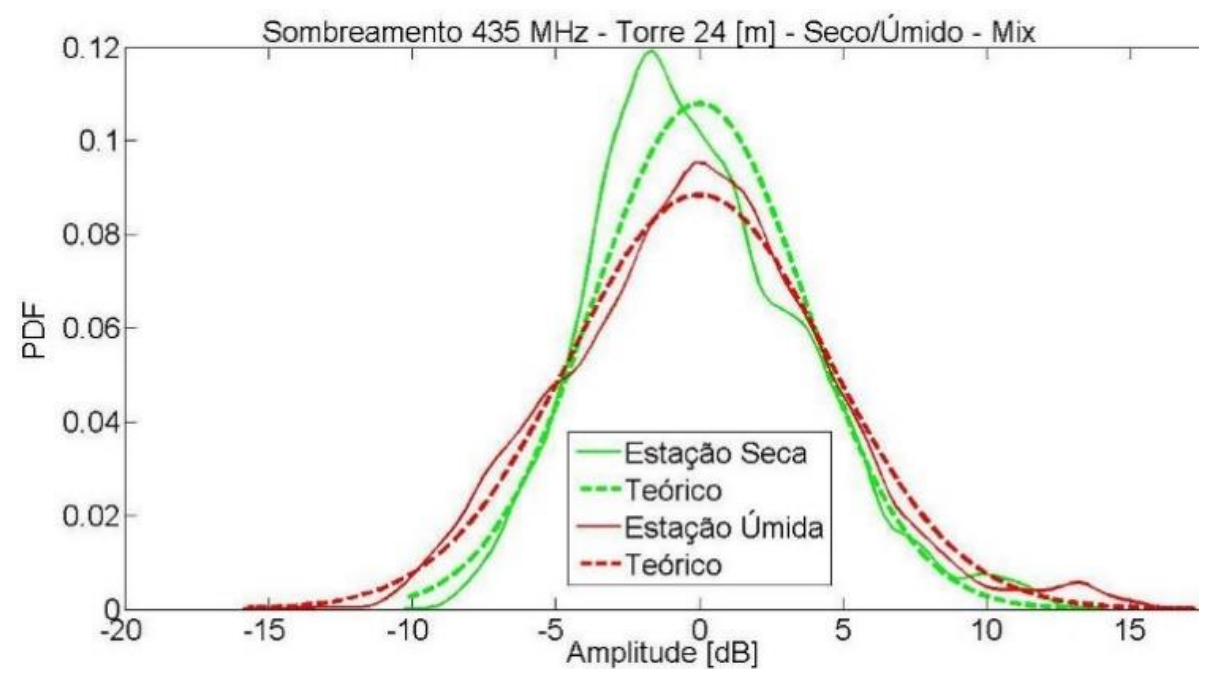

Figura V.1 Sombreamento teórico $x$ experimental.

\section{Descrição:}

Os arquivos oriundos dos programas que traçam a reta de regressão dos pontos experimentais (modelo Lei de Potência) são carregados no que diz respeito ao sombreamento. Histogramas teórico e experimental para fins e efeito de comparação e determinação das regiões divergentes entre modelo e predição. O programa tem como opção plotar o sombreamento em função da distância de forma a facilitar a identificação da região em que se encontram as barreiras geomorfológicas que acentuam 0 sombreamento. A localização das barreiras na geomorfologia do ambiente de medidas é obtida mediante solicitação da plotagem indicativa da distância a ser traçada no mapa georreferênciado que abrange o percurso.

2-Aplicação: Pareamento da Reta de Regressão com modelos de propagação consagrados, versão 1 .

Tela:

importfile_ex('C:|MAgio|Giovanni\Fazenda12outr.meas');

load('C:|Program Files\MATLAB\Giovanni|Ganho_Antena_Fazenda12outr.mat');

distancia = data(:,2);

potencia $=$ data $(:, 4)$;

peq_escala=data(:,5);

vpequena_escala $=0.22361 * 10 . \wedge$ (peq_escala./20);

perda $=(47+1.5+1.73)-$ potencia + Ganho_Compensado;

\section{Entradas:}

Arquivo de medidas após a dupla filtragem realizada no CoP e o arquivo com os diagramas das antenas de transmissão corrigidos em termos de ganho considerando o ambiente de obstáculos geográficos em azimute, em 
elevação e obstáculos metálicos e não metálicos presentes nas torres de transmissão.

\section{Saídas:}

Valores numéricos dos parâmetros do modelo Lei de Potência e histogramas dos desvanecimentos, Fig. 5.2.

\section{Descrição:}

Os arquivos são separados em valores de potência média, distância. 0 programa aplica a técnica dos mínimos quadrados para chegar à melhor reta que se ajusta à nuvem de pontos amostrais.

3-Aplicação: Pareamento da Reta de Regressão com modelos de propagação consagrados, versão 2 - acrescido da determinação do desvio padrão entre retas: regressão linear da nuvem de pontos experimentais e modelos consagrados que melhor se ajustaram à reta de regressão.

\section{Tela:}

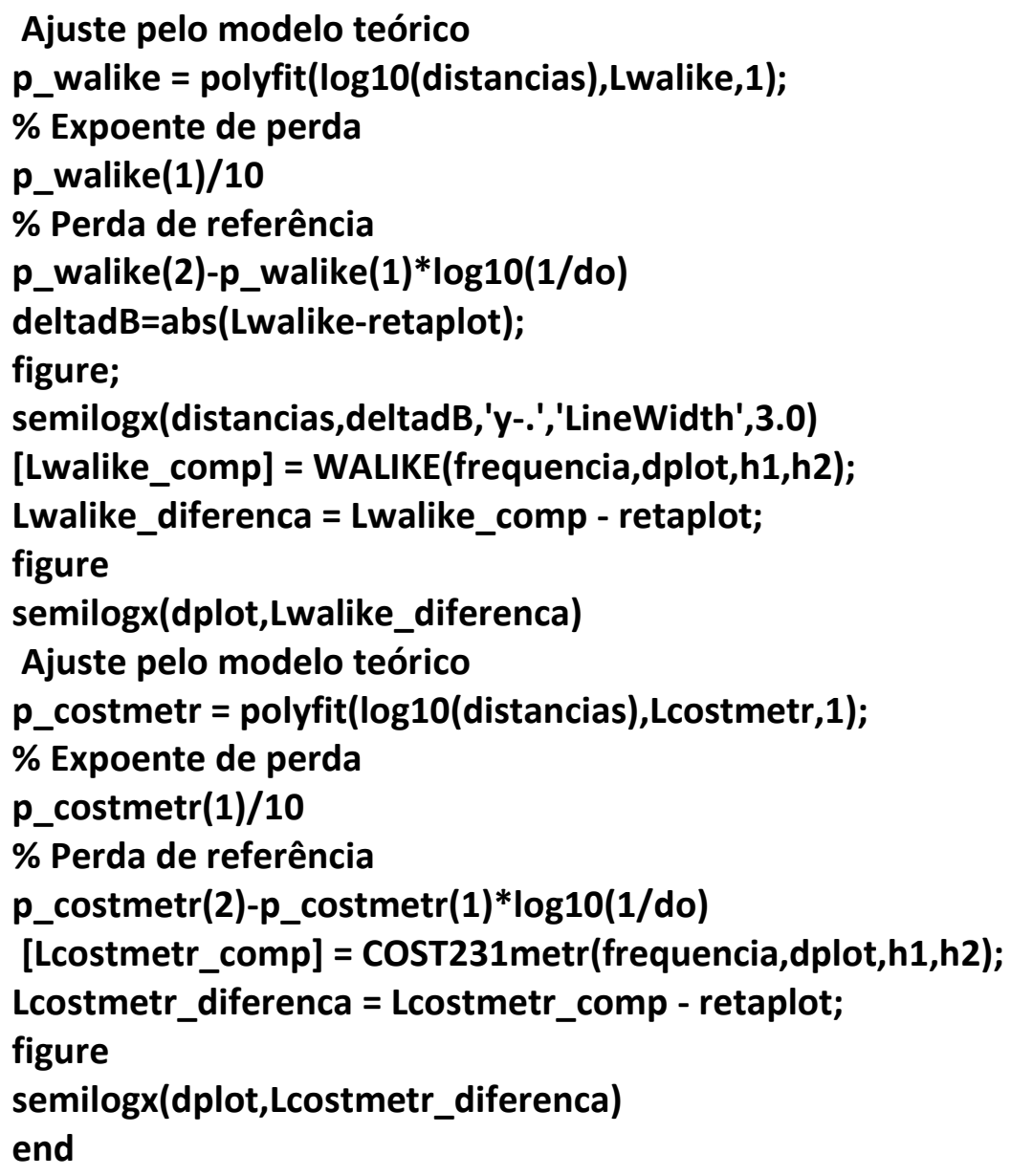




\section{Saídas:}

Similar a versão 1, acrescidas de retas ilustrando o módulo da diferença entre os modelos consagrados selecionados e a reta de regressão e valor numérico do desvio padrão.

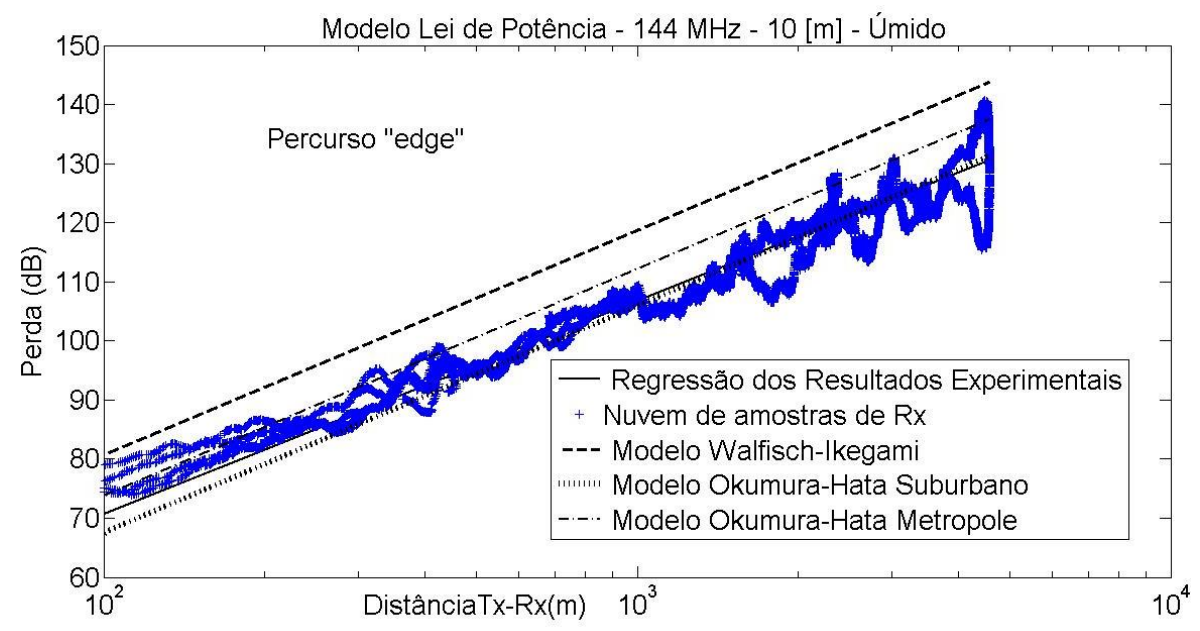

Figura V.2 Saída do programa Matlab aplicação 3.

4-Aplicação: Pareamento da Reta de Regressão com modelos de propagação consagrados, versão 3 - os modelos consagrados são parametrizados em função de altura efetiva das torres de transmissão.

Tela:

\% comparação com o modelo COST-231

frequencia = 144.00e6;

distancias $=$ dplot;

h1 = 24;

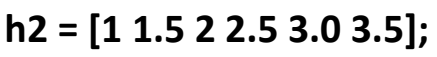

$\%$ texto_legenda $\{2\}=$ 'medidas';

$\mathrm{cc}=\mathrm{hsv}($ length $(\mathrm{h} 2))$;

for ii = 1:length(h2)

[Lcostitu] = COST231itu(frequencia,distancias,h1,h2(ii));

semilogx(distancias,Lcostitu,'color',cc(ii,:),'LineWidth',1.5)

texto_legenda $\{i i+1\}=$ [num2str(h2(ii)) ' $m$ '];

[Lwalike] = WALIKE(frequencia,distancias,h1,h2);

semilogx(distancias, Lwalike, 'y','LineWidth',2.5)

[Lcostmetr] = COST231metr(frequencia, distancias,h1,h2);

semilogx(distancias,Lcostmetr,' 'g','LineWidth',1.5)

[Lcostopen] = COST231open(frequencia,distancias, h1,h2);

semilogx (distancias, Lcostopen, 'g-.','LineWidth',1.5)

[Lcostsub] = COST231sub(frequencia, distancias, h1,h2);

semilogx(distancias,Lcostsub, 'g:', 'LineWidth',5.0)

[Lcostmc] = COST231 mc(frequencia,distancias,h1,h2); 
semilogx(distancias,Lcostmc, 'g--','LineWidth',4.0)

$\%$ OUTROS MODELOS VALIDOS...

[Lsiwak]=SIWAK(frequencia,distancias,h1,h2);

semilogx(distancias,Lsiwak, 'K-.','LineWidth',2.0)

\%comparação com o modelo IBRAHIM-PARSONS EMPÍRICO

[Lparsons]=PARSONS2(frequencia,distancias,h1,h2);

semilogx(distancias,Lparsons, 'k','LineWidth',3)

[Likegami]=IKEGAMI(frequencia,distancias,h1,h2);

semilogx(distancias,Likegami, 'g','LineWidth',5.0)

\% comparação com o modelo IBRAHIM-PARSONS SEMI-EMPÍRICO

[Librahim]=IBRAHIM2(frequencia,distancias,h1,h2);

semilogx(distancias,Librahim, 'm','LineWidth',2)

comparação com o modelo EGLI

[Legli]=EGLI(frequencia,distancias,h1,h2);

semilogx(distancias,Legli, 'c','LineWidth',2.5)

end

Saídas:

Similar à versão 1 acrescida da plotagem de retas parametrizadas conforme os valores de altura efetiva carregadas no programa.

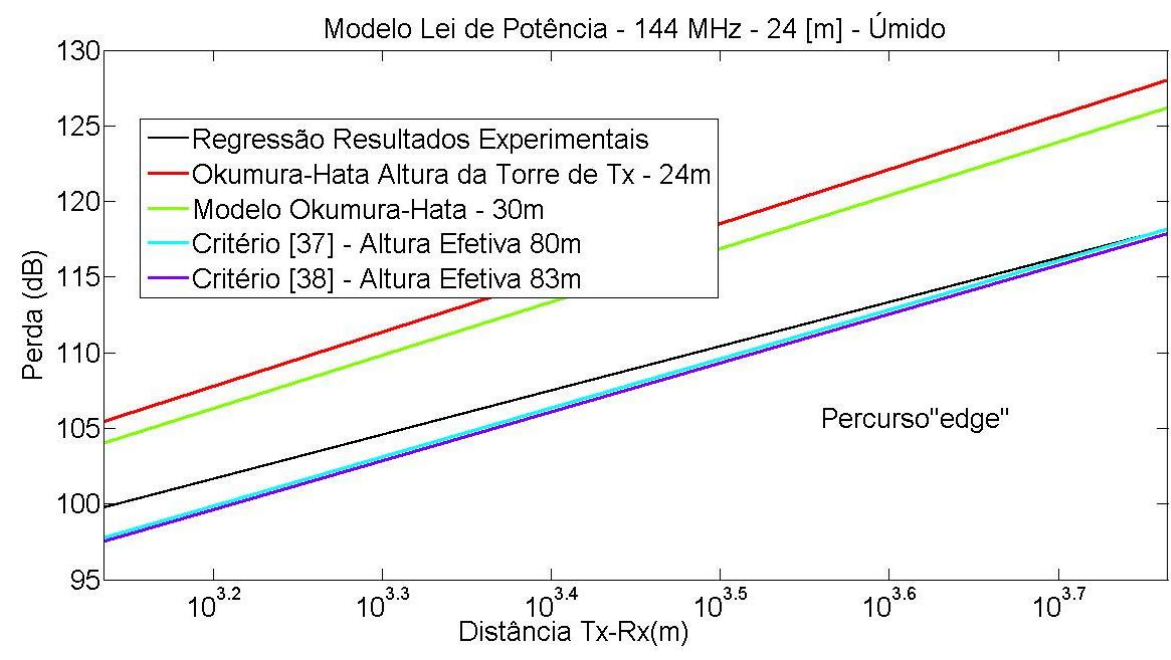

Figura V.3 Saída do programa Matlab aplicação 4.

5-Aplicação: Verificação teórica dos resultados experimentais baseado no modelo semi-empírico de Saunders + Bonar + Ikegami.

Tela:

function $[S]=S \_S a u n d e r s 2(t, n)$

$\mathrm{Sn}=\operatorname{zeros}(1, \mathrm{n}+1)$;

$\operatorname{Sn}(1)=1$;

for $i i=2:(n+1)$

$\mathrm{jj}=1:(\mathrm{ii}-1)$; 
$\operatorname{Sn}(i i)=1 /(i i-1) * \operatorname{sum}\left(\operatorname{Sn}(j \mathrm{j}) .{ }^{*} \mathrm{~F} 2\right.$ jt $\left.(-\mathrm{t} * \operatorname{sqrt}((\mathrm{ii}-1)-(\mathrm{jj}-1)))\right)$;

end

$S=\operatorname{Sn}($ end);

\section{Entradas:}

Ângulo rasante ao estrato superior da sequência de blocos de floresta e quantidade de blocos de floresta correspondente à porção do link em que o sinal encontra-se propagando por entre galhos, ramos, gravetos e copas.

\section{Saídas:}

Curvas de perdas em função do ângulo rasante e resultado numérico da perda, Tabela 6.1 .

\section{Descrição:}

O ângulo rasante é obtido do perfil altimétrico detalhado em escala milimétrica da radial de interesse. De posse do perfil altimétrico, tamanho do link e modelo de bloco de floresta chega-se ao número de blocos que estão interpostos entre a estação rádio base e o drive-test. Para isso devese traçar a linha de visada entre torre de transmissão e o ponto da radial em que se encontra o drive-test.

6-Aplicação: Recuperação e Recomposição de arquivos ou parcelas de arquivos de medidas que foram corrompidos por falha na recepção do sinal de GPS ou queda do sinal de transmissão.

Tela:

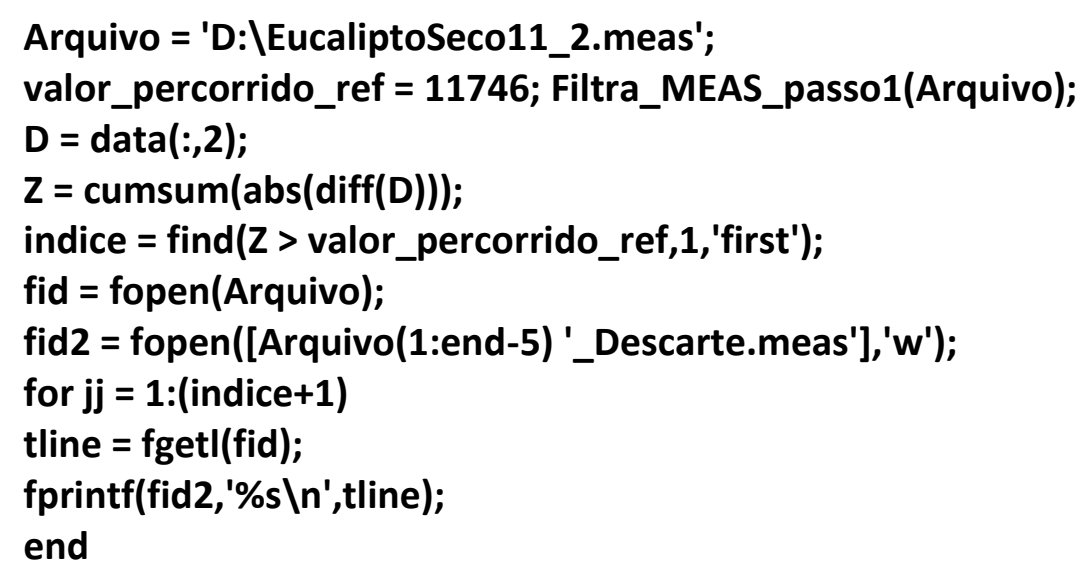

\section{Entradas:}

Arquivo de medidas bruto com falhas nas etiquetas georreferênciadas ou com sinal de recepção a patamares abaixo do limiar de ruído.

\section{Saídas:}


Arquivo bruto restaurado e pronto para a etapa de processamento pelo CoP, Fig. 3.7.

\section{Descrição:}

Primeiramente descartam-se as linhas do arquivo bruto de medidas corrompidas e degradadas. Em seguida, particiona-se o arquivo editado em subarquivos menores. Os subarquivos são enfileirados respeitando o sequenciamento das coordenadas geográficas. Por fim o arquivo completo (reagrupado e restaurado) é processado.

7-Aplicação: Apresentação gráfica da simulação TLM-SC-3D.

TELA:

close all

Campo = 9999 - Plan1;

$h=$ fspecial('gaussian', size(Campo), 1.0);

$\mathrm{g}=$ imfilter(Campo, h);

$\mathrm{J}=$ imagesc(g);

axis equal

colorbar('YTickLabel',...

$\{'-100 \mathrm{dBm}$ ','-90 dBm','-80 dBm',,...

'-70 dBm','-60 dBm','--50 dBm',,...

'-40 dBm','-30 dBm','-20 dBm'\})

end

\section{Entradas:}

Matriz de valores de atenuação conforme simulação TLM-SC-3D.

\section{Saídas:}

Visualização do resultado da simulação explicitado por um diagrama de cores com níveis de intensidade do sinal desbloqueado, associando um código de cores graduado de vermelho (maior magnitude) a azul (menor magnitude, maior bloqueio), Fig. 6.3.

\section{Descrição:}

O arquivo resultante da simulação é convertido em uma planilha Excel. 0 Matlab importa o sinal da pasta Excel e configura o resultado em termos de cores conforme a magnitude do sinal desbloqueado.

8-Aplicação: $C D F$ e Probability Plot que caracteriza o desvanecimento pequena escala em ambiente Rice.

\section{Tela:}

sigma $=0.139625$;

$s=0.19474$ 


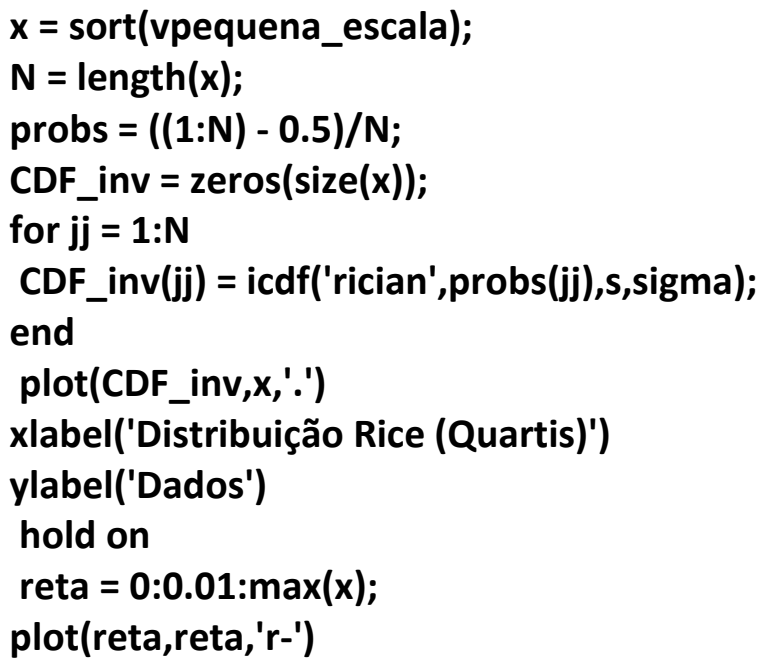

\section{Entradas:}

Coluna de valores do desvanecimento em pequena escala ou segmento do arquivo de medidas processado pelo CoP correspondente à última coluna da esquerda para direita da tela de resultados do CoP (desvanecimento de pequena escala em volts).

Parâmetros do statistics tool box, PDF Rice: $\sigma$ e s.

\section{Saídas:}

Plotagem das estatísticas, Probability Plot e $C D F$, referentes ao ambiente de multipercursos modelado pela função distribuição de Rice, Fig 5.7.

\section{Descrição:}

O Matlab não compatibiliza de forma automática a CDF e o Probability Plot do ambiente Rice com os resultados experimentais. O programa faz esta tarefa após algumas iterações. Ao editar a PDF de Rice aplicada aos resultados experimentais do desvanecimento de pequena escala, extraí-se os valores correspondentes aos parâmetros $\sigma$ e s. Estes valores são transcritos para dentro do programa de forma a normatizar a curva de Rice.

9-Aplicação: Correção da VSWR da antena omnidirecional do drive-test.

\section{Tela:}

clear all

close all

arquivo = 'C: \MAgio $\mid$ Giovanni $\mid$ Volta1_435MHz.txt';

SomaPotenciadB = 6;

newData1 = importdata(arquivo);

vars = fieldnames(newData1);

for ii $=1$ :length (vars)

assignin('base', vars $\{i i\}$, newData1.(vars $\{i i\}))$;

end 


\section{Entradas:}

Arquivo de medidas bruto

\section{Saídas:}

Arquivo de medidas bruto corrigido por um fator de potência devido ao desacoplamento em termos de VSWR, Fig. 3.7.

\section{Descrição:}

Em campanhas de medidas com transmissão de sinal em frequência distinta da sintonia física da antena omnidirecional do drive-test faz se necessário que os resultados experimentais sejam corrigidos para eliminar a desadaptação entre a transmissão e recepção.

10-Aplicação: Obtenção da melhor reta de regressão que atenda as distintas campanhas de medidas no mesmo percurso e na mesma estação ou que atenda aos arquivos restaurados.

\section{Tela:}

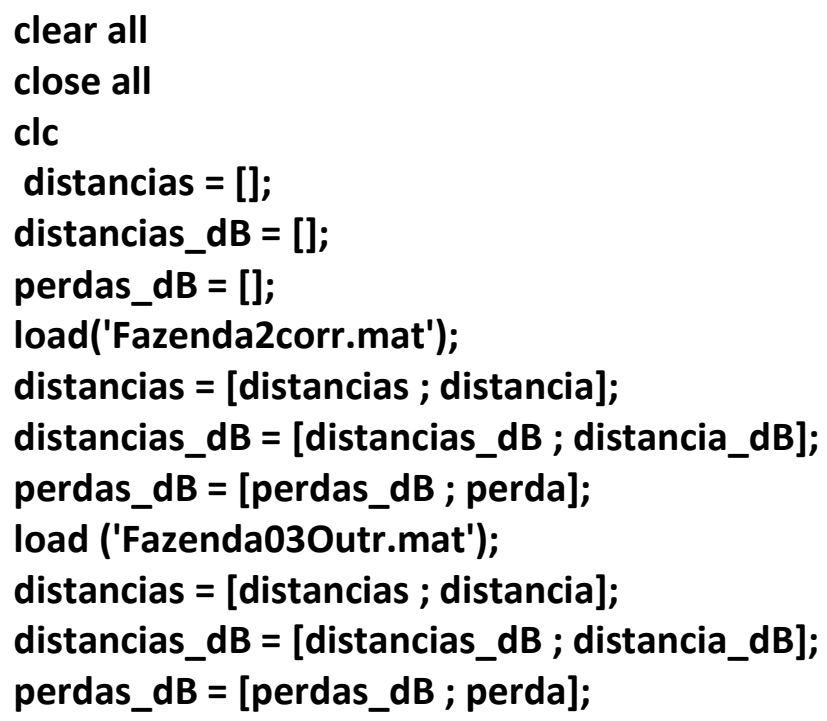

Arquivos de medidas pós-processado pelo Matlab, já submetido ao programa de regressão linear.

\section{Saídas:}

Uma única reta representando o percurso e a estação climática, Fig. 5.13.

\section{Descrição:}

Os arquivos pós-processados oriundos do Matlab em extensão ".mat" são carregados e aglutinados em um único arquivo. $O$ programa otimiza as retas 
com inclinações similares e, usando do conceito de minimização dos erros quadráticos, gera uma nova reta de regressão.

11-Aplicação: Correção das distorções nos diagramas polares radiação das antenas de 144 e $435 \mathrm{MHz}$.

Tela:

clear

clc

Tabela_Coordenadas $=[]$;

Tabela_Altitudes $=[] ;$

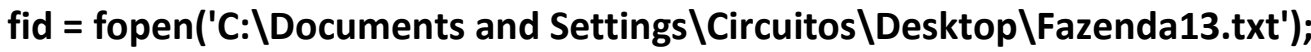

tline $=$ fgetl(fid);

ii $=0$;

while ischar(tline)

dm_LAT = zeros(1,2);

dm_LONG = zeros $(1,2)$;

Alt $=0$;

dm_LAT(1) $=(-1) *$ str2num(tline(15:16));

dm_LAT(2) = (0.001)*str2num(tline(17:21));

dm_LONG(1) = (-1)*str2num(tline(23:25));

dm_LONG(2) = (0.001)*str2num(tline(26:30));

Alt $=$ str2num(tline(36:40));

Lat $=\mathrm{dm} 2$ degrees $\left(\mathrm{dm} \_\right.$LAT $)$;

Lon = dm2degrees $\left(\mathrm{dm} \_\right.$LONG);

[x,y,utmzone] = deg2utm(Lat,Lon);

Tabela_Coordenadas $=[$ Tabela_Coordenadas; $\mathbf{y}$ ]

Tabela_Altitudes $=$ [Tabela_Altitudes;Alt];

tline = fgetl(fid);

end

\section{Entradas:}

Dados numéricos dos diagramas polares das antenas de transmissão nos planos E e H;

Arquivos brutos de medidas;

Arquivos de medidas processados pelo CoP; e

Altura de torres e correspondente posição georreferênciada.

\section{Saídas:}

Traçados dos diagramas polares corrigidos;

Traçado do percurso georreferênciado ensaiado pelo drive-test;

Telas explicitando, em função do número de pontos amostrais, os seguintes resultados: variação do ângulo de azimute, altimétria, distância da torre, ângulo de elevação e ganho compensado; 
Altura média da rugosidade do terreno tomada em relação ao percurso (não em relação às radiais); Figs. 3.10 e 3.11.

Apresentação gráfica em uma mesma tela: distância axial em relação a torre de transmissão e altura do terreno, ambos em função do número de pontos amostrais; e

Mosaico do percurso montado com base na rugosidade do relevo e distância axial em relação a torre de transmissão.

\section{Descrição:}

No intuito de dar credibilidade aos resultados experimentais e subsídios para análise das campanhas de medidas os arquivos pós-processados são refinados pelo programa no intuito de minimizar fontes de erros sistemáticos e, assim, ampliar a aplicabilidade dos resultados com vistas à aplicação em outros biomas. O programa elimina todas as fontes de erros externos deixando que apenas a morfologia do ambiente atue na modelagem do canal.

12-Aplicação: Animação do deslocamento do drive-test no percurso concomitante com a distância radial em relação à torre de transmissão.

\section{Tela:}

close all

figure

plot(Posicao)

for ii = 1:100:length(Posicao)

plot(Posicao)

hold on

plot(Posicao(ii),'ro')

drawnow

pause(0.1)

end

\section{Entradas:}

Campanha de Medidas pós-processada oriunda do programa de correção dos diagramas polares das antenas.

\section{Saídas:}

Traçado georreferênciado do percurso localização do drive-test no percurso e distância correspondente ao inicio da campanha de medidas. A cada clique o drive-test avança na animação e a distância por sua vez é atualizada na área de trabalho do Matlab, Fig. 3.12.

\section{Descrição:}


Após ter sido aplicado o programa de correção dos diagramas polares o programa de animação pode ser acionado para esmiuçar o posicionamento do drive-test em relação à torre de transmissão. O programa é muito útil para determinar radiais de interesse.

13-Aplicação: Modelo Múltiplas Morfologias aplicável em até 3 inflexões da reta modelo Lei de Potência.

Tela:

rbp1 = 200;

rbp2 = 2000;

$r=1: 1: 16000$;

L1 = 100;

$\mathrm{n} 1=3.5 ;$

$\mathrm{n} 2=5.8$

n3 = 2.5;

Perda $=$ zeros $(\operatorname{size}(r))$;

Perda $=(\mathrm{L} 1+10 * n 1 * \log 10(\mathrm{r})) \cdot{ }^{*}(\mathrm{r}<=\mathrm{rbp} 1) ;$

Perda $=$ Perda $+(L 1+10 * n 2 * \log 10(r / r b p 1)+10 * n 1 * \log 10(r b p 1)) \cdot{ }^{*}((r>r b p 1) \&(r<=$ rbp2));

Ajuste $=10 * n 2 * \log 10(\mathrm{rbp} 2 / \mathrm{rbp} 1)+10 * \mathrm{n} 1 * \log 10(\mathrm{rbp} 1)$;

Perda $=$ Perda $+($ L1 + 10*n3*log10(r/rbp2) + Ajuste $) . *((r>r b p 2))$;

semilogx(r,Perda)

hold on

PerdaSuave $=\mathrm{L} 1+10 * \mathrm{n} 1 * \log 10(\mathrm{r})+\ldots$

$10 *(n 2-n 1) * \log 10(1+r / r b p 1)+\ldots$

$10 *(n 3-n 2) * \log 10(1+r / r b p 2)$;

semilogx(r,PerdaSuave, 'r')

Entradas:

Expoentes de perda de morfologias distintas, até 3 morfologias distintas. Por exemplo, plantação de eucalipto, plantação de bambu e cerrado denso.

\section{Saídas:}

Traçado do comportamento da perda de propagação em função da distância, segmentos de reta com distintas inclinações e o correspondente traçado continuo que melhor se aproxima assintoticamente do conjunto de retas segmentadas, Fig. 2.15

\section{Descrição:}

A individualização de expoentes de perda, obtidos de forma experimental ou teórica, e a individualização de distâncias de abrangência das distintas 
morfologias são carregadas no programa. O programa concatena as retas com distintas inclinações.

14-Aplicação: Comparação entre retas de regressão oriundas das campanhas de medidas

Tela:

clear all

close all

clc

load('Fazenda2corr.mat');

semilogx(dplot,retaplot,'r--','LineWidth', 1.5);

hold on

load ('Fazenda030utr.mat');

semilogx(dplot,retaplot, 'r-.','LineWidth', 1.5);

hold on

load('Fazenda13.mat');

semilogx(dplot,retaplot,' 'y-.','LineWidth', 1.5);

hold on

load('Fazenda3setembroTudo144MHz.mat');

semilogx(dplot,retaplot, 'y','LineWidth', 1.5);

hold on

load('Agosto3.mat');

semilogx(dplot,retaplot,' 'r','LineWidth', 1.5);

hold on

load('Eucalipto13.mat');

semilogx(dplot,retaplot,' 'm--','LineWidth', 1.5);

hold on

load('AgostoSeco3.mat');

semilogx(dplot,retaplot,'m','LineWidth', 1.5);

hold on

load('SetembroSeco3.mat');

semilogx(dplot,retaplot,' 'k','LineWidth', 1.5);

hold on

load('Dezembro3.mat');

semilogx(dplot,retaplot,'k--','LineWidth', 1.5);

hold on

xlabel('Distância Tx-Rx (m)')

ylabel('Perda (dB)')

title('Modelo Lei de Potência 435 MHz X 144 MHz Trecho Cerradão')

legend ('2,1,3,1,03/02/2012','2,1,3,1,04/06/2013',

'1,1,3,1,05/04/2013','1,1,3,2,07/09/2013','2,1,3,2,16/08/2014','1,2,3,1,14/06/2014',...

'1,2,3,2,23/08/2014','2,2,3,2,06/09/2014','2,2,3,1,13/12/2014')

Entradas:

Arquivos de medidas pós-processados em termos das retas de regressão linear, programa versão 1. 


\section{Saídas:}

Gráficos cartesianos traçados em uma única tela para fins e efeito de comparação entre as retas de regressão referentes a qualquer morfologia, clima, frequência e altura de torre, de acordo com indexação apresentada no texto, Fig. 5.15.

\section{Descrição:}

Os arquivos pós-processados, oriundos do Matlab, em extensão ".mat" são carregados e reapresentados em uma única plataforma gráfica para análise minuciosa.

\section{Programa em $\mathrm{C}^{++}$}

15-Aplicação: Programa de processamento - CoP.

\section{Tela}

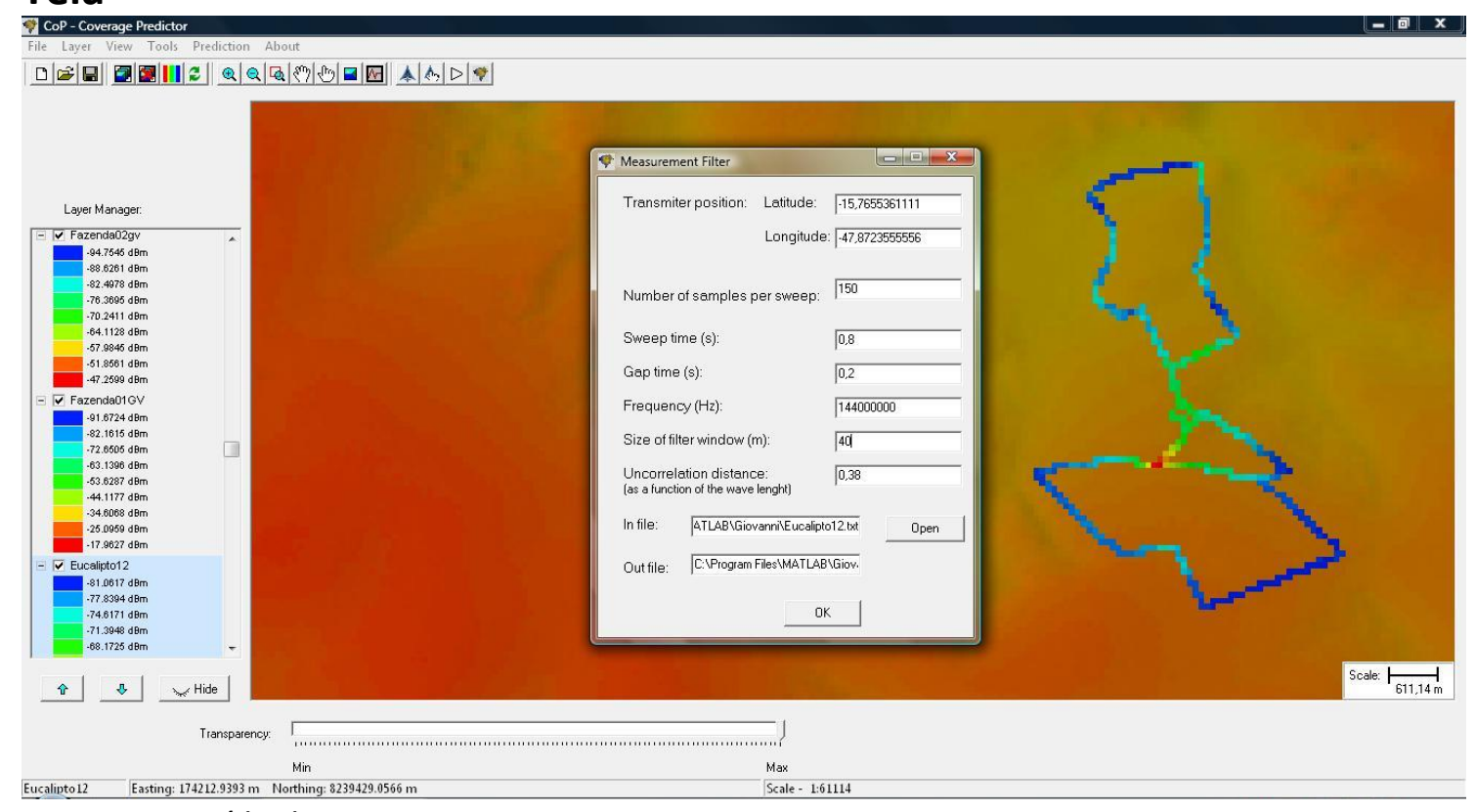

Figura V.4 Saída do CoP.

\section{Entradas:}

Conforme tela na cor cinza: latitude e longitude em graus decimais da localização da torre de transmissão, número de pontos amostrais por varredura do analisador de espectro conforme $[49,50]$, tempo de varredura ajustado em 800 milissegundos, 200 milissegundos para transferência das amostras de uma varredura para a memória do Notebook, frequência em Hertz de transmissão, tamanho da janela de filtragem [1, 2] e distância de descorrelação $[49,50]$. 


\section{Saídas:}

Contornos georreferênciados dos percursos em termos de coordenadas UTM, potência média, desvanecimento em larga escala e desvanecimento em pequena escala, altimetria básica do relevo do ambiente de medidas digitalizada em quadrículas de 800 por 800 metros. Saídas gráficas: em azul, sombreamento sobreposto à perda de propagação, em verde, desvanecimento em pequena escala. Campanha de medidas realizada na FAL em $435 \mathrm{MHz}$, percurso "cerradão". Componentes dos desvanecimentos em pequena escala e larga escala em função do deslocamento do móvel em relação a antena de transmissão. Na parte baixa da figura, eixo das ordenadas: distância do móvel em relação à torre de transmissão e na abscissa: distância acumulada a cada volta. Representação gráfica dos percursos com graduação em códigos de cores correspondente à amplitude do sinal recebido.

\section{Descrição:}

Os arquivos de medidas provenientes do GPSpectrum em extensão ".txt" são processados pela técnica das médias móveis e convertidos em extensão ".meas" apropriada para as etapas de pós-processamento no Matlab.

\section{Programa em VEE}

16-Aplicação: Aquisição de medidas - GPSpectrum

\section{Tela:}

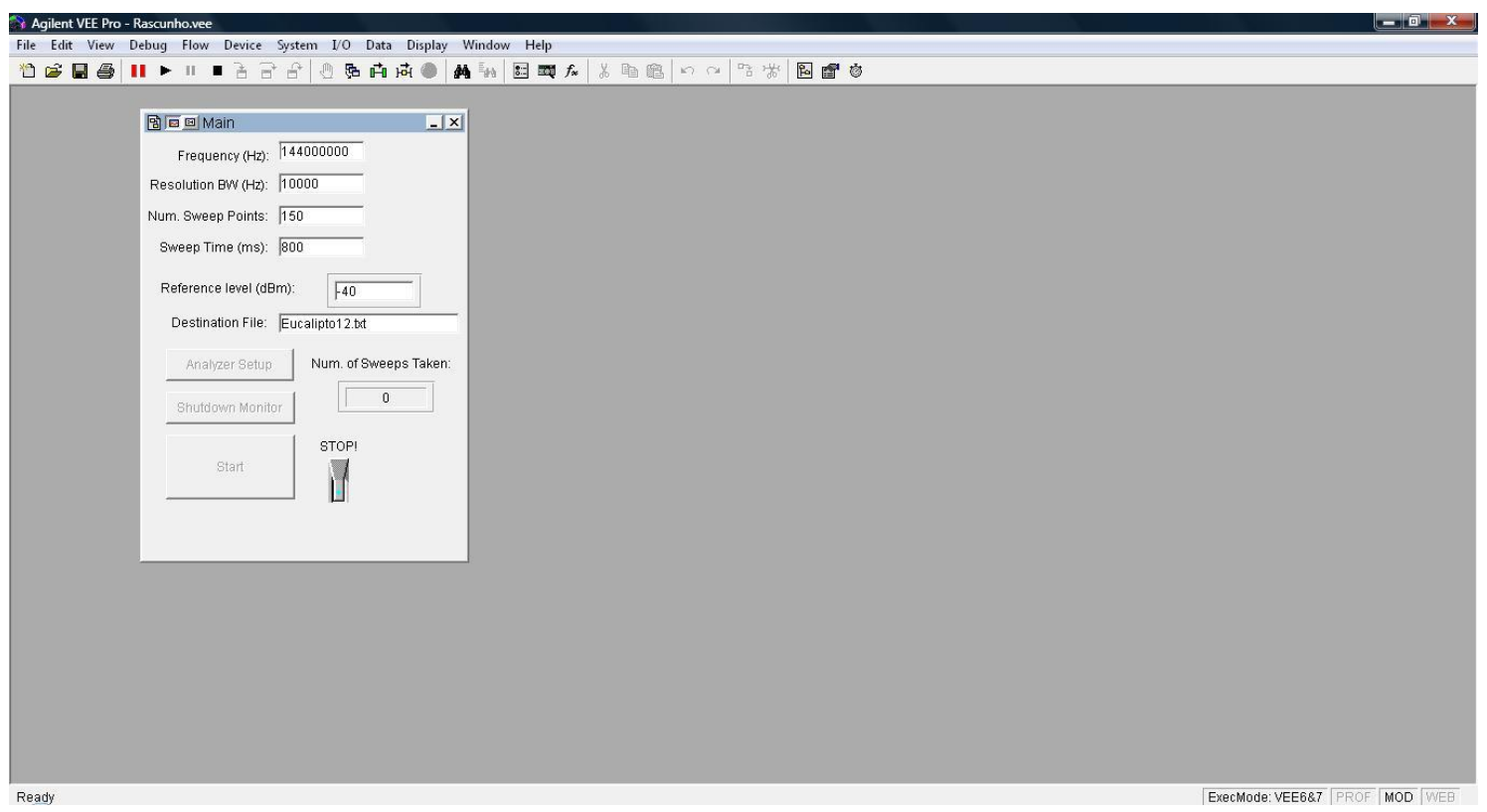

Figura V.5 Tela do GPSpectrum. 


\section{Entradas:}

Conforme tela em cinza claro: frequência em Hertz da transmissão, RBW do analisador de espectro, número de pontos amostrais por varredura do analisador de espectro, tempo de varredura de 800 milissegundos, nível de potência de referência em $\mathrm{dBm}$ (conforme prospecção precursora realizada no ambiente de medidas) e nome do arquivo a ser criado no notebook conectado via porta GPIB.

\section{Saídas:}

Arquivos de medidas em extensão ".txt". Os valores captados pela antena omnidirecional do drive-test em dBm são gravados no notebook.

\section{Descrição:}

O programa é previamente carregado no notebook. Ao ser acionado o botão virtual Analyzer Setup, abre-se no notebook a tela para entrada de dados. Após inserção dos dados, aciona-se o botão virtual Shutdown Monitor. $\mathrm{O}$ analisador se configura para iniciar a coleta de dados. Por fim, aciona-se o botão virtual Start para dar início à aquisição de dados da campanha de medidas. Após o término das voltas pelo percurso, aciona-se o botão virtual stop.

\begin{tabular}{|c|c|c|c|c|c|c|c|c|c|c|}
\hline 30907 & & & & & & U & 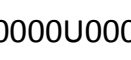 & & -56.337 & $-55.6 s$ \\
\hline-55.588 & -55.891 & -55.869 & -55.699 & -56.149 & -56.161 & -56.05 & -56.184 & -56.326 & -56.159 & -56.159 \\
\hline-56.223 & -55.706 & -55.733 & -55.728 & -55.242 & -55.07 & -55.528 & -54.768 & -54.647 & -55.358 & -54.671 \\
\hline-54.6 & -55.522 & -54.934 & -55.036 & -56.29 & -55.426 & -55.585 & -57.123 & -56.159 & -56.458 & -57.938 \\
\hline-56.967 & -56.964 & -58.253 & -57.375 & -57.399 & -58.314 & -57.69 & -57.618 & -58.015 & -57.813 & -57.647 \\
\hline-58.164 & -58.199 & -58.16 & -58.405 & -59.069 & -58.967 & -59.388 & -60.362 & -60.296 & -60.695 & -61.91 \\
\hline-61.889 & -62.313 & -63.22 & -63.088 & -63.249 & -63.823 & -62.981 & -62.761 & -62.696 & -61.625 & -61.31 \\
\hline-61.206 & -59.93 & -59.666 & -59.714 & -58.384 & -58.208 & -58.634 & -57.111 & -56.72 & -57.614 & -56.224 \\
\hline-56.128 & -56.931 & -55.642 & -55.518 & -56.061 & -55.199 & -55.127 & -55.393 & -55.138 & -55.072 & -55.336 \\
\hline-55.336 & -55.077 & -55.376 & -55.769 & -55.474 & -55.889 & -56.54 & -56.302 & -56.669 & -57.558 & -57.339 \\
\hline-57.625 & -58.606 & -58.335 & -58.674 & -59.524 & -58.763 & -58.904 & -59.017 & -58.359 & -58.137 & -58.357 \\
\hline-57.109 & -57.006 & -57.422 & -55.927 & -55.995 & -56.65 & -55.335 & -55.265 & -56.129 & -55.003 & -54.98 \\
\hline-55.826 & -55.399 & -55.381 & -55.946 & -56.306 & -56.308 & -56.768 & -57.421 & -57.458 & -58.11 & -58.838 \\
\hline-58.851 & -58.929 & -59.6 & -59.012 & -59.038 & -58.863 & -58.062 & -57.938 & -57.691 & -57.04 & -57.188 \\
\hline-57.066 & -56.301 & -56.209 & -56.8 & -56.084 & & & & & & \\
\hline
\end{tabular}

Programa em Linguagem Fortran IV

17-Aplicação: Simulação TLM-SCN-3D

Tela: 


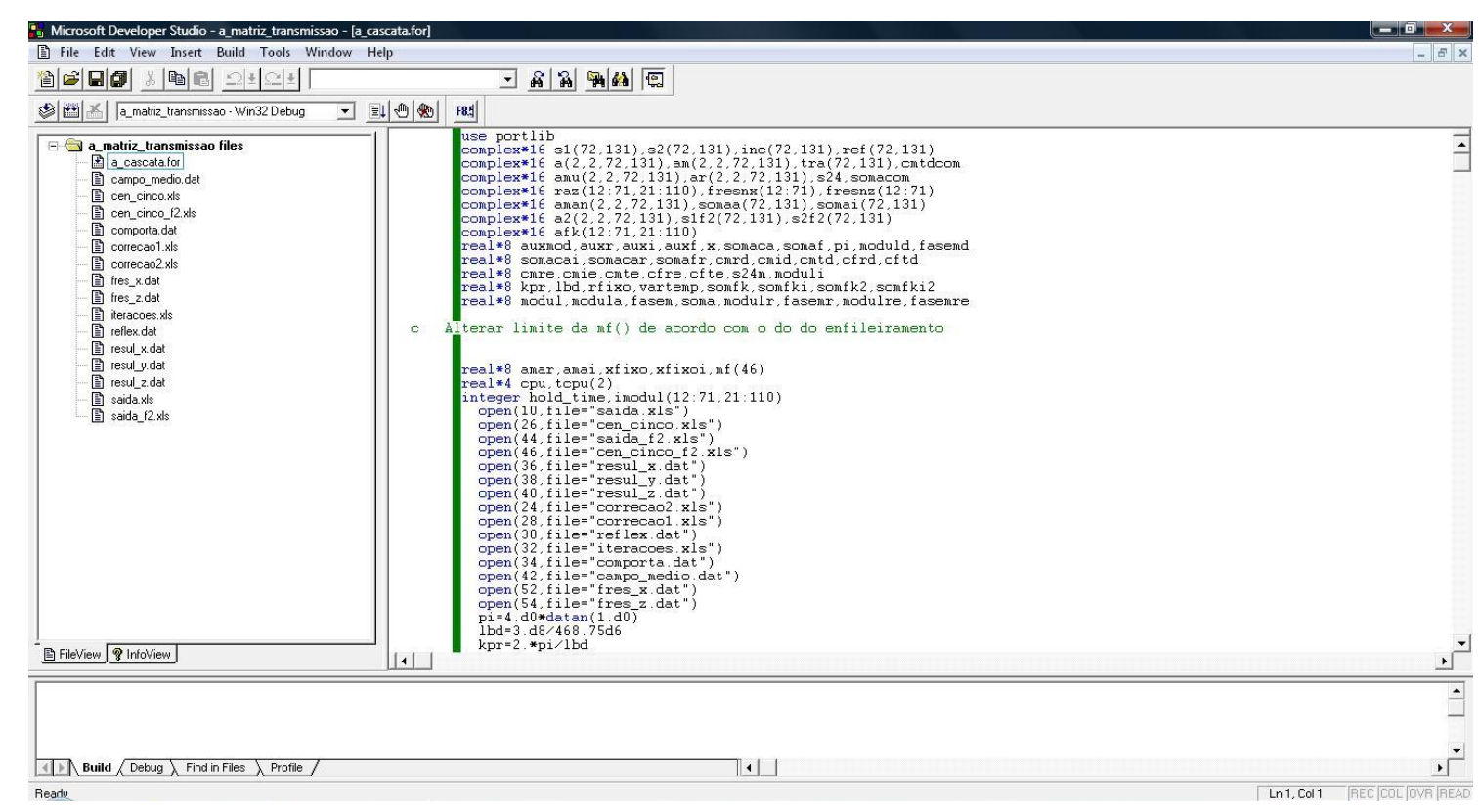

Figura V.6 Tela Fortran simulação TLM

\section{Entradas:}

Número de blocos que modelam a floresta, conforme tamanho do enlace em análise, quantidade de enfileiramentos randômicos a ser mapeado pelo programa de simulação.

\section{Saídas:}

Valor numérico da atenuação do enlace e mapa formatado em planilha Excell conforme o grau de obstrução e desobstrução discretizado em valores absolutos atribuídos de acordo com a robustez do impedimento à propagação.

\section{Descrição:}

Após o levantamento do perfil plani-altimétrico das radiais selecionadas para análise e verificação do desvio entre o resultado experimental e teórico, chega-se ao quantitativo de blocos de floresta que modelam o percurso. O programa enfileira estes blocos de floresta de forma aleatória e ao final do programa entrega na tela do notebook o valor da atenuação média e abre um arquivo para armazenar o mapa de propagação da energia eletromagnética pela floresta. 


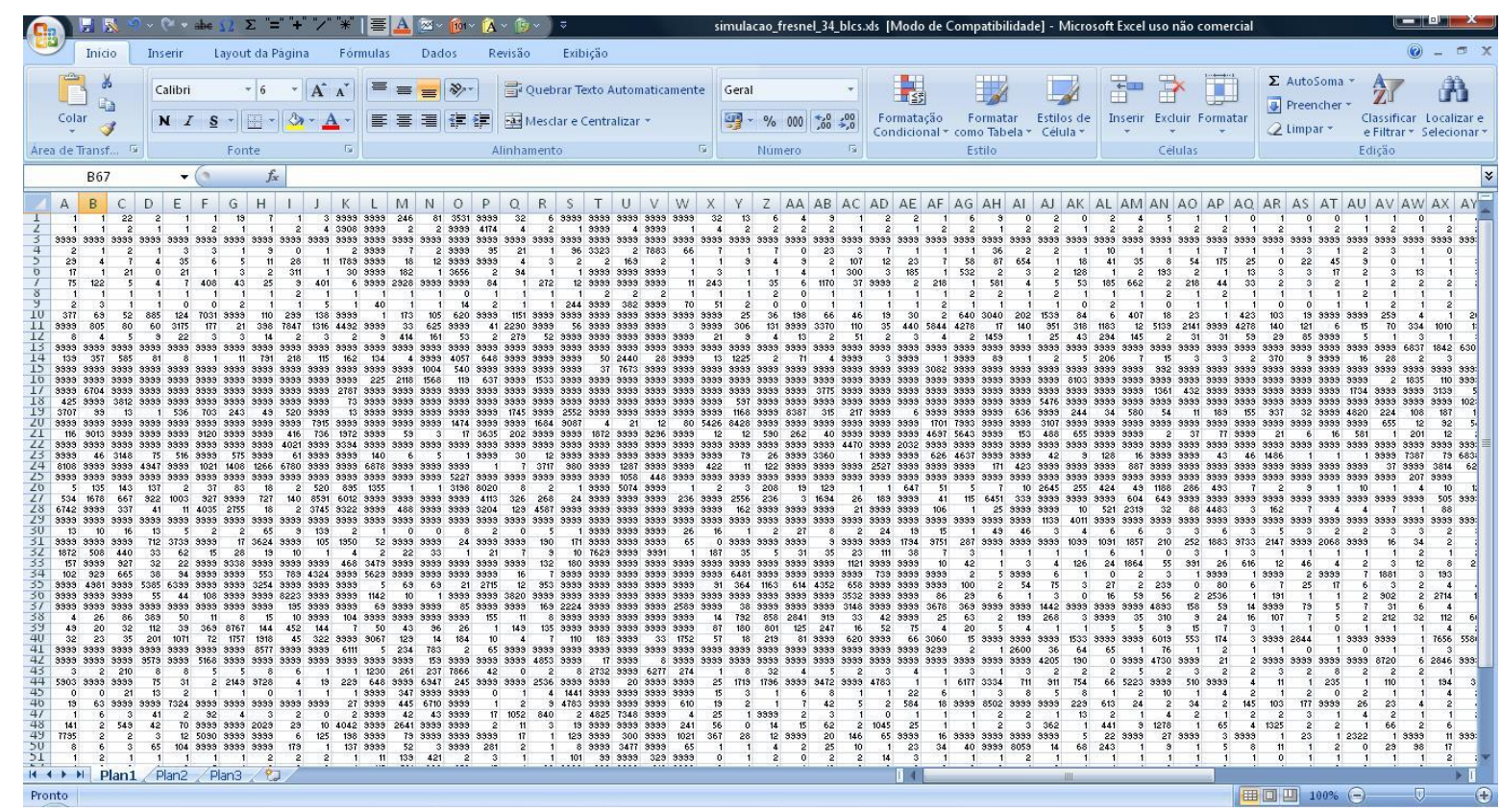

Figura V.7 Saída numérica TLM-SCN-3D

\section{FOTOS DOS PERCURSOS: “MIX”, "CERRADÃO" E "EDGE”} "MIX":

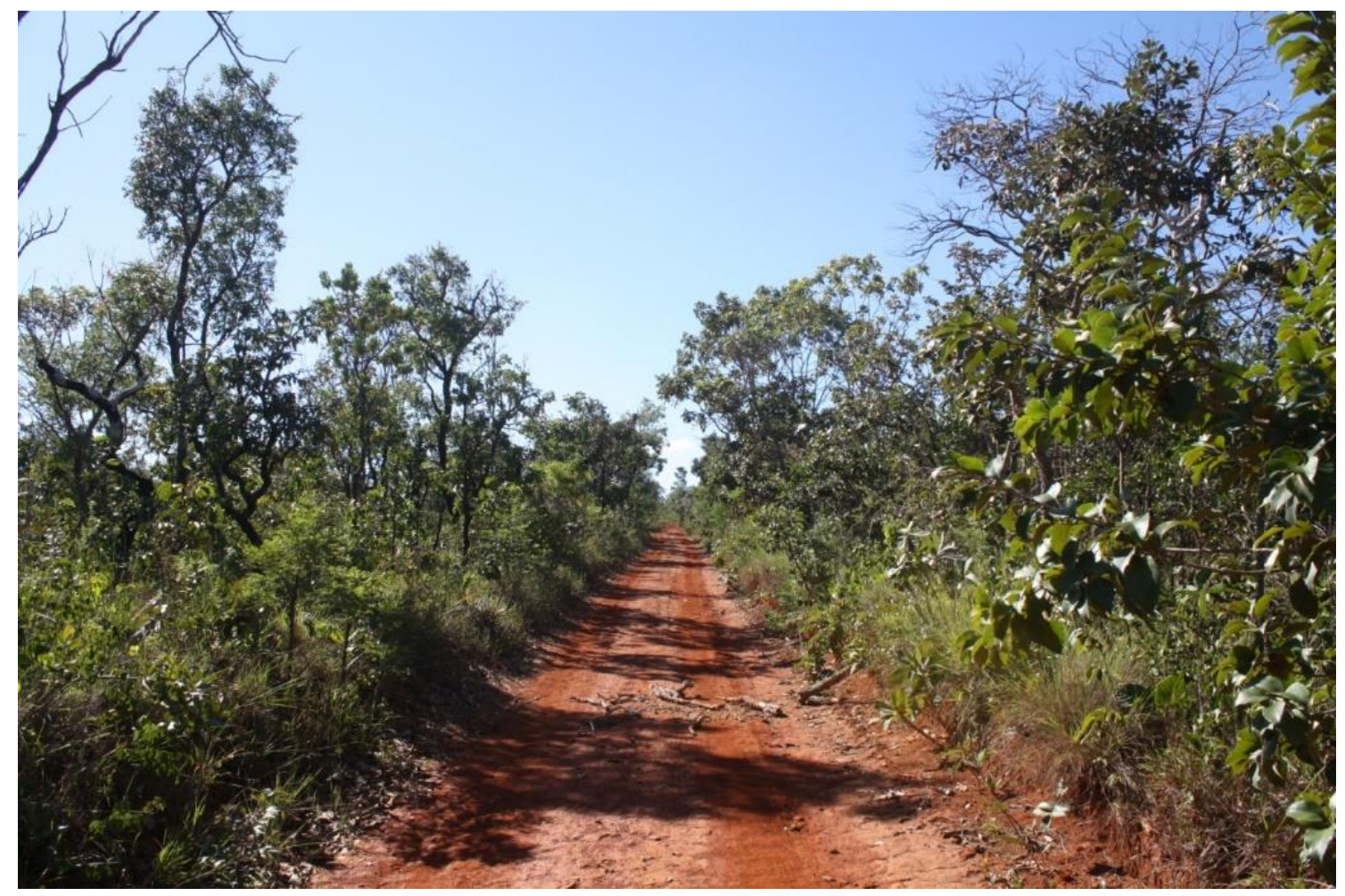

Figura VI.1 "mix" - foto do percurso. 


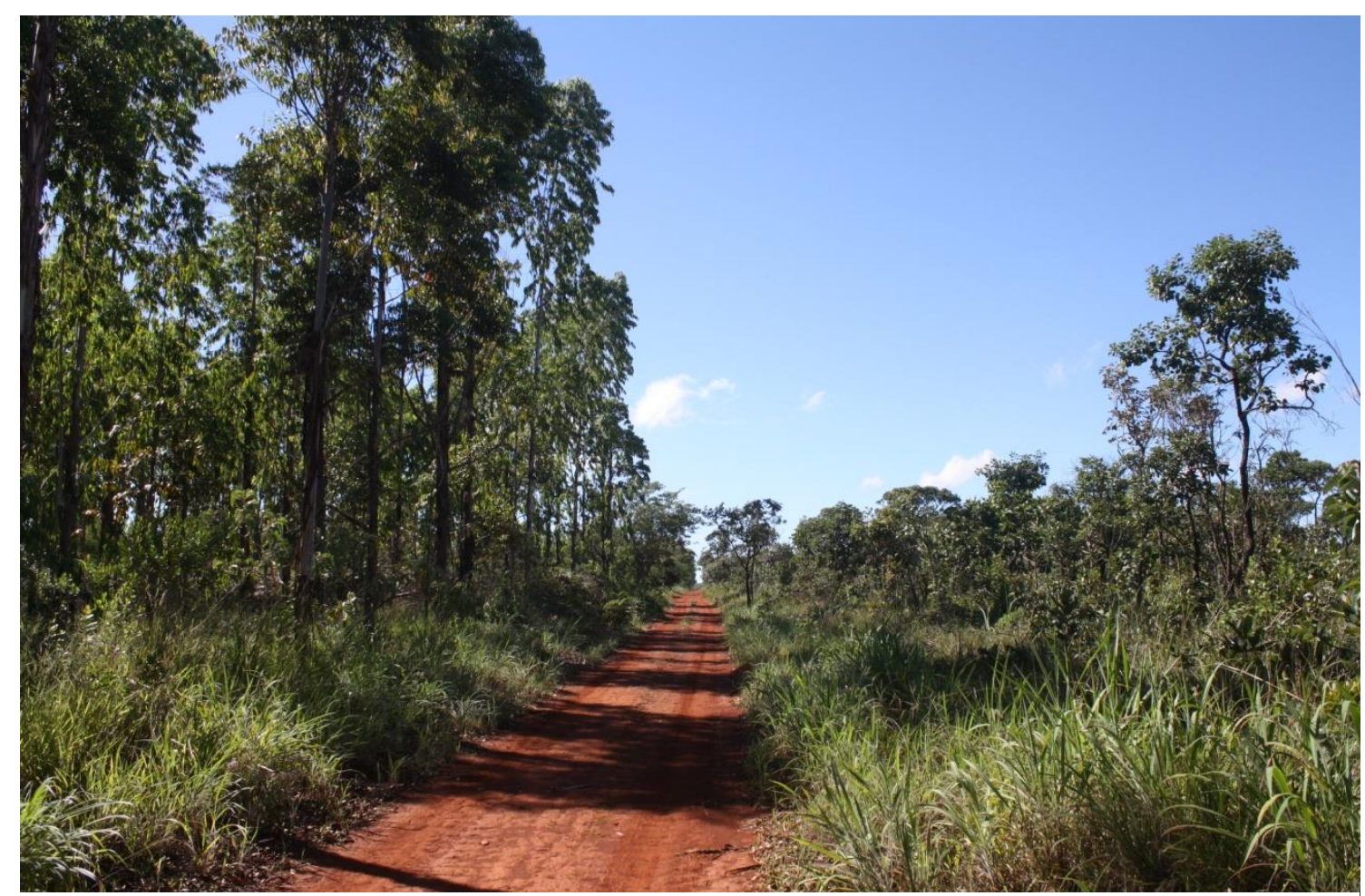

Figura VI.2 "mix" - foto do percurso.

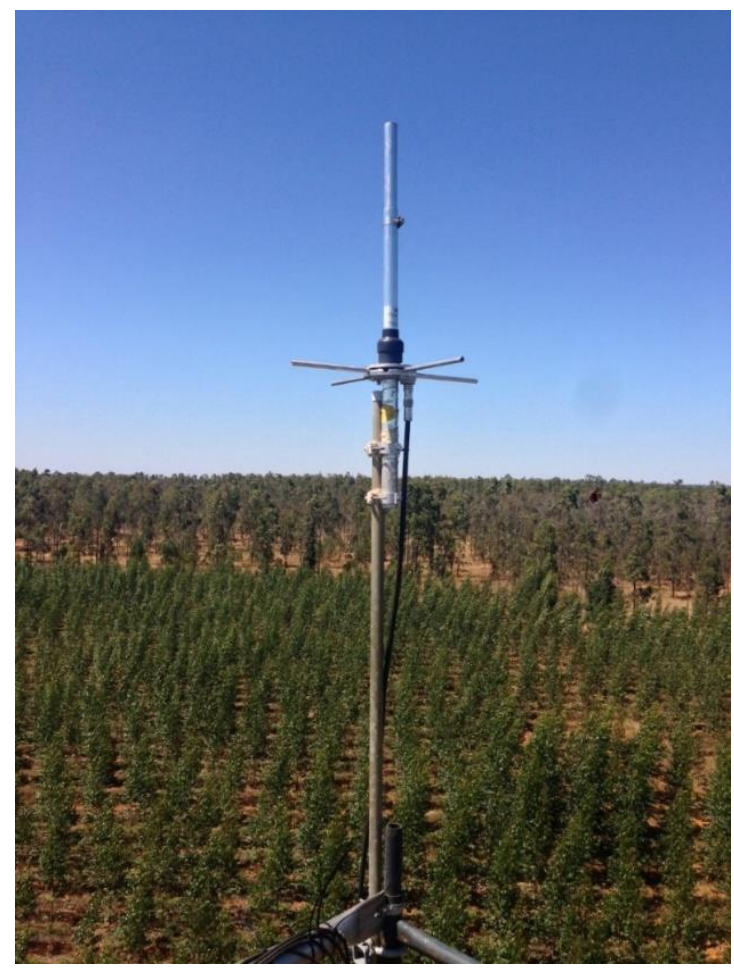

Figura VI.3 "mix" - foto do percurso. 
"CERRADÃO":

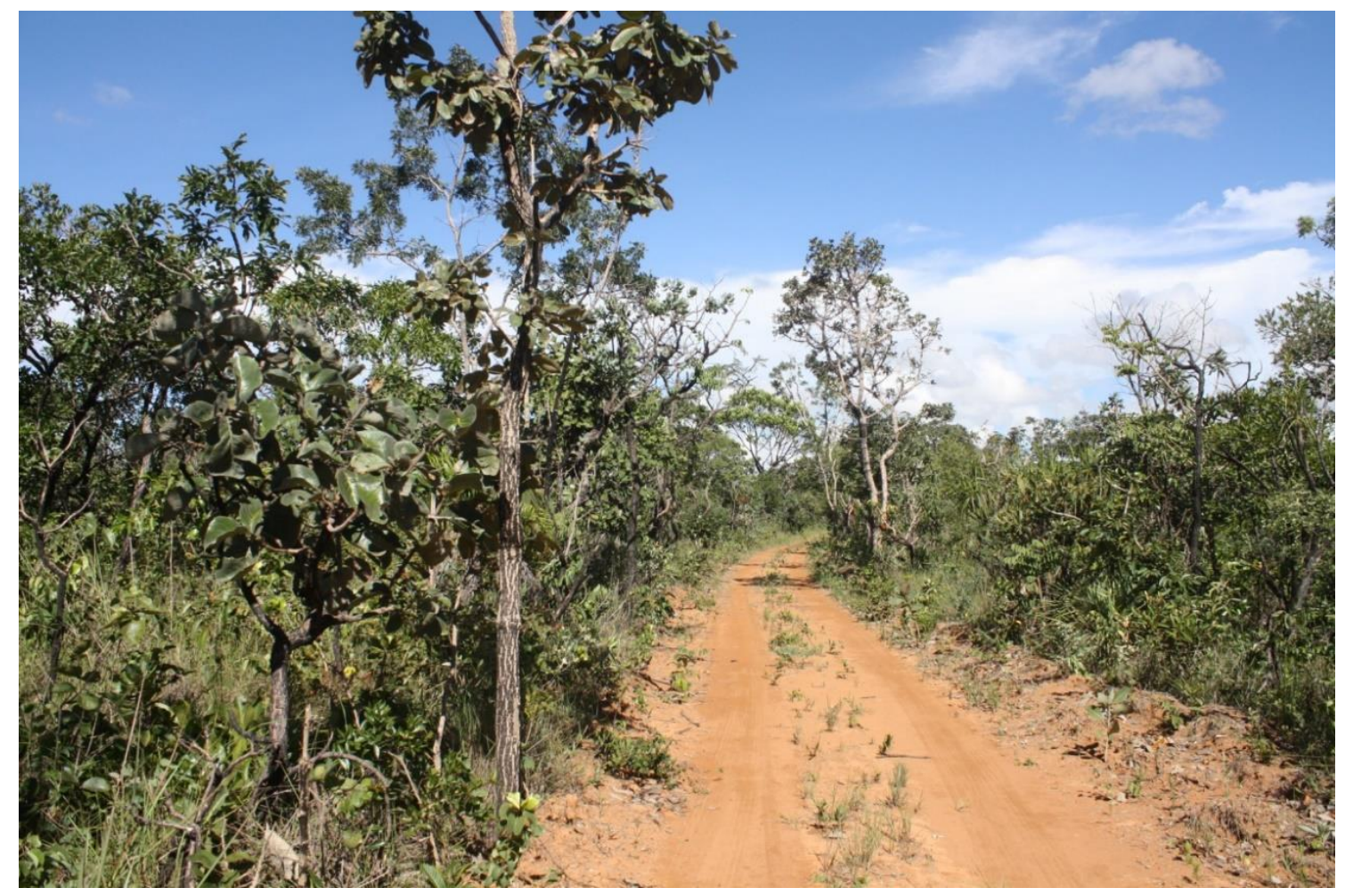

Figura VI.4 "cerradão" - foto do percurso.

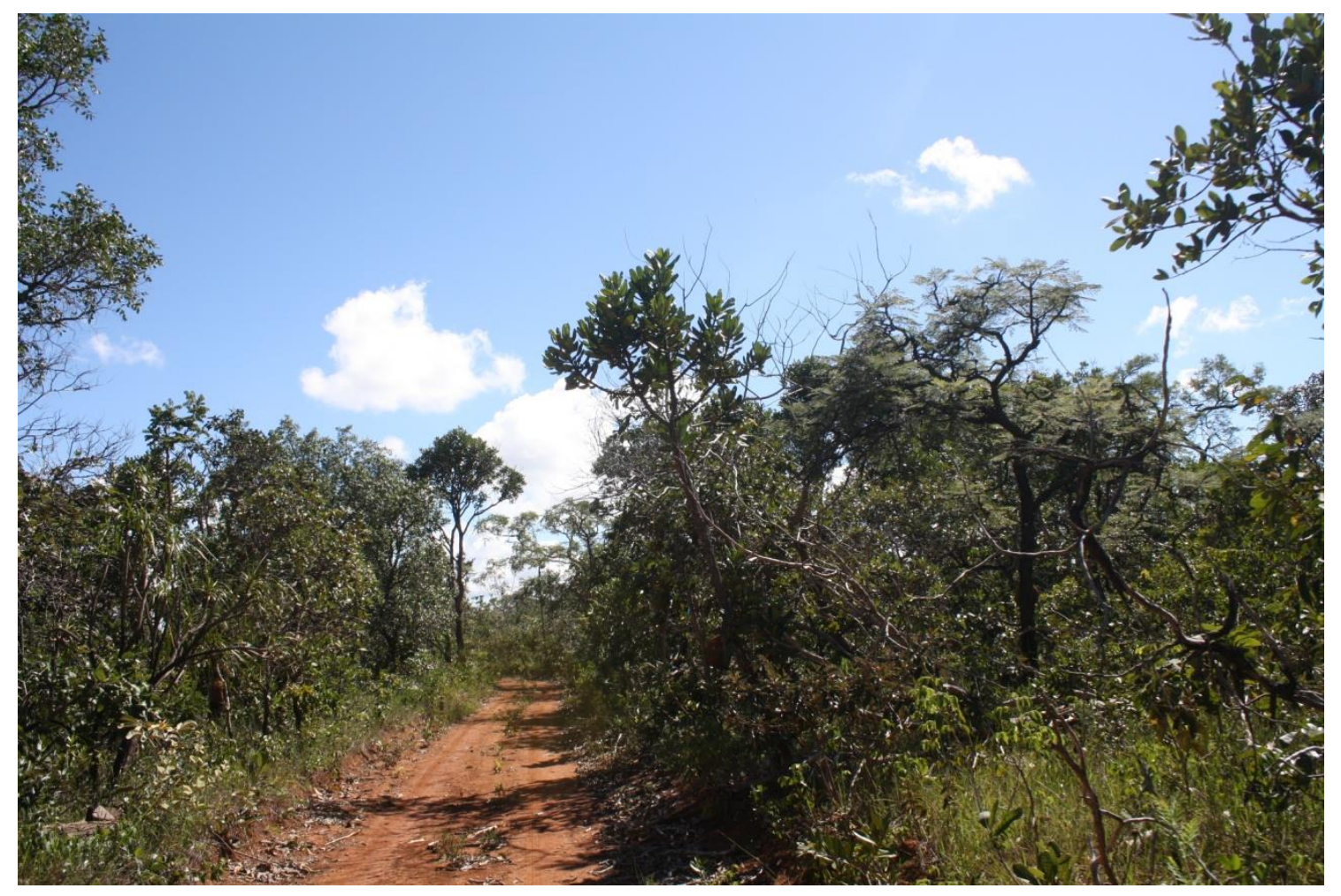

Figura VI.5 "cerradão" - foto do percurso. 


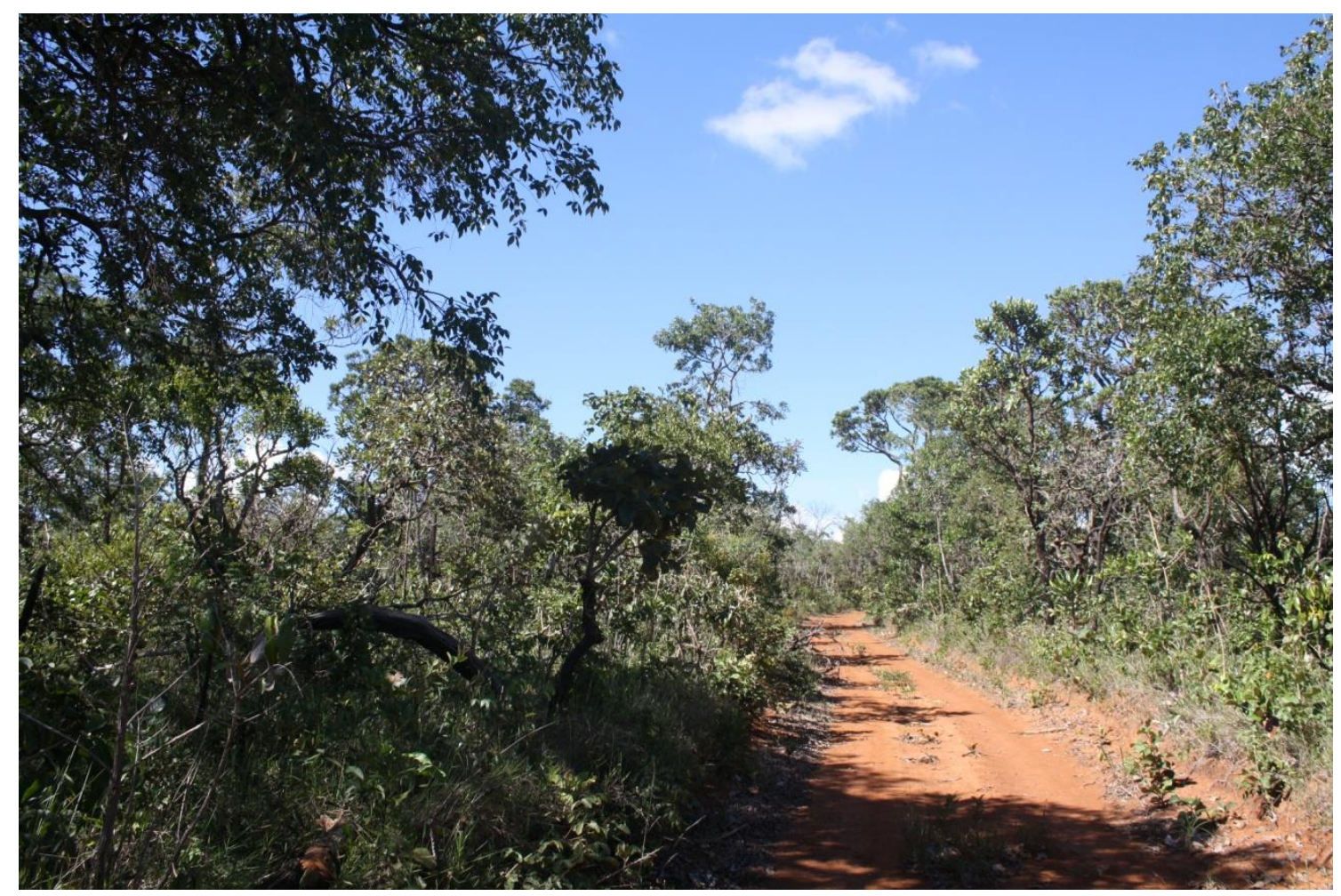

Figura VI.6 "cerradão" - foto do percurso. 
"EDGE":

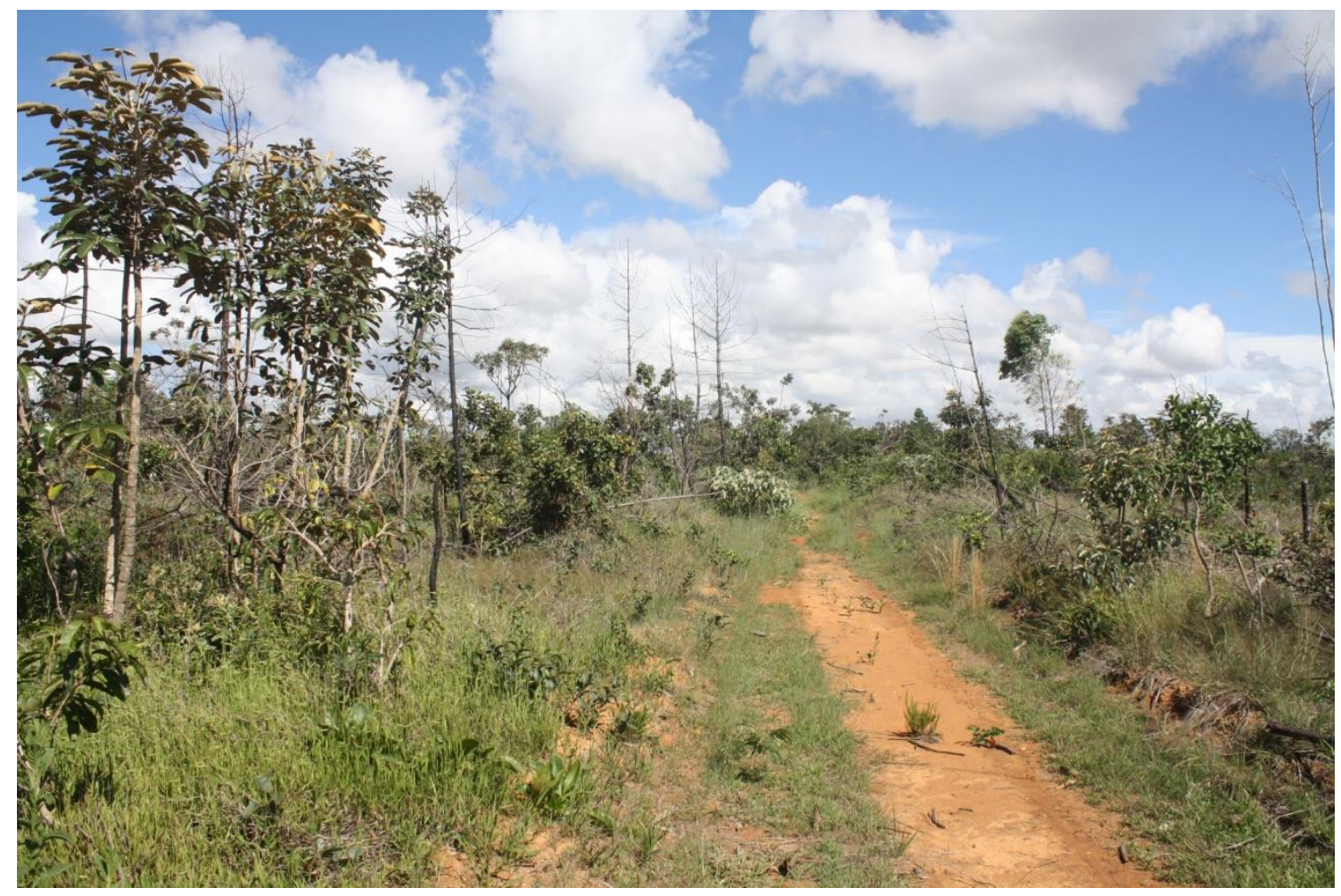

Figura VI.7 "edge" - foto do percurso. 


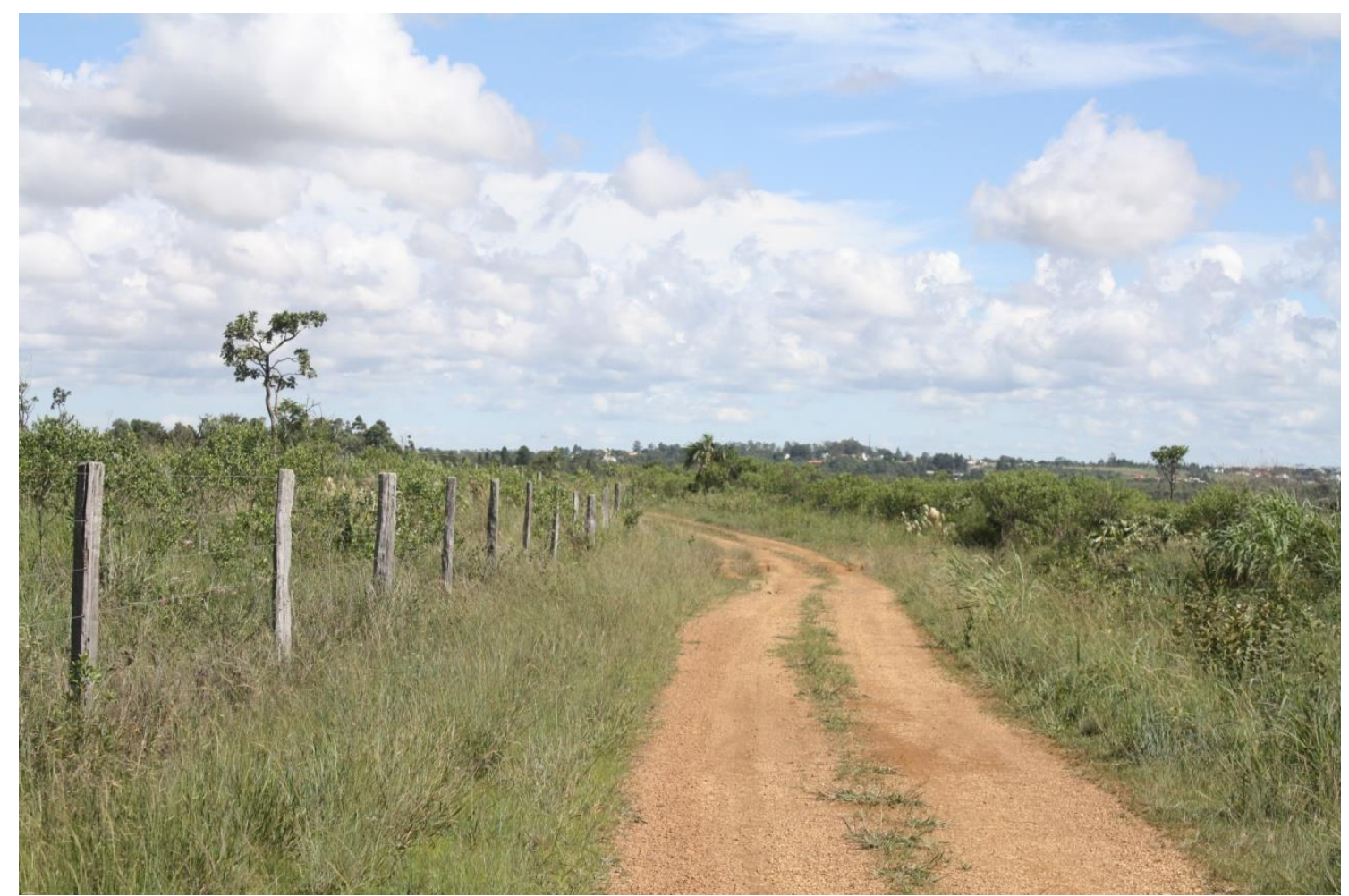

Figura VI.8 "edge" - foto do percurso.

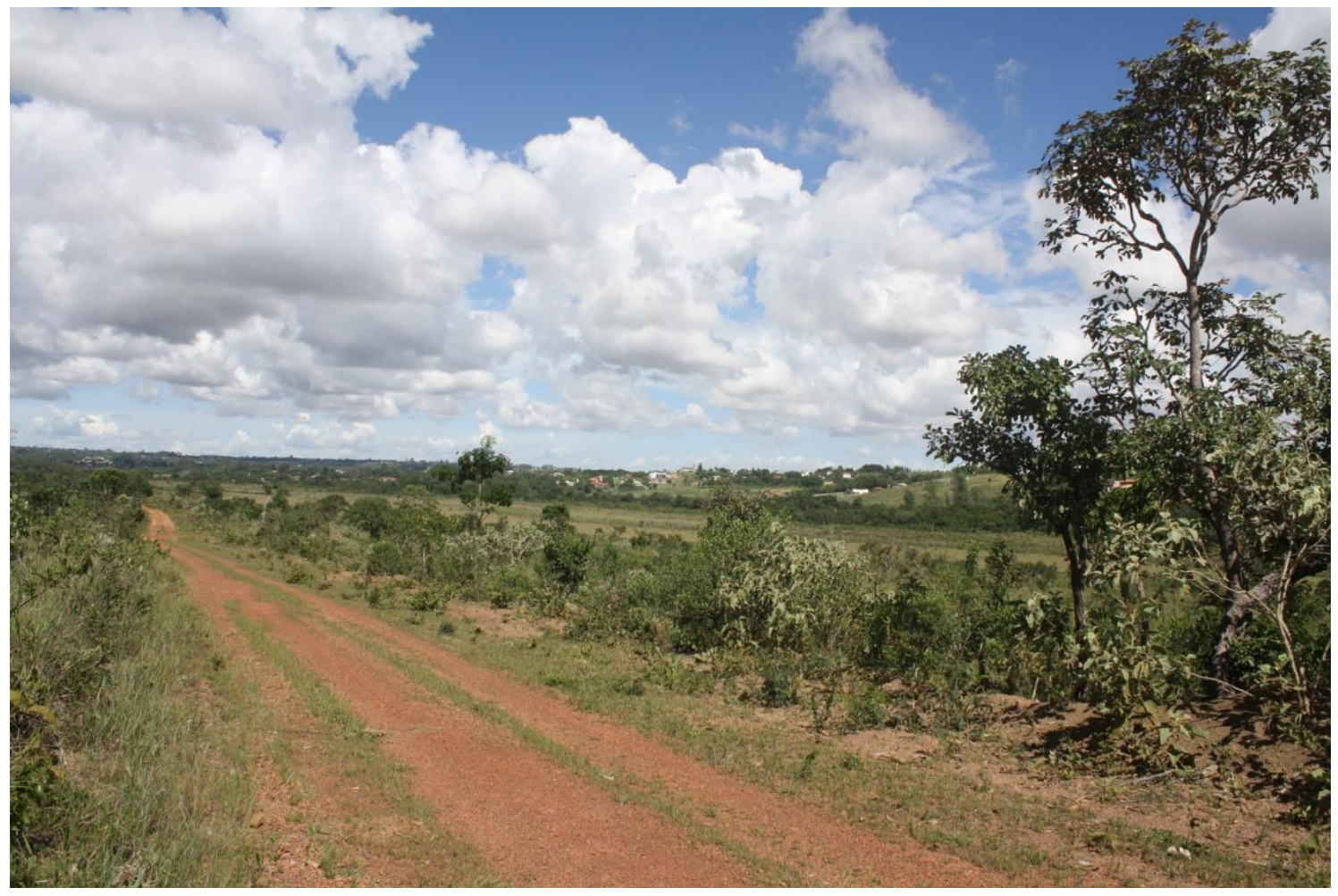

Figura VI.9 "edge" - foto do percurso. 


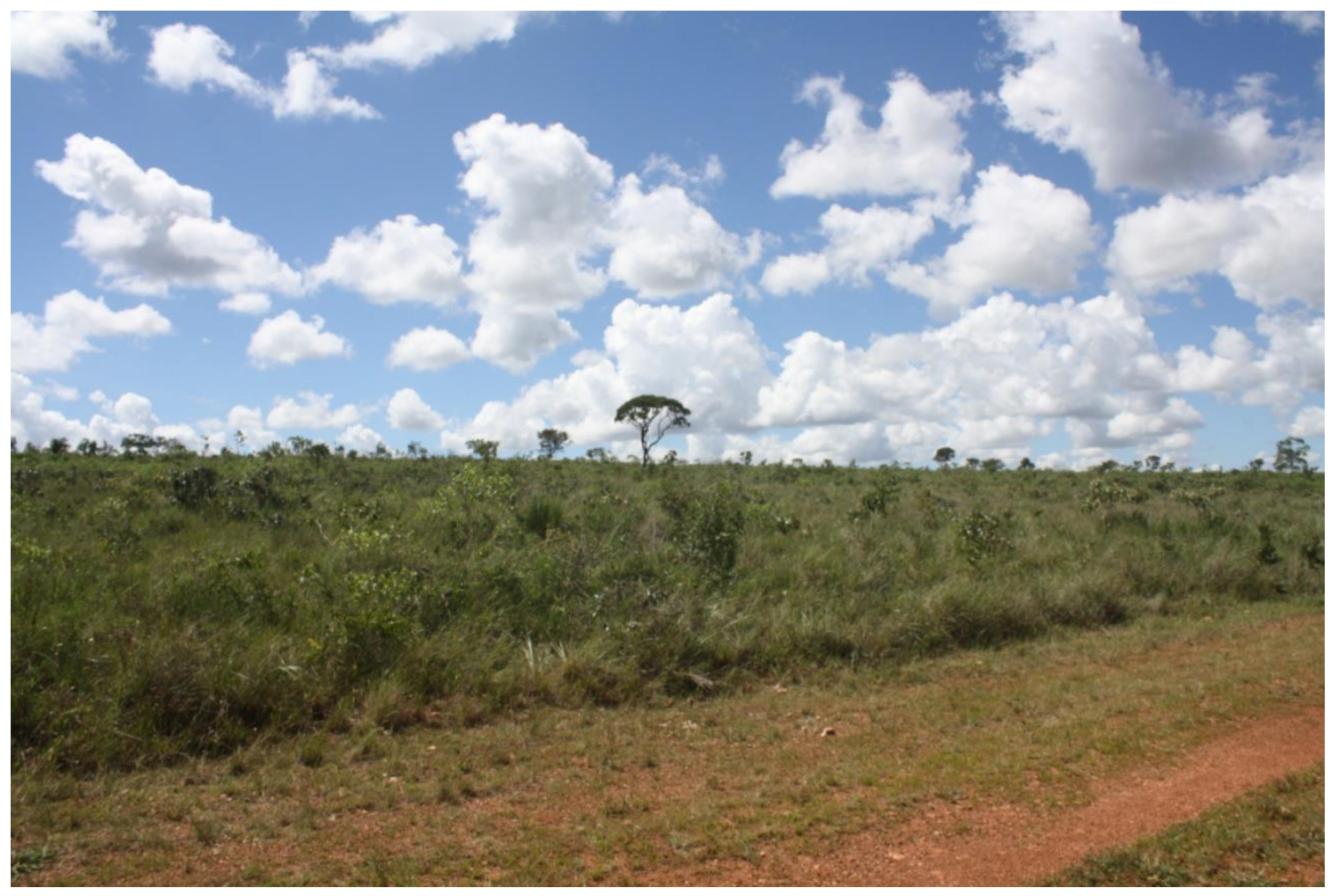

Figura VI.10 "edge" - foto do percurso.

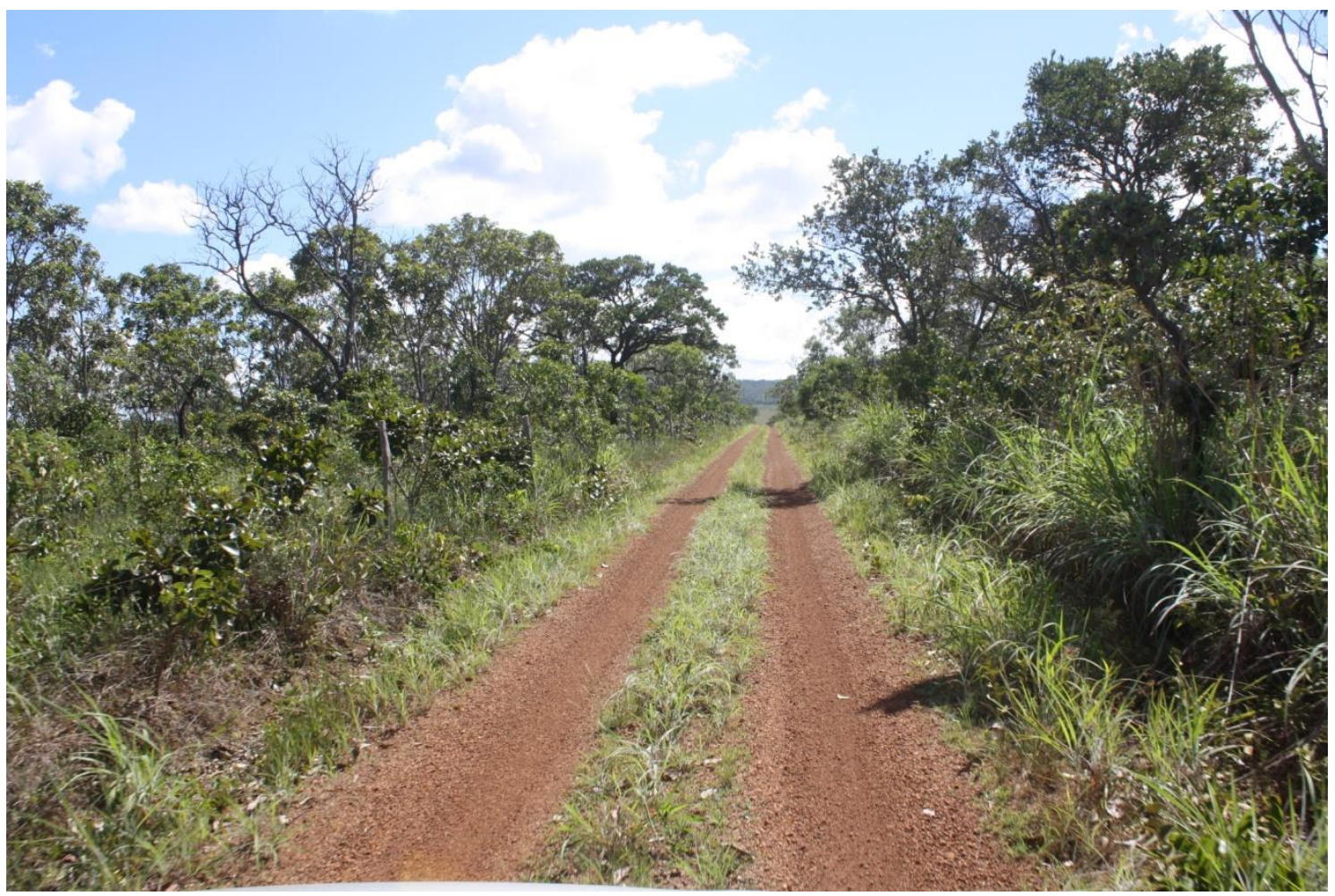

Figura VI.11 "edge" - foto do percurso. 